\title{
DECISÕES BASEADAS EM RISCO \\ - MÉTODO APLICADO NA INDÚSTRIA DE GERAÇÃO DE ENERGIA ELÉTRICA PARA A SELEÇÃO DE EQUIPAMENTOS CRÍTICOS E POLÍTICAS DE MANUTENÇÃO
}

Tese de Doutorado apresentada à Escola Politécnica da Universidade de São Paulo para a obtenção de título de Doutor em Engenharia.

São Paulo 


\title{
DECISÕES BASEADAS EM RISCO \\ - MÉTODO APLICADO NA INDÚSTRIA DE GERAÇÃO DE ENERGIA ELÉTRICA PARA A SELEÇÃO DE EQUIPAMENTOS CRÍTICOS E POLÍTICAS DE MANUTENÇÃO
}

\author{
Tese de Doutorado apresentada à Escola \\ Politécnica da Universidade de São Paulo para \\ a obtenção de título de Doutor em Engenharia.
}

Área de Concentração:

Engenharia Mecânica de Projeto de Fabricação

Orientador:

Prof. Dr. Gilberto Francisco Martha de Souza

São Paulo 
Este exemplar foi revisado e alterado em relação à versão original, sob responsabilidade única do autor e com a anuência de seu orientador.

São Paulo, 19 de maio de 2011.

Assinatura do autor

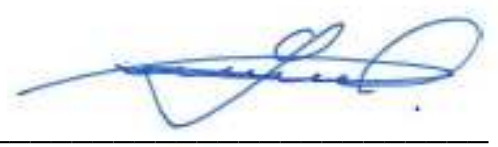

Assinatura do orientador

\section{FICHA CATALOGRÁFICA}

Guevara Carazas, Fernando Jesus

Decisões baseadas em risco: método aplicado na indústria de geração de energia para a seleção de equipamentos críticos e políticas de manutenção / F.J. Guevara Carazas. -- ed.rev. -- São Paulo, 2011. 218p.

Dissertação (Mestrado) - Escola Politécnica da Universidade de São Paulo. Departamento de Engenharia Mecatrônica e de Sistemas Mecânicos.

1. Análise de risco (Manutenção) 2. Usinas termoelétricas (Confiabilidade) 3. Ciclo combinado I. Universidade de São Pau-lo. Escola Politécnica. Departamento de Engenharia Mecatrônica e de Sistemas Mecânicos II. t. 


\section{DEDICATÓRIA}

Dedico este trabajo, a mi Padre Fernando, ejemplo de vida transparente, honesta y trabajadora, su empeño y fuerza para seguir siempre adelante lo hacen una fuente de fuerza, coraje.

A mi Madre Blanca, siempre con una sonrisa es poseedora de una capacidad de servicio sin comparación, me ha demostrado que la entrega y el servicio a los demás son una fuente interminable de felicidad y alegría.

A mi hermana Cecilia, ejemplo de coraje, fortaleza y amor, que reflejadas en Rodrigo, me alimentan para seguir adelante.

A mi hermano Carlos, muestra viva de que el amor, el estudio y la perseverancia llevan al éxito. Su felicidad, facilidad para encontrar alegría y su sonrisa, heredadas por sus hijos (Christopher y Daniel), son fuente de alegría y orgullo.

A mi querida Carmen Elena, ejemplo de vida luchadora, discreta colaboradora de algunos de los pasos más importantes de mi vida. Cómplice, compañera y amiga incondicional es fuente de fortaleza e inmensa felicidad.

A la memoria de mi abuelo Emiliano, ejemplo de que la capacidad de cambio y adaptación al paso del tiempo sin perder sus principios y su propia esencia llevan a un hombre a la felicidad y a trascender, aún después de la vida. 


\section{AGRADECIMENTOS}

Ao Professor Dr. Gilberto Francisco Martha de Souza, pela confiança depositada neste trabalho, por acreditar no meu trabalho desde a minha chegada no Mestrado até hoje. Agradeço pela orientação, pelo apoio para resolver as dificuldades enfrentadas nestes anos. O Professor Gilberto teve a capacidade de descobrir e explorar habilidades que desconhecia. Agradeço especialmente pela amizade e os sempre sinceros e calmos conselhos de pai na ciência, de amigo no atuar e de irmão no pessoal.

Aos Professores do Departamento de pós-graduação de Engenharia da Escola Politécnica da Universidade de São Paulo, que contribuíram direta ou indiretamente na elaboração do presente trabalho de Doutorado.

À AES Tietê, pelo apoio financeiro e técnico prestado ao trabalho.

À FUSP (Fundação de Apoio à Universidade de São Paulo) pela concessão da bolsa de estudos, no período inicial deste trabalho de pesquisa.

À CAPES pela bolsa de estudos concedida, para a conclusão do trabalho de pesquisa.

Aos meus pais Blanca e Fernando, pelo apoio moral, À Professora Carmen Elena Patiño Rodriguez, pela cooperação na elaboração desde trabalho, pelos acertados conselhos, pela amizade e companhia.

Ao meu grande amigo Eng. Matheus Ribeiro Lovato, pela colaboração na elaboração do trabalho e especialmente pela amizade sincera e transparente que me permite ver a grandeza dos brasileiros. 
Aos meus colegas e amigos do laboratório de Confiabilidade: Érico, Erick, Dennis, William, Luciana, Natalia, Guilherme e Alyne, pela colaboração e pela amizade.

Aos meus colegas e amigos, Engenheiros: Luis Chaves, Carlos Montalban, Gian Carlo Obando, David Lira, e Roger Valencia, assim como Diego Gonzalez, Juan Carlos Burbano, Pablo Correa, Miguel Montoya, Natalia Lara, Pedro Angel, Diana Lopez, Ana Maria Arteaga, Claudia Ossa e Hector Velasquez, pela amizade e pelo apoio desde o começo até hoje.

A todos os amigos, pelo apoio, pela confiança e a amizade que apesar da distancia nunca se viu afetada. Também aos meus companheiros da Kostka-95, que mesmo de longe sempre me apoiaram. 
“A mayor gloria de Dios"

(São Ignácio de Loyola, S. J.) 


\section{RESUMO}

No mercado mundial de geração e comercialização de energia elétrica, termos como Sustentabilidade, Responsabilidade Ambiental, Satisfação do Consumidor, Alta Disponibilidade e Redução de Custos direcionam os objetivos das empresas geradoras. Com a intenção de cumprir com estes objetivos, são investidas grandes quantidades de recursos para conseguir um desenvolvimento técnico-científico das diversas áreas da empresa, e de forma especial às de Operação e Manutenção (O\&M), responsáveis diretas pela operação das instalações.

Neste contexto, a filosofia da Manutenção Centrada em Confiabilidade (MCC) proporciona uma metodologia bem estruturada para a seleção de políticas de manutenção que permitem a redução de intervenções desnecessárias, dos custos relacionados a estas, e permite a operação com alta confiabilidade, produto da redução da probabilidade de ocorrência de falhas. Apesar destas vantagens, o MCC carece de um mecanismo que estime os riscos relacionados com uma determinada condição de operação, o que leva aos operadores a procurar estratégias de seleção de políticas de manutenção que complementem a filosofia do MCC. A análise de risco de operações industriais proporciona um mecanismo para a tomada de decisões estratégicas relacionadas à instalação de equipamentos de segurança e/ou mudanças nas políticas de manutenção, por meio da quantificação das probabilidades de ocorrência de falhas e dos custos relacionados às possíveis conseqüências produto da ocorrência de falhas.

Este trabalho apresenta um método baseado nos conceitos de confiabilidade e análise de risco que auxilia a tomada de decisões na seleção de estratégias de operação que visem a alta disponibilidade das usinas de geração de energia elétrica, por meio da seleção de políticas de manutenção e/ou identificação da necessidade da instalação de novos equipamentos críticos. Desta forma, as decisões serão auxiliadas por um método de análise bem estruturado, que permite identificar os sistemas e componentes que em caso de ocorrência de falhas poderiam ocasionar conseqüências perigosas relacionadas à segurança, ao meio ambiente, à vida dos operadores, à integridade física das instalações e às atividades comerciais das empresas geradoras. O método é aplicado em uma usina termelétrica com potencia de cerca de 500MW. 


\begin{abstract}
In the global market of electricity generation, terms such as Sustainability, Environmental Responsibility, Customer Satisfaction, High Availability and Reduced Costs guide the actions of businesses as main goals in planning their activities. With the determination to meet these goals, companies invest large amounts of resources to achieve a technical-scientific development in the various areas of the company, especially in the Operation and Maintenance $(\mathrm{O} \& \mathrm{M})$, responsible for direct operation of the facilities.
\end{abstract}

In this context, the philosophy of Reliability Centered Maintenance (RCM) provides a well structured methodology for the selection of maintenance policies, which allow the reduction of maintenance unnecessary interventions, reducing costs related to these, and increasing system reliability due decreasing the probability of failure. Despite these advantages, RCM lacks a mechanism to estimate the risks associated with a given operating condition, which motivates operators to seek strategies for selecting maintenance policies that complement the RCM philosophy. Risk analysis of industrial operations provide a mechanism for making strategic decisions related to the installation of safety equipment and / or changes in maintenance policies, by quantifying the probability of failures and the costs related to the possible consequences of failures occurrence.

This Doctoral thesis presents a method based on the concepts of reliability and risk analysis to aid decision making in the selection of operating strategies that address the high availability of electric power plants through the selection of maintenance policies and/or the identification of the need of installing new equipment. Thus, decisions will be aided by a well structured method of analysis helping, to identify systems and components that in case of failures could lead to very dangerous consequences related to safety, environment, operators' life, integrity of facilities and commercial activities the company. The method is applied on the analysis of a $500 \mathrm{MW}$ thermal power plant. 


\section{RESUMEN}

En el mercado mundial de comercialización y generación de energía eléctrica, términos como Sustentabilidad, Responsabilidad Ambiental, Satisfacción al Consumidor, Alta Disponibilidad y Reducción de Costos, nortean los objetivos de las empresas generadoras. Con la determinación de cumplir con estos objetivos, son invertidos grandes cantidades de recursos para lograr un desarrollo técnico-científico en las diversas áreas que conforman la empresa y de manera especial la de Operación y Mantenimiento (O\&M), responsable directa de la operación de la instalación.

En este contexto, la filosofía del Mantenimiento Centrado en Confiabilidad (MCC) proporciona una metodología bien estructurada para la selección de políticas de mantenimiento, que permite la reducción de intervenciones innecesarias, de costos relacionados con estas y permite la operación del sistema con alta confiabilidad, resultado de la reducción de la probabilidad ocurrencia de fallas. A pesar de estas ventajas, el MCC carece de un mecanismo para estimar el riesgo asociado con una determinada condición de operación. Esto motiva a los operadores a buscar estrategias para la selección de políticas de mantenimiento que complementen el MCC. El análisis de riesgos de las operaciones industriales proporciona un mecanismo para la toma de decisiones estrategias relacionadas con la instalación de equipos de seguridad y/o cambios en las políticas de mantenimiento, mediante la cuantificación de la probabilidad de fallas y los costos relacionados con las posibles consecuencias de estas.

Este trabajo de Doctorado presenta un método basado en los conceptos de confiabilidad y análisis de riesgos, para auxiliar la toma de decisiones en la selección de estrategias operativas que garanticen alta disponibilidad de planta de generación energía eléctrica, a través de la selección de políticas de mantenimiento y/o la identificación de la necesidad de instalación de nuevos equipos críticos. De esta manera, las decisiones son auxiliadas por un bien estructurado método de análisis, que permite la identificar los sistemas y componentes que en caso de falla podrían traer consecuencias peligrosas, tanto para la seguridad, el medio ambiente, de las vidas de los operadores, las instalaciones y las actividades comerciales de la empresa generadora. El método es aplicado en una planta de genracion de 500 MW aproximadamente. 


\section{LISTA DE FIGURAS}

Figura 1.1. Representação dos Fatores da Decisão .......................................................

Figura 1.2. Fluxograma da pesquisa de Doutorado...................................................... 8

Figura 2.1. Função de probabilidade acumulada $F(t)($ LEITCH 1995) .......................... 16

Figura 2.2 Função de confiabilidade $R(t)$ (LEITCH 1995) ............................................. 18

Figura 2.3. Representação da curva da banheira (LEWIS, 1987) ................................. 19

Figura 2.4 Implementação do MCC em sistemas complexos (CARAZAS e

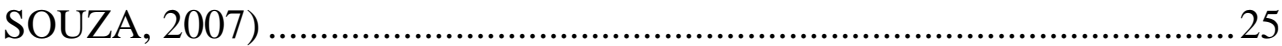

Figura 2.5. Diagrama de classificação das consequiências das falhas (LAFRAIA, 2001)

Figura 2.6. Diagrama de decisões para a seleção de práticas de manutenção modos de falha envolvendo conseqüências de segurança (MOUBRAY, 2000)

Figura 2.7. Diagrama de decisões para a seleção de práticas de manutenção modos de falha envolvendo conseqüências operacionais e nãooperacionais (MOUBRAY, 2000)

Figura 2.8. Diagrama de decisões para a seleção de práticas de manutenção modos de falha envolvendo consequiências ocultas (MOUBRAY, 2000) 30

Figura 3.1. Processo de análise de risco (ARENDT, 1990). 39

Figura 3.2 Requisitos para a elaboração da Árvore de Falhas (RAUSAND e HOYLAND, 2004)..... 52

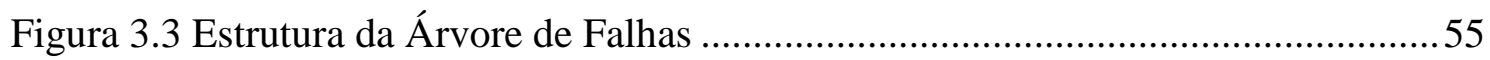

Figura 3.4 Representação da Árvore de Eventos .......................................................56

Figura 3.5. Caixa de decisão no Diagrama Causa-Conseqüência ..................................58

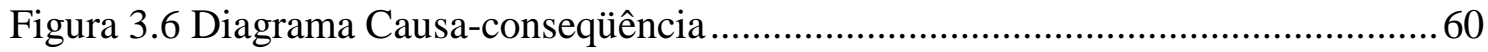

Figura 3.7. Classificação dos problemas de decisão (adaptado de SHIMIZU, 2001) .71

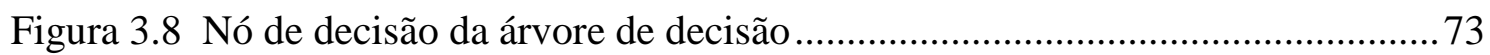

Figura 3.9. Nó de mudança da árvore de decisão ....................................................... 74

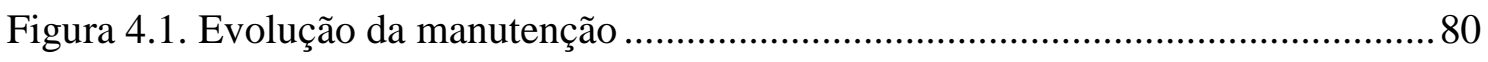

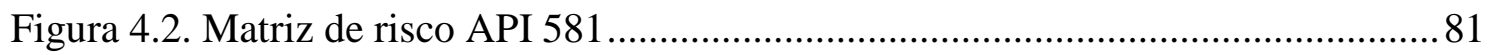


Figura 4.3. Níveis de análise de inspeção baseada em risco (ABS, 2003)

Figura 4.4 Representação do método de tomada de decisões baseadas na análise de risco

Figura 4.5 Procedimento para a definição do escopo no processo de análise.. 87

Figura 4.6. Árvore funcional ilustrativa do sistema de bombeamento de água... 88

Figura 4.7. Arranjo geral de árvore funcional...... 89

Figura 4.8. Procedimento para a aplicação das técnicas de análise de risco. 91

Figura 4.9. Procedimento para a quantificação do risco . .94

Figura 4.10. Procedimento do cálculo de disponibilidade (CARAZAS et al., 2007e)

Figura 4.11. Custos relacionados com a operação de sistemas geração de energia elétrica. 95

Figura 4.12. Estrutura de custos de geração. .96

Figura 4.13. Estrutura dos custos fixos de O\&M. 97

Figura 4.14. Estrutura de custos variáveis .97

Figura 4.15. Estrutura de custos de disponibilidade 98

Figura 4.16. Exemplo de matriz de risco 100

Figura 4.17. Processo de decisão em manutenção 101

Figura 6.1. Arranjo da usina Termelétrica sob análise...... 113

Figura 6.2. Árvore funcional da usina Termelétrica a ciclo combinado. 114

Figura 6.3 Árvore funcional da caldeira de recuperação (HRSG). 116

Figura 6.4. Árvore funcional do sistema de resfriamento de condensado e água de circulação

Figura 6.5. Diagrama de pareto das falhas do HRSG 1

Figura 6.6. Sistema de alimentação de água da caldeira de recuperação.

Figura 6.7. Árvore funcional do sistema de alimentação de água da caldeira de recuperação.

Figura 6.8. TRIPs do sistema de alimentação de água da HRSG 1 (Adaptado).

Figura 6.9. Diagrama Causa-Conseqüência para o sistema de alimentação de água da caldeira de recuperação .

Figura 6.10 Distribuição de confiabilidade da bomba de alimentação 1

Figura 6.11 Distribuição de confiabilidade da bomba de alimentação 2

Figura 6.12. Distribuição de confiabilidade da válvula ARC 1 
Figura 6.13. Distribuição de confiabilidade da válvula ARC 2

Figura 6.14. Representação da primeira etapa da decisão 153

Figura 6.15. Representação da decisão ..... 153

Figura 6.16. Árvore de decisão 156

Figura 6.17 Distribuição das custos relacionados com a instalação do sistema redundante de alimentação de água em função das probabilidades 158

Figura 6.18. Diagrama de blocos do sistema de alimentação de água da caldeira 159

Figura 6.19. Diagrama de blocos de representação da usina termelétrica 161 


\section{LISTA DE TABELAS}

Tabela 2.1. Evolução das filosofias de manutenção (MOLINARI, 2007; LEE, 2003; ARUNRAJ e MAITI, 2007)

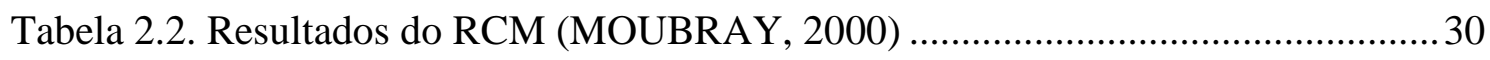

Tabela 3.1 Análise Preliminar de Risco (APP) ..............................................................4 43

Tabela 3.2. Análise de Modos e Efeitos das Falhas (CARAZAS, 2006)........................4 47

Tabela 3.3. Classificação da Severidade (CARAZAS, 2006)....................................... 49

Tabela 3.4. Simbologia utilizada na construção de uma Árvore de Falhas

(RAUSAND e HOYLAND, 2004) ..........................................................54

Tabela 3.5 Comparação das Principais Técnicas de analise de risco.............................63

Tabela 3.6 Tipos de problemas e nível de decisão (adaptado de SHIMIZU, 2001) .......69

Tabela 4.1. Definição das categorias de conseqüências e probabilidades de falha para a matriz de risco (ECKSTEIN et al., 2002) ........................................81

Tabela 4.2. Formulário empregado na análise FMEA................................................92

Tabela 5.1. Análise comparativa dos métodos baseados na análise de risco para seleção de políticas de manutenção.

Tabela 6.1. Classificação de severidade para o sistema de geração de energia elétrica (CARAZAS, 2006).

Tabela 6.2. Resultados da aplicação da análise de modos e efeitos de falhas em uma usina termelétrica a ciclo combinado.

Tabela 6.3. Características e recomendações para a caldeira de recuperação e torres de resfriamento em função do tipo de política de manutenção 125

Tabela 6.4. Lista de eventos iniciadores do diagrama causa-conseqüêencia.................. 131

Tabela 6.5. Dados de operação da bomba 1 ................................................................ 141

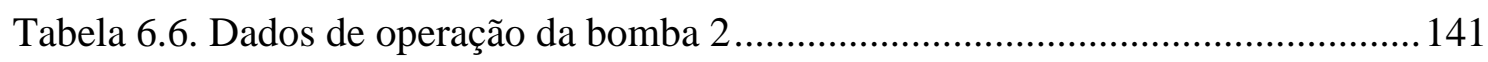

Tabela 6.7. Dados de operação de válvula ARC 1 ..................................................... 141

Tabela 6.8. Dados de operação de válvula ARC 2 ...................................................... 142

Tabela 6.9. Parâmetros das distribuições de confiabilidade .......................................... 144

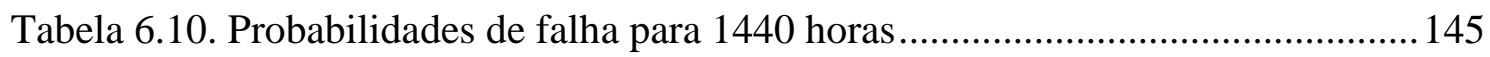

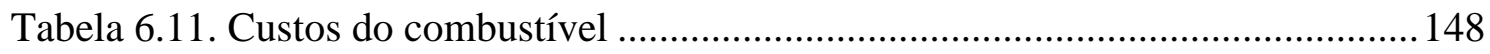

Tabela 6.12. Custos relacionados com a falha do sistema de bombeio ....................... 149

Tabela 6.13. Custos de compra energia para uma parada de 68 horas.......................... 150 
Tabela 6.14. Custos dos cenários de operação com bomba redundante para um período de $1440 \mathrm{~h}$

Tabela 6.15. Custos dos cenários de operação atual para um período de 1440 horas (sem sistema de redundante) ...................................................... 155

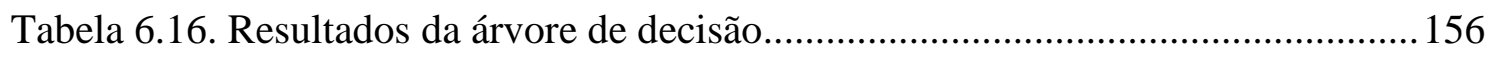

Tabela 6.17. Análise de sensibilidade para o problema de decisão ............................... 157

Tabela 6.18. Parâmetros das distribuições de Mantenabilidade .................................... 158

Tabela 6.19. Disponibilidade dos sistemas de alimentação de água da caldeira ..........159

Tabela 6.20. Recomendações de inspeção e manutenção para o sistema de alimentação de água da caldeira ............................................................ 160

Tabela 6.21. Simulação da variação da disponibilidade do sistema de alimentação

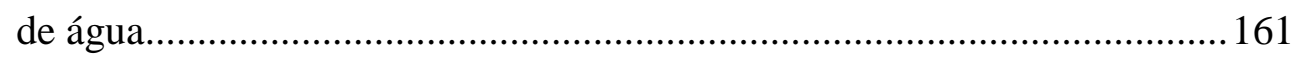

Tabela 6.22. Parâmetros para o cálculo de disponibilidade da Usina ........................... 162 


\section{LISTA DE SIGLAS}

ARC Automatic Recirculation Valve

DCS Distributed Control System (Sistema de Controle Distribuído)

FMEA Análise de Modos e Efeitos de Falhas (Failure Modes and Effect Analysis)

GT Gas Turbine (Turbina a Gás)

HRSG Heat Recovery Steam Generator

O\&M Operação e Manutenção

MTBF Tempo Médio Entre Falhas (Mean Time Between Failure)

MTBRA Tempo Médio de Execução das Atividades Associadas com a Manutenção Preventiva (Mean Time Between Repair Activities)

MTTR Tempo Médio para Reparo (Mean Time To Repair)

MCC Manutenção Centrada em Confiabilidade

RCM Reliability Center Maintenance

RBM Risk Based Maintenance

SMBR Método de Seleção de Políticas de Manutenção Baseado em Risco

UTE Usina Termelétrica 


\section{LISTA DE SIMBOLOS}

$T \quad$ Tempo até ocorrer a falha

$f(t) \quad$ Função densidade de probabilidade no tempo $t$

$F(t) \quad$ Função de probabilidade acumulada no tempo $\mathrm{t}$

$R(t) \quad$ Confiabilidade no tempo $\mathrm{t}$

$R_{m}(t)$ Confiabilidade do sistema após manutenção preventiva

$\lambda(t) \quad$ Taxa de falha no tempo $t$

$\mu \quad$ Média de um conjunto de dados

$\sigma \quad$ Desvio padrão de um conjunto de dados

$x_{0} \quad$ Constante de localização da distribuição de Weibull

$\eta \quad$ Constante de escala da distribuição de Weibull

$\beta \quad$ Constante de forma da distribuição de Weibull

$R_{s}(t) \quad$ Confiabilidade do sistema no tempo $\mathrm{t}$

$R_{i}(t) \quad$ Confiabilidade do componente i no tempo $\mathrm{t}$

$F_{s}(t) \quad$ Função distribuição acumulada de falhas para o sistema no tempo $t$

$F_{i}(t)$ Função distribuição acumulada de falhas para o componente i no tempo t

$m(t)$ Função distribuição de probabilidade para a execução do reparo no tempo $t$

$t_{\text {rep }} \quad$ Tempo de reparo do equipamento

$M(t) \quad$ Função distribuição acumulada para a execução do reparo no tempo $t$

$v(t) \quad$ Taxa de reparo

$A(T) \quad$ Disponibilidade ao longo de um intervalo de tempo

$A^{*}(T)$ Disponibilidade média no intervalo de tempo

$\hat{A}(t) \quad$ Indisponibilidade no tempo $\mathrm{t}$

$\Phi \quad$ Símbolo da distribuição normal reduzida

$p_{i} \quad$ Probabilidade de falha

$c_{i} \quad$ Consequiência da falha 


\section{SUMÁRIO}

CAPÍTULO 1 - INTRODUÇÃO 1

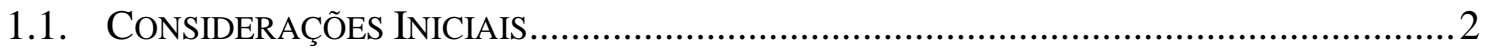

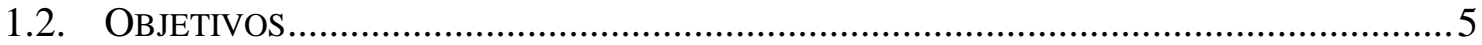

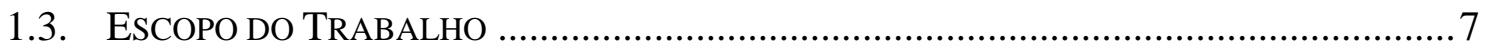

CAPÍTULO 2 - FUNDAMENTO TEÓRICO I - A CONFIABILIDADE E MANUTENÇÃO CENTRADA EM CONFIABILIDADE (MCC) .............................. 10

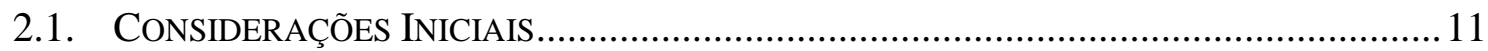

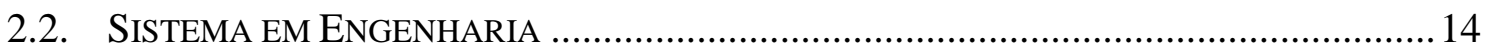

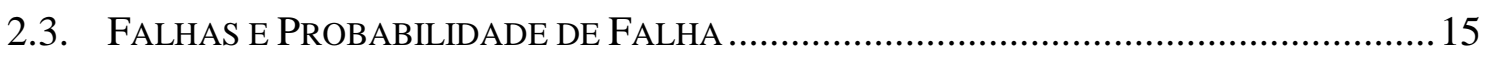

2.4. CONFIABILIDADE, MANTENABILIDADE E DisPONIBILIDADE ...................................... 16

2.5. A MANUTENÇÃo CENTRADA EM CONFIABILIDADE (MCC) OU RELIABILITY

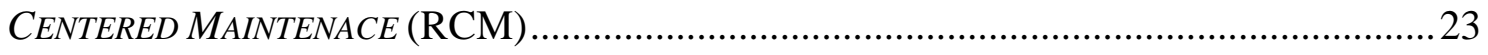

CAPÍTULO 3 - FUNDAMENTO TEÓRICO II - ANÁLISE DE RISCO E TEORIA

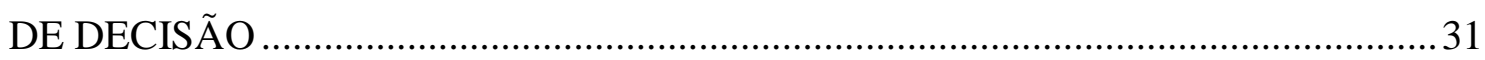

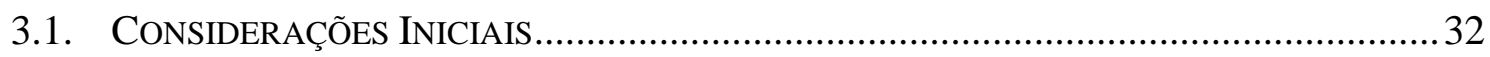

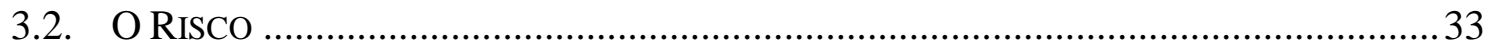

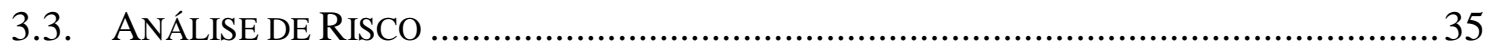

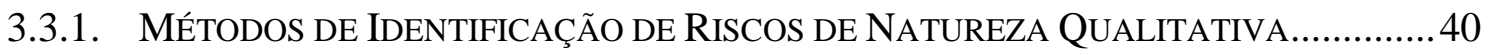

3.3.2. MÉtodo de IdENTIFICAÇÃO DE Riscos DE NATUREZA QUANTITATIVA ..............51

3.3.3. CONSIDERAÇÕES FINAIS EM RELAÇÃo ÀS TÉCNICAS DE ANÁLISE DE RISCO........61

3.4. ANÁLISE DE DECISÃO - CONCEITOS INICIAS ........................................................... 64

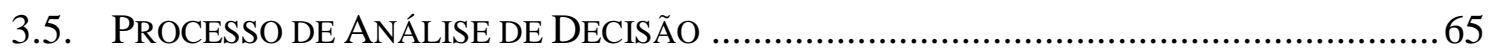

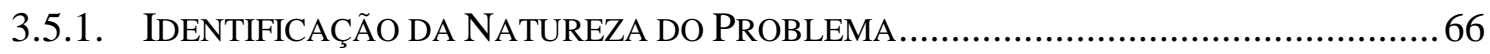

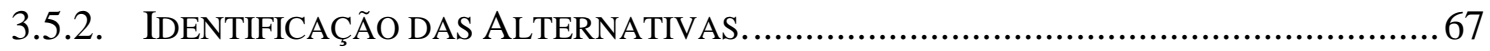

3.5.3. CLASSIFICAÇÃO DOS PROBLEMAS DE DECISÃO. ................................................... 70

3.5.4. SELEÇÃO DO MÉTOdO DE TOMADA DE DECISÃO.............................................. 71

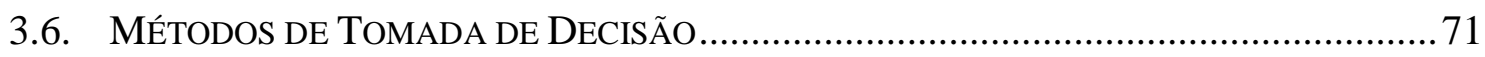




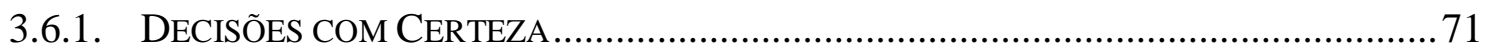

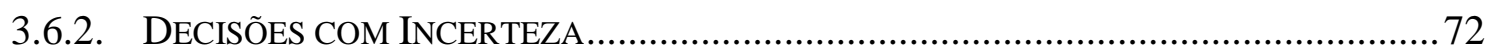

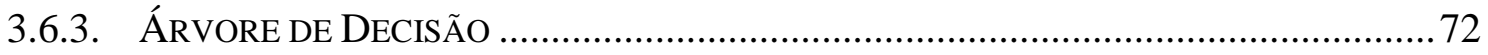

CAPÍTULO 4 - MÉTODO PARA A SELEÇÃO DE POLÍTICAS DE MANUTENÇÃO NA INDÚSTRIA DE GERAÇÃO DE ENERGIA ELÉTRICA - A

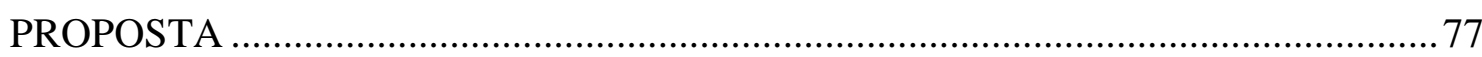

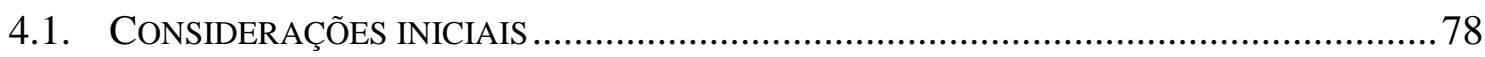

4.2. AnÁlise de Risco APlicada À MANUTEnÇão e InSPeÇão de Processos

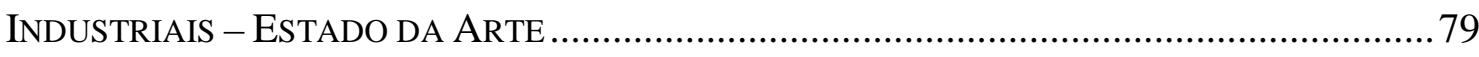

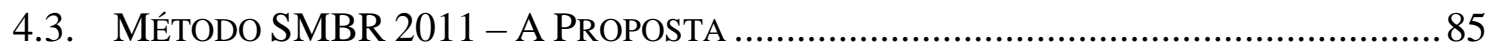

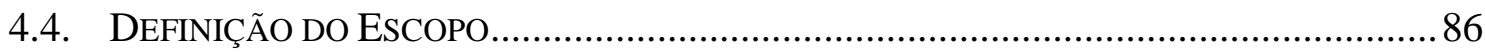

4.5. IdentificaÇão do Risco e Modelagem dos CenáRIos de OPERAÇÃo / FalHa 89

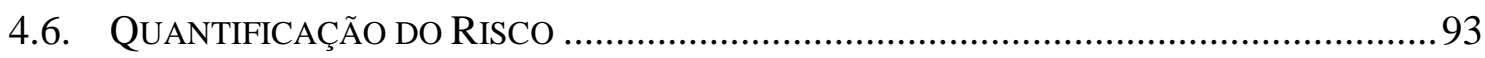

4.6.1. Custos Relacionados à Operação de Sistemas de Geração de ENERgia

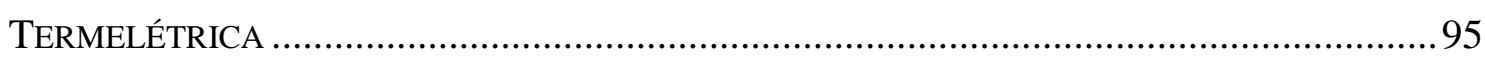

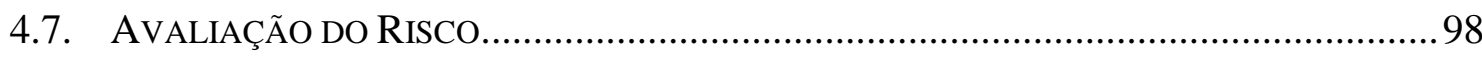

CAPÍTULO 5 - DISCUSSÃO - AS INOVAÇÕES DA PROPOSTA ………………...103

5.1. Análise Comparativa entre os Diversos Métodos da Bibliografia e o

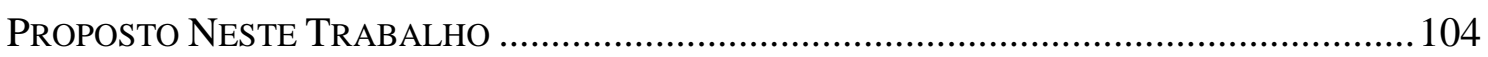

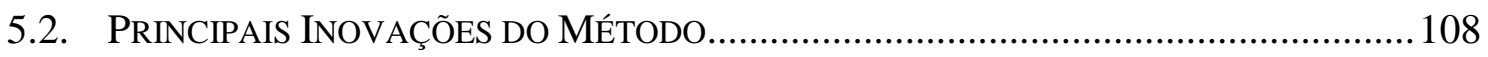

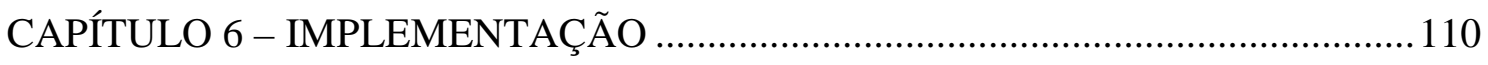

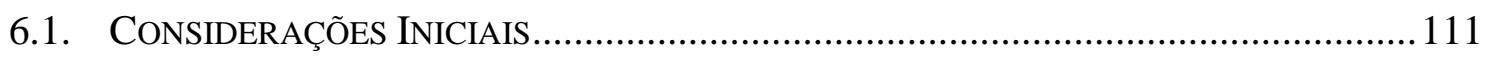

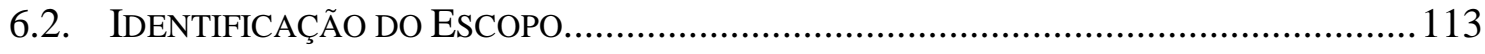

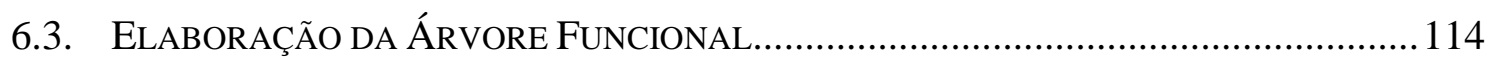

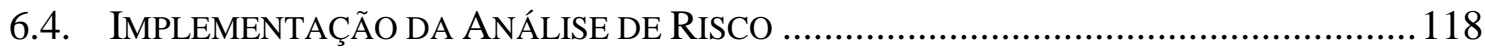

6.5. Aplicação da Análise de Para o Sistema de AlimentaÇão de Água das

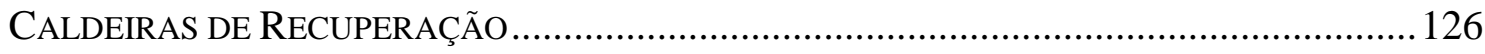


6.6. QuantificaÇÃo do Risco - Sistema de AlimentaÇão da CALDEIRA DE

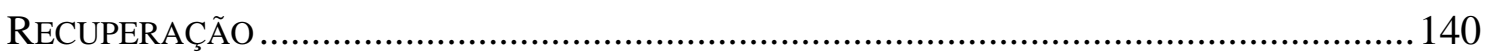

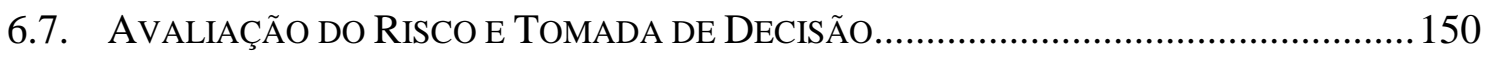

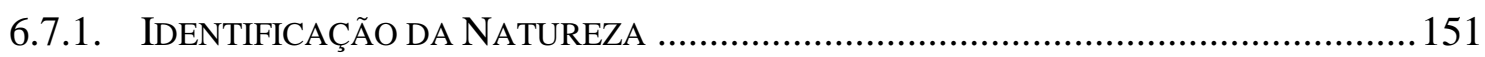

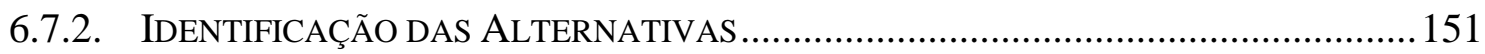

6.7.3. ClLASSIFICAÇÃo dos PRoblemas de DeCISÃo ................................................. 151

6.7.4. SELEÇÃo do Método de Tomada de DecisÃo................................................. 152

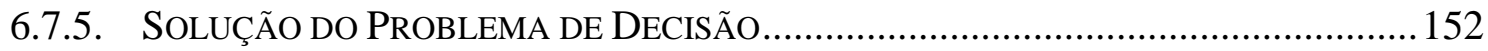

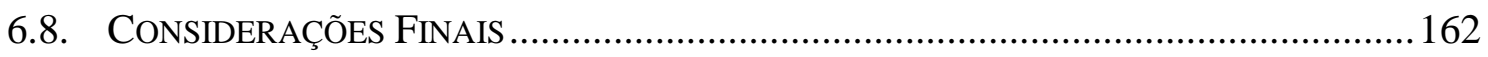

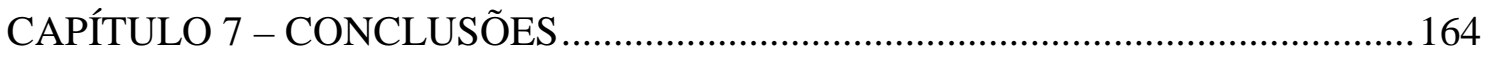

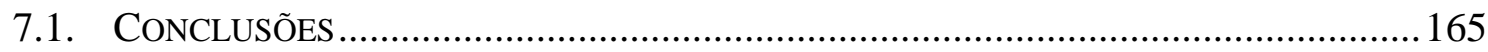

7.2. RECOMENDAÇÕES PARA TRABALHOS FUtUROS BASEAdOS NO SMBR $2011 \ldots \ldots . . . .171$

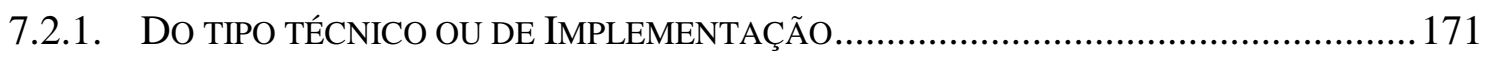

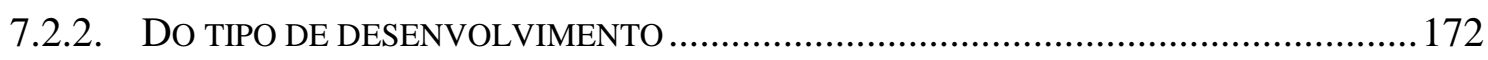

CAPÍTULO 8 - REFERÊNCIAS BIBLIOGRÁFICAS ............................................ 173

APÊNDICE A - REAVALIAÇÃO DO PROBLEMA DO PONTO DE VISTA

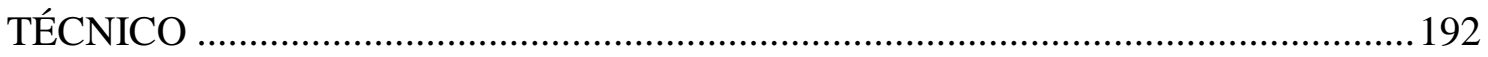

A.1. AnÁlise do Problema do Ponto de Vista TÉCNICO ........................................... 193

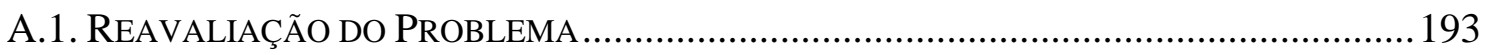

APÊNDICE B - ANÁLISE DE MODOS E EFEITOS DE FALHAS PARA O SISTEMA DE ALIMENTAÇÃO DE ÁGUA DAS CALDEIRAS DE

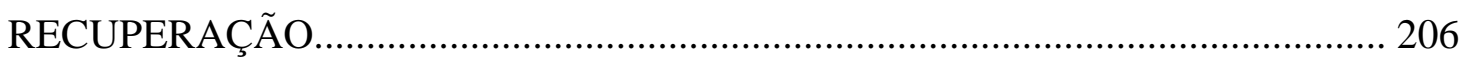




\section{CAPÍTULO 1 - INTRODUÇÃO}

O capítulo de introdução apresenta, de forma resumida, os antecedentes e necessidades da indústria de geração de energia elétrica que motivaram o desenvolvimento do presente trabalho de tese de doutorado. Aqui são apresentados os objetivos, um breve resumo dos sete capítulos do texto, e finalmente o diagrama de fluxo que representa a estrutura do trabalho. 


\subsection{Considerações Iniciais}

Grandes sistemas eletros-mecânico com numerosos componentes e interconexões, interações ou interdependências que são difíceis de descrever, compreender, predizer, projetar e/ou reparar são chamados de "sistemas complexos" (MAGEE e WECK, 2004). Estes sistemas exigem que todos os seus componentes estejam operando de forma satisfatória, cumprindo as suas funções particulares especificas e individuais para poder cumprir com uma única função em conjunto. No caso em que o sistema não consiga realizar sua função ou a atenda com um desempenho abaixo do esperado, define-se que este se encontra em um estado de falha. No caso específico de sistemas de geração de energia elétrica (instalações hidrelétricas, termelétricas ou termonucleares indistintamente), cumprir a sua função é estar com capacidade para geração de energia elétrica acima de uma potência previamente definida ou simplesmente disponível, como é chamado no mercado de comercialização de energia elétrica. Além disso, o sistema deve operar com segurança, tanto no sentido de evitar danos às instalações e aos operadores como ao meio ambiente. Diante do exposto, neste tipo de sistema, o planejamento e a execução da atividade de manutenção são de grande importância.

A manutenção por definição é a combinação de atividades, conhecimentos e destrezas aplicadas em um sistema ou equipamento para manter um estado específico de operação ou recuperá-lo após a ocorrência de uma falha ao longo da vida útil planejada. Em grandes sistemas, garantir este estado de operação pode ser uma tarefa complexa devido à quantidade de componentes a serem submetidos às ações de manutenção.

Com a finalidade de garantir a disponibilidade do sistema, os próprios projetistas e fabricantes desenvolvem planos de manutenção. As equipes encarregadas da execução da manutenção encontram um plano bem definido de atividades, onde são exigidas rotinas de inspeção, limpeza e troca de componentes, em períodos também rigidamente 
definidos. Ainda no caso de ocorrência de falhas de alguns componentes específicos que afetam fortemente o desempenho do sistema de geração de energia elétrica, estas equipes estão impedidas de atuar em função de contratos de garantia, que não permitem a realização de trabalhos de manutenção em alguns componentes. Para estes componentes os fabricantes enviam equipes que executam atividades de manutenção preventivas em períodos específicos da vida útil operacional. Estes fatos tornam a manutenção uma elevada parcela do orçamento anual de Operação e Manutenção (O\&M), reduzindo o lucro do agente gerador.

As diretorias das empresas de geração de energia, frente a este cenário, estudam a possibilidade de modificar os contratos de manutenção com os fabricantes na intenção de reduzir os custos. Contudo, são conscientes de que enfrentam um grande desafio que é "pelos seus próprios meios garantir a disponibilidade do sistema, com as mesmas margens de confiabilidade e segurança durante a operação, por meio da implementação de um novo modelo de manutenção".

Há diversas filosofias de seleção de políticas de manutenção que auxiliam as empresas que buscam este tipo de mudança no planejamento da manutenção de sistemas complexos. Destas, duas são tradicionalmente citadas: a filosofia da Manutenção da Produtividade Total, TPM (do inglês Total Productive Maintenance), e a filosofia da Manutenção Centrada em Confiabilidade, MCC ou RCM (do inglês Reliability Centred Maintenance), (DUFFUAA et al., 1999; CARDOSO, 2000; SMITH e HINCHCLIFFE, 2004; LEE, 2003). Atualmente, somam-se a estas, as modernas filosofias baseadas nos conceitos da análise de risco, como por exemplo, Inspeção Baseada em Risco, RBI (do inglês Risk Based Inspection) e a Manutenção Baseada em Risco, RBM (do inglês Risk Based Maintenance) (FUJIYAMA et al., 2004; JANJIC, 2007; APELAND e AVEN, 2000; KHAN e HADDARA 2004; NILSON 2003).

A filosofia do TPM nasceu no Japão por volta de 1970, e foi aplicada pela primeira vez na empresa Nippondenso, do grupo Toyota (COELHO, 2008). A implementação do TPM é composta de um conjunto de atividades de manutenção que visam o aumento do desempenho e da produtividade, mas o ponto chave da filosofia está no envolvimento de todos os funcionários da empresa nas atividades de 
manutenção. Por este mesmo motivo é que a filosofia do TPM é complexa e puramente operacional. (TAJIRI e GOTOH 1999).

A filosofia do MCC utiliza um critério de seleção que prioriza as políticas de manutenção em função do tipo de falha que um componente pode apresentar. Os quatro tipos de falhas funcionais consideradas para a seleção das políticas de manutenção são: as que afetam a segurança, a operação (aquelas que reduzem o desempenho), as não operacionais (falhas que param a operação do sistema) e as ocultas (definidas como aquelas que não manifestam sintomas de ocorrência durante a operação normal do sistema) (MOUBRAY, 2000; SMITH e HINCHCLIFFE, 2004). Uma vez identificadas as falhas, é iniciado o processo de decisão que envolve um estudo sistemático de qual das três práticas básicas de manutenção - corretiva, preventiva e preditiva - poderia ser aplicada no componente, a fim de minimizar sua probabilidade de falha ao longo de um determinado período de operação. O processo de seleção é auxiliado pelos "diagramas de decisão" do MCC, que consideram como critérios de seleção a possível aplicabilidade das práticas e a sua eficácia para retardar ou evitar a ocorrência de um dado modo de falha, que poderia desencadear conseqüências graves para a operação do sistema. Os diagramas de decisão empregados pelo MCC são apresentados em diversas referências (LAFRAIA, 2001; CARDOSO, 2000; CARAZAS, 2006; MOUBRAY, 2000 e SMITH E HINCHCLIFFE, 2004).

Carazas (2006) verifica que qualquer que seja a conseqüência da falha, busca-se preferencialmente a aplicação da prática de manutenção preditiva, apesar de ser custosa e não ser simples de aplicar, devido à complexidade na operação dos equipamentos de inspeção e interpretação de resultados da medição que auxiliam à prática de manutenção preditiva. O processo de seleção de políticas de manutenção através da aplicação do MCC está fortemente relacionado com a tecnologia dos equipamentos de medição e monitoração e visa principalmente à segurança. Entretanto, os critérios de seleção não incluem um mecanismo de avaliação dos custos em função das incertezas associadas com a adoção de uma nova política de manutenção. Em termos de análise de planejamento de manutenção, o risco é definido como a combinação da probabilidade de falha e das suas consequiências em termos de custos associados à perda do desempenho operacional da planta, incluindo o componente de segurança, considerando 
que os componentes são submetidos a uma determinada política de manutenção (SCHUYLER, 2002; SCHÖDER e KAUER, 2004).

Nestes termos, este trabalho apresenta um método que visa auxiliar os critérios de tomada de decisão em manutenção, avaliando, além da segurança, confiabilidade e disponibilidade do sistema, os custos associados à implementação de novas estratégias de manutenção e/ou instalação de novos equipamentos, e as possíveis conseqüências, em termos de custo, no caso da ocorrência de falha mesmo sob a ação de uma nova política de manutenção ou após a execução de uma modificação da planta. O método proposto está baseado nos conceitos de análise de risco, decisões baseadas em risco e está em sintonia com as novas filosofias para a seleção de políticas de manutenção baseadas em risco. Desta forma este é denominado "método para a seleção de políticas de manutenção baseado em risco", SMBR.

A Figura 1.1 representa, de forma esquemática, os elementos de um processo de decisão como parte do método SMBR, onde são comparados os benefícios (financeiros) da aplicação de uma determinada política de manutenção com as despesas decorrentes da falha do componente submetido à nova política de manutenção. O propósito é selecionar uma política que minimize os custos associados com a operação do sistema em longo prazo, quando submetido à ação de uma nova política de manutenção.

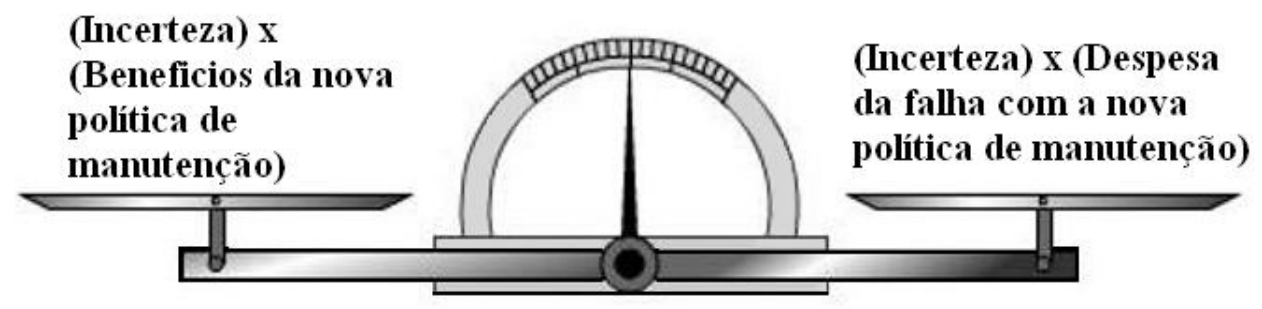

Figura 1.1. Representação dos Fatores da Decisão

\subsection{Objetivos}

Quando se trata de sistemas de grande porte, uma das maiores preocupações dos operadores e investidores diz respeito ao custo de se manter o sistema operando de forma a trazer um retorno satisfatório para a empresa. Esta questão freqüentemente é 
respondida pelos próprios fabricantes do sistema. Com o passar do tempo e à medida que os operadores aprendem a operar e trabalhar com o sistema, tal resposta é cada vez menos satisfatória (considerando os elevados custos das atividades de manutenção).

Neste contexto, as empresas partem à procura de soluções satisfatórias - em termos de custos - sem perder capacidade e qualidade produtiva. Este trabalho apresenta uma proposta baseada na análise de risco que fornece às empresas uma alternativa na busca de uma filosofia de planejamento de manutenção e seleção de novos componentes nos seus sistemas produtivos.

Assim, esta Tese de Doutorado tem como objetivo desenvolver um método que auxilie na tomada de decisões estratégicas no campo operacional - mudanças e seleção de políticas de manutenção, instalação de novos equipamentos ou mesmo equipamentos redundantes - em sistemas de geração de energia elétrica aplicando, de forma combinada, a filosofia do MCC e as ferramentas da Análise de Risco.

O método visa assegurar que o sistema de geração e todos os seus componentes continuem cumprindo as funções requeridas, através da seleção da atividade de manutenção preventiva ou preditiva mais adequada para todos os componentes do sistema baseando-se na quantificação do risco associado à falha dos componentes, considerando os possíveis cenários de operação decorrentes da falha. Ainda estes cenários estão relacionados ao montante de potencia que uma usina está fornecendo (de forma porcentual, em relação à capacidade total de geração) e ao tipo de contrato de fornecimento que ela mantém com o cliente, incluindo o Operador Nacional do Sistema (ONS). Estes afetam os denominados custos da conseqüência da falha.

O método permite identificar as consequiências das principais falhas funcionais (chamadas falhas operacionais pela filosofia do MCC), sob o ponto de vista da segurança dos operadores, do meio ambiente e, como mencionado anteriormente, dos custos associados à operação e manutenção como consequiências de um determinado cenário de operação indesejado, produto da ocorrência de uma falha. 
Como estudo de caso a Tese apresenta a implementação do método a uma Usina Termelétrica (UTE) em ciclo combinado, utilizando os seguintes passos:

- Identificação dos sistemas e componentes críticos de uma usina termelétrica através da aplicação da filosofia da Manutenção Centrada em Confiabilidade, basicamente com a aplicação da Análise de Modos e Efeitos de Falhas (FMEA) e das Arvores Funcionais.

- Avaliação, quantificação e modelagem dos possíveis cenários de falha do sistema, através da aplicação das ferramentas da Análise de Riscos, tais como os Diagramas Causa-Conseqüência. Por meio do estudo dos históricos de operação da usina, é possível quantificar as probabilidades relacionadas com a ocorrência de falha de um determinado componente ou sistema. Com o mesmo banco de dados, foram quantificados os custos das intervenções de manutenção corretiva associadas aos componentes críticos identificados anteriormente.

- Aplicação das ferramentas da teoria de decisão para auxiliar na seleção da melhor alternativa de proposta de manutenção e/ou as possíveis mudanças nas instalações da usina termelétrica a ciclo combinado.

\subsection{Escopo do Trabalho}

Na Figura 1.2 é apresentado o fluxograma de como as atividades do presente trabalho de pesquisa de doutorado foram seguidas, a fim de cumprir com objetivos propostos. 


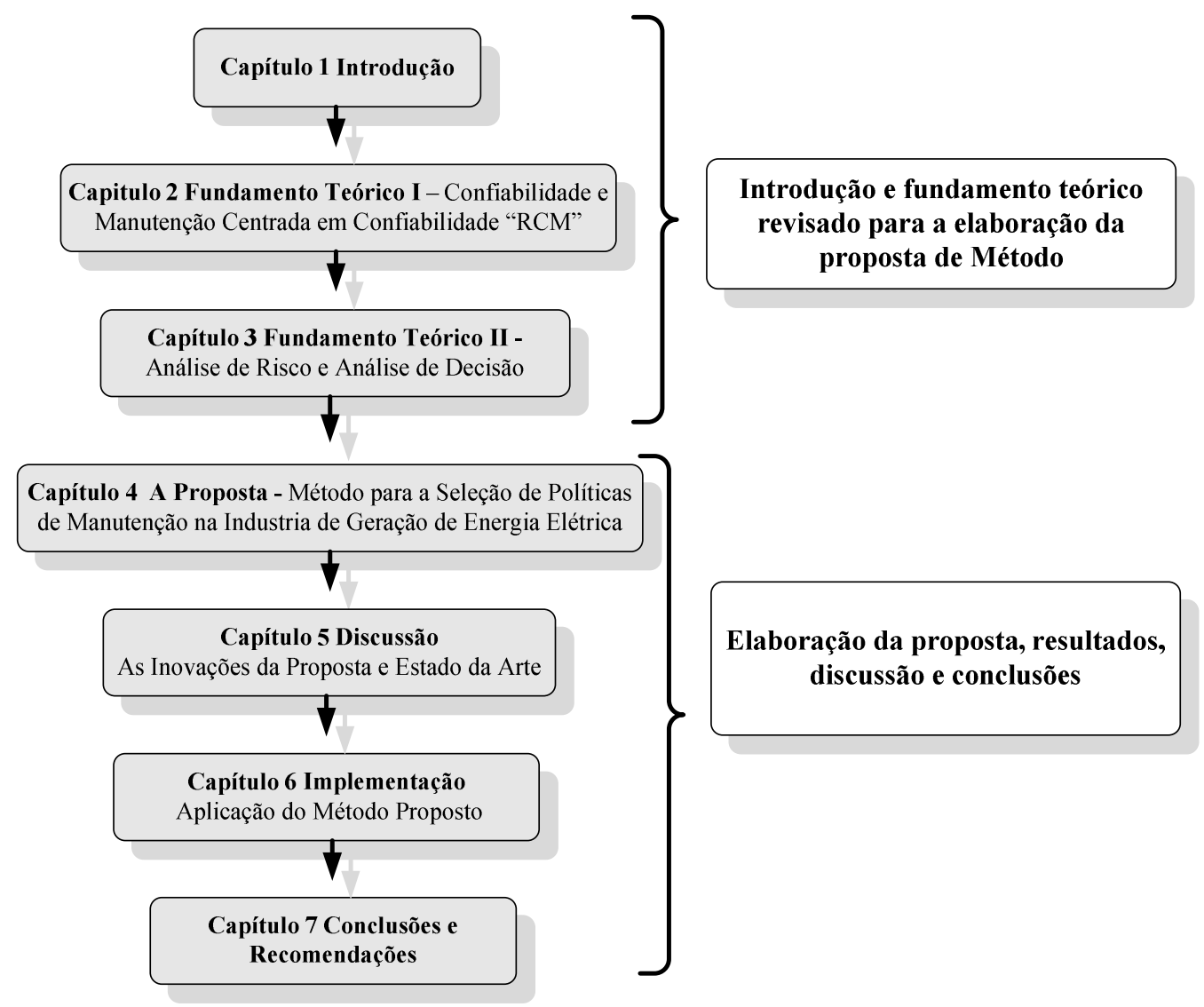

Figura 1.2. Fluxograma da pesquisa de Doutorado

No Capítulo 1 são apresentadas a introdução e os objetivos do trabalho de pesquisa, assim como sua aplicação no planejamento de manutenção para sistemas complexos. No Capítulo 2 são apresentados os principais conceitos de manutenção e a evolução das técnicas de manutenção ao longo do tempo, além dos principais conceitos que deram origem à manutenção baseada em risco. Estes conceitos estão relacionados à engenharia da confiabilidade e à filosofia da Manutenção Centrada na Confiabilidade.

No Capítulo 3 são apresentados os conceitos da análise de risco e como estes influenciam a programação e planejamento da manutenção de sistemas complexos.

No Capítulo 4 apresenta-se o estado da arte e a proposta do método para seleção de políticas de manutenção na indústria de geração de energia elétrica. Adicionalmente é feita uma comparação desta proposta com a técnica mais popular para o planejamento de manutenção estratégica de grandes sistemas, o MCC. 
No Capítulo 5, é elaborada uma comparação entre os diversos métodos propostos nas referencias bibliografias com a proposta do método do autor do presente trabalho de Doutorado (Seleção de Políticas de Manutenção Baseado em Risco SMBR), para finalmente destacar as inovações da proposta aqui apresentada.

O trabalho toma um cunho prático no Capítulo 6, onde é apresentado o caso de aplicação do método proposto a uma usina termelétrica a ciclo combinado. A aplicação do método permite a comprovação da eficácia da estratégia proposta que se viu refletida na economia de aproximadamente US\$ 8 milhões, relacionados ao investimento na instalação de um sistema redundante de bombeamento de água da caldeira de recuperação.

As principais conclusões da pesquisa são apresentadas no Capítulo 7, bem como as recomendações para trabalhos futuros. Finalmente, é apresentada a lista com as referências bibliográficas utilizadas para cumprir com os objetivos apresentados neste capítulo. 


\section{CAPÍTULO 2 - FUNDAMENTO TEÓRICO I - A CONFIABILIDADE E MANUTENÇÃO CENTRADA EM CONFIABILIDADE (MCC)}

No presente capítulo é apresentado o fundamento teórico, estruturado para a compreensão da evolução do planejamento da manutenção e como esta se relaciona com os conceitos de confiabilidade. Dessa forma, o leitor consegue dispor não apenas do fundamento teórico, mas também de um levantamento de caráter introdutório, dos termos utilizados pela engenharia de confiabilidade e sua relação com a evolução da atividade de planejamento da manutenção. 


\subsection{Considerações Iniciais}

A concepção da atividade de manutenção nas diferentes empresas tem mudado bastante durante as últimas duas décadas. Há alguns anos, a manutenção e as equipes de manutenção eram consideradas por algumas empresas apenas como uma fonte de perdas. Atualmente, esta atividade deixou de ser vista apenas como a desenvolvida para repor o sistema em operação após uma falha. Hoje, as equipes de manutenção planejam intervenções, selecionam peças e materiais que permitam aumentar a vida útil dos equipamentos, entre outras atribuições. Desta forma, a atividade de manutenção é considerada como parte vertebral da empresa, pois dependendo da natureza do produto produzido os custos associados a uma parada não planejada para manutenção dos equipamentos da linha de produção podem acarretar em perdas de milhões de reais, fora as possíveis consequiências detrimentais aos operadores, às instalações fabris e ao meio ambiente.

Assim, o planejamento da manutenção transformou-se numa ferramenta de planejamento estratégico que visa a alta disponibilidade, ou seja, a capacidade de uma equipe de manutenção em garantir uma determinada disponibilidade do sistema produtivo por um período de tempo. Entretanto, esse objetivo não é alcançado de uma forma rápida. É preciso um processo de mudanças na filosofia de planejamento as quais, de forma resumida, são descritas nos parágrafos seguintes deste texto.

As grandes mudanças no planejamento da manutenção são produto da necessidade de tornar eficientes as linhas de produção, que até antes da segunda guerra mundial eram pouco mecanizadas e de baixa produtividade, conseqüência de atividades de manutenção basicamente corretivas. No contexto histórico da manutenção, este período, entre os anos 40 e 50, é denominado como a primeira geração da manutenção (MOUBRAY, 2000). Após o término da Segunda Guerra Mundial até a década de 70, 
período denominado de segunda geração da manutenção. Neste período, as atividades das plantas industriais se tornaram mais complexas devido à grande utilização de máquinas no processo de mecanização da produção de bens (MOLINARI, 2007; ARUNRAJ e MAITI, 2007). Desta forma, em função do aumento de componentes nos processos industriais, os custos de manutenção viessem a representar uma alta parcela do custo operacional (ARUNRAJ e MAITI, 2007). As atividades de manutenção passaram então a ser atividades planejadas envolvendo: a) planejamento de manutenção preventiva; b) manutenção baseada em períodos de operação (tempos) e c) sistemas de planejamento e controle das atividades. Não obstante, esta geração foi muito criticada por impor atividades desnecessárias que levavam a interromper a produção freqüentemente, paralisando as operações normais e aumentando dramaticamente os custos diretamente associados à de manutenção (KRISHNASAMY et al., 2005), embora aumentando também a disponibilidade operacional da planta.

As décadas que seguiram este período marcam a terceira geração da manutenção especificamente o período, entre os anos 70 e os anos 90 (ARUNRAJ e MAITI, 2007). Este período pode ser divido em duas etapas. A primeira foi fortemente caracterizada pelo uso do planejamento de atividades preventivas, com o início do emprego da automação industrial e a grande evolução da indústria aeronáutica, especificamente com a construção do Boeing 747, que foi o primeiro jato de passageiros com características de "fuselagem larga" (Wide Body) (NOWLAN e HEAP, 1978). Conseqüentemente, pela grande quantidade de passageiros que a aeronave iria comportar a FAA (Federal Aviation Administration) estipulou que o programa de manutenção preventiva teria que ser mais rigoroso (NOWLAN e HEAP, 1978). Considerando a grande dificuldade econômica por trás desta mudança, a United Airlines liderou uma equipe para reavaliar os conceitos de manutenção associados com a prática preventiva e determinar novas estratégias de manutenção para buscar o equilíbrio entre a segurança e economia na operação das aeronaves comerciais (SMITH e HINCHCLIFFE, 2004).

O resultado foi empregado no planejamento das atividades de manutenção da aeronave 747 e posteriormente em todas as aeronaves modernas, dando origem ao que hoje é conhecido como RCM. Esta experiência gerou o relatório que, anos depois, iria 
se tornar o trabalho pioneiro na exposição dos conceitos de confiabilidade aplicados à manutenção e da filosofia da Manutenção Centrada em Confiabilidade (NOWLAN e HEAP, 1978).

A segunda parte da terceira geração é representada pela súbita demanda de qualidade dos produtos e serviços, trazendo consigo uma grande normatização da qualidade dos produtos e serviços (LEE, 2003). O planejamento da manutenção e a programação de intervenções é sem duvida uma boa estratégia para manter os sistemas produtivos. Na busca pela otimização destes períodos de intervenção, é que os conceitos de confiabilidade, até então empregados apenas na indústria aeronáutica, começaram a ser aplicados em outros setores industriais. Inicialmente na indústria de geração de energia elétrica, mas precisamente em usinas termonucleares, posteriormente na indústria de gás e petróleo e finalmente estendendo-se à indústria em geral (RAUSAND, 1998), o que caracteriza a última etapa da terceira geração da manutenção (ARUNRAJ e MAITI, 2007).

A aplicação dos conceitos de confiabilidade na programação da manutenção deu início à nova geração da manutenção, preocupada com a produção de produtos e serviços de alta qualidade, mas também com uma grande preocupação pela segurança do pessoal da operação e com o meio ambiente (KHAN e HADDARA, 2003).

Adicionalmente, um novo conceito foi incrementado ao planejamento da manutenção, que tenta, de alguma forma, representar o cenário de quanto poderiam custar as conseqüências da ocorrência de uma falha indesejada na operação de sistemas complexos. Assim, esta geração moderna da manutenção está caracterizada pelas técnicas de conservação baseada em risco, tais como inspeção baseada em risco (RBI) e a manutenção baseada em risco (RBM). A Tabela 2.1 apresenta, de forma resumida, a evolução da manutenção nas quatro gerações, destacando as principais características de cada uma delas. 
Tabela 2.1. Evolução das filosofias de manutenção (MOLINARI, 2007; LEE, 2003; ARUNRAJ e MAITI, 2007)

\begin{tabular}{|c|c|c|c|}
\hline Geração & Período & Características & $\begin{array}{l}\text { Filosofia e Técnicas de } \\
\text { Manutenção }\end{array}$ \\
\hline Primeira & $\begin{array}{l}\text { Antes da } \\
\text { segunda } \\
\text { Guerra } \\
\text { Mundial }\end{array}$ & $\begin{array}{l}\text { Equipamentos e projetos simples, fáceis de } \\
\text { reparar, pouco mecanizados. }\end{array}$ & $\begin{array}{l}\text { Manutenção corretiva, } \\
\text { quando quebrar, conserta. }\end{array}$ \\
\hline Segunda & $\begin{array}{l}\text { Durante e } \\
\text { após da } \\
\text { segunda } \\
\text { guerra } \\
\text { mundial }\end{array}$ & $\begin{array}{l}\text { Sistemas mais complexos, demanda por bens } \\
\text { de produção capazes de alimentar a máquina } \\
\text { de guerra, aumento da mecanização da } \\
\text { produção, necessidade de redução dos tempos } \\
\text { de reparo, programação dos tempos de reparo. }\end{array}$ & $\begin{array}{l}\text { Planejamento de } \\
\text { manutenção preventiva. }\end{array}$ \\
\hline Terceira & $\begin{array}{l}\text { A partir dos } \\
\text { anos } 1980\end{array}$ & $\begin{array}{l}\text { Aumento da complexidade da produção, } \\
\text { introdução da automatização, construção de } \\
\text { grandes aeronaves. } \\
\text { Introdução de normas de qualidade para } \\
\text { produtos e serviços, inclusão de normas de } \\
\text { segurança, Uso da Confiabilidade para o } \\
\text { planejamento de manutenção preventiva. } \\
\text { Predição de falhas, evolução dos sistemas de } \\
\text { computacionais. }\end{array}$ & $\begin{array}{l}\text { Manutenção Centrada em } \\
\text { Confiabilidade RCM. } \\
\text { Análise de ocorrência. } \\
\text { Manutenção preditiva }\end{array}$ \\
\hline Atual & $\begin{array}{l}\text { Final dos } 90 \\
\text { s até hoje }\end{array}$ & $\begin{array}{l}\text { Aperfeiçoamento do RCM, inclusão dos } \\
\text { conceitos de Risco. }\end{array}$ & $\begin{array}{l}\text { Manutenção/Inspeção } \\
\text { baseada em Risco. }\end{array}$ \\
\hline & & $\begin{array}{l}\text { Inclusão de normas de controle ambiental e de } \\
\text { segurança, sistemas totalmente automatizados, } \\
\text { e computadorizados. }\end{array}$ & $\begin{array}{l}\text { Manutenção baseada em } \\
\text { diagnose. }\end{array}$ \\
\hline
\end{tabular}

Apresenta-se a seguir dos os conceitos e definições associados à engenharia de confiabilidade e a forma como estes influenciaram na formação da nova concepção do planejamento da manutenção baseada em risco para sistemas complexos.

\subsection{Sistema em Engenharia}

Etimologicamente, a palavra sistema vem do latim systema e esta do grego sustema, que significa um conjunto de elementos relacionados ordenadamente cooperando para o cumprimento de um objetivo (RAE, 2008). Na linguagem de engenharia, é definido como o agrupamento lógico de componentes que irão realizar uma série de funções-chaves requeridas para atender os requisitos de operação de uma instalação industrial (SMITH e HINCHCLIFFE ,2004). Na área de Planejamento e Controle de Sistemas de Manutenção é definido como uma coleção de componentes que 
trabalham juntos em direção a um objetivo comum (DUFFUAA et al., 1999). Esses componentes configuram a arquitetura funcional do sistema e garantem a sua operação. Estes componentes, na linguagem da engenharia, são definidos como o agrupamento ou conjunto de elementos ou partes que cumprem uma função específica, sendo a mesma necessária para cumprir a função do sistema (SMITH e HINCHCLIFFE, 2004). Assim, diversos arranjos de elementos formam componentes e estes por sua vez, dispostos de diversas formas, compõem os sistemas. Da mesma forma, grandes sistemas são agrupados para cumprir em conjunto um mesmo objetivo, uma mesma função, e são denominados como sistemas complexos.

Estes sistemas, combinando as suas funções-chave, permitem o cumprimento de uma grande função, mas também combinam as suas debilidades e fraquezas, criando uma combinação desconhecida de possibilidades de que alguma coisa sair errado, o que na engenharia da manutenção e confiabilidade é definido como "estado de falha".

\subsection{Falhas e Probabilidade de Falha}

O termo falha é de difícil definição uma vez que depende de cada caso particular. De forma geral, o termo é definido como a incapacidade de um componente, ou sistema fazer frente ou satisfazer o seu desempenho esperado (SMITH e HINCHCLIFFE, 2004). Para o Carazas a falha é um estado temporal característico da operação, no qual o sistema ou componente não é capaz de cumprir a função-chave para a qual foi projetado.

Assim, a falha não está relacionada especificamente com a quebra de um componente. Para esta análise, a falha pode ser associada a uma probabilidade de ocorrência de um desempenho insatisfatório dentro de um intervalo de tempo $t$. Assim uma variável aleatória $T$ pode adotar valores dentro deste intervalo, e a sua correspondente função densidade de probabilidade como $f(t)$, representada pela eq. (2.1) (SOUZA, 2003; BAJENESCU e BÂZU, 1999).

$$
f(t) \cdot \Delta t=P\{t<T<t+\Delta t\}
$$


E $F(t)$ é a função de probabilidade acumulada de $f(t)$, representado por:

$$
F(t)=P\{T<t\}
$$

Ou seja, $F(t)$ expressa a probabilidade de ocorrer falha até um tempo $t$.

A função probabilidade acumulada de falha $F(t)$ é crescente com o tempo, atingindo o valor unitário quando $T$ tende a $\infty$, tal como indicado na Figura 2.1.

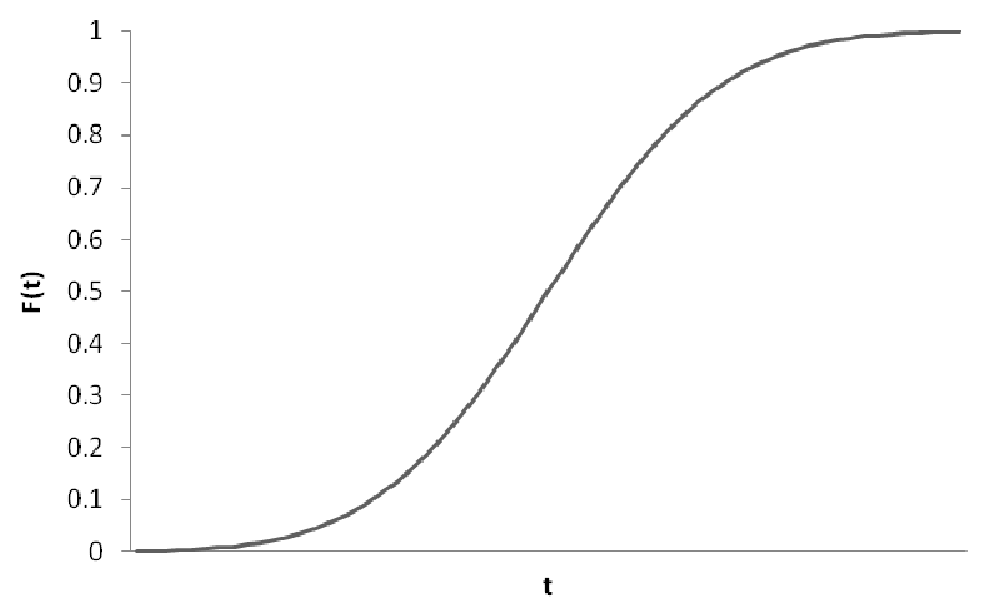

Figura 2.1. Função de probabilidade acumulada $F(t)($ LEITCH 1995)

Sob o ponto de vista da lógica de operação de sistemas, um componente ou equipamento, ou está operando adequadamente e, portanto cumprindo com a sua função, ou está em estado de falha. Pode-se afirmar que estes dois estados são mutuamente excludentes, em outras palavras não podem ocorrer os dois estados simultaneamente. Da mesma forma que o estado de falha foi definido, é importante definir o significado do estado adequado de operação, que é chamado também de confiabilidade.

\subsection{Confiabilidade, Mantenabilidade e Disponibilidade}

A confiabilidade é definida formalmente como a probabilidade que um dispositivo irá executar satisfatoriamente uma determinada função por um determinado 
período de tempo e sob condições operacionais pré-definidas (SMITH e HINCHCLIFFE, 2004). A norma NBR 5462/1994 define a confiabilidade como a capacidade de um item desempenhar uma função requerida sob condições específicas durante um dado intervalo de tempo (ABNT, 1994), e esta capacidade é medida como uma probabilidade (LEWIS, 1987). Há muitas outras definições na literatura para a confiabilidade, como as propostas por Moubray (2000), Leitch (1995) e Lewis (1987), entre outros, mas todas elas têm pontos chaves em comum que determinam a correta operação do sistema (SOUZA, 2003; SMITH e HINCHCLIFFE, 2004), que são:

- Cumprir a sua função com desempenho esperado;

- Período de operação;

- Condições de operação (ambientais, ciclos, etc.) e

- Grandeza estatística.

Em termos da grandeza estatística, a operação satisfatória (confiabilidade) está associada com uma probabilidade, como mostra a eq. (2.3), e esta é complementar à probabilidade de estar em estado de falha, como mostra a eq. (2.4):

$$
R(t)=P\{T>t\}
$$

$\mathrm{e}$

$$
R(t)+F(t)=1
$$

onde:

$R(t)=$ Confiabilidade

$F(t)=$ Função de probabilidade acumulada de falha .

A Figura 2.2 representa a Função de Confiabilidade em função da eq. (2.4), complementar à função probabilidade acumulada de falha. 


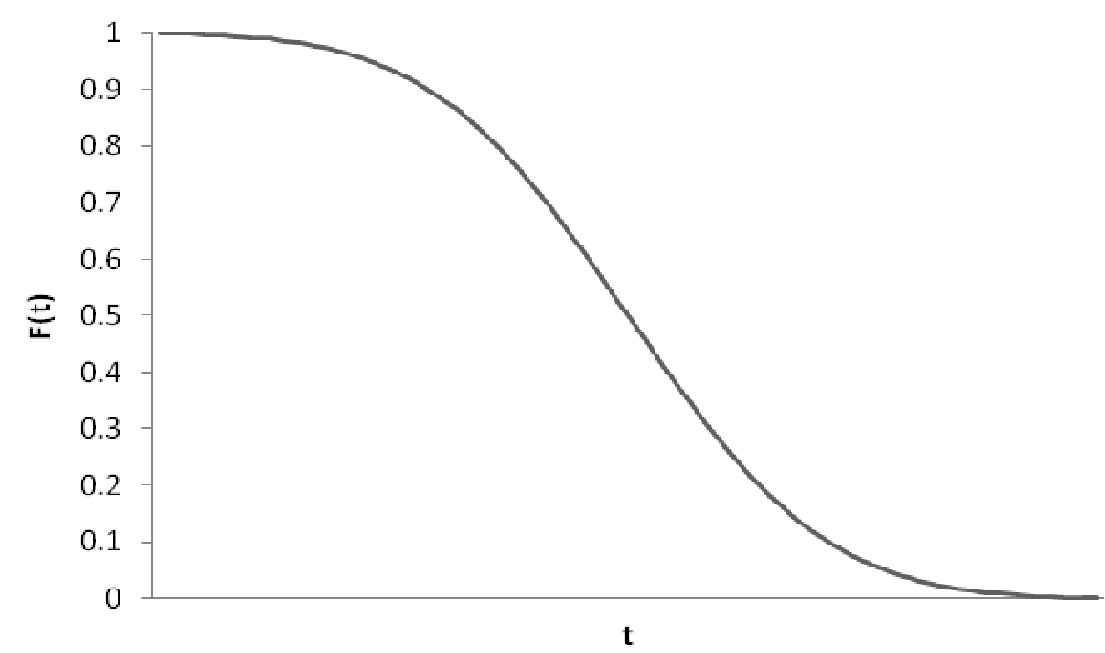

Figura 2.2 Função de confiabilidade $R(t)$ (LEITCH 1995)

Como decorrência da definição da função distribuição acumulada, tem-se:

$$
\begin{aligned}
& R(t=0)=1 \\
& R(t=\infty)=0
\end{aligned}
$$

A partir da curva de confiabilidade apresentada na Figura 2.2, verifica-se que a confiabilidade de um sistema decai ao longo do tempo, ou seja, quanto maior o tempo de operação maior será a probabilidade de encontrar-se em estado de falha. Adicionalmente, pode-se afirmar que a confiabilidade não é restaurada, ou seja, mesmo que a manutenção de um sistema seja perfeita (o mesmo é restaurado na condição "tão bom quanto novo") a confiabilidade não dá saltos ao longo da vida operacional, pois esta é uma função cumulativa ao longo do tempo (SOUZA, 2003; LEWIS, 1987).

Fica claro, então, a relação entre os conceitos de confiabilidade e de falha, mas para o estudo do comportamento da degradação de um sistema ou componente ao longo da sua vida operacional é usada adequadamente a taxa de falha. A taxa de falha $\lambda(t)$ está relacionada com o tempo e pode ser usada como indicador de causas de falhas (LEWIS, 1987), e é definida em termos de confiabilidade como: "Sendo $\lambda(t) \cdot \Delta t$ a probabilidade de que o sistema falhará em um tempo $T<t+\Delta t$, dado que ainda não falhou até o tempo $T=t$, tem-se que $\lambda(t) \cdot \Delta t$ é a probabilidade condicional indicada na eq. (2.7)." 


$$
\lambda(t) \cdot \Delta t=P(T<t+\Delta t \mid T>t)
$$

Assim, com base na definição de probabilidade condicional, tem-se:

$$
P(T<t+\Delta \mid T>t)=\frac{p[(T \geqslant t) n(T<t+\Delta t)]}{P(T \geqslant t)}
$$

Como o numerador da eq. (2.8) é a própria $f(t) \cdot \Delta t$ e o denominador é a $R(t)$, a taxa de falhas instantânea é expressa pela relação:

$$
\lambda(t)=\frac{f(t)}{R(t)}
$$

Com:

$f(t)$ : função densidade de probabilidade de falha;

$R(t)$ : confiabilidade.

A representação gráfica da taxa de falhas durante um período de tempo é conhecida como Curva da Banheira. Na Figura 2.3 é apresentada uma representação genérica da curva da banheira para um sistema sem redundâncias.

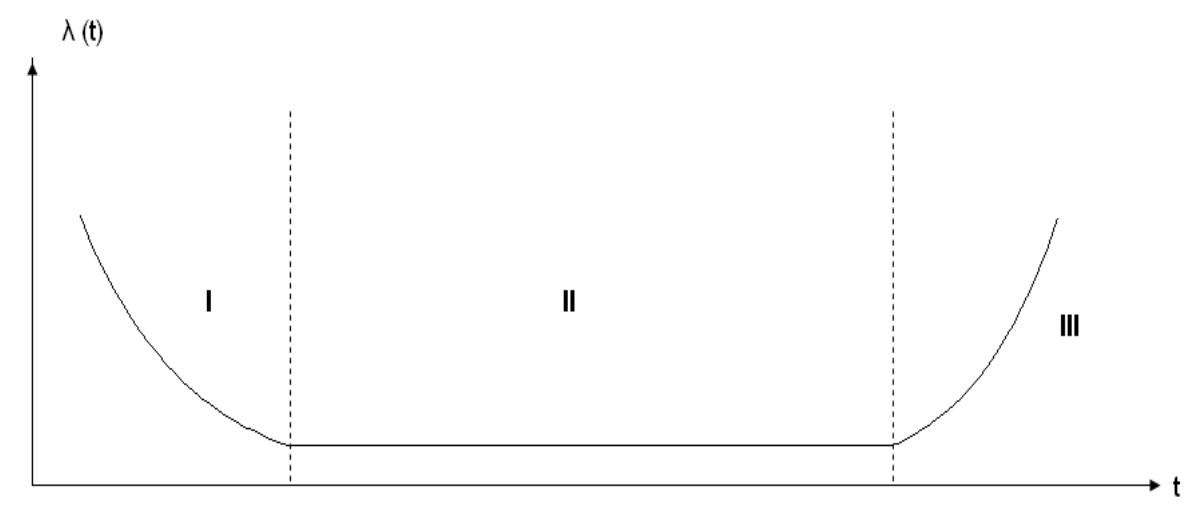

Figura 2.3. Representação da curva da banheira (LEWIS, 1987)

O primeiro intervalo da curva da Figura 2.3 apresenta o comportamento de taxa de falhas que decresce a partir de $t=0$. Esta primeira região é chamada de região das falhas precoces, em analogia com os seres humanos este intervalo é chamado de 
mortalidade infantil. Sob este parâmetro de comparação, as mortes neste período são causadas por defeitos congênitos ou fraquezas nos primeiros períodos de utilização. No caso de sistemas mecânicos complexos, este intervalo representa problemas no início da sua vida operacional, causados por erros de manufatura, e/ou montagem e projeto. Ainda em relação a esta primeira parte da curva da banheira, em sistemas que possuem complexos sistemas de controle, as falhas estão relacionadas com um processo de aprendizagem e calibração dos sensores e o próprio sistema de controle (SOUZA, 2003).

O segundo intervalo é o denominado de período de falhas aleatórias, onde a taxa de falhas é próxima a uma constante. Neste período, as atividades de manutenção e de operação podem ser consideradas ideais e as falhas da primeira etapa da curva da banheira são totalmente superadas. A distribuição que representa este comportamento é a distribuição exponencial, dada sua propriedade de carência de memória, ou seja, o tempo no qual o componente está operando não influencia na probabilidade de ocorrência futura de falhas, sendo os componentes eletrônicos um exemplo típico deste comportamento (CARAZAS, 2006).

No último intervalo da curva da banheira a taxa de falha é crescente no tempo e está relacionada com o envelhecimento próprio dos sistemas mecânicos, tais como, os fenômenos de dano acumulado associado aos fenômenos de desgaste e fadiga, entre outros. Neste período, o planejamento da manutenção encontra dificuldades, pois a ocorrência de falhas inesperadas é mais freqüente, o que obriga a equipe de manutenção a reprogramar as atividades para o equipamento. Esta característica é típica do final da vida operacional do sistema mecânico (CARAZAS, 2006).

Outros parâmetros produtos da análise estatística dos dados de operação são usados pela filosofia do MCC para o planejamento de manutenção, tais como o tempo médio até a falha, representado, para uma função densidade de probabilidade $f(t)$, como mostra a eq. (2.10):

$$
\mu(t)=\int_{0}^{\infty} t \cdot f(t) d t
$$


Se a distribuição é dos tempos médios até a falha, este valor médio é chamado de Tempo Médio até a Falha (do inglês Mean Time To Failure), e este pode ser calculado pela eq. (2.11):

$$
M T T F=\mu(t)=\int_{0}^{\infty} t \cdot f(t) d t
$$

Assim mesmo e de forma analítica pode-se definir o parâmetro Mantenabilidade como a capacidade de um componente ou equipamento ser restaurado a uma condição operacional após a execução de uma manutenção corretiva (O’CONNOR, 1985). Desta forma, o tempo para a execução do reparo pode ser considerado uma variável aleatória, devido às incertezas associadas com a habilidade e conhecimento dos técnicos das equipes de manutenção, bem como à disponibilidade de peças e ferramentas para execução do reparo e ao grau de deterioração do equipamento em função da ocorrência de falhas, entre outras. O tempo necessário para a execução do reparo então é caracterizado por uma função distribuição de probabilidade expressa por $m(t)$, obtendose:

$$
m(t) \cdot \Delta t=P\left(t \leq t_{r e p} \leq t+\Delta t\right)
$$

Onde:

$t_{\text {rep }}=$ tempo de reparo.

A mantenabilidade $(M(t))$ é expressa na forma apresentada na eq. (2.13).

$$
M(t)=\int_{0}^{t} m\left(t^{\prime}\right) d t^{\prime}=P\left(t_{\text {rep }} \leq t\right)
$$

Da mesma forma como com os tempos de operação até a falha, pode-se calcular uma taxa de falha, com os tempos de reparo pode-se calcular uma taxa de reparo $v(t)$ com o emprego da relação da eq. (2.14). 


$$
v(t) \Delta t=\frac{P\left(t \leq t_{r e g} \pm \Delta t\right)}{P\left(t_{r e p} 3 t\right)}
$$

com $v(t) \Delta t$ representando a probabilidade de execução do reparo no intervalo de tempo $[t, t+\Delta t]$, dado que o componente ainda não foi reparado até o instante de tempo $t$.

Outro parâmetro resultante da análise dos dados de operação é o Tempo Médio para Reparo (do inglês Mean Time to Repair ou MTTR), calculado pela relação apresentada na eq. (2.15):

$$
M T T R=\int_{0}^{\infty} t \times m(t) d t
$$

Além da mantenabilidade e da confiabilidade, a disponibilidade é outro parâmetro usado no planejamento de manutenção e, no caso de sistemas de geração de energia, é utilizado como ponto chave para a comercialização da energia com o órgão regulador (no caso do Brasil, o ONS - Operador Nacional do Sistema).

O termo disponibilidade é definido como a fração da porcentagem de tempo que um sistema é capaz de produzir seu produto final com uma qualidade previamente especificada (SMITH e HINCHCLIFFE, 2004). Também é definida como a probabilidade de um componente ou sistema estar operando satisfatoriamente em um instante de tempo $t$, sendo descrito pelo símbolo $A(t)$, também denominado de disponibilidade pontual (CARAZAS, 2006).

Vesely et al. (1994) definem a disponibilidade como a medida do grau em que um sistema compromete-se em cumprir com sua missão quando chamado a cumpri-la com um desempenho mínimo, previamente especificado, em um ponto aleatório no tempo. Em outras palavras, prontidão operacional.

De forma prática, a disponibilidade é a relação entre o tempo de operação ou de funcionamento (confiabilidade) e o tempo de inatividade por manutenção corretiva ou 
simplesmente o tempo para manutenção (Mantenabilidade) (VESELY et al., 1994). De outra forma, é a combinação dos principais parâmetros de uma análise de confiabilidade, descritos a seguir:

- Tempo médio entre falhas ou MTTF (Mean Time to Failure), definido como a medida de quanto tempo, em média, uma planta, sistema ou equipamento, irá realizar sua função, conforme o especificado, antes de uma falha inesperada ocorrer.

- Tempo médio para reparos ou MTTR (Mean Time To Repair), definido como a medida de quanto tempo, em média, será utilizado para trazer sistemas ou equipamentos, por meio da manutenção corretiva, de volta às suas condições normais de operação após falhar.

Vesely et al. (1994) e Smith e Hinchcliffe (2003) afirmam que o MTTF é uma medida da confiabilidade da planta ou do sistema, e MTTR é a medida da mantenabilidade. Matematicamente, a disponibilidade assintótica $(A)$ pode ser definida conforme a eq. (2.16).

$$
A=\frac{M T T F}{M T T F+M T T R}
$$

Esta relação é uma expressão genericamente empregada no cálculo da disponibilidade, independentemente das distribuições associadas com a confiabilidade e mantenabilidade (O’CONNOR, 1985).

\subsection{A Manutenção Centrada em Confiabilidade (MCC) ou Reliability Centered Maintenace (RCM)}


Em relação à filosofia do MCC há muitas publicações que concordam que esta metodologia de planejamento da manutenção teve início no final da década de 60 , como resultado da necessidade da certificação de uma nova geração de aeronaves comerciais (NOWLAN e HEAP, 1978; SMITH e HINCHCLIFFE, 2004; MOUBRAY, 2000 e RAUSAND, 1998). O MCC mudou a forma de planejar a manutenção através da combinação da teoria da confiabilidade e da engenharia da manutenção. Durante a implementação do MCC, é necessário identificar os principais objetivos da filosofia, que são: garantir o nível de desempenho necessário para que cada componente ou sistema possa cumprir com suas funções-chave, o que torna necessária a elaboração de uma análise funcional do sistema; analisar a confiabilidade do sistema e, desta forma, mantê-la por meio da seleção de intervenções de manutenção acertadas, reduzindo as atividades desnecessárias. Para tal, sugere-se responder às sete questões do MCC, que são (ALADON, 2008; CHALIFOUX e BAIRD, 1999; MOUBRAY, 2000; NOWLAN e HEAP, 1978; RAUSAND, 1998):

- Quais são as funções e os níveis de desempenho do sistema no contexto operacional atual?

- De que modo ele falha e para de satisfazer suas funções?

- O que causa cada falha funcional?

- O que acontece quando cada falha ocorre?

- De que modo cada falha importa?

- O que pode ser feito para predizer ou prevenir cada falha?

- O que deve ser feito se uma tarefa de manutenção pró-ativa não puder ser determinada?

Baseado nestes conceitos, Carazas (2007) apresenta um método para a seleção de políticas de manutenção visando a melhoria da disponibilidade de um sistema de geração de energia elétrica, especificamente para uma turbina a gás. A proposta do método é esquematicamente apresentada na Figura 2.4, que mostra os passos a serem seguidos para a aplicação do mesmo. 


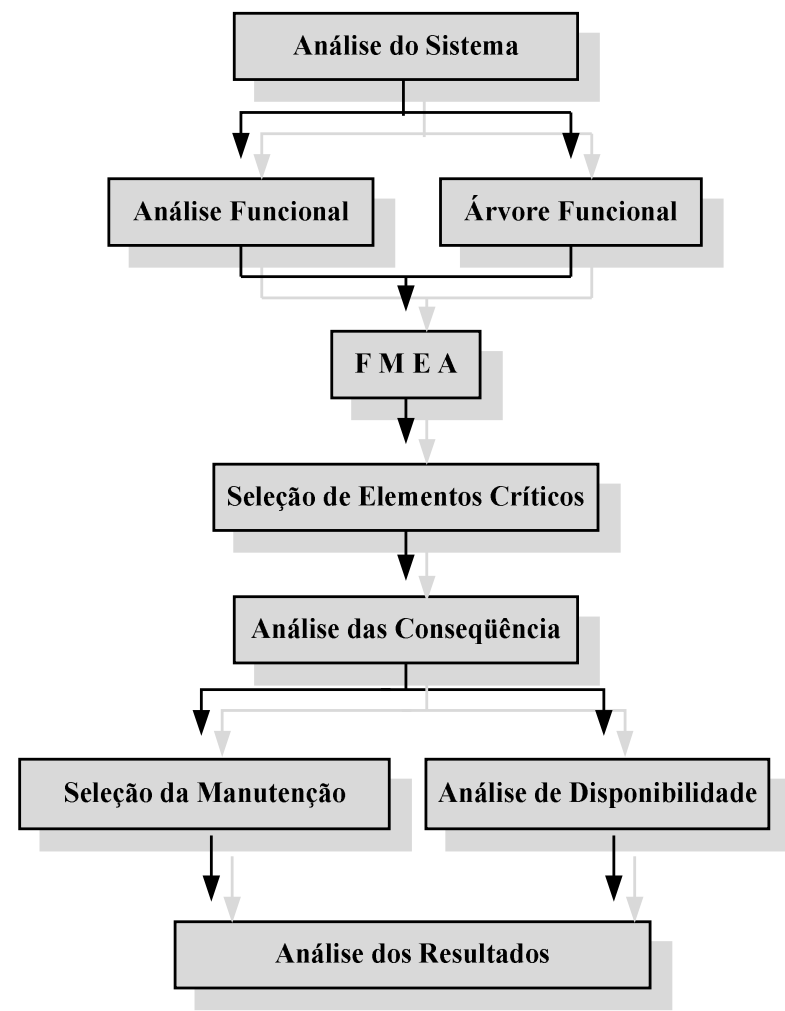

Figura 2.4 Implementação do MCC em sistemas complexos (CARAZAS e SOUZA, 2007)

A filosofia do MCC considera que um item está em estado de falha quando este desempenha sua função de forma insatisfatória. Assim, a diferença entre um desempenho satisfatório ou insatisfatório estará relacionada com a função do componente e também com o tipo e contexto operacional do sistema (CARAZAS, 2006). A filosofia do MCC para a seleção de políticas de manutenção, através de diagramas de decisão específicos, classifica as falhas em funcionais ou potenciais. Esses tipos de falha estão descritos a seguir:

- A falha funcional é representada pela incapacidade do componente executar a sua função de acordo com o desempenho mínimo esperado. A parada total do componente também é uma falha funcional;

- A falha potencial é caracterizada pela presença de uma evidência física de que um processo de deterioração está ocorrendo, o qual culminará com uma falha funcional. A presença dessa evidência física é a premissa básica para a aplicação da manutenção 
preditiva. A correta monitoração deste processo permite utilizar ao máximo o componente e repará-lo (ou substituí-lo) antes da ocorrência da falha funcional.

A ocorrência tanto das falhas funcionais como das potenciais só é detectada quando o operador do sistema verifica alguma anomalia na condição operacional que causa a perda de desempenho do sistema. Em sistemas complexos, a habilidade do operador em detectar a presença de falhas é auxiliada pelo emprego de sistemas de monitoração também complexos, compostos por uma grande quantidade de sensores e sistemas computacionais associados a alarmes, que indicam com sinais sonoros e/ou luminosos a ocorrência de alguma falha funcional.

Embora muitas das falhas funcionais possam ser detectadas pelo operador do sistema, podem ocorrer falhas de componentes que não são imediatamente observadas. Dessa forma, uma falha funcional pode ser classificada em:

- Falha evidente, a qual é imediatamente observada no sistema quando acorre;

- Falha oculta, a qual não é detectada quando da sua ocorrência, ou seja, não há evidências que a mesma ocorreu. As falhas ocultas podem ser de dois tipos: ativa, quando durante a operação normal do sistema não há indicação da redução de seu desempenho e inativa quando durante a operação normal do sistema não há condição de avaliar se o componente estará a pro a operar caso seja requerida sua operação, ou seja, a falha só e descoberta quando o componente é solicitado a operar (SMITH e HINCHCLIFFE, 2004; CARAZAS, 2006).

Da mesma forma que com as falhas, suas conseqüências para o desempenho operacional são classificadas com o objetivo de priorizar as atividades de manutenção ou mesmo de melhoria no projeto do sistema ou componente, visando prevenir a ocorrência das falhas e, portanto, de suas consequiências. 
Quanto maior a complexidade do sistema, maior será o número de possíveis modos de falhas que o sistema pode apresentar em função da ocorrência de falhas nos elementos que o compõem. O fato de um sistema complexo estar em estado de falha é consequiência da ocorrência de falhas nos componentes. As consequiências da falha podem ser classificadas em:

- Conseqüências de segurança, envolvendo possíveis danos ao sistema, podendo causar efeitos adversos à sua segurança operacional, colocando em risco os seres humanos ou o meio ambiente;

- Conseqüências operacionais que envolvem uma perda econômica em função da redução do desempenho operacional abaixo do mínimo esperado, incluindo nesta perda o próprio custo do reparo;

- Consequiências não operacionais, que não afetam o desempenho do sistema no contexto operacional do mesmo, porém exigem reparo, o qual deverá ser efetuado em algum momento futuro, sendo associado ao mesmo um custo de reparo;

- Consequiências de falhas ocultas, que não tem impacto imediato sobre o desempenho operacional do sistema, mas podem ser o evento inicial (gatilho) para o desenvolvimento de outras falhas funcionais (LAFRAIA, 2001; CARDOSO, 2000; MOUBRAY, 2000).

A filosofia do MCC apresenta um diagrama para classificação de uma falha funcional nas categorias acima citadas, apresentado na Figura 2.5. A classificação é baseada em perguntas, cujas respostas são do tipo sim ou não, e associadas com as consequiências da falha funcional do componente sobre o desempenho do sistema, (MOUBRAY, 2000; LAFRAIA, 2001). 


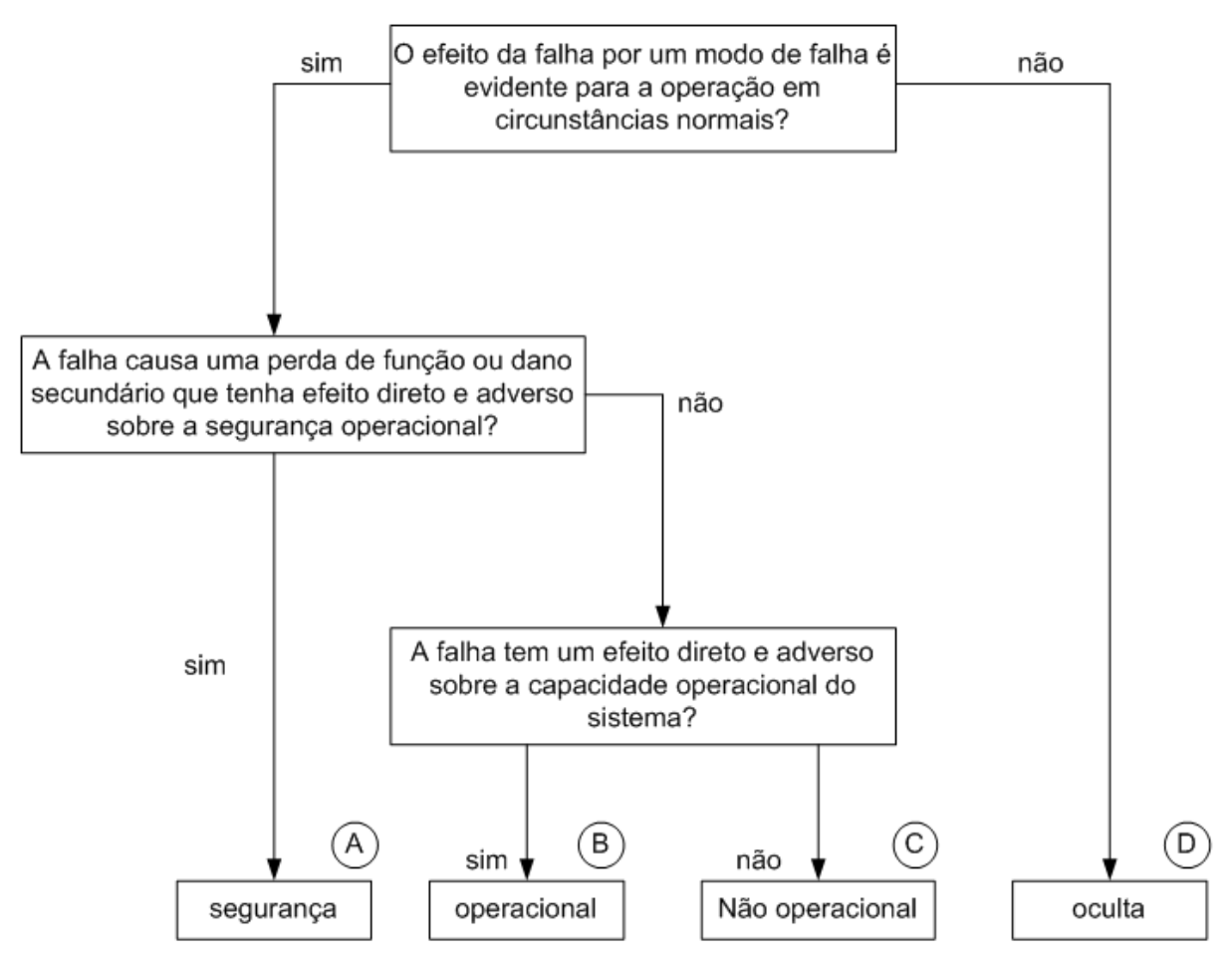

Figura 2.5. Diagrama de classificação das conseqüências das falhas (LAFRAIA, 2001)

Uma vez classificadas as falhas funcionais dos componentes em função das conseqüências destas sobre o desempenho operacional do sistema, segue-se para o processo de seleção das práticas de manutenção recomendadas para cada um dos componentes do sistema, elaborando-se assim a política de manutenção. Tal processo decisório envolve um estudo sistemático de qual das três práticas básicas de manutenção (corretiva, preventiva e preditiva) pode ser aplicada a um componente. O critério de seleção visa a possível aplicabilidade das práticas e a sua eficácia para retardar ou evitar a ocorrência de um dado modo de falha.

Os diagramas de decisão empregados pelo MCC são apresentados nas Figuras 2.6 a 2.8. Destaca-se que, qualquer que seja a conseqüência da falha, busca-se preferencialmente a aplicação da prática de manutenção preditiva. Na seqüência, o diagrama de decisão indica preferência por tarefas de reparo ou substituição do componente em intervalos pré-definidos de tempo, caracterizando a aplicação da prática preditiva. Finalmente, na impossibilidade de aplicação das práticas acima citadas, podese utilizar a prática corretiva, ou seja, intervir no componente após a falha do mesmo. 


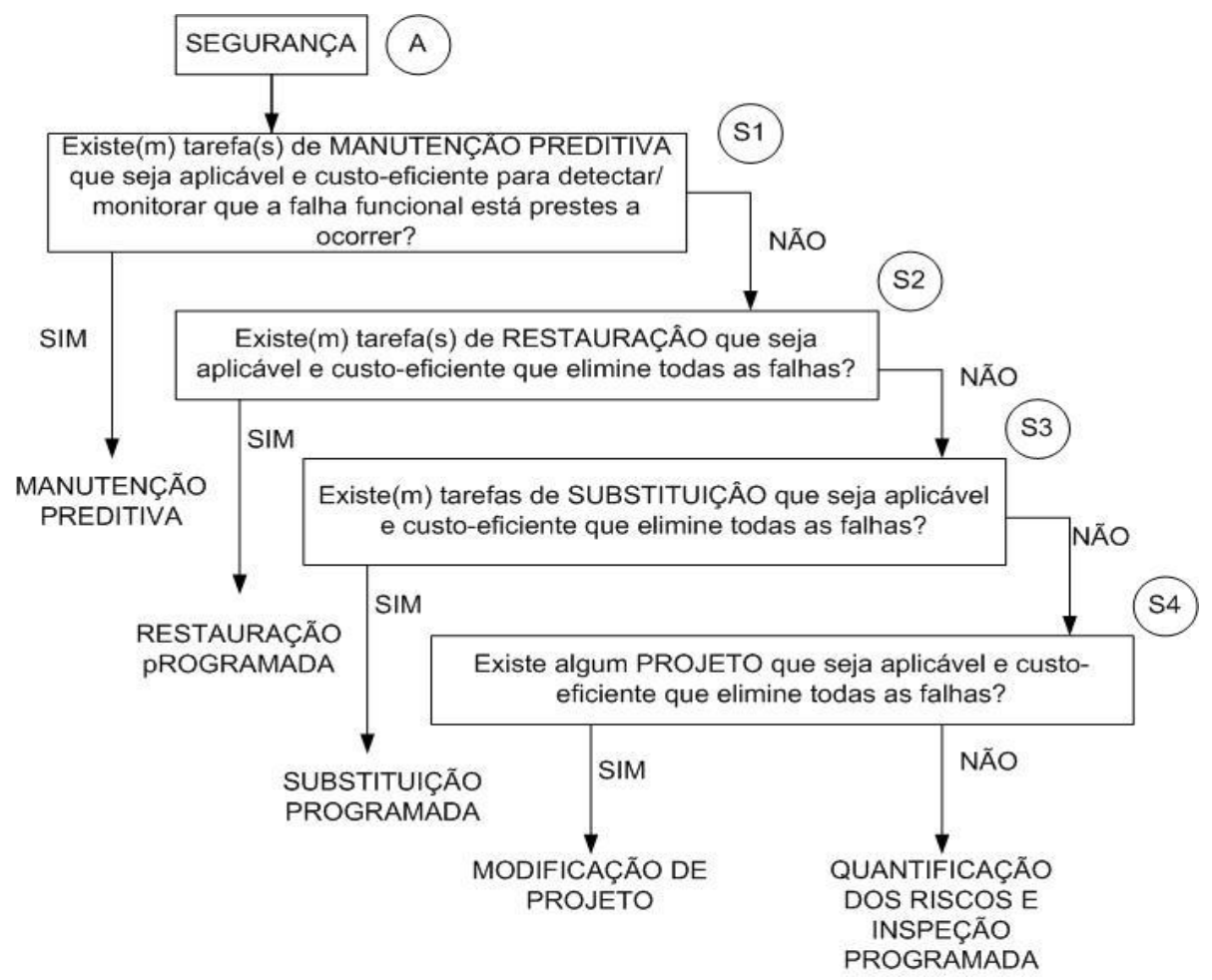

Figura 2.6. Diagrama de decisões para a seleção de práticas de manutenção - modos de falha envolvendo consequiências de segurança (MOUBRAY, 2000)

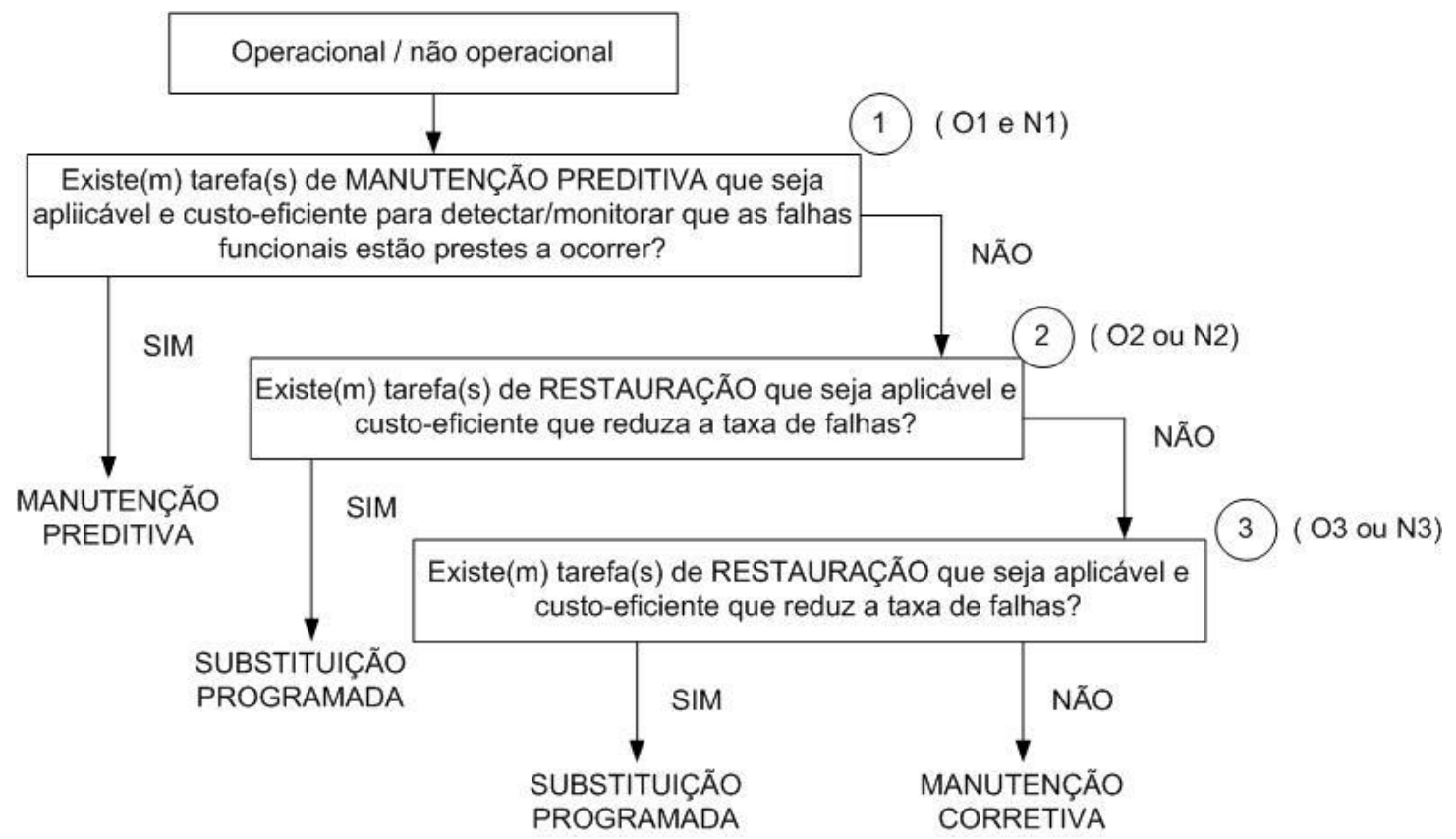

Figura 2.7. Diagrama de decisões para a seleção de práticas de manutenção - modos de falha envolvendo conseqüências operacionais e não-operacionais (MOUBRAY, 2000) 


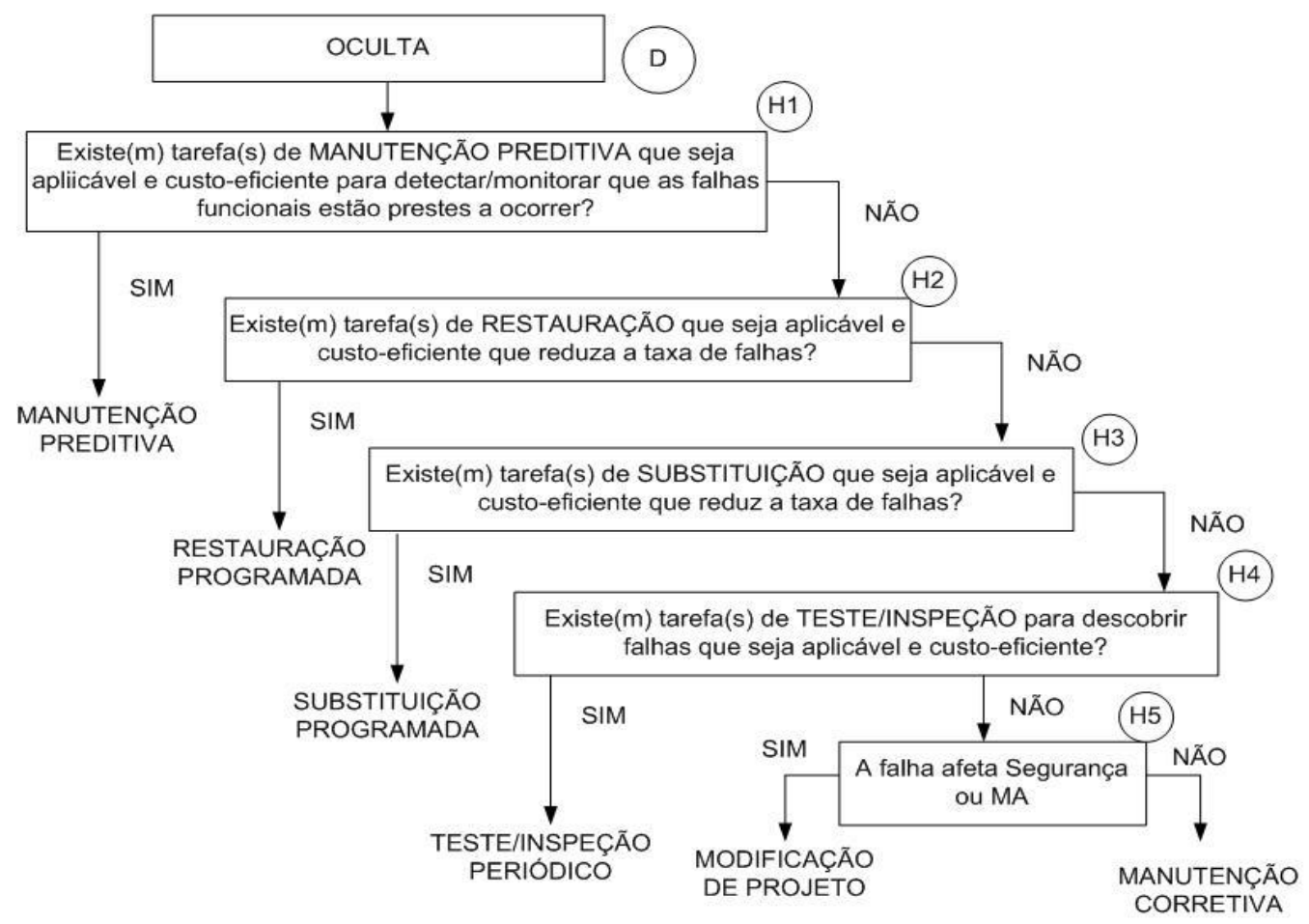

Figura 2.8. Diagrama de decisões para a seleção de práticas de manutenção - modos de falha envolvendo conseqüências ocultas (MOUBRAY, 2000)

Para facilitar o entendimento, os resultados da aplicação dos diagramas de decisões do MCC podem ser dispostos em uma tabela, tal como indicado na Tabela 2.1, onde se marca "SIM" ou "NÃO" para as diversas respostas, permitindo a seleção da prática de manutenção mais indicada para o componente, considerando-se um modo de falha específico.

Tabela 2.2. Resultados do RCM (MOUBRAY, 2000)

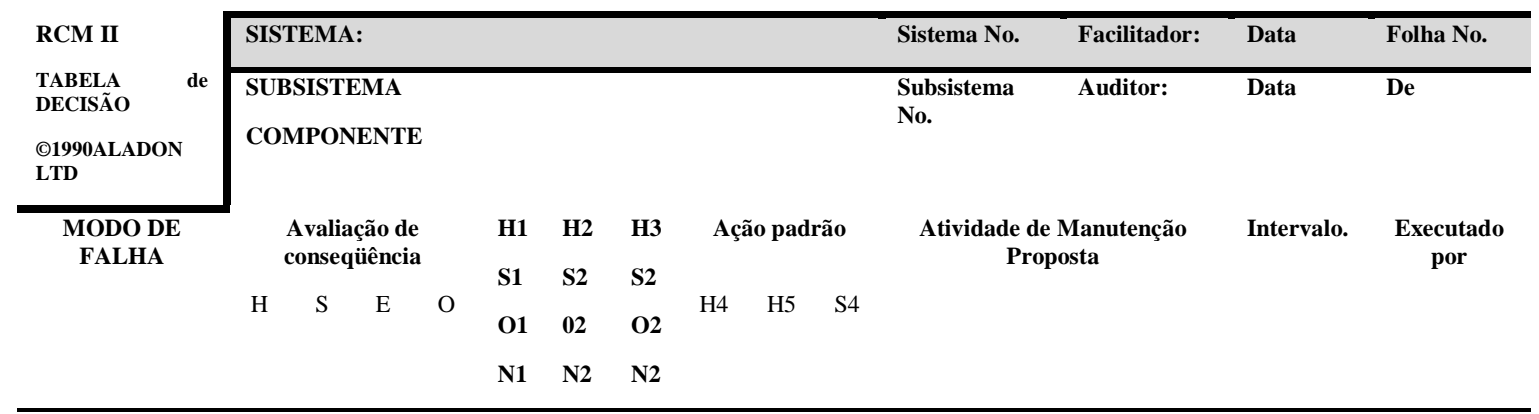

Até o momento foram apresentados os conceitos relacionados à origem da filosofia da Manutenção Centrada em Confiabilidade. A partir daqui serão apresentados os conceitos que, somados aos anteriores, darão origem à Manutenção Baseada em Risco (RBM, do inglês Risk Based Maintenance). 


\section{CAPÍTULO 3 - FUNDAMENTO TEÓRICO II - ANÁLISE DE RISCO E TEORIA DE DECISÃO}

Neste capítulo são apresentados os conceitos e as principais técnicas da análise de risco, assim como os conceitos da teoria de decisão. O texto é elaborado sob o ponto de vista da engenharia da manutenção. Com o objetivo de mostrar ao leitor como estes conceitos podem ser aplicados na elaboração de uma ferramenta para a seleção de políticas de manutenção elou equipamentos redundantes visando segurança aos operadores e ao meio ambiente, assim como a alta disponibilidade e o retorno para os investidores dos diversos ramos industriais do mercado. 


\subsection{Considerações Iniciais}

Nas atividades das empresas e nas operações industriais, o processo de previsão de ações futuras é de vital importância para a sobrevivência do negócio, mesmo sob um cenário de incerteza. Desta forma, fortunas são gastas a fim de modelar o possível cenário futuro para as suas operações comerciais. Duarte (2003) afirma que o risco está presente na rotina de qualquer investimento, financeiro ou não, e já vem sendo estudado há mais de quatro décadas. $\mathrm{O}$ autor em referência ainda sugere que o risco é um conceito "multidimensional" que cobre quatro grandes grupos: risco de mercado, risco de operação, risco de crédito e risco legal. Estas afirmações estão relacionadas à grande preocupação de perdas econômicas como resultado do procedimento incorreto na hora de tomar uma decisão que, no caso de mercado, é um investimento inadequado.

Nas operações industriais, o panorama tampouco é diferente. Existe uma relação entre operação com sucesso (confiabilidade) e a ausência de falhas, que determinará a possibilidade de comercializar o produto e desta forma obter receita ou lucros. Entretanto, podem ser observadas algumas diferenças. A mais importante é que, além das perdas econômicas em caso de ocorrência de falhas, os equipamentos poderão causar danos às pessoas que os operam e ao meio ambiente e estas conseqüências não podem ser estimadas apenas como perdas em valores econômicos.

Atualmente, as indústrias estão conscientes de que a forma mais adequada de manter seu parque industrial operando com segurança, qualidade, confiabilidade e baixo risco é investindo na manutenção. É nesse cenário que surge o marco da atual geração da manutenção, chamada de manutenção baseada em risco (RBM).

Entre os trabalhos pioneiros na aplicação do conceito de risco no planejamento da manutenção se encontra o método de Avaliação Probabilística do Risco (PRA, do inglês Probabilistic Risk Assessment), proposto por Vesely et al. (1993) para a 
priorização dos componentes críticos, objeto de maior cuidado quando da aplicação da manutenção. O trabalho apresenta um procedimento que, mediante a determinação de parâmetros de corte ou de aceitação de risco e em combinação com a análise PRA, permite identificar os componentes que possuem a maior freqüência de falhas. Desta forma, são direcionadas as atividades de manutenção para os equipamentos com maior incidência de falhas com a finalidade de atingir o ponto de corte mínimo de risco, representado à equivalência de $10 \%$ de probabilidade de falha.

Com o passar dos anos, os conceitos de risco passam a ser utilizados na programação de inspeção de componentes críticos de sistemas complexos, o que dá início à filosofia chamada de RBI (do inglês Risk Based Inspection) (NITZ, 2004). Em termos de engenharia de manutenção, uma atividade de inspeção em um componente, caso este apresente um sintoma conhecido que possa indicar a evolução de um modo de falha, irá fornecer necessariamente recomendações para a intervenção da manutenção, seja esta preventiva ou corretiva. E é justamente desta forma como Khan e Haddara (2003) analisam esta ligação entre a inspeção e a manutenção, sendo eles os que pela primeira vez chamam a esta nova filosofia da manutenção de RBM.

\subsection{O Risco}

Etimologicamente, a palavra risco vem do italiano Risico ou Rischio, que decorre da palavra em árabe clássico Rizq que significa "o que depara o destino" (RAE, 2008). Seu significado literal é "exposto ou em perigo" (PRIBERAM, 2008) ou "circunstância que pode decorrer em uma conseqüência negativa não desejada". Em outras palavras, risco pode ser definido como a possibilidade de que algo desfavorável aconteça, seja na operação de um sistema ou em qualquer outra situação.

Do ponto de vista da própria análise de risco, o risco pode ser definido como a possibilidade de ocorrência de condição operacionais indesejáveis, que afetem a segurança do sistema (SCHUYLER, 2002). Para sistemas complexos, Haimes (1998) define o risco como a medida da probabilidade de ocorrência de um efeito indesejado e severidade dos seus efeitos sobre um sistema. O conceito de risco combina as chances 
da falha com as conseqüências de sua ocorrência, sendo seu elemento essencial a incerteza o que, em linguagem de engenharia, se traduz como "não sabemos quando ou onde acontecerá a falha” (WANG e ROUSH, 2000). Segundo Casal (1999), o risco está associado à probabilidade de que um perigo se converta em um acidente com conseqüências graves.

Neste trabalho, o risco é definido como a medida da conseqüência da ocorrência de uma falha inesperada e é expressa em termos econômicos, como apresenta a eq. (3.1).

$$
\text { Risco }=\left(p_{i}, c_{i}\right)
$$

Onde:

$p_{i}=$ Probabilidade da ocorrência do evento $i$.

$c_{i}=$ Conseqüência da ocorrência do evento $i$.

Segundo Sánchez (2005), o termo " $c_{i}$ " representa as perdas relacionadas com a ocorrência das falhas e o termo " $p_{i}$ " a estimativa da probabilidade do sistema cair em determinado estado de falhas.

No caso de grandes e/ou complexos sistemas, como uma usina termelétrica a ciclo combinado, a ocorrência de um evento indesejável está relacionada com um fato inicial, ou falha inicial, que acontece em um componente específico. Assim, segundo diversos autores tais como Khan e Haddara (2003), Cardoso (2004) e Nilson (2003) para cada um dos componentes que compõem o sistema torna-se necessário conhecer as probabilidades das principais falhas que estes podem apresentar, assim como as consequiências das mesmas, estruturando assim a relação de análise de risco com a confiabilidade. Ainda em relação ao parâmetro de custo das consequiências, haveria uma grande dificuldade para representar realmente um determinado cenário de falha, já que os custos das falhas de sistemas produtivos complexos dependem de condições temporais do mercado que, por sua vez, dependem de parâmetros diversos. Assim, a expressão do risco é: 


$$
\text { Risco }=\Sigma_{i} p_{i} c_{i}
$$

Diferentes autores afirmam que, ao se referir à risco, necessariamente se faz referência à análise de risco. Sánchez (2005), Schuyler (2002), Aven e Korte (2003) e Arunraj e Maiti (2007) afirmam adicionalmente que a análise de risco é a ferramenta mais importante num processo de tomada de decisão, seja qual for a sua natureza (de investimento, de produção de novos produtos, de seleção de políticas de manutenção, entre outras), porque permitirá crias parâmetros comparativos para a eleição da melhor alternativa de decisão.

\subsection{Análise de Risco}

Uma análise de risco é um processo bem estruturado que visa definir e qualificar as incertezas associadas a um evento ou a um determinado cenário de operação, onde são modeladas e quantificadas as probabilidades de ocorrência de um determinado fato (falha) indesejável que reduza o desempenho na operação do sistema. Tais probabilidades estão relacionadas às conseqüências da ocorrência do evento, também previamente quantificadas e expressas em termos de custo.

Uma análise de riscos é composta por diversas etapas, dependendo da natureza da análise. No caso de sistemas produtivos, a análise deve responder basicamente às seguintes perguntas para cumprir com a necessidade de quantificar um potencial modo de falha (WANG e ROUSH, 2000):

- O que pode dar errado na operação do sistema?

- Qual é a chance da ocorrência da falha?

- O que será causado como consequiência da ocorrência da falha? 
As respostas a estas perguntas fornecerão ao avaliador um panorama do sistema. Estas respostas, entretanto, são difíceis de serem obtidas e, para tanto, a análise de risco faz uso de ferramentas de análise do tipo quantitativo e qualitativo que permitirão modelar o cenário de operação. Antes de entrar em detalhes na descrição das ferramentas da análise de risco, é importante definir os conceitos de perigo e de segurança, que freqüentemente são usados na aplicação destas.

Perigo: O perigo pode ser definido como um prejuízo potencial que pode recair sobre pessoas, bens ou o meio ambiente, sendo que este pode ser um agente químico ou físico (KUMAMOTO e HENLEY, 1996). Esta definição corresponde a uma situação bem determinada, pois pode se referir às situações de perigo de natureza aleatória, de origem natural, tecnológica ou econômica, assim como às de natureza determinística, relacionadas com ações intencionais (CASAL et al., 1999).

O conceito de perigo segundo Wang e Roush (2000) está baseado somente nas conseqüências potenciais de um evento indesejado (E), sem considerar as probabilidades do evento acontecer realmente. Estas conseqüências podem ser classificadas por uma escala hierárquica de gravidade ou severidade (S), tal que um perigo será tanto maior quanto mais graves forem as suas conseqüências. Perigo é, então, um conceito associado unicamente à gravidade das conseqüências do evento "E".

Incerteza: A incerteza é definida como a expressão do grau de desconhecimento de uma determinada condição futura como, por exemplo, a operação de um sistema mecânico. Formalmente, entende-se por incerteza uma situação na qual não se conhece completamente a probabilidade de que ocorra um determinado evento. Caso o evento em questão seja a operação de um sistema mecânico, tomando o mesmo exemplo, não é possível conhecer com certeza o desempenho que o mesmo produzirá num determinado período. A incerteza significa, então, a incapacidade de predizer ou a previsão imperfeita dos eventos futuros (KUMAMOTO e HENLEY, 1996; SÁNCHEZ, 2005).

Em se tratando da operação de sistemas físicos, as incertezas podem se derivar de uma falta de informação ou pela existência de desacordo entre o que se sabe e o que 
se poderia saber, em termos da operação do próprio sistema. A incerteza pode ter várias origens, desde erros quantificáveis dos dados ou dos parâmetros de operação até a terminologia definida de forma ambígua ou variações no comportamento dos operadores. Desta forma, a incerteza pode ser representada por medidas quantitativas ou por afirmações qualitativas (por exemplo, ao atender a recomendação de um grupo técnico).

Seguranca: Etimologicamente, segurança vem do latim securus que significa sem perigo ou em ausência de perigo, dano ou risco (ERA, 2008). O conceito de segurança para o estudo de risco está relacionado à operação bem sucedida do sistema.

A definição de segurança da operação do sistema é a capacidade do sistema cumprir com sucesso a função para o qual foi projetado sem que ocorram eventos com consequiências indesejadas, tanto para os componentes do próprio sistema como para o pessoal de operação ou o meio ambiente. É neste contexto que a segurança de operação do sistema está relacionada com as habilidades de avaliação, previsão e controle de falhas no mesmo (SÁNCHEZ, 2005).

Do conceito acima mencionado, considera-se "a função para o qual foi projetada" como uma série de funções com um desempenho específico e, a partir deste ponto, conceitos como disponibilidade, confiabilidade e mantenabilidade passam a ter uma importância adicional na caracterização da segurança da operação.

O conceito de segurança é definido como a capacidade de uma entidade de evitar a ocorrência, dentro de condições pré-estabelecidas, de eventos críticos para o seu funcionamento ou catastróficos para seus operadores e para o meio ambiente. A segurança é medida pela probabilidade de que, dentro de condições específicas, uma entidade não dê oportunidade à ocorrência de um conjunto de conseqüências catastróficas ao longo de sua vida útil (SÁNCHEZ, 2005). 
Para a execução de uma análise de riscos, deve-se definir quais os níveis de riscos que podem ser tolerados e, por outro lado, enfrentados, considerando os custos decorrentes da perda de capacidade de produção, causados pela ocorrência de falha de um dos seus componentes. Em outras palavras, quanto se está disposto a arriscar na previsão de um perigo às instalações, às pessoas e ao meio ambiente, ou mesmo de uma perda econômica.

Assim, para poder saber quais são os níveis de risco aceitáveis, é necessário estimá-los de forma sistemática e o mais abrangente possível tentando alcançar as consequiências que se apresentariam às pessoas, ao meio ambiente e à própria instalação industrial.

A análise de risco avalia e quantifica o risco e as conseqüências da ocorrência de um evento indesejado ocasionado pelas falhas dos sistemas, equipamentos ou mesmo dos processos operacionais e das atividades de manutenção. Assim a análise de risco é uma ferramenta usada para auxiliar a tomada de decisão sob uma condição de incerteza. Já a tomada de decisão decorrente da análise está relacionada aos custos, aos tempos de indisponibilidade e ao desempenho (SCHUYLER, 2002).

Diferentes são as etapas sugeridas para uma análise de risco. Souza (2006), por exemplo, sugere seis passos para a avaliação de riscos visando a análise da integridade de sistemas mecânicos. Esses seis passos são: i) descrição do empreendimento e da região; ii) identificação dos perigos; iii) estimativa de conseqüências; iv) estimativa da freqüência; v) estimativa de risco; vi) avaliação e gerenciamento do risco. Outras formas de avaliação são propostas na literatura e variam em relação ao sistema e a natureza da análise.

Nesta pesquisa é proposto um procedimento de análise de risco que envolverá quatro etapas principais: a primeira é a identificação do escopo; a segunda, a quantificação de risco, etapa esta relacionada com a estimativa das probabilidades de ocorrência de cada um dos possíveis eventos inesperados ou acidentes; a terceira etapa 
trata da avaliação de riscos, que avalia as consequiências e os custos decorrentes da ocorrência de falhas; e, finalmente, a quarta que envolve as decisões em relação à seleção de políticas de manutenção. Dependendo dos resultados da análise de risco será possível avaliar a possibilidade de modificação do projeto caso as atividades de manutenção não reduzam o risco à um nível aceitável determinado pelos operadores do sistema. A descrição de cada uma das etapas serão tratadas mais adiante, no Capítulo 4.

Assim, este capítulo tem por objetivo, além de apresentar os conceitos anteriores, apresentar as ferramentas, técnicas ou métodos mais utilizados em uma análise de riscos, sejam estes de natureza quantitativa ou qualitativa. Na Figura 3.1 é apresentado um processo de análise de risco onde são combinadas as técnicas quantitativas e qualitativas. As técnicas quantitativas permitiriam calcular as frequiências de ocorrência e as conseqüências em termos de custo. Esta análise só é adequada quando o analista possui dados numéricos apropriados, de forma que seja possível o cálculo. As origens destes normalmente são os próprios históricos de operação, bem como os registros decorrentes das diversas intervenções para manutenção, no caso de análises de custos (ARENDT, 1990; ABS, 2000).

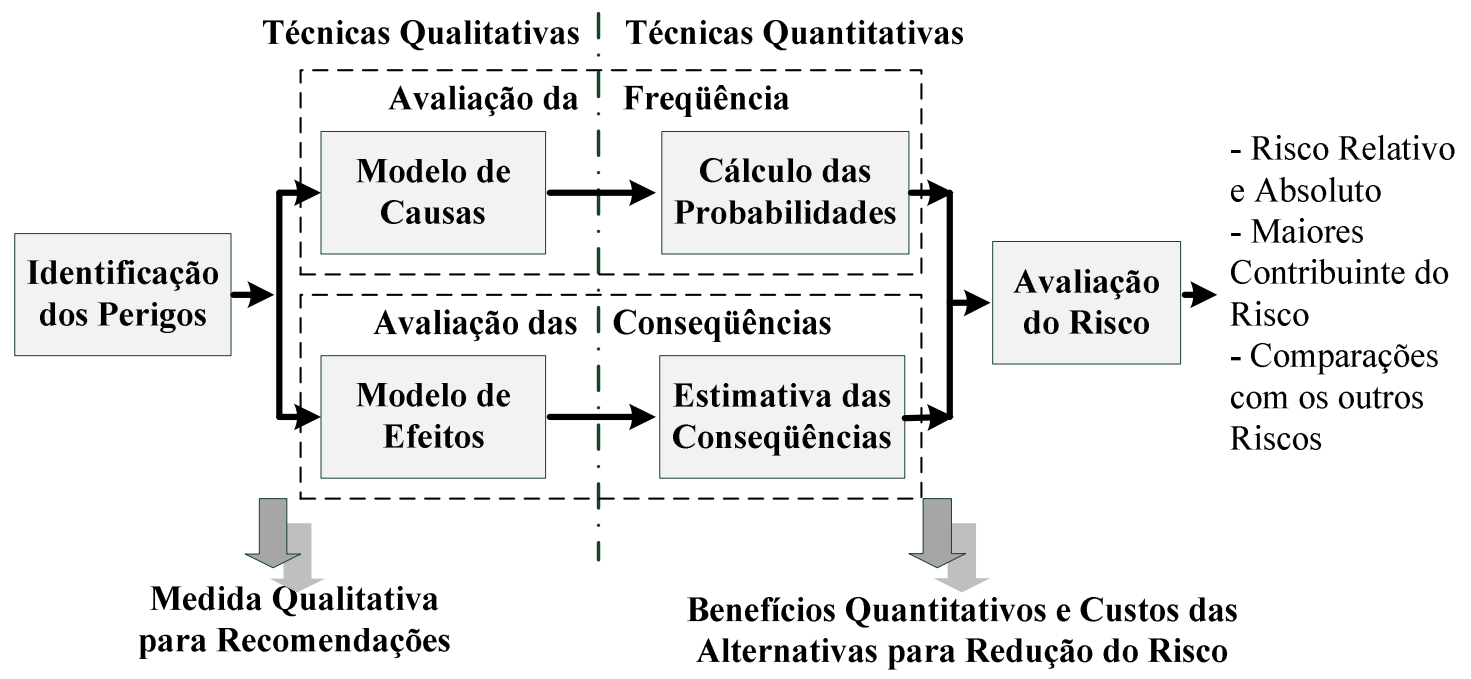

Figura 3.1. Processo de análise de risco (ARENDT, 1990)

Em relação às técnicas qualitativas de risco, estas têm a finalidade de identificar as ameaças ao sistema e o impacto das conseqüências, de forma que sejam levantados aspectos tais como o impacto ambiental, os efeitos sobre a população local, as 
exigências legais e as conseqüências internas à organização (perdas de produção, geração de produtos/serviços de qualidade comprometida, acidentes de trabalho).

Teixier et al. (2002) apresentam uma lista de 62 métodos para a análise de risco em plantas industriais, sendo estes diferenciados em três categorias: determinísticos (para análise de conseqüências relacionadas principalmente a fenômenos físicos); probabilísticos (quando a natureza da análise está relacionada a eventos aleatórios) e combinação (combinação de métodos probabilísticos e determinísticos).

Para cumprir com os objetivos deste trabalho, são apresentados alguns destes métodos tais como a Análise Preliminar de Riscos ou PHA (Preliminary Hazard Analysis), a Análise Crítica de Processos (ACP) ou HAZOP (Hazard and Operability Study) e a Análise de Modos e Efeitos de Falhas (FMEA - Failure Modes and Effects Analysis). Estas poderiam ser consideradas as técnicas mais conhecidas para análises de natureza qualitativa (CHIN et al., 2008; TSURU et al., 2008; PINNA et al., 1998; BOUTI e KADI, 1994).

Entre os métodos de natureza quantitativa (podendo ser encaixados dentro do grupo dos métodos combinados entre determinísticos e probabilísticos, com certas adaptações), são explorados no presente capítulo: a Árvore de Eventos (Event Trees), a Árvore de Falhas (FTA - Fault Tree Analysis) e o Diagrama de Causa-Conseqüência (Cause-Consequence Diagram) (TIXIER et al., 2002).

\subsubsection{Métodos de Identificação de Riscos de Natureza Qualitativa}

Estes métodos se caracterizam por não fazerem uso de cálculos numéricos. Além disso, podem ser subdivididos em métodos comparativos e generalizados. As técnicas ou métodos de análise do tipo comparativo são baseadas na utilização da experiência adquirida em operação de sistemas ou equipamentos similares já existentes, assim como 
em análises de efeitos em sistemas similares ao estudado. São quatro os principais métodos de análise comparativa:

- Manuais técnicos ou códigos e normas de projeto;

- Listas de verificação ou Check lists;

- Análise histórica de acidentes;

- Análise preliminar de riscos ou PHA (Preliminary Hazard Analysis).

Os métodos generalizados de identificação de risco são baseados no estudo das instalações e processos através de técnicas estruturadas. Estes usam um procedimento lógico de desenvolvimento de conseqüências de falhas em equipamentos e processos. Os principais métodos generalizados são:

- Análise "e se...?" ou em inglês "What if...?";

- Análise Crítica de Processos (ACP) ou HAZOP (Hazard and Operability Study);

- Análise de Modos e Efeitos de Falhas (FMEA - Failure Modes and Effects Analysis).

$\mathrm{Na}$ seqüência serão descritos os principais métodos quantitativos de identificação de risco.

\subsubsection{Listas de Verificação ou Check Lists}

As listas de verificação ou check lists são chamadas na análise de risco como listas de verificação de segurança e são utilizadas para o controle de um determinado processo de operação, montagem, procedimento de adaptação de equipamentos, procedimento de manutenção, etc.. Em outras palavras são um guia de procedimentos que deverão ser seguidos numa atividade qualquer. 
Este método consiste no preenchimento de listas de fácil acesso, que permitem ter um controle de parâmetros de pressão, temperatura e vazão dependendo do sistema sob análise. Essas listas devem ser elaboradas por pessoas com experiência na operação e/ou projeto do processo de produção ou podem também serem baseadas em uma norma ou em parâmetros padrões de operação para o sistema em estudo.

Por possuírem uma estrutura de fácil e rápido entendimento, elas são utilizadas também como um meio de comunicação entre as equipes de monitoração e de controle com as equipes de operação e manutenção. Tais listas, por se tratarem de documentos escritos, geram automaticamente um histórico de operação do sistema. As listas de verificação podem ser usadas também no desenvolvimento de um novo projeto ou mesmo de um projeto de modificação da planta em estudo. O resultado da aplicação deste método é completamente qualitativo, limitado ao cumprimento ou não das normas de referência (SOUZA, 2006).

\subsubsection{Análise Preliminar de Risco - PHA}

Este método é conhecido pela sigla em inglês PHA (Preliminary Hazard Analysis) e também é chamado de análise preliminar de perigos - APP (AGUIAR, 2008). Esta análise foi desenvolvida inicialmente pelas Forças Armadas dos Estados Unidos e é aplicada principalmente na etapa de projeto ou em sistemas os quais não tenham sido postos em operação anteriormente (RAUSAND e HOYLAND, 2004).

O principal objetivo deste método é identificar os "perigos", produtos perigosos (líquido e gases inflamáveis, por exemplo), ou os componentes críticos dentro do sistema e revisar os pontos nos quais seja possível acontecer uma liberação de energia de forma descontrolada. Desta forma, são analisados materiais perigosos que operam no sistema, os equipamentos e os componentes, assim como processos, operações e equipamentos de segurança. $\mathrm{O}$ resultado da análise proporciona recomendações para reduzir ou eliminar estes perigos (SÁNCHEZ, 2005). 
Entre os recursos necessários para a aplicação deste método, de relativo baixo investimento econômico, estão pessoas com experiência em segurança, códigos de projeto e especificações técnicas dos equipamentos e materiais. Com estes recursos e com o auxílio de uma tabela é possível concluir a análise. A Tabela 3.1 mostra um exemplo do que é feito na análise do tipo APP, havendo possibilidade de adaptação de acordo com o sistema em análise. Não é necessária a utilização de um programa de computador complexo, sendo suficiente um processador de texto.

Tabela 3.1 Análise Preliminar de Risco (APP)

\begin{tabular}{lllc}
\hline Descrição do perigo & \multicolumn{1}{c}{ Causa } & Conseqüiência & Medidas preventivas /corretivas \\
\hline $\begin{array}{l}\text { Vazamento de } \\
\text { combustível }\end{array}$ & $\begin{array}{l}\text { Quebra do } \\
\text { reservatório }\end{array}$ & $\begin{array}{l}\text { Contaminação, } \\
\text { explosão... }\end{array}$ & $\begin{array}{c}\text { Inspeções periódicas de tanques e } \\
\text { tubulações... }\end{array}$ \\
\hline
\end{tabular}

Como resultado da aplicação deste método, é gerado um documento onde são claramente identificados os perigos, as causas, as conseqüências potenciais e as diferentes medidas preventivas ou corretivas associadas, facilitando a tomada de medidas que possam prevenir a ocorrência dos perigos ainda na fase de projeto do sistema (AGL, 2006).

\subsubsection{Análise "What if...?"}

A tradução para o nome deste método é “o que aconteceria se...?”. Este método não é tão estruturado quanto os outros métodos, mas é de fácil adaptação por parte do usuário para o sistema em estudo. Como o seu nome indica, o método consiste em questionar o resultado da presença de eventos indesejados que poderiam provocar consequiências perigosas. O método questiona a possibilidade de eventos perigosos durante as etapas de projeto, implementação, modificação e operação de um determinado sistema produtivo. Como os outros métodos, esse solicita um conhecimento básico do sistema e a capacidade de sintetizar as possíveis combinações de eventos dentro do processo (SÁNCHEZ, 2005). 
Devido à facilidade de adaptação, este método é de ampla aplicação, dependente apenas do direcionamento das perguntas a serem feitas. Assim, pode ser aplicado a sistemas de segurança contra incêndios, segurança pessoal, segurança elétrica, etc. As perguntas são formuladas em função da experiência prévia em sistemas com características similares ou através do estudo prévio do sistema em questão.

3.3.1.4. Estudo de Perigos de Operação (HAZOP - Hazard and Operability Studies)

Esta técnica é chamada Estudo de Perigos de Operação (AGUIAR, 2008) e provem da sigla HAZOP - Hazard and Operability Studies - ou, segundo Sánchez (2005) de Hazard Operation. Esta análise foi desenvolvida a partir de 1963 pela companhia ICI (Imperial Chemical Industries) e visa identificar possíveis problemas de operabilidade de uma instalação industrial revisando-a metodicamente por completo. Baseia-se em uma análise sistemática do problema através do planejamento e respostas a uma seqüência de perguntas (como?, quando?, por quê?, etc.).

O HAZOP é um método indutivo de identificação de riscos baseado no princípio de que acidentes acontecem em conseqüência da perda de controle de algumas das variáveis do processo, em relação aos parâmetros normais de operação. O método de análise pode ser dividido em cinco etapas principais: 1) definição do sistema em estudo; 2) definição de nós; 3) definição dos caminhos alternativos; 4) elaboração do HAZOP e, por fim, 5) a redação do informe de resultados.

O método do HAZOP apresenta algumas vantagens, pois é uma oportunidade para se obter diferentes pontos de vista da operação e da segurança da planta. É um método sistemático que auxilia o projetista a criar uma planta. Do ponto de vista da segurança operacional, proporciona aos operadores uma melhora no conhecimento da operação do sistema e não requer maiores recursos além do tempo desprendido nas seções de elaboração do HAZOP. 
O HAZOP enfoca tanto os problemas de segurança, buscando identificar os perigos que possam colocar em risco os operadores e os equipamentos da instalação, como também os problemas de operabilidade que, embora não sejam perigosos sob o ponto de vista de ameaça à integridade da planta, podem causar perda de produção ou podem afetar a qualidade do produto e a eficiência do processo. Portanto, o HAZOP identifica tanto problemas que possam comprometer a segurança da instalação como aqueles que possam causar perda de continuidade operacional ou perda de especificação do produto.

Entre as desvantagens desta técnica tem-se, devido a sua natureza puramente qualitativa, a impossibilidade de uma estimação da freqüência das falhas, nem das consequiências, sob o ponto de vista de custos. Os resultados obtidos estão diretamente ligados ao conhecimento das equipes utilizadas na elaboração da análise. Como o método está baseado nas informações disponíveis e na experiência dos operadores, podem-se omitir riscos em função do desconhecimento ou conhecimento incorreto da operação do sistema.

Portanto, para a execução de uma análise do tipo HAZOP de boa qualidade, exige-se, além da participação de especialistas experientes, informações precisas, detalhadas e atualizadas a respeito do projeto e procedimentos de operação da instalação analisada. Para a execução do HAZOP deve-se dispor de materiais atualizados e informações sobre o processo, instrumentação e operação da instalação. Estas informações podem ser obtidas através de documentação, tais como especificações técnicas, procedimentos de operação e de manutenção ou por pessoas com qualificação técnica e experiência. A documentação atualizada, que pode ser necessária para execução do HAZOP está indicada abaixo (AGUIAR, 2008):

- Fluxogramas de engenharia;

- Fluxogramas de processo e balanço de materiais;

- Memoriais descritivos, incluindo a filosofia de projeto;

- Folhas de dados de todos os equipamentos da instalação; 
- Dados de projeto de instrumentos, válvulas de controle, etc.; especificações e padrões dos materiais das tubulações;

- Diagrama lógico de intertravamento, juntamente com descrição completa;

- Matrizes de causa e efeito;

- Diagrama elétrico;

- Especificações das utilidades, tais como vapor, água de refrigeração, ar comprimido, etc.;

- Desenhos mostrando interfaces e conexões com outros equipamentos na fronteira da unidade/sistema analisados.

\subsubsection{Análise de Modos e Efeitos de Falhas}

A Análise de Modos e Efeitos de Falhas (FMEA), proveniente do inglês Failure Modes and Effects Analysis, segundo Bouti e Ati (1994), é uma técnica do "menor ao maior", ou seja, e baseada na lógica indutiva para determinar o nível de dependência entre sistemas. O FMEA remonta ao final da década de 40, quando as Forças Armadas dos Estados Unidos da América desenvolveram um procedimento militar para o estudo de armamento denominado de MIL-P-STD 1629 (Procedures for performing a failure mode, effects and criticality analysis). Posteriormente, o Departamento de Defesa elaborou e revisou o procedimento, publicando a guia (diretriz ou norma) MIL-STD1629A em 1977 (RAUSAND e HOYLAND, 2004). Tempos depois, na década dos anos 80, a Ford Motor Company publicou manuais de instrução sob a aplicação do FMEA que foram embriões para a criação da norma técnica SAE J1739, publicada pela Society of Automotive Engineers para a indústria automotiva.

Outras normas que fazem referência da análise do tipo FMEA são: a AIAG FMEA-3 para a indústria automotiva, desenvolvida pela Automotive Industry Action Group; a ARP5580 da SAE, para aplicações não automotivas; a EIA/JEP131 norma para indústria de eletrônicos da JEDEC/EIA (Electronic Industries Alliance) e a P-302720, que proporciona diretrizes da NASA para a indústria aeroespacial (RAUSAND e HOYLAND, 2004). 
A análise do tipo FMEA é um dos métodos de análise de confiabilidade de sistemas mais utilizados e de maior eficácia, pois tem a capacidade de identificar possíveis modos pelos quais os componentes falham, e conjuntamente identifica as consequiências e os efeitos destas falhas. O FMEA é empregado na melhoria de projetos de sistemas, na determinação dos pontos vulneráveis, na concepção de testes, sendo usado também no projeto de linhas de produção e no planejamento da manutenção. O método é inicialmente qualitativo, mas podem ser incluídas estimativas de cálculo de probabilidades de falha (LEWIS, 1987).

Como método, o FMEA tem diretrizes gerais as quais norteiam sua elaboração. Desta forma, é necessário refletir sobre cinco questões a respeito do sistema como base para a elaboração do FMEA (SOUZA, 2003):

- Como pode falhar o componente (quais são seus modos de falha)?

- Quais são os efeitos destas falhas sobre o sistema?

- Quão críticos são estes efeitos?

- Como detectar a falha?

- Quais as medidas contra estas falhas (evitar, prevenir a ocorrência das mesmas ou minimizar seus efeitos)?

Usualmente o método emprega uma tabela, similar à indicada na Tabela 3.2.

Tabela 3.2. Análise de Modos e Efeitos das Falhas (CARAZAS, 2006)

\begin{tabular}{|c|c|c|c|c|c|c|c|c|c|c|c|}
\hline $\mathbf{N}^{\mathbf{0}}$ & 胥 & $\begin{array}{l}\text { Modos } \\
\text { De } \\
\text { Falhas }\end{array}$ & $\begin{array}{l}\text { Causas e } \\
\text { Mecanismos } \\
\text { Falhas }\end{array}$ & $\begin{array}{l}\text { Efeitos } \\
\text { das } \\
\text { Falhas }\end{array}$ & $\begin{array}{l}\text { Modo de } \\
\text { Detecção }\end{array}$ & $\begin{array}{l}\text { Medidas } \\
\text { De } \\
\text { Prevenção }\end{array}$ & & 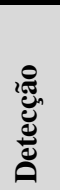 & & $\frac{\text { a }}{\bar{Z}}$ & 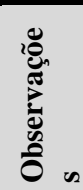 \\
\hline
\end{tabular}

Na primeira coluna apresentam-se a identificação do componente e na segunda coluna é descrita a função do componente. A terceira coluna é usada para descrever as possíveis falhas que podem ser apresentadas pelo componente denominado de modos de 
falha. Para uma análise mais profunda, eventualmente podem ser mencionados todos os mecanismos de falha. Na coluna seguinte (quinta coluna) são discutidos os efeitos de cada modo de falha do componente, incluindo os efeitos locais sobre os subsistemas, e propagando-as até o sistema como um todo. Pode-se também apresentar possíveis formas de se detectar um determinado modo de falha, ou a indicação de que a mesma está próxima a acontecer, e assim possibilitar a intervenção de manutenção antes da ocorrência do mesmo e a conseqüente propagação de seus efeitos sobre o sistema. Podem existir outras colunas onde se indica a classificação da severidade de um modo de falha, a qual tem como objetivo fornecer uma idéia qualitativa do efeito do modo de falha do componente sobre todo o sistema. A norma MIL-STD-1629A (1977), para efeito de aplicação do FMEA, classifica a severidade nas seguintes categorias:

- Catastrófica: falha que tem severas conseqüências com graus de dano elevados e que pode causar danos físicos ou fatalidades.

- Crítica: falha que degrada completamente o desempenho do sistema e/ou ferimentos graves.

- Marginal: falha que degrada o sistema, mas não causa a parada do sistema, ou que cause ferimentos leves.

- Menor ou Desprezível: falha que não causa ferimentos ou degradação no desempenho do sistema, mas resulte na perda da capacidade operacional de um componente, exigindo manutenção não programada.

Por fim, na última coluna da tabela, podem-se adicionar notas esclarecedoras sobre os pontos abordados na tabela de análise. A classificação de severidade apresentada pela norma MIL-STD-1629A não é única. Outras normas, como por exemplo, a proposta pela SAE - Society of Automotive Engineers (SAE, 2002), propõe esta classificação em 10 categorias, este padrão também foi utilizado pela antiga norma ISO 9000, (1994). Desta forma, O autor (CARAZAS, 2006) propõe uma classificação 
da severidade específica para sistemas de geração de energia elétrica tal como é apresentada na Tabela 3.3.

Tabela 3.3. Classificação da Severidade (CARAZAS, 2006)

\begin{tabular}{|c|c|}
\hline Grau de Severidade & Efeito sobre a Operacionalidade do Sistema de Geração de Energia Elétrica \\
\hline 1(Sem Efeito) & $\begin{array}{l}\text { - Falha de componentes que exigem reparo ou substituição, mas não imediata; } \\
\text { - Não afeta o desempenho da máquina ou sistema ou sem efeito sobre o meio ambiente. }\end{array}$ \\
\hline 2 (Efeito Leve) & $\begin{array}{l}\text { - Falha de componentes que exigem reparo ou substituição, mas não imediata; } \\
\text { - Desempenho da máquina ou sistema muito pouco degradado, sem efeito sobre o meio } \\
\text { ambiente. }\end{array}$ \\
\hline 3 (Efeito Menor) & $\begin{array}{l}\text { - Falha de componentes que exigem reparo ou substituição, mas não imediata; } \\
\text { - Desempenho da máquina pouco degradado, sem efeito detrimental sobre o meio ambiente.. }\end{array}$ \\
\hline 4(Efeito Moderado) & $\begin{array}{l}\text { - Falha de componentes, com necessidade de reparo ou substituição. } \\
\text { - Desempenho do sistema de geração de energia pouco degradado, mas ainda permite } \\
\text { - Perda de desempenho notência gerada reduzida; } \\
\text { dificuldades de manutenção das mesmas. } \\
\text { - Possibilidade de efeito pouco detrimental sobre o meio ambiente. }\end{array}$ \\
\hline 5(Efeito Significante) & $\begin{array}{l}\text { - Falha de componentes, com necessidade de reparo ou substituição. } \\
\text { - Desempenho do sistema de geração afetado, mas ainda permite operação, porém com } \\
\text { - Perda de desempenho nos sistemas de controle das condições de operação, com dificuldade } \\
\text { de manutenção das mesmas. } \\
\text { - Possibilidade de algum efeito detrimental sobre o meio ambiente. }\end{array}$ \\
\hline 6 (Efeito Maior) & $\begin{array}{l}\text { - Falha de componentes, com necessidade de reparo ou substituição. } \\
\text { porém com potência gerada bastante reduzida; } \\
\text { - Severa perda de desempenho nos sistemas de controle das condições de operação.. } \\
\text { - Possibilidade de efeito detrimental sobre o meio ambiente, chance de exceder alguma } \\
\text { regulamentação ambiental. }\end{array}$ \\
\hline 7 (Efeito Extremo) & $\begin{array}{l}\text { - Falha de componente, sem danos a outros componentes. Necessidade de substituição e/ou } \\
\text { reparo do componente, com tempo de parada reduzido; } \\
\text { - Falha que não afeta segurança do sistema de geração e dos operadores; } \\
\text { - Falha causa parada de máquina, com não cumprimento de regulamentação governamental. } \\
\text { - Efeito ambiental grave, possibilidade de multa. }\end{array}$ \\
\hline 8(Efeito Sério) & $\begin{array}{l}\text { - Falha de componente que causa danos moderados ao sistema de geração de energia, sem } \\
\text { dano a outros componentes. Necessidade de substituição e/ou reparo do componente; } \\
\text { - Falha que não afeta segurança do sistema de geração e dos operadores; } \\
\text { - Falha causa parada de máquina, com não cumprimento de regulamentação governamental. } \\
\text { - Efeito ambiental muito grave, possibilidade de multa. }\end{array}$ \\
\hline 9 (Efeito Perigoso) & $\begin{array}{l}\text { - Falha de componente que causa danos severos ao sistema de geração, incluindo dano a } \\
\text { outros componentes. Necessidade de substituição e/ou reparo de vários componentes; } \\
\text { - Falha que afeta a segurança do sistema de geração e dos operadores; } \\
\text { - Falha causa parada de máquina, com não cumprimento de regulamentação governamental. } \\
\text { - Efeito ambiental perigoso, vazamento de substâncias perigosas, aplicação de multa. }\end{array}$ \\
\hline
\end{tabular}

A ênfase desta análise é definir as conseqüências de um determinado modo de falha sobre a operação do sistema e fornece subsídios para definir a severidade da falha de alguns componentes sobre a segurança do sistema, indicando pontos onde há necessidade da utilização de componentes redundantes. 
Dada a dificuldade da definição da taxa de falha associada ao componente, bem como da chance de ocorrência de um dado modo de falha, propõe-se a execução desta análise de criticidade de uma forma um pouco mais qualitativa, com o emprego do índice denominado de Número de Prioridade de Risco ou simplesmente NPR.

Este número é uma avaliação do denominado "risco associado com a ocorrência de um determinado modo de falha". Considerando que a avaliação das consequiências de uma falha é uma tarefa trabalhosa e que a própria avaliação da probabilidade de ocorrência de um dado modo de falha seja também uma tarefa complexa, as normas associadas com a análise de processos e projetos, tais como a norma ISO 9000 e a norma SAE J-1739 (SAE, 2002), propõem o cálculo deste risco com o emprego do índice NPR. Este varia de 1 a 1000 sendo 1000 o mais crítico e 1 o menos crítico, sendo calculado pela relação:

$$
N P R=S \cdot O \cdot D
$$

onde:

$S$ = Indicação da severidade das conseqüências associadas a um dado modo de falha, variando de 1 a 10 .

$O=$ A probabilidade de ocorrência de um dado modo de falha, variando de 1 a 10 , e $D=$ A detecção, que avalia os meios de detectar o desenvolvimento de um modo de falha, permitindo a sua correção antes da ocorrência da falha, variando de 1 a 10.

Os modos de falha considerados críticos para a operacionalidade do sistema são aqueles que apresentam o índice NPR elevado. Para esses modos de falha, o projetista deve revisar o projeto ou o próprio processo de fabricação a fim de minimizar a ocorrência ou a severidade do mesmo, ou maximizar a sua detecção ainda em fase de desenvolvimento. O valor limite aceitável de NPR não é claramente definido em normas, de forma que a indústria automotiva usualmente utiliza o valor 125 como limite máximo aceitável para o NPR. Situações nas quais a severidade é igual ou maior que 7 e/ou a ocorrência é superior a 6 também devem ser reavaliadas. 
Executar a análise do tipo FMEA exige pessoal especialmente preparado para esta função, pois além de dominar o conhecimento acerca do sistema (suas características, princípios de funcionamento e especificações), exige conhecimento dos conceitos relativos à confiabilidade, uma vez que as taxas e as probabilidades de falhas devem ser calculadas.

\subsubsection{Método de Identificação de Riscos de Natureza Quantitativa}

Estes métodos são usados para a avaliação quantitativa das frequiências de ocorrência de falhas. Os principais métodos são descritos na sequiência:

\subsubsection{Análise de Árvore de Falhas}

A Análise de Árvore de Falhas (FTA - Fault Tree Analysis) foi idealizada em 1961 nos laboratórios da empresa de telefonia Norte Americana Bell para avaliar o sistema de controle de lançamento dos mísseis Minuteman visando avaliar a combinação de eventos que causariam estes lançamentos de forma não autorizada (NIST, 2008). Atualmente, as FTAs são empregadas pela indústria de eletrônicos, termonuclear, química e aeroespacial. A árvore de falhas é uma técnica dedutiva que está centrada em um evento particular acidental (falha) nomeado de evento topo, e proporciona um método para determinar as causas que o produzem. A grande vantagem que este método apresenta é que se podem obter tanto resultados qualitativos na procura de caminhos críticos quanto quantitativos, em termos de probabilidades de ocorrência do evento topo calculada a partir das probabilidades de falha associadas às falhas dos componentes que influem no evento topo.

Há certas dificuldades para a elaboração da árvore de falhas, sendo uma delas a identificação do evento topo ou evento principal. Para a montagem da árvore de falhas existe uma lógica a ser levada em consideração. Um sintoma de falha necessariamente 
tem um número finito - e não necessariamente conhecido - de causas as quais ocasionam e podem ocasionar a parada do sistema. Estas causas devem ser pesquisadas e determinadas com precisão, estando normalmente relacionadas às falhas em algum dos componentes do sistema. Por este motivo é recomendável, na elaboração da árvore, uma adequada representação do sistema ou seu diagrama de blocos. Ainda, segundo os autores na área, o objetivo da construção de qualquer diagrama do tipo árvore é elaborar uma estrutura lógica para definir a "raiz" ou origem do problema estudado (SOUZA, 2003; RAUSAND e HOYLAND, 2004). A Figura 3.2 apresenta o mecanismo para a elaboração da árvore de falhas.

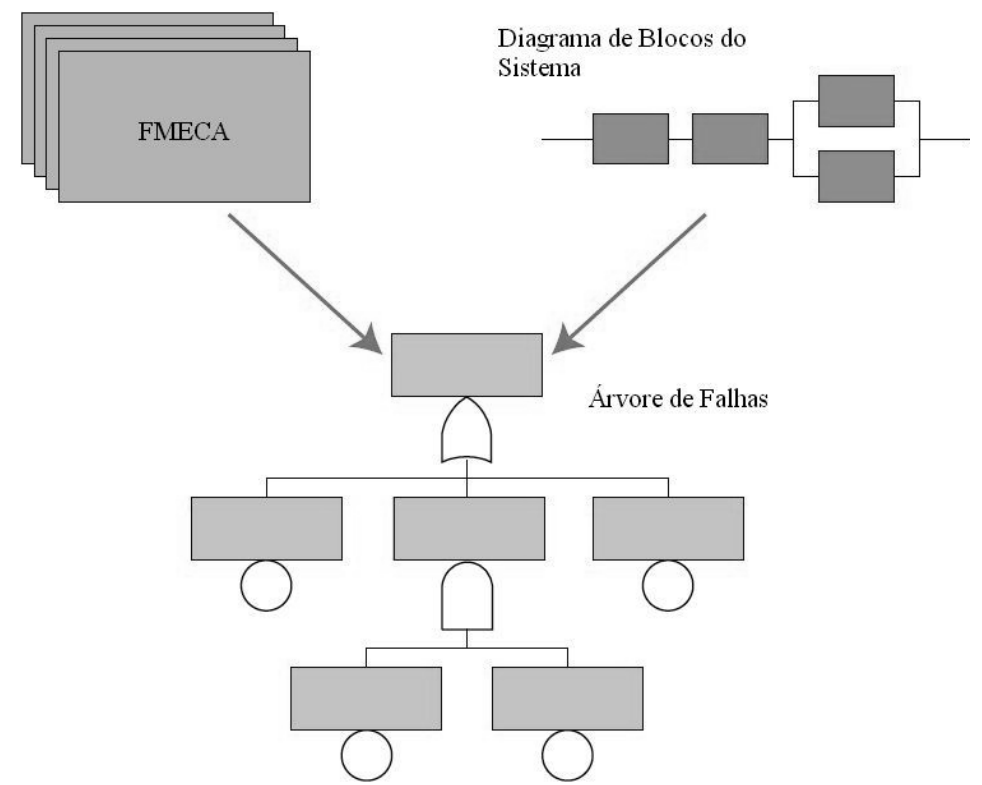

Figura 3.2 Requisitos para a elaboração da Árvore de Falhas (RAUSAND e HOYLAND, 2004)

Para a representação das falhas é usado um método gráfico que apresenta as diferentes combinações de falhas de componentes e/ou erros humanos, cuja ocorrência simultânea é suficiente para gerar um evento acidental. A construção da árvore de falhas segue três etapas, sendo que não é um procedimento rígido, e conforme as necessidades, os passos segundo e terceiro podem coexistir:

- Elaboração do diagrama;

- Análise qualitativa; 
- Análise quantitativa.

A FTA usa a lógica Booleana (de portas lógicas) para descrever a combinação das falhas individuais que podem levar a uma falha crítica ou evento topo. A equação que permite a definição das combinações de falhas que geram o evento topo descrito na árvore é representada em expressões Booleanas. Se os analistas conhecem as probabilidades de ocorrência dos eventos de base, que são na realidade complexos e pouco freqüentes, calcula-se a probabilidade de ocorrência do evento topo (RAUSAND e HOYLAND, 2004; VOLKANOSVSKI et al., 2009).

Em resumo, o método consiste em um processo dedutivo baseado nas leis da Álgebra Booleana, que permite determinar a expressão de eventos complexos estudados em função das falhas dos elementos que os compõem. A representação gráfica é feita através de portas lógicas como mostrado na Tabela 3.3.

Com esta simbologia a árvore é desenvolvida partindo, como já mencionado, de um evento indesejado ou acidental que ocupa o topo da árvore (evento topo). A partir deste evento, é possível situar de forma sistemática todas as causas imediatas que caracterizam a sua ocorrência. Em outras palavras, eventos compostos por vários elementos podem ser separados, de forma que cada elemento possa ser estudado isoladamente sem perder de vista o evento topo.

Entre as principais vantagens deste método pode-se destacar a facilidade para evidenciar os pontos críticos do sistema (conjunto de falhas), aspecto fundamental em matéria de prevenção de acidentes. Através da análise, podem ser melhorados os sistemas que operam dentro do conjunto original e/ou instalados novos componentes visando à redução de ocorrências de falhas severas e aumentando a segurança durante a operação do sistema. 
Tabela 3.4. Simbologia utilizada na construção de uma Árvore de Falhas (RAUSAND e HOYLAND, 2004)

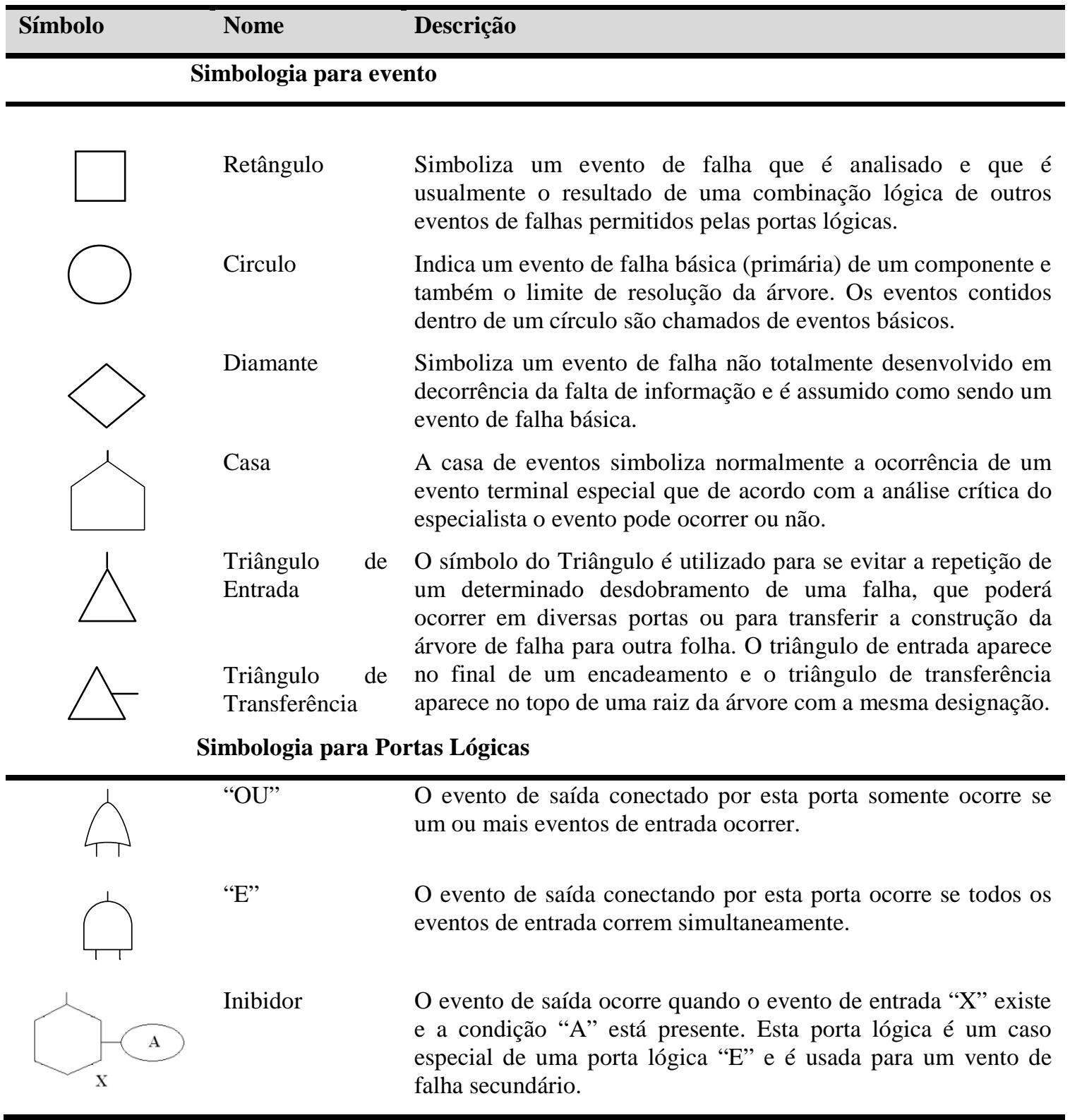

A elaboração da árvore é relativamente complexa e requer pelo menos uma pessoa com conhecimento do método de análise. Para a elaboração da árvore de falhas, precisam ser integrados os conhecimentos sobre o funcionamento e operação da instalação, e por este motivo deve fazer parte da equipe de análise pessoas que estejam familiarizadas com o sistema, a fim de que se obtenham resultados satisfatórios. 
Em relação aos recursos necessários para a elaboração da FTA, deve-se usar toda a documentação que permita esclarecer a operação do sistema (manuais, diagramas, planos de manutenção e a própria árvore de elementos). Na Figura 3.3 é apresentada uma árvore de falhas para uma possível falha em uma caldeira de recuperação em uma usina termelétrica a ciclo combinado, com o intuito de somente apresentar a morfologia da árvore de falhas.

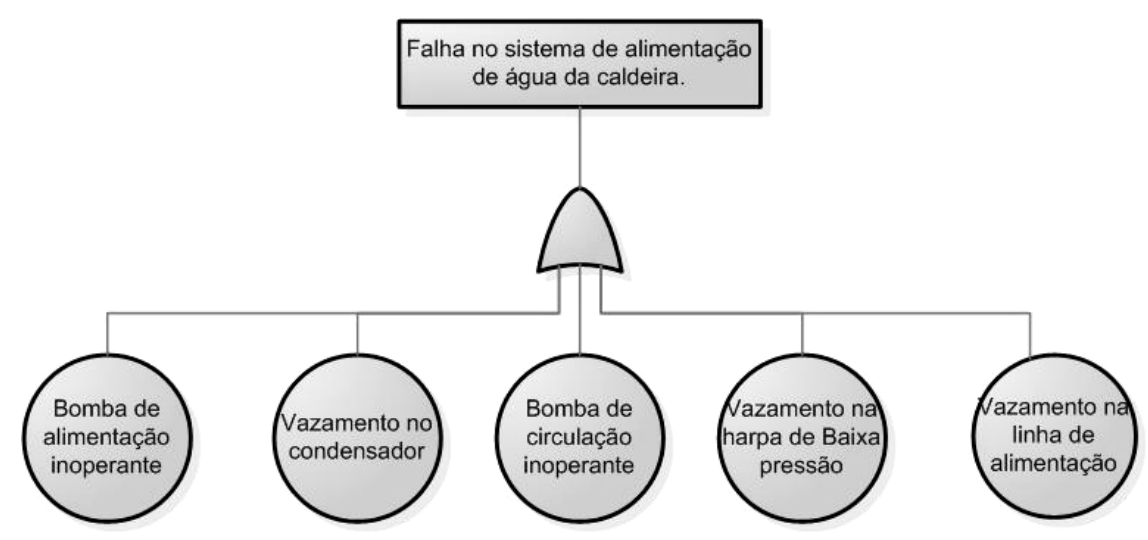

Figura 3.3 Estrutura da Árvore de Falhas

\subsubsection{Análise por Árvore de Eventos}

A árvore de eventos, também chamada de árvore de análise de conseqüências, é um método indutivo que descreve a evolução de um evento iniciador acidental (falha ou parada de algum componente) e mostra todos os possíveis resultados da ocorrência da mesma. O método é também chamado de ETA (Event Tree Analysis) ou accidentsequence event tree (KUMAMOTO e HENLEY, 1996).

Este método tem uma lógica horizontal, onde é descrita de forma seqüencial as consequiências acidentais que conduzem a diferentes cenários de operação. Assim, de forma esquemática, obtém-se a aparência de uma árvore. Esta ferramenta permite uma análise visando à segurança do sistema desde a etapa de projeto de mesmo, identificando os pontos fracos na operação do sistema (RAUSAND e HOYLAND, 2004; KUMAMOTO e HENLEY, 1996). 
A elaboração da árvore se inicia com a identificação dos $\mathrm{N}$ "fatores condicionantes" da evolução do evento iniciador. Na seqüência, coloca-se o evento inicial como ponto de partida da estrutura gráfica. Assim, partindo do evento iniciador, exploram-se duas bifurcações (em forma de ramos): na parte superior, representa-se o sucesso e a ocorrência do evento condicionante e na parte inferior representa-se a falha, ou a não ocorrência deste, como mostra a Figura 3.4.

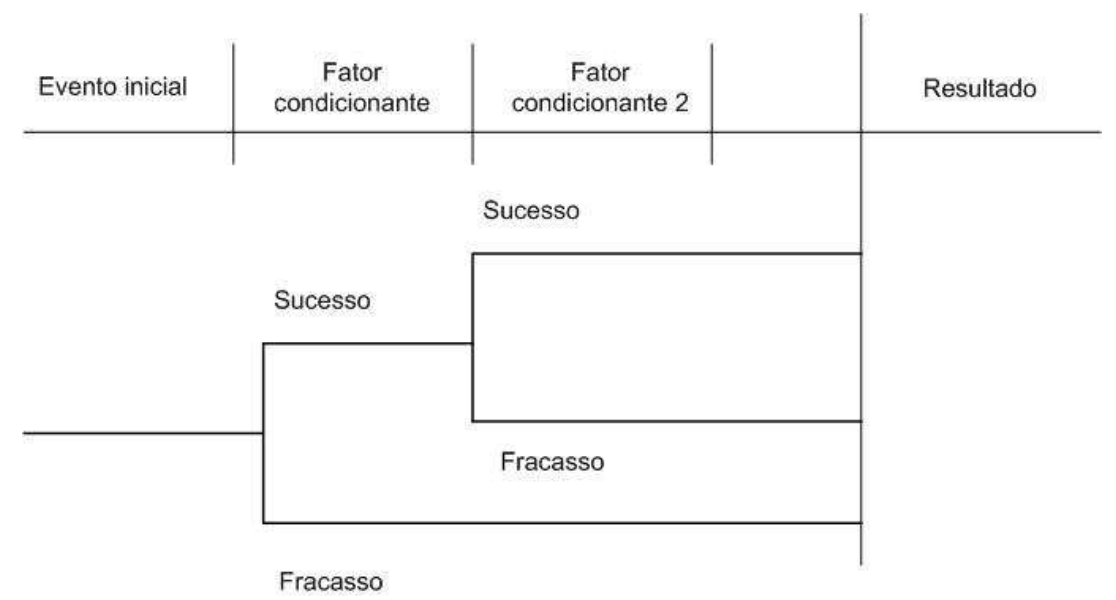

Figura 3.4 Representação da Árvore de Eventos

Desta forma, são obtidas $2^{\mathrm{N}}$ combinações ou seqüências de eventos. A influência do "fator condicionante" sob um determinado evento provoca a ocorrência de uma falha (denominada de fracasso) ou sucesso (evento em ausência de falhas). As dependências entre os eventos fazem com que alguns deles possam eliminar a possibilidade de ocorrência de outros, reduzindo assim o número final de sequiências. A aplicação do método proporciona uma lista de seqüências dos possíveis eventos, sendo estes fracassos ou sucesso (SOUZA, 2006).

O método pode ser aplicado em diversos sistemas. A árvore de eventos permitirá à equipe do planejamento da manutenção analisar as seqüências acidentais a partir de um evento iniciador, com a finalidade de propor barreiras que interrompam a propagação destas. Em relação à elaboração da árvore de eventos pode-se afirmar que é pouco laborioso e não requer preparação específica para o uso da mesma, mas é 
importante ter conhecimento da operação, dos componentes e das matérias com as quais o sistema interage.

A principal vantagem do método é que este permite um estudo sistemático e profundo da evolução de um evento inicial considerado determinante. Sua aplicação é simples e, devido a sua natureza gráfica, é de fácil entendimento para explicação e desenvolvimento de mecanismos de segurança no sistema. Este método, em combinação com outros métodos de análise de risco (PHA, HAZOP), permitirá representar os cenários e seqüência das falhas para cada ocorrência de falha específica ou evento inicial (MODARRES, 1993).

\subsubsection{Diagrama Causa-Conseqüência}

Este método de análise de risco consiste em uma combinação de dois métodos tradicionais para o estudo de confiabilidade e risco: a árvore de falhas e a árvore de eventos. O método foi desenvolvido pela Riso Laboratories na Dinamarca por volta dos anos 70 para auxiliar os estudos de confiabilidade e risco nas usinas nucleares dos países escandinavos (KUMAMOTO e HENLEY, 1996).

O método combina a estrutura dedutiva da árvore de eventos com a análise indutiva da árvore de falhas. O diagrama causa-conseqüência (CCDM - CauseConsequence Diagram Method) é, devido a sua natureza esquemática, bastante ilustrativo para mostrar as conseqüências dos possíveis acidentes causados por um evento iniciador que é, normalmente, uma falha (VILLLEMEUR, 1992).

O diagrama causa-conseqüência pode ser executado de forma qualitativa e quantitativa, podendo relacioná-lo às probabilidades dos eventos e determinando as consequiências dos mesmos em valores econômicos. A vantagem do método é que permite "mover-se" para os cenários provocados pela ocorrência de uma falha "à 
esquerda", com o método da árvore de eventos, e às falhas (para trás) com o método da árvore de falhas.

A elaboração do diagrama causa-conseqüência consiste em identificar um evento iniciador, da mesma forma como com a técnica da árvore de eventos. Esta etapa inicial pode se tornar bastante trabalhosa se não se tem um conhecimento adequado da operação do sistema e do fundamento teórico desta ferramenta. Logo, definidos os eventos iniciadores, são definidos os caminhos críticos ou de consequiências das falhas. Em cada um dos caminhos podem ser identificadas duas partes: a causa, representada por uma falha ou uma condição inaceitável de operação (condição) e as conseqüências. Os pontos de união entre as causas e as conseqüências podem ser representados por caixas de decisão como mostra a Figura 3.5 e, para cada condição, o diagrama propõe dois caminhos de conseqüências indicadas por SIM e NÃO. Estas respostas podem ser condicionadas pelo evento topo da árvore de falha e associadas a uma probabilidade de falha, caso em que a análise de árvore de falhas seja de natureza quantitativa (VILLLEMEUR, 1992).

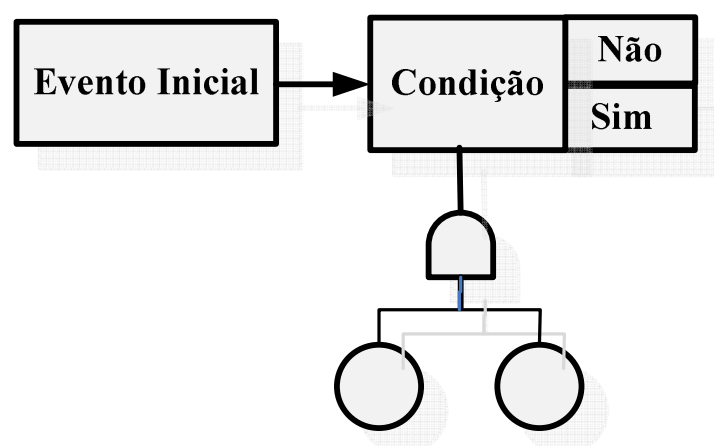

Figura 3.5. Caixa de decisão no Diagrama Causa-Conseqüência

Os autores Kumamoto e Henley (1996), Modarres (1993), Villlemeur (1992) e Ridley e Andrews (2000) recomendam, para a elaboração do Diagrama CausaConsequiência, a seguinte seqüência: 
- Seleção do evento iniciador a ser avaliado

Este evento é uma condição temporal do sistema, como por exemplo, um determinado estado de falha ou uma condição inaceitável de operação (desempenho abaixo do esperado). Tal evento pode ser mesmo selecionado como "evento topo" na análise de árvore de falhas ou o "evento iniciador" da análise de árvore de eventos.

- Identificação das funções de segurança e desenvolvimento das $\underline{\text { seqüências acidentais }}$

Esta etapa é realizada em paralelo à listagem dos eventos inesperados, onde são identificadas as possíveis falhas dos sistemas ou funções de segurança.

Esta etapa do método permite analisar a operação do sistema de segurança que deveria atuar em um ponto determinado da seqüência acidental de forma a criar uma barreira de segurança. A operação correta ou incorreta do sistema de segurança encaminhará a duas situações diferentes. Na representação gráfica se obterá, para cada evento, uma chance relacionada a ela e uma resposta SIM ou NÃO, como apresentado na Figura 3.5.

- Desenvolvimento do evento e as falhas de operação dos sistemas de segurança para determinar as causas principais

Este passo consiste na aplicação da análise de árvore de falhas para cada um dos eventos iniciais ou das falhas dos sistemas de segurança identificados no diagrama causa-consequiência, visando à definição da combinação de eventos causadores das mesmas.

- Desenvolvimento dos conjuntos mínimos de falhas das seqüências de $\underline{\text { acidentes }}$ 
Para cada uma das seqüências acidentais identificadas no diagrama, determinam-se os conjuntos mínimos de falhas que serão os caminhos críticos, necessários que aconteçam para que se produza o evento final indesejado.

- Elaboração dos resultados

Os resultados do método são apresentados da seguinte forma: são estabelecidos em ordem decrescente entre as conseqüências avaliadas, em função da gravidade e da importância para a segurança do meio, das pessoas e das instalações. Posteriormente, para cada uma das seqüências acidentais é estabelecida uma classificação de caminhos críticos de falha para determinar as falhas principais ou causas mais importantes que poderiam provocar os acidentes identificados.

A Figura 3.6 mostra a estrutura de um diagrama causaconsequiência. Esta figura mostra de forma gráfica as probabilidades de um evento acontecer, determinadas pelas árvores de falhas.

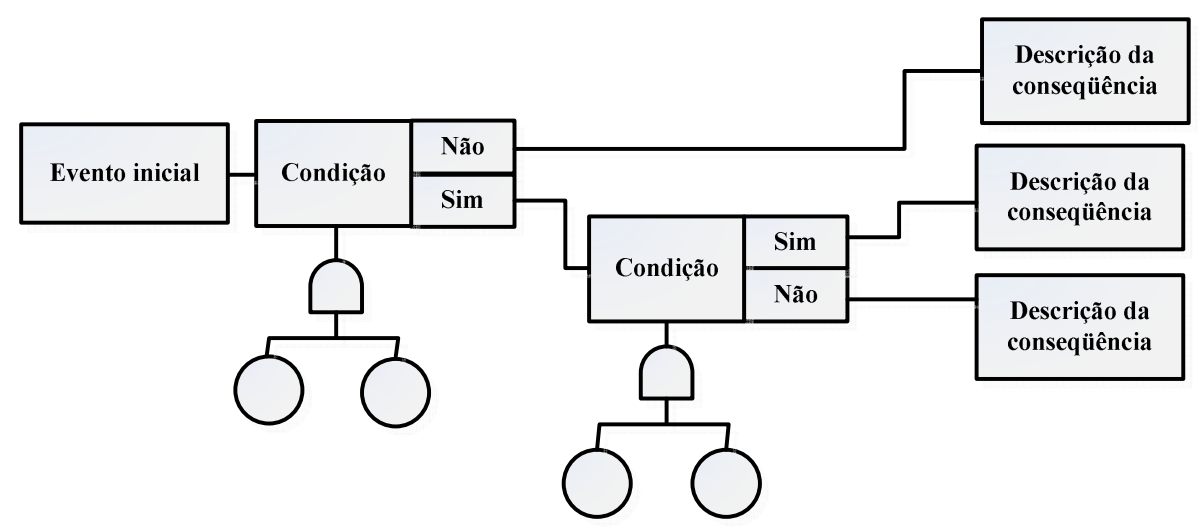

Figura 3.6 Diagrama Causa-conseqüência

Devido à semelhança com os métodos de árvore de falhas e árvore de eventos, o diagrama causa-conseqüência pode ser usado nos mesmos casos citados anteriormente. Neste sentido, este é o melhor método de análise na etapa de projeto de qualquer 
instalação, o que facilita a implantação das recomendações derivadas do estudo. Isto não exclui a aplicação do método em instalações já existentes.

Como este método é uma combinação de árvore de falhas e árvore de eventos supõe-se que, para a elaboração do método, é necessária a participação de uma pessoa ou grupo de pessoas com conhecimento dos métodos acima citados. Os integrantes da equipe de elaboração e aplicação do método devem possuir um profundo conhecimento da operação, das instalações do sistema, assim como dos componentes deste.

Para finalizar esta etapa da análise, deve-se planejar o processo de quantificação do risco, que dependerá da natureza do sistema sob análise. Portanto, a aquisição dos dados relacionados às ocorrências de falhas e os custos relacionados às operações serão dependentes da qualidade da base de dados.

Em relação aos custos decorrentes da ocorrência de um evento indesejado, estes são, na maioria das vezes, aproximações baseadas na experiência dos operadores. Para o caso específico de sistemas de geração energia elétrica, as variações do mercado não permitem uma representação exata destes custos, representando uma situação baseada em um estado especifico deste mercado. Todas estas análises são importantes, pois, em uma eventual tomada de decisão relacionada ao investimento em sistemas que aumentem a segurança operacional e evitem ou mitiguem os efeitos decorrentes da ocorrência de um evento indesejado acidental, ter-se-á um valor aproximado ao real para a tomada de decisão (destacando que este será aceitável apenas para um cenário especifico de análise).

\subsubsection{Considerações Finais em Relação às Técnicas de Análise de Risco}

Todas as técnicas apresentadas são muito úteis, dependendo do objetivo da análise e tipo de sistema que seja sujeito de uma análise de risco. Com a finalidade de destacar as principais características de cada uma delas é apresentada a Tabela 3.5, que 
auxilia a seleção de uma determinada técnica em função do tipo de análise a ser executada. A tabela apresenta três colunas principais, onde na primeira coluna são apresentadas as técnicas de análise de risco. A segunda coluna apresenta as características de cada uma das técnicas de analise de risco, como a natureza da técnica (quantitativa ou qualitativa), e se é do tipo de controle ou de identificação de risco.

A terceira coluna destaca as capacidades de cada uma das técnicas, em primeiro lugar, para representar o cenário de operação do sistema; em segundo lugar a capacidade de identificar componentes críticos, dentro do sistema sob análise, em função de um determinado nível de risco aceitável ou algum outro parâmetro vinculado ao risco operacional. Em terceiro lugar se indica a capacidade da técnica de avaliar o risco; em quarto lugar a Tabela 3.5 indica a capacidade da técnica de identificar causas e/ou consequiências que levam a um estado de falha e conseqüentemente geram um nível de risco inaceitável para a operação do sistema. Em quinto lugar a Tabela assinala a capacidade da técnica de fazer recomendações relacionadas à: instalação de barreiras que evitem a propagação das conseqüências de uma falha, (em outras palavras, equipamentos de segurança ou sistemas de monitoração com a finalidade de evitar a propagação do risco); capacidade de recomendar a necessidade de atividades de inspeção, tal como sugere, por exemplo, a implementação da técnica do PHA, amplamente utilizada pela filosofia da inspeção baseada em risco; a capacidade para sugerir atividades ou rotinas de manutenção, o que se encaixaria neste caso em particular à análise do tipo FMEA, técnica que atende às necessidades da filosofia da manutenção baseada em risco e os objetivos do atual método SMBR aqui proposto para seleção de políticas de manutenção na indústria de geração de energia elétrica.

Da elaboração da Tabela 3.5, se observa que a técnica de Check List pode ser utilizada para o controle do risco, embora de natureza qualitativa, por exemplo. Já as técnicas como o FMEA, HAZOP e PHA proporcionam recomendações em relação à atividades de mitigação ou prevenção de riscos, com recomendações de inspeção e/ou manutenção. Em relação à recomendação de instalação de barreiras de contenção de risco também se pode fazer uso da técnica do Diagrama Causa-Conseqüência. 
Das técnicas de natureza quantitativa se destaca a capacidade destas de avaliar o risco e ainda a capacidade de identificação das causas e as possíveis consequiências associados a uma eventual falha e, a capacidade de representar o cenário de operação, combinando eventos ou a sucesso de eventos que levariam a um cenário de operação com risco. Na sequiência é apresentada a tabela de comparação das principais técnicas de análise de risco.

Tabela 3.5 Comparação das Principais Técnicas de analise de risco

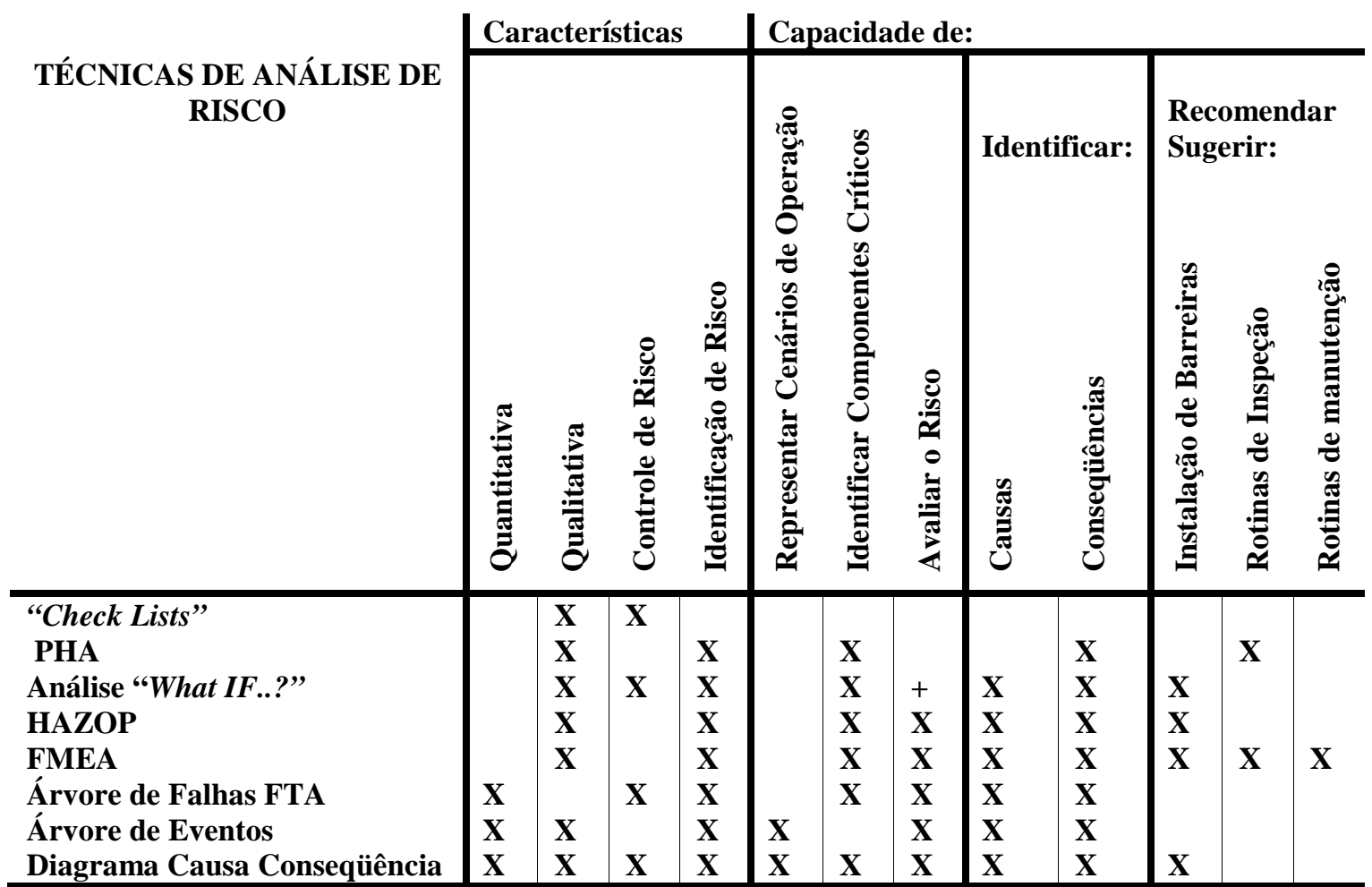

(+) Avaliação quantitativa

Até aqui foram apresentados os conceitos para identificar os riscos, os quais permitem modelar e/ou representar os possíveis cenários de falha ou de condições de operação inaceitáveis. Se uma determinada análise visa propor modificações no planejamento da manutenção com as ferramentas de análise de risco até aqui apresentadas, estas tornam-se suficientes para esta tarefa. Em outras palavras, os conceitos apresentados permitem à equipe de planejamento da manutenção a identificação dos elementos críticos para a operação do sistema, das fraquezas do sistema de segurança, dos possíveis caminhos que a ocorrência de evento acidental 
poderia tomar do ponto de vista operacional, entre outras conclusões, as quais auxiliam o gestor da planta de geração de energia elétrica a adotar uma política de manutenção especifica, com o objetivo de minimizar riscos.

Este trabalho de tese de Doutorado propõe um método (denominado de SMBR,) que tem por objetivo ser uma ferramenta estratégica, não apenas para o planejamento da manutenção, mas também para análise de investimentos relacionados à modernização ou instalação de novos equipamentos visando manter a alta disponibilidade do sistema. Os conceitos da análise de decisão, normalmente estudados pelas ciências econômicas, estão incluídos no presente trabalho e são apresentados na seqüência deste texto.

\subsection{Análise de Decisão - Conceitos Inicias}

O processo de seleção de políticas de manutenção é similar ao processo de tomada de decisão em qualquer outro processo industrial/comercial, ou seja, é necessário selecionar uma entre várias alternativas, aquela que melhor atende aos requisitos da atividade industrial, que podem ser expressos em termos quantitativos de custos, desempenho ou qualidade, entre outros. No caso da seleção de políticas de manutenção deve-se buscar a minimização da probabilidade de falha do equipamento, mas as atividades de manutenção e as possíveis mudanças no projeto do sistema devem estar em sintonia com as atividades econômicas da empresa (em relação a investimentos coerentes). Desta forma, a seleção da alternativa manterá o equilíbrio entre a minimização da probabilidade de falha e os custos das ações de manutenção, levando em consideração as próprias conseqüências da falha (objeto de estudo da análise de risco).

Esta parte do capítulo tem por objetivo apresentar os conceitos relacionados com os problemas de decisão visando selecionar a técnica de tomada de decisão mais adequada para a seleção de políticas de manutenção. Com o objetivo de minimizar o risco associado com a operação de uma usina de geração de energia elétrica. 


\subsection{Processo de Análise de Decisão}

Frente à necessidade de tomar uma decisão de melhoria ou alteração da política de manutenção de um sistema de geração de energia elétrica, encontram-se os riscos e as incertezas. Estes riscos podem ser operacionais (que mudariam o comportamento normal do sistema); riscos às pessoas, já que a mudança na operação normal poderia gerar um cenário de falha desconhecido, no qual os operadores do sistema, na tentativa de resolver algum problema, poderiam desencadear uma conseqüência grave, incluindo a paralisação do sistema; e/ou riscos ao meio ambiente. É por isso que as decisões a serem tomadas têm que ser bem estruturadas através de um processo de decisão. Segundo Schuyler (2002), a tomada de decisões em projetos é bem sucedida se caracterizada por dez passos, onde pode se destacar o quarto passo, que se refere ao desenvolvimento de um modelo de decisão específico para cada caso. Os passos para o desenvolvimento de um processo de tomada de decisão em projeto são (SCHUYLER, 2002):

- Identificação das oportunidades de decisão;

- Definição do problema;

- Identificação das alternativas;

- Desenvolvimento do modelo de decisão;

- Quantificação dos critérios sobre a incerteza;

- Desenvolvimento do modelo de avaliação;

- Cálculo do valor esperado para cada alternativa;

- Reavaliação o problema;

- Aplicação da melhor alternativa;

- Análise complementar da decisão.

Da mesma forma, a filosofia do RBM mostra um método para a tomada de decisão em manutenção focado, principalmente, na redução dos riscos associados à ocorrência de uma falha (KHAN e HADDARA, 2003; KRISHNASAMY et al., 2005). Segundo Khan e Haddara (2003), o planejamento da manutenção se divide em duas 
etapas: estimativa do tempo ótimo de manutenção e reavaliação e estimativa dos novos riscos, introduzidos após a alteração do procedimento de manutenção.

O processo para a tomada de decisão pode ser estruturado pelos seguintes passos, em função da caracterização das opções possíveis para as ações de manutenção:

- Identificação da natureza do problema;

- Identificação das alternativas;

- Classificação dos problemas de decisão;

- Seleção do método de tomada de decisão;

- Solução ao problema de decisão;

- Planejamento da manutenção (aplicação da opção selecionada);

- Reavaliação do problema.

Cada uma destas etapas é composta por uma série de atividades descritas a seguir.

\subsubsection{Identificação da Natureza do Problema}

Esta primeira etapa da solução do problema é necessária para uma seleção adequada do método de tomada de decisão. Envolve a identificação do tipo de problema entre as três principais classificações dos problemas de decisão: problemas estruturados, semi-estruturados e não estruturados (SHIMIZU, 2001).

A primeira classificação, problemas bem estruturados, refere-se aos problemas de decisão chamados de bem definidos. São aqueles cuja definição e fases de operação para alcançar resultados desejados são bem claras e cuja repetição da execução é sempre possível, obtendo-se os mesmos resultados.

Os problemas de decisão semi-estruturados são aqueles com operação bem conhecida, mas que possuem critérios ou fatores de comportamento variável, que podem influenciar no resultado. Como exemplo deste tipo de problema de decisão, 
pode-se citar a previsão de compras de peças de reposição para manutenção em um determinado período.

Nos problemas de decisão não estruturados, tanto cenários quanto critérios de decisão não estão fixados à priori, ou seja, existem diversas alternativas previstas, mas que podem ser substituídas de última hora. O exemplo mais adequado para este tipo de problema de decisão é a publicação de uma capa de revista semanal (SHIMIZU, 2001).

\subsubsection{Identificação das Alternativas.}

Durante a operação normal de um sistema, não é normal sair à procura de problemas, operacionais ou não. Entretanto, podem surgir oportunidades que poderiam agregar valor ao ganho ou mesmo ao desempenho operacional, em função de um fator de oportunidade. O processo de criar ou identificar oportunidades da tomada de decisão é pró-ativo (SCHUYLER, 2002).

Para a identificação destas oportunidades existem diversas técnicas, mas o objetivo é identificar no sistema: as suas fraquezas, os pontos fortes, as oportunidades e as ameaças em cada um dos diferentes cenários de operação. Esta análise é chamada de SWOT (Strengths Weaknesses Oportunities Threats) (SCHUYLER, 2002).

A identificação das oportunidades para uma adequada tomada de decisão e seleção das melhores alternativas é o ponto mais importante neste processo. Mesmo que as diferentes técnicas de identificação de oportunidades permitam modelar de forma preliminar o problema de decisão, na realidade operacional de sistemas complexos (chão de fábrica) há incertezas e até receio em relação aos resultados de cada decisão em relação à aplicação de mudanças no sistema.

Nestes termos, para um problema complexo como a seleção de uma atividade de manutenção na operação de uma usina termelétrica, existe com frequiência uma 
diversidade de estágios de decisão. Assim, o líder encarregado da equipe de decisão, deve determinar as melhores tecnologias e em primeiro lugar considerar a afinidade do ajuste com a configuração já operante.

Da mesma forma, as decisões a serem tomadas também deverão ser bem identificadas. Segundo Shimizu (2001), as decisões para qualquer um dos três tipos de problemas (estruturado, semi-estruturado e não estruturado) podem se diferenciar por nível de decisão: estratégico, tático, operacional e decisões de despacho ou liberação. Cada um dos tipos de decisão são descritas abaixo:

- Decisões Estratégicas: são decisões que, quando implementada em um determinado sistema, há influência no resultado das suas operações produtivas ou comercias por um período de 2 a 5 anos.

Este tipo de decisão pode estar relacionado, por exemplo, às mudanças no projeto do sistema em função de uma nova regulamentação ambiental da região de operação da usina.

- Decisão do tipo tática: decisões desta natureza influenciam o resultado das operações produtivas ou comercias durante um período de alguns meses a até 2 anos. Estas decisões são tomadas devido à necessidade de serem aplicadas alterações para atingir algum parâmetro de desempenho pontual, a fim de serem competitivos em um determinado panorama de mercado ou simplesmente operar de forma mais segura em função de um parâmetro externo, como por exemplo, ajustes em função das mudanças climáticas na região de operação do sistema. No caso específico do mercado de geração de energia no Brasil isto é comum segundo disserta Carazas (2006).

- Decisão do tipo operacional: este tipo de decisão influencia o comportamento do sistema por um período de alguns dias a alguns meses.

- $\quad$ Decisões de despacho ou liberação: este tipo de decisão influencia na operação normal apenas por períodos de algumas horas ou alguns dias. Estas decisões são 
chamadas, pela engenharia da manutenção, de "ajustes". Geralmente este tipo de decisão é apenas para a resolução de um problema que não causa danos maiores à operação do sistema.

Em relação ao tipo de decisão, Shimizu (2001) define a decisão estratégica como a que se preocupa com problemas externos, ou a empresa e o seu ambiente. As decisões táticas são as que se preocupam com a estruturação dos recursos da empresa de modo a criar alternativas de execução visando à melhoria de resultados. As decisões operacionais visam maximizar a eficiência do processo de conversão dos recursos, isto é, aumentam o desempenho com o objetivo de se maximizar a rentabilidade das operações.

Embora as decisões sejam distintas, todas interagem entre si, ou seja, as decisões são interdependentes e complementares (SCHUYLER, 2002). Na Tabela 3.6 apresentase um resumo dos tipos de problemas e níveis de decisão (característica) que podem ser adotados por uma empresa.

Tabela 3.6 Tipos de problemas e nível de decisão (adaptado de SHIMIZU, 2001)

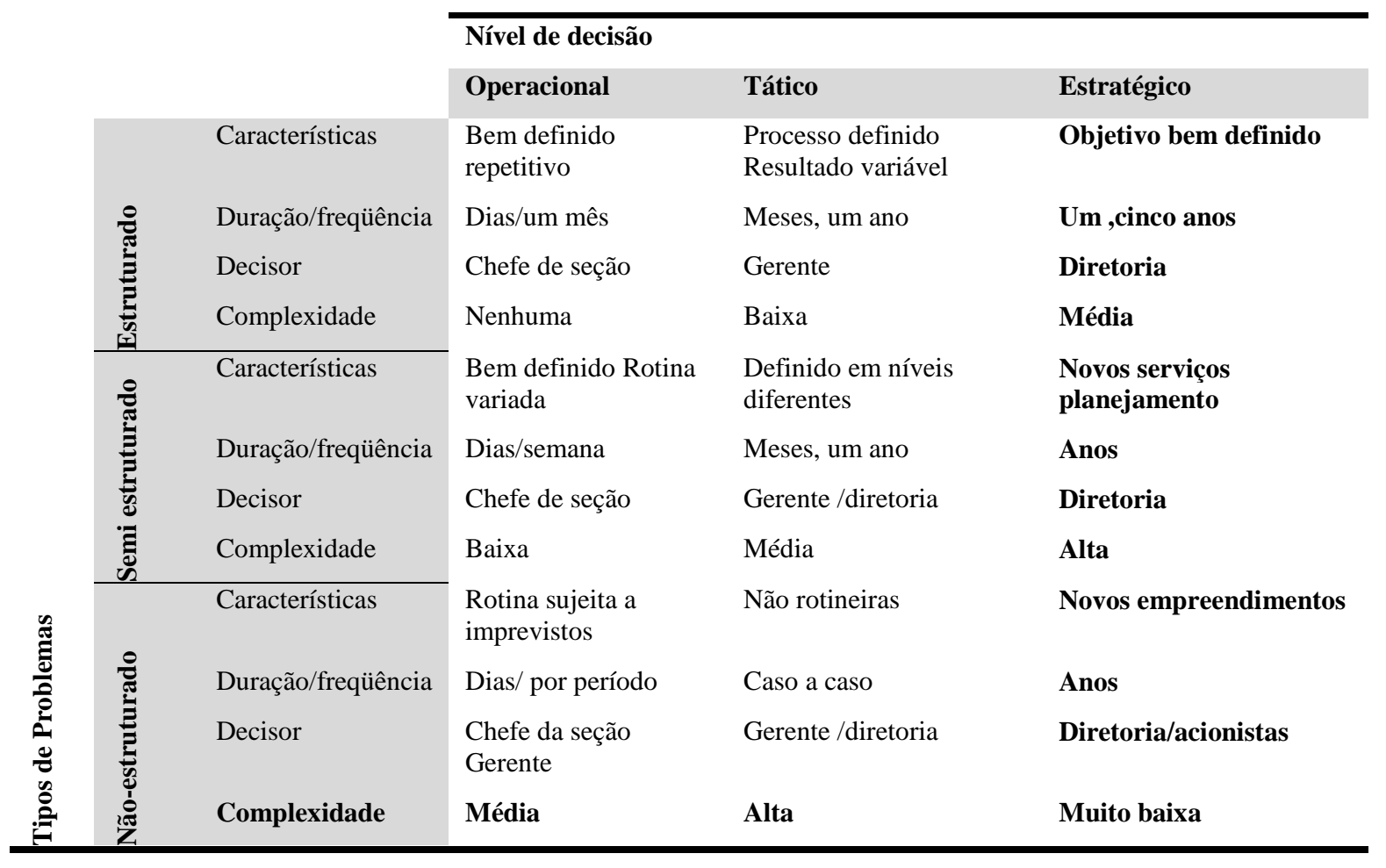




\subsubsection{Classificação dos problemas de decisão.}

Segundo Moore e Weatherford (2005) o resultado (ganho econômico) de uma decisão individual depende da ação de outro participante (natureza), sobre o qual não se tem nenhum controle. Nestes termos é chamada de natureza à incerteza que vem fortemente ligada a ela. A Figura 3.7, classifica os problemas de decisão de acordo com o nível de incerteza, envolvendo possibilidades de risco e descrição imprecisa ou difusa do problema, e nível de conflito de objetivos, envolvendo problemas complexos e não estruturados.

A Figura 3.7 apresenta a classificação dos problemas de decisão em função do conflito de objetivos e da ambigüidade pela incerteza e imprecisão. Em um processo de tomada de decisão, pode haver múltiplos pontos de vista sobre as decisões, individuais ou de grupo, sendo que as decisões estratégicas são tomadas pelo grupo e as operacionais por indivíduos. Assim, a escolha do modelo de decisão depende do tipo de decisão, da limitação de tempo e de custo e da complexidade do problema. Os problemas são considerados complexos quando:

- O número de variáveis aumenta, chamados também de problemas multidimensionais com múltiplos objetivos;

- Quando a ocorrência dos valores das variáveis e/ou dos objetivos estão sujeitos a riscos ou incertezas e;

- Quando os valores das variáveis e os objetivos são definidos de modo impreciso, nebuloso ou difuso (fuzzy).

O risco é intermediário entre a certeza e a incerteza, destacando que entre os modelos não existe uma fronteira bem definida. Assim, os problemas poderiam ter maior risco ou menor risco, em função do nível de incerteza (SHIMIZU, 2001). 


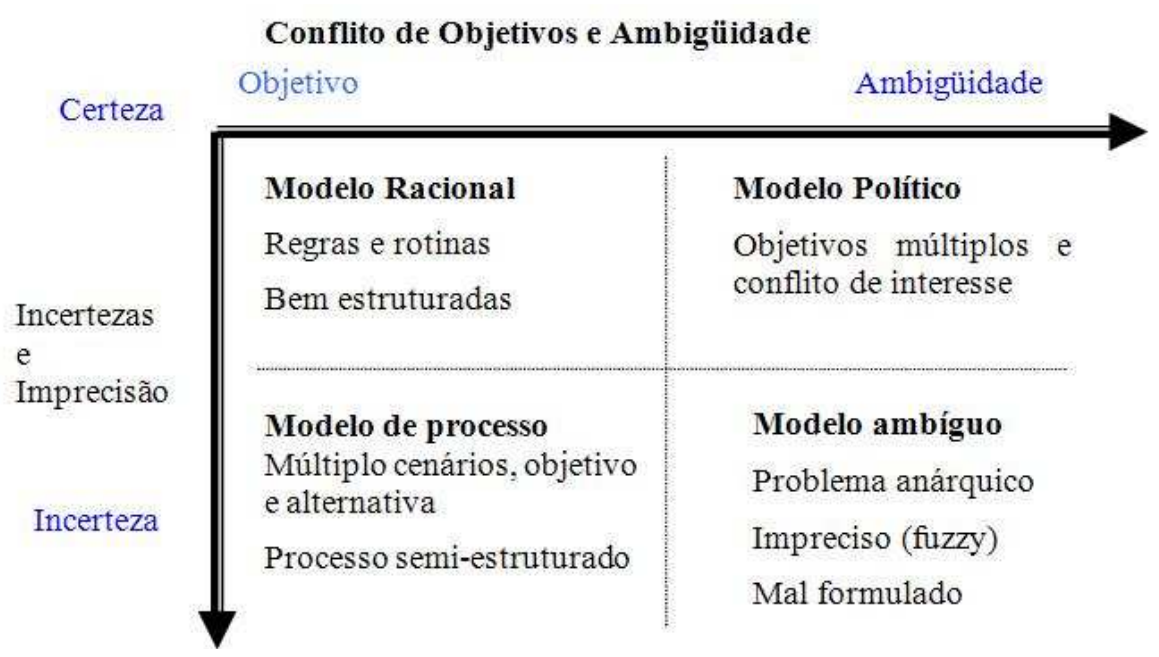

Figura 3.7. Classificação dos problemas de decisão (adaptado de SHIMIZU, 2001)

\subsubsection{Seleção do Método de Tomada de Decisão}

Os problemas de decisão não podem apenas ser resolvidos pela aplicação de meios científicos. Deste modo, para definir um modelo de tomada de decisão, é necessário adotar o "modelo satisfatório" que a equipe de tomada de decisão selecione. Para a seleção de políticas de manutenção em sistemas de geração de energia elétrica, os problemas poderão ser classificados em duas classes, em relação à sua natureza, que são: decisões com certeza, decisões com risco ou incerteza.

\subsection{Métodos de Tomada de Decisão}

\subsubsection{Decisões com Certeza}

Uma decisão com certeza é aquela na qual se sabe que estado de resultados será obtido. Como alternativa, pode-se pensar nela como um caso com um único estado de resposta. Os problemas de decisão sem risco, ou com certeza, podem ter várias alternativas de decisão (por exemplo, a forma de pagamento de um determinado produto) e vários critérios ou objetivos (exemplo, a necessidade do aumento do desempenho). Por se tratar de problemas sem risco, toda a informação relevante (ganhos ou resultados referentes a cada alternativa de decisão) é conhecida e o responsável pela 
decisão escolhe a alternativa que corresponde ao melhor resultado possível (SHIMIZU, 2001).

Este tipo de decisão até pode ser aplicado a um sistema complexo, mas no caso específico da seleção de políticas de manutenção e das reformas na configuração do projeto da planta não podem, pois as mudanças nas políticas de manutenção envolvem risco.

\subsubsection{Decisões com Incerteza}

A incerteza sobre acontecimentos futuros é uma característica de muitos modelos decisórios gerenciais. Em muitos dos problemas de decisão, as alternativas que compõem um cenário (sua natureza) acontecem com certa probabilidade de risco (HAIMMES, 1998). Nesta situação, é necessário usar as técnicas de avaliação do risco de forma que nos permitam tomar uma decisão visando à redução das perdas ou aumento do valor dos ganhos. Entre estas técnicas para a tomada de decisões com incerteza se destaca a técnica da Árvore de Decisão

Diante de um problema com risco, múltiplos objetivos e múltiplos cenários, como no caso de seleção de políticas de manutenção de um sistema de geração de energia elétrica, os problemas se tornam, segundo a literatura de tomada de decisão, problemas complexos de decisão, desta forma as técnicas para a tomada de decisão são mais complexas.

\subsection{3. Árvore de Decisão}

Uma árvore de decisão é uma representação gráfica para analisar decisões de problemas complexos. A árvore de decisão é classificada como um método extremadamente explícito pela facilidade de representar problemas com vários cenários e níveis de decisão. Assim as árvores de decisão se destinam aos modelos onde há uma 
seqüência de decisões, cada uma delas pode levar a um resultado diferente e incerto. Segundo a bibliografia, é possivelmente a técnica mais utilizada para tomada de decisões (SOUZA, 2006; SCHUYLER, 2002; SHIMIZU, 2001).

As árvores de decisões têm a capacidade de representar de forma simples cenários complexos, mostrando as diferentes alternativas de decisão e o cenário característico para cada uma delas, ou seja, as probabilidades e a quantificação das consequiências. Além disso, permitem a identificação das oportunidades potenciais para a melhoria dos processos como, por exemplo, o aumento do lucro ou ganho em uma atividade comercial qualquer.

A estrutura de uma árvore de decisão é organizada e disciplinada para representar alternativas e estados da natureza ou cenários possíveis, através de nós, que são:

- Nó interno ou de decisão, também chamados de pontos de decisão, consiste em uma pergunta da decisão a ser tomada, sendo representado por um quadrado. De cada nó de decisão partem tantos ramos quantos necessários como respostas à pergunta. No caso de sistema de seleção de políticas de manutenção, as possíveis práticas a serem aplicadas a um sistema específico dentro do sistema de geração de energia elétrica são as possíveis perguntas do nó de decisão. A Figura 3.8 mostra a representação gráfica do nó de decisão.

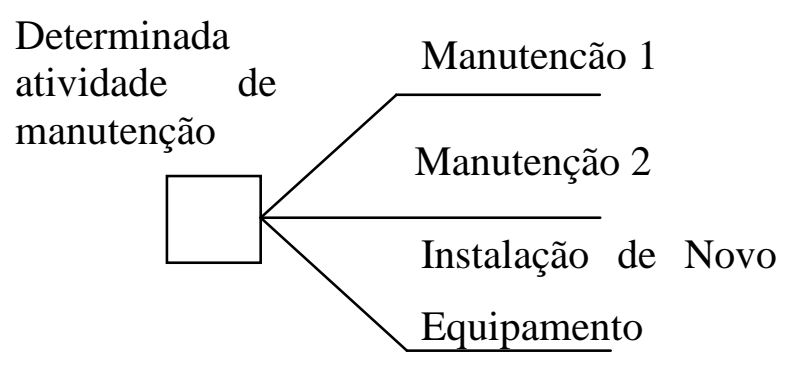

Figura 3.8 Nó de decisão da árvore de decisão 
- Nó de incerteza ou mudança de eventos, representado por um círculo, indica um desvio no caminho das informações sobre o qual não temos controle. Ao nó de incerteza normalmente se tem relacionada uma determinada probabilidade, que indica a chance de ocorrência de umas das alternativas.

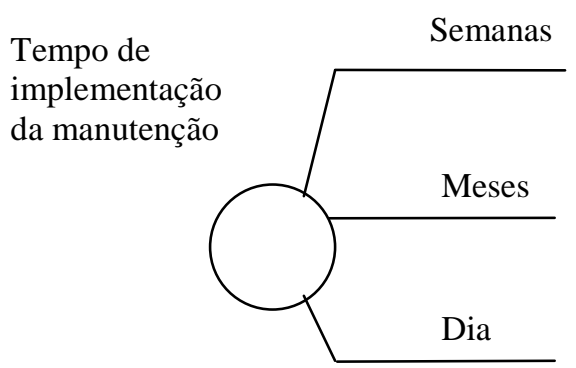

Figura 3.9. Nó de mudança da árvore de decisão

- "Ramo" terminal ou nó final, representado na árvore de decisão com um "ramo" (linha ao final da árvore) com os valores representativos de cada um dos cenários após o nó de incerteza, isto é, aqueles valores que reapresentam as perdas, normalmente representados em valores monetários.

A técnica de nós para a solução da Árvore de Decisão envolve o cálculo de valores médios (valor esperado) das consequiências associadas a cada nó de probabilidade, ou seja, a solução se inicia a partir dos nós de probabilidade localizados à esquerda da árvore, sendo que em seus respectivos ramos localizam-se os valores das conseqüências.

Para os nós probabilísticos localizados mais a esquerda, definem-se os valores esperados. Repete-se o cálculo para todos os nós probabilísticos, até que seja atingido um nó de decisão. A este nó estão usualmente associados vários ramos, cada qual representado por valores esperados, calculados a partir dos nós probabilísticos. Neste nó define-se a alternativa mais viável, expressa em termos do maior valor esperado, em caso de problemas de maximização de resultados, ou de menor valor esperado, em problemas de minimização de resultados. Elimina-se da árvore os ramos associados 
com as alternativas que não foram selecionadas no nó de decisão (HAIMMES, 1998; SOUZA, 2006; MOORE e WEATHERFORD, 2005).

Executa-se o processo anterior até que seja atingido o nó de decisão que foi empregado como base para a construção da árvore. Em cada nó probabilístico, calculase o valor esperado empregando o Teorema da Probabilidade Total, expresso pela relação da eq. (3.2).

$$
\text { ValorEsperado }=\sum_{i=1}^{k} p_{i} \cdot C_{i}
$$

Onde $k$ é o número de ramos que convergem em um nó probabilístico, $p_{i}$ é a probabilidade de ocorrência do evento associado ao ramo $i$ e $C_{i}$ é a conseqüência associada com o evento representada pelo ramo $i$. 


\section{CAPÍTULO 4 - MÉTODO PARA A SELEÇÃO DE POLÍTICAS DE MANUTENÇÃO NA INDÚSTRIA DE GERAÇÃO DE ENERGIA ELÉTRICA - A PROPOSTA}

Neste capítulo apresenta-se o método para a seleção de políticas de manutenção baseado na Análise de Risco. São apresentadas as etapas de forma gráfica, visando uma clara compreensão de forma que possa ser aplicado elou reproduzido por qualquer equipe de manutenção que tenha como objetivo avaliar decisões estratégicas utilizando o risco das operações industriais e econômicas. 


\subsection{Considerações iniciais}

Nos últimos 10 anos diversos métodos baseados em risco para o estudo de operações industriais têm sido apresentados. Métodos, por exemplo, para a elaboração de procedimentos de inspeção em sistemas de transporte de combustível até procedimentos de planejamento de manutenção baseados em risco para a indústria farmacêutica. A aparição desta considerável quantidade de métodos deve-se à necessidade das indústrias de operar sistemas complexos livres de acidentes. Acidentes esses que poderiam ocasionar graves conseqüências à integridade dos operadores do sistema (podendo incluir perda de vidas humanas), ao meio ambiente, às próprias instalações, assim como, ao próprio negócio, ou seja, as consequiências podem afetar os clientes interessados no produto da empresa. (TIXIER et al., 2002; AVEN e KORTE, 2003).

Segundo a Federação Européia de Associações Gerenciadoras de Risco (FERMA - Federation of European Risk Management Associations) (2002), seria praticamente impossível recolher em um único método todas as técnicas para análise de riscos. E da mesma forma, seria praticamente impossível resolver todos os casos com um único método de análise de risco, motivo pelo qual cada ramo da indústria implementa um método diferente, fazendo uso das diversas técnicas de análise de risco em combinações distintas.

Neste sentido os diferentes métodos podem ser classificados em função: 1) da forma como o risco é identificado; 2) do mecanismo para a avaliação e quantificação do risco; 3 ) pela capacidade que possui para a definição dos cenários críticos de operação e 4) pela capacidade de avaliação do risco e capacidade de seleção de alternativas assim como a capacidade de auxiliar a decisão (TIXIER et al., 2002). 
Os métodos de análise de risco podem ser de natureza qualitativa ou quantitativa, sendo que nesta ultima se encaixam as técnicas de análise determinísticas, probabilísticas e a combinação entre estas. Desta forma, os métodos de análise de risco podem ser caracterizados de diversas formas, como por exemplo, pelo tipo de dados a serem analisados (dados de entrada e pelos dados de saída), e pela natureza da análise, entre outros.

Tixier et. al. (2002) apresenta um estudo com 62 métodos de análise de risco aplicados às diversas atividades industriais, permitindo selecionar diversas técnicas e métodos de análise em função da necessidade do estudo que se pretende executar. Dentre estes 62 métodos citados no estudo, não foi apresentado nenhum método específico para a seleção de políticas de manutenção. O estudo destaca que como feito por outros autores, cada caso precisará da seleção das técnicas que melhor se adéquiem às necessidades da análise de risco específica.

Em 2003 nasce a filosofia da Manutenção Baseada em Risco (RBM), chamada assim pela primeira vez pelos autores Khan e Haddara (2003), com o propósito de, por meio da aplicação das técnicas e conceitos de análise de risco selecionar políticas de manutenção nas diversas áreas da indústria. Pouco tempo antes o Instituto Americano do Petróleo (API), publica um guia, baseado nos mesmos conceitos, para "Inspeção Baseadas em Risco (RBI)", a norma técnica API 580 e 581 - 2002. A seguir, é apresentado o estado da arte das diversas técnicas que baseiam-se nos conceitos da análise de risco.

\subsection{Análise de Risco Aplicada à Manutenção e Inspeção de Processos Industriais - Estado da Arte}

Como descrito no Capítulo 2 deste trabalho, a engenharia da manutenção nas últimas duas décadas sofreu mudanças radicais, que a tornou parte estratégica do planejamento das atividades industriais. Estas mudanças começam com a incorporação dos conceitos de confiabilidade no planejamento da manutenção nos anos 80 , chamada 
de terceira geração da manutenção (NOWLAN e HEAP, 1978; MOUBRAY 2000; RAUSAND, 1998; SMITH e HINCHCLIFFE, 2004; CARAZAS, 2006; LAFRAIA, 2001). A Figura 4.1 representa a evolução da manutenção, destacando às caracteristicas de cada uma das gerações da manutenção (MOUBRAY, 2000; TEIXEIRA, 2008; ARUNRAJ e MAITI, 2007; CARAZAS, 2010).

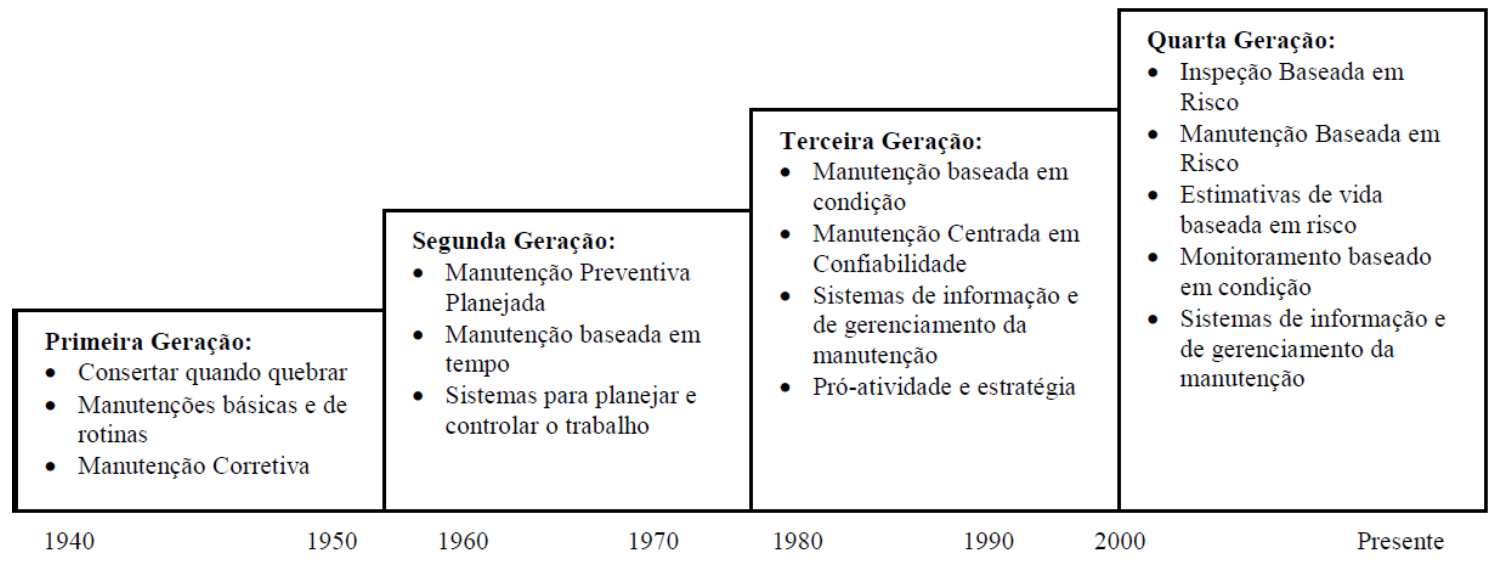

Figura 4.1. Evolução da manutenção (Teixeira, 2009)

O próximo passo na evolução da manutenção foi a incorporação dos conceitos da análise de risco, que caracteriza a Quarta Geração da Manutenção (CARAZAS, 2010; TEIXEIRA, 2009; ARUNRAJ e MAITI, 2007). Segundo Khan, Haddara e Krishnasamy (2008), a implementação destes conceitos começa com a programação de inspeções baseadas em risco na indústria de gás e petróleo, com as normas API 580 e 581. A outra vertente é a que visa o planejamento da manutenção em processos industriais, sendo esta a que este trabalho se encaixa. Esta seção do trabalho apresenta o estado da arte, as modernas técnicas e métodos de planejamento e melhoramento das atividades de manutenção baseadas em risco.

Tratar-se-á inicialmente da Inspeção Baseada em Risco tendo em vista que a literatura a situa como primeira das filosofias a implementar os conceitos da análise de risco, para o melhoramento de atividades relacionadas à manutenção na produção industrial. 
A filosofia da Inspeção Baseada em Risco (RBI do inglês Risk Based Inspection) (KHAN, HADDARA E KRISHNASAMY, 2008; JOVANOVIC, 2003), se desenvolveu a partir das normas técnicas publicadas pelo Instituto Americano do Petróleo API 580 e API 581 (American Petroleum Institute - Risk-Based Inspection). A elaboração desta se iniciou em 1993 para ser publicada no ano de 2000, com o patrocínio de um grupo de empresas da área de gás e petróleo, como por exemplo, BP (British Petroleum), Chevron, Mobil, Petro-Canada, Shell, Texaco, entre outras (PEZZI, 2003). As normas API 581 e 580 são direcionadas para a verificação de equipamentos e tubulações nas indústrias petroquímicas e usa o risco para priorizar e gerenciar um programa de inspeções, de forma a evitar a ocorrência de uma falha estrutural que cause um vazamento no processo de transporte dutoviário. Para tal, é construída uma matriz constituída a partir de faixas de probabilidades (denominadas como sub-fator do modulo técnico) e da área atingida pelo eventual vazamento (conseqüência), cujos valores adotados para os diferentes níveis são apresentados na Tabela 4.1 (ECKSTEIN et al., 2002). A Figura 4.2 apresenta a matriz de risco proposta pela norma API 581.

Tabela 4.1. Definição das categorias de conseqüências e probabilidades de falha para a matriz de risco (ECKSTEIN et al., 2002)

\begin{tabular}{cccc}
\hline $\begin{array}{c}\text { Categoria de } \\
\text { conseqüência }\end{array}$ & $\begin{array}{c}\text { Área } \\
\text { afetada }\end{array}$ & $\begin{array}{c}\text { Categoria de } \\
\text { probabilidade }\end{array}$ & $\begin{array}{c}\text { Sub-fator módulo do } \\
\text { técnico }\end{array}$ \\
A & $<10$ & 1 & $<2$ \\
B & $10-100$ & 2 & $2-20$ \\
C & $100-300$ & 3 & $20-100$ \\
D & $300-1000$ & 4 & $100-1000$ \\
E & $>1000$ & 5 & $>1000$ \\
\hline
\end{tabular}

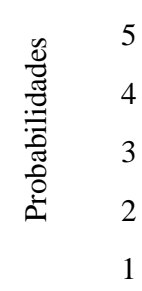

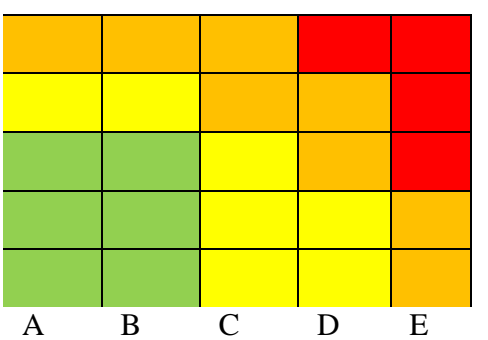

Conseqüências

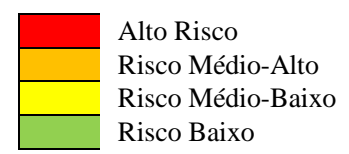

Figura 4.2. Matriz de risco API 581 
A ABS (American Bureau of Shipping), em junho de 2000, apresenta a primeira publicação visando implementação da análise de risco na indústria marítima de gás e petróleo, chamada Risck Assessment Applications for Marine and Offshore Oil and Gas Industries (ABS, 2000). Posteriormente em dezembro de 2003, publica um guia para a implementação da inspeção baseada em risco, chamada de Surverys using Risk-Based Imspection for the Offshore Industry (ABS, 2003). O estudo apresenta uma guia para a implementação de técnicas de análise de risco formado por quatro etapas principais: identificação do risco; análise de frequências, análise e avaliação das consequiências e avaliação do risco. Destaca também que, a medida que a análise se torna mais detalhada e/ou pontual necessariamente se torna mais quantitativa, certeira e custosa, tal como representa a Figura 4.3 .

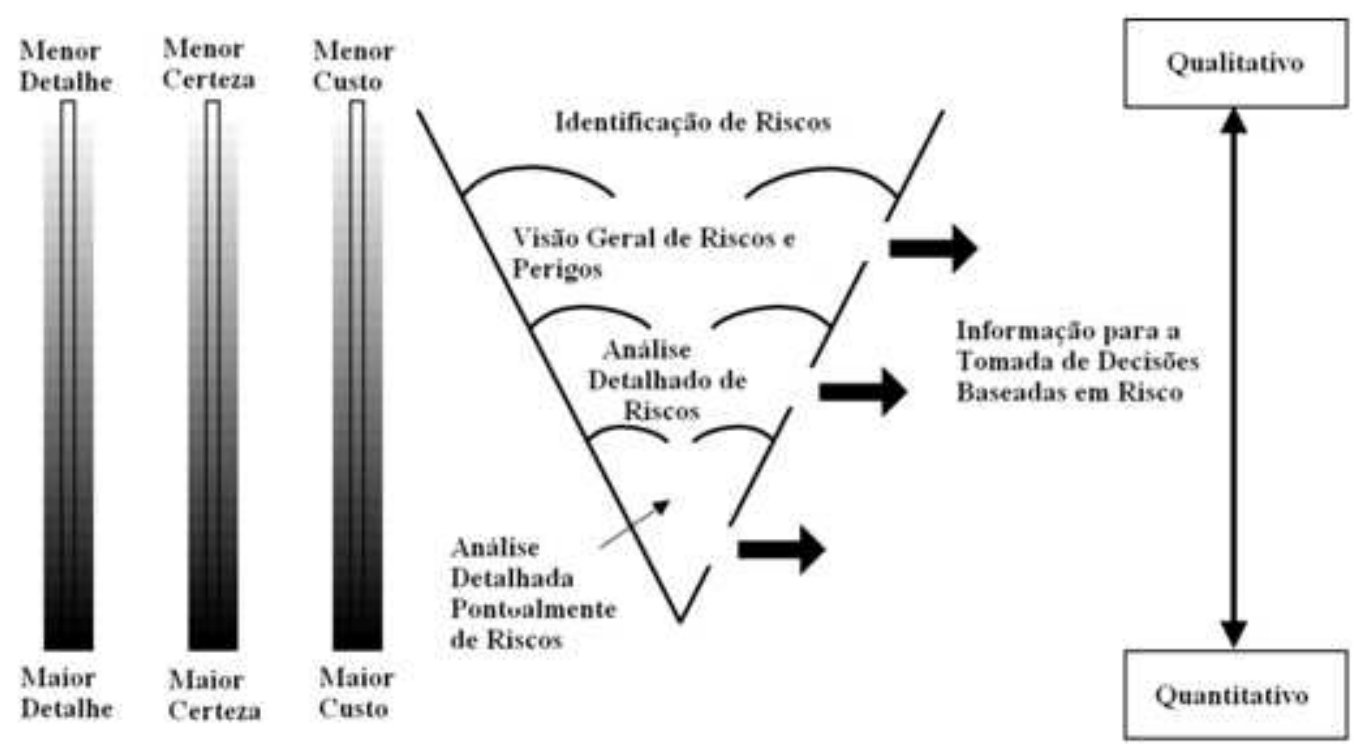

Figura 4.3. Níveis de análise de inspeção baseada em risco (ABS, 2003)

Por outro lado, Jovanovic (2002) é um dos primeiros autores que apresenta uma proposta de método para a inspeção baseada em risco aplicada à indústria termelétrica de geração de energia na Europa. Posteriormente, o mesmo Jovanovic juntamente com um grupo de pesquisadores apresentam a proposta européia para o Planejamento de Inspeção e Manutenção Baseado em Risco, dentro do projeto de pesquisa chamada RIMAP (Risk Based Inspection and Maintenance Procedures for European Industry), que envolveu mais de 15 empresas basicamente do ramo da geração de energia elétrica, consolidando um método para a Inspeção baseada em risco chamado de RBLM (RiskBased Life Management) (JOVANOVIC, 2002; 2003; RIMAP, 2001). 
Fujiyama et al. (2004) junto à Toshiba Power Systems Company (2000) apresentam um procedimento para a inspeção e manutenção baseada em risco para a indústria de geração de energia termelétrica composto de 7 etapas: elaboração de árvores de componentes; elaboração de árvores de eventos; estudo dos dados históricos de operação; cálculo da confiabilidade; inspeção e estudo de vida; análise de risco e elaboração do plano de manutenção. A primeira etapa do método é a que mais chama a atenção, pois recomenda a elaboração de árvores de componentes, que são muito parecidas com as árvores funcionais utilizadas nesta proposta. Estas árvores são elaboradas para dividir, analisar e interpretar a operação funcional de sistemas complexos do ponto de vista dos seus componentes (CARAZAS 2006).

Outro trabalho nesta mesma linha é o apresentado por Chang et al. (2005), onde é aplicada a norma API 581 para a implementação de um programa de inspeção nos sistemas que compõem uma refinaria e o sistema de transporte de combustível. Aplicações similares são apresentadas por Bareiß et al., (2004), Tien et al. (2007), Simpson (2007), entre outros autores. Posteriormente a estes trabalhos há outros onde é apresentado o resultado da implementação desta filosofia do RBI, sempre com resultados vantajosos, mas sem a implementação de grandes mudanças na metodologia.

Por outro lado, o aumento da implementação da filosofia do RBI levou outros autores a fazerem mudanças na estrutura da metodologia, de forma a chamá-la de Inspeção e Manutenção Baseada em Risco (RBIM), pois não era apenas utilizada para a seleção de rotinas de inspeção, mas também de manutenção. Esta adaptação e/ou nova aplicação do RBI trouxe como resultado a publicação do trabalho "Requisitos regulamentários relacionados com a manutenção e inspeção baseadas em risco" apresentado em 2004 por Schröder e Kauer (2004), com a finalidade de proporcionar uma directriz única para a implementação da metodologia. Por outro lado, outros autores começam a modificar a estrutura da metodologia de forma a utilizar os mesmos conceitos e técnicas de análise de risco para o planejamento e seleção de atividades de manutenção, chamando esta nova filosofia de Manutenção Baseada em Risco. 
Desta forma, na literatura são encontrados trabalhos como os apresentados por Vesely et al. (1994) e Perryman et al. (1995), que implementam os conceitos da análise de risco para o planejamento de atividades de manutenção. Esses trabalhos partem de um método de análise denominado de PRA (Probabilistic Risk Assessment). Pouco depois Vesely publica o livro intitulado Risk-Based Maintenance Modeling em 1995, motivo pelo qual se atribui como este o primeiro autor em chamar de RBM a filosofia de planejamento de manutenção baseada em risco.

Anos depois, já dentro da geração atual da manutenção, os métodos de aplicação da análise de risco para a seleção de atividades de manutenção passam a ser chamados de RBM de forma geral. Entre outros, encontra-se a aplicação apresentada por Apeland e Aven (2000), para a indústria offshore. Khan e Haddara (2003) apresentam um método baseado em RBM para priorizar a redução do risco por meio da redução das probabilidades de falha e desta forma reduzir as possíveis consequiências, sejam elas de natureza operacional, econômica, ambiental ou de segurança. O método é consolidado com diversas aplicações, publicadas pelos mesmos autores, Khan e Haddara, que mostram as aplicações do método nas áreas de: gás e petróleo (KHAN 2004a; 2004c); de geração termelétrica (KHAN et al., 2005; 2008) e na indústria química (KHAN e HADDARA, 2004b).

Nos últimos cinco anos, trabalhos baseados em RBM foram adaptados paras necessidades específicas das diversas áreas da indústria, como por exemplo, na indústria petroquímica (HU et al., 2009; MARMO et al., 2009); na indústria de gás e petróleo (BERTOLINI et al., 2009; GHOSH e ROY, 2009) e na indústria de geração de energia elétrica (CARAZAS e SOUZA, 2008; 2010; KHAN et al., 2008). Da mesma forma, indústrias renomadas implementam a filosofia do RBM como estratégia de operação, como na Toshiba Power Systems Company (2000), Hitachi e a ABB (2003), entre outras. 


\subsection{Método SMBR 2011 - A Proposta}

Em um processo de análise de riscos existem diversos objetivos a serem atingidos. Um dos pontos-chave é definir quais os níveis de risco os quais se está disposto a tolerar e, por outro lado, a enfrentar, considerando os custos decorrentes da perda da capacidade de produção, ou seja, quanto se está disposto a arriscar na previsão de um perigo às instalações, às pessoas e ao meio ambiente, ou mesmo de uma perda econômica.

Para poder saber quais são os níveis de risco aceitáveis, é necessário estimá-los, quantificá-los e deixá-los muito bem identificados, de forma a permitir que os operadores possam evitar sua ocorrência ou, em último caso, mitigá-las. Tal representação do cenário de falha terá que ser o mais fidedigno possível, de forma a representar as conseqüências que se apresentariam nas pessoas, no meio ambiente e na própria instalação industrial (física e economicamente), ou como chamado pelos investidores e operadores de sistemas desta natureza, riscos à operação sustentável.

Com base no citado anteriormente, nesta seção do trabalho é apresentada a proposta de um método que permita auxiliar a tomada de decisões em sistemas complexos (SMBR), basicamente em sistemas de geração de energia elétrica. Quando se pensa no termo "método" imediatamente se imagina um processo e não é para menos, pois literalmente a definição diz que "um método é um processo racional que se segue para chegar a um fim". Desta forma, acredita-se que a melhor forma de se apresentar um método que envolve várias etapas é com o uso de forma gráfica, onde claramente se pode seguir uma estrutura com uma lógica seqüencial. De forma resumida, a proposta é apresentada na Figura 4.4. 


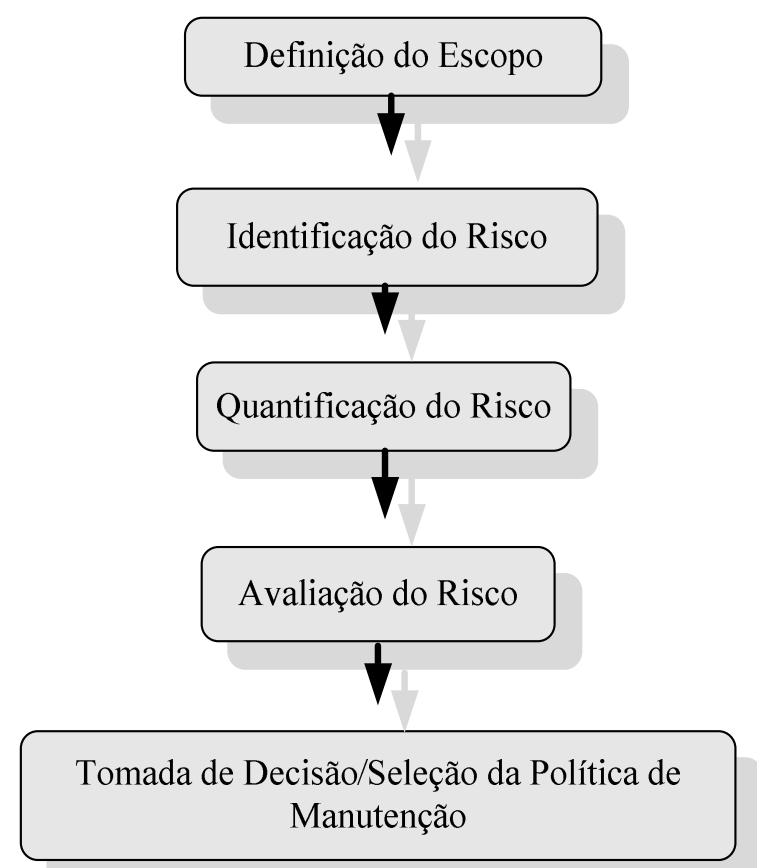

Figura 4.4 Representação do método de tomada de decisões baseadas na análise de risco

Como mostra a Figura 4.4 o método SMBR proposto consta de 5 (cinco) etapas principais, descritas a seguir:

\subsection{Definição do Escopo}

Esta primeira etapa é caracterizada por uma sequiência de atividades que visam informar ao analista as características do sistema, a definição de limites e o levantamento de informações que permita a realização da análise. A definição do escopo pode então seguir alguns passos específicos, tal como ilustrado na Figura 4.5. Da correta realização deste primeiro passo dependerá o êxito da análise, pois, além da identificação dos componentes, subsistemas e setores principais, será definido até que ponto a análise se aprofundará no sistema.

A “definição do escopo" começa com a identificação do sistema sob análise que, por sua vez, consiste em identificar os principais subsistemas e componentes. 


\section{Definição do Escopo}

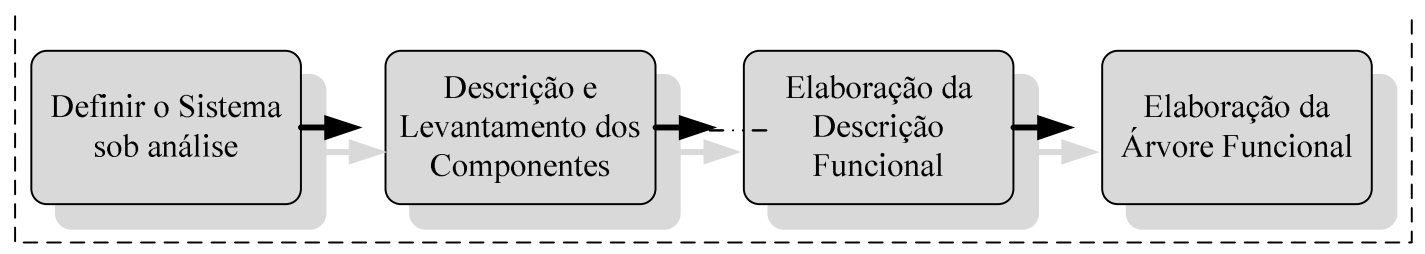

Figura 4.5 Procedimento para a definição do escopo no processo de análise

É necessário realizar um levantamento da informação técnica - planos, diagramas de fluxo, catálogos, manuais, entre outros - sendo possível que, já nesta primeira etapa, sejam enfrentadas as primeiras dificuldades, pois não são em todas as instalações industriais que tais informações estão disponíveis. Além disso, no caso de sistemas sofisticados, o fato destes estarem vinculados a contratos de manutenção com os fabricantes, pode incluir informações de difícil acesso ou mesmo indisponíveis.

Após a seleção do sistema a ser analisado e da definição da sua estrutura de operação - com a sua respectiva documentação - é possível dar continuidade à próxima parte da definição do escopo, a análise funcional.

A análise funcional - sob o ponto de vista da engenharia de manutenção baseada em confiabilidade - é muito importante, já que permite estabelecer a interligação entre os componentes que formam o sistema. Segundo Krishnasamy et al., (2005), os sistemas podem ser divididos em subsistemas, pequenos subsistemas e componentes. Assim, cada um deles poderá ser analisado de modo independente. Desta forma, a união lógica de todos representa a operação do sistema sob análise, como um todo.

As árvores funcionais são representações gráficas onde os componentes do sistema são identificados por retângulos e são unidos por linhas, de forma a representar o sistema do qual fazem parte. Estes diagramas formam figuras com aparência de diagramas hierárquicos onde, no final dos ramos, estão representados os elementos básicos do sistema, como mostra a Figura 4.6. 
a) Diagrama de Planta

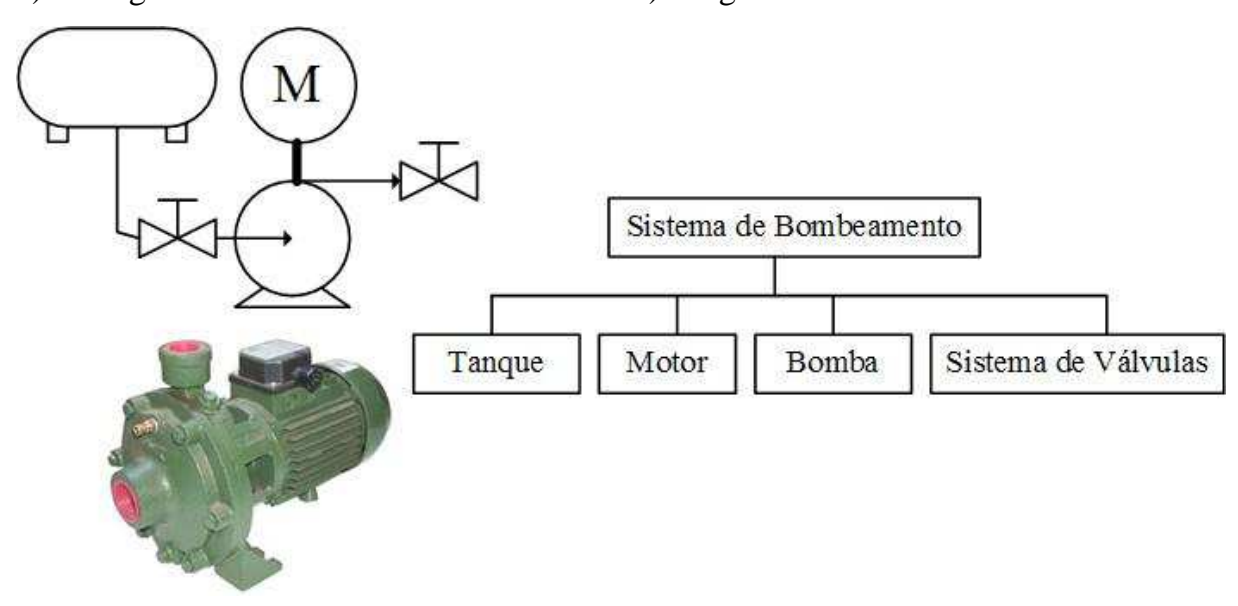

Figura 4.6. Árvore funcional ilustrativa do sistema de bombeamento de água

Outras fontes bibliográficas chamam estes diagramas de Árvores de Elementos, já que aqui são representados os elementos que compõem o sistema (FUJIYAMA et al., 2004).

Na Figura 4.6 a análise do sistema de bombeamento de água pode chegar até os elementos muito pequenos como parafusos e elementos do motor elétrico (escovas, estator, etc) e, por este motivo, a definição do escopo é fundamental para a definição dos limites da análise (CARAZAS, 2006; KHAN e HADDARA, 2003).

Ainda em relação à elaboração da árvore funcional, autores como Krishnazamy et al. (2005; 2008) e Fujiyama et al. (2004) afirmam em suas análises que a elaboração de uma árvore funcional é a primeira etapa para uma análise de riscos bem sucedida.

A elaboração da árvore funcional proporcionará ao analista um conhecimento mais profundo da composição do sistema, assim como da lógica de como os eventos se propagam pelo sistema no caso de ocorrência de uma falha. Ainda como resultado da elaboração da árvore funcional, obtém-se uma representação gráfica do sistema que mostra, de forma estruturada, os principais componentes e a sequiência lógica das informações em cada um dos subsistemas principais, participantes do sistema sob análise. 
Para a elaboração da árvore funcional, pode-se usar a metodologia apresentada por Carazas e Souza (2007b) onde, depois de listados os componentes do sistema e definidas as suas funções principais e secundarias, procede-se a responder às perguntas: “Como é executada (cumprida) uma determinada função? Por que uma determinada função deve ser executada?"

A resposta a primeira pergunta terá um nível primário, que permite definir quais componentes devem ser utilizados para executar esta função. Assim, deve-se continuar até chegar ao último nível, que é o nível do componente. A segunda pergunta serve para verificar se a árvore baseada na primeira pergunta está correta. A Figura 4.7 ilustra a metodologia para a elaboração da árvore funcional.

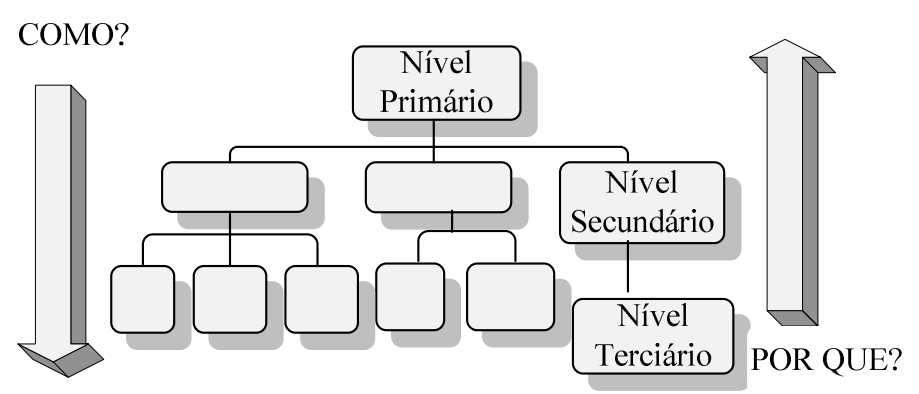

Figura 4.7. Arranjo geral de árvore funcional

Ainda na etapa de definição do escopo, são partes importantes a revisão e a análise dos históricos de operação e manutenção de todos os sistemas, subsistemas e componentes identificados na árvore funcional com a finalidade de quantificar as probabilidades relacionadas às ocorrências de falhas.

\subsection{Identificação do Risco e Modelagem dos Cenários de Operação / Falha}

Se o objetivo do método proposto fosse apenas identificar os riscos envolvidos na operação de um determinado sistema, nesta etapa o trabalho seria concluído. Entretanto, o presente método visa atender também à necessidade de tomar uma 
decisão, reduzindo as incertezas associadas com uma determinada forma de operação e, por este motivo, a quantificação do risco ganha uma etapa de análise.

Essa etapa é formada por duas sub-etapas: a primeira, a própria identificação dos riscos por meio da aplicação das técnicas de análise de risco (PHA, HAZOP, FMEA) (ARUNRAJ e MAITI 2007), a segunda etapa envolve uma modelagem dos possíveis cenários de operação e falha (DHILLON, 2002; KHAN e HADDARA, 2003). A segunda etapa envolve ainda a quantificação dos riscos. Como este método envolve um procedimento de tomada de decisão baseado em risco, a quantificação do risco merece um maior cuidado.

Parte importante da filosofia de análise de risco é a modelagem dos cenários de operação, assim como dos possíveis cenários de falha. Estas modelagens são importantes porque permitem ao analista desenvolver uma representação da realidade para poder analisá-las. O método permite a identificação dos potencias iniciadores de uma falha e, com auxílio de ferramentas como a árvore funcional ou os diagramas de blocos, proporcionar de forma lógica a informação da ligação dos componentes dentro do sistema, propagando os efeitos das falhas destes componentes sobre a operação do sistema. À medida que o sistema se torna mais complexo, maior é a complexidade da elaboração do modelo.

As atividades a serem realizadas nesta etapa são graficamente apresentadas na Figura 4.8. Segundo a literatura, nesta etapa é aplicada a técnica do PHA, que permite, de forma relativamente simples, identificar os perigos na operação do processo produtivo. Podem ser usadas também outras técnicas igualmente eficientes como, por exemplo, análise do tipo FMEA (AVEN e KORTE, 2003; ARENDT, 1990; MOTA, 2003). Finalmente, visando a criação de um modelo dos possíveis cenários de operação e de falha, são aplicadas outras técnicas de análise de risco, tais como o diagrama causaconseqüência, diagrama de eventos e mesmo árvore de falhas (CARAZAS e SOUZA, 2008). 
Identificação dos Riscos

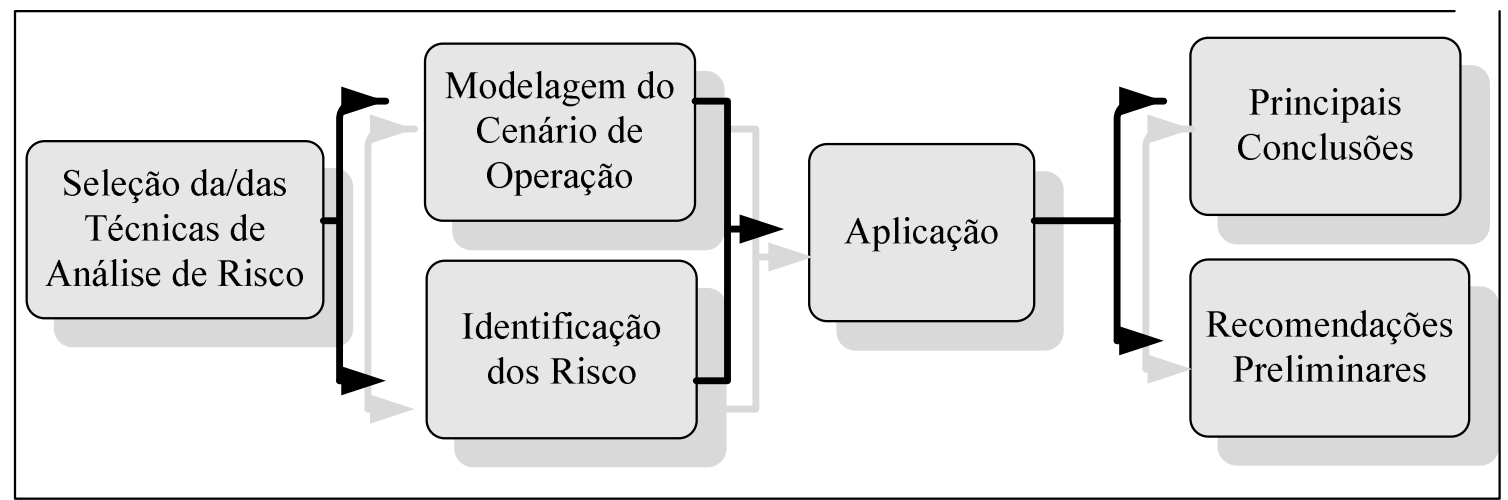

Figura 4.8. Procedimento para a aplicação das técnicas de análise de risco

Conforme sugerido pelo fluxograma da Figura 4.8, o primeiro passo é a seleção das técnicas de análise de risco a serem utilizadas tanto para a modelagem do sistema como na identificação do risco. Neste método em particular será aplicada a Análise de Modos e Efeitos de Falhas para a identificação dos componentes críticos do sistema.

Gomes (2006) seleciona o FMEA como ferramenta de análise e diagnóstico de processos porque "é uma ferramenta que ajuda a selecionar de maneira muito clara os pontos críticos de um processo", sendo estes: a função, o modo de falha, causa da falha e as consequiências das falhas sobre o sistema. Além disso, o FMEA permite fazer uma priorização dos pontos de melhorias por meio do RPN (Risk Priority Number ou número de priorização de risco) (SAE, 2002; DOD, 1998; 1977; BOUTI e AIT, 1994).

Da mesma forma, outros analistas utilizam a análise FMEA para a identificação de componentes críticos, concordando com a eficácia desta análise (LEMES, 2006; TEIXEIRA, 2008). Para a aplicação desta ferramenta, a tabela tradicional do FMEA foi transformada em uma tabela mais simples, conforme as características apresentadas na Tabela 4.2 (CARAZAS, 2006). 
Tabela 4.2. Formulário empregado na análise FMEA.

\begin{tabular}{|c|c|c|c|c|c|c|c|c|}
\hline Função & $\begin{array}{l}\text { Modo de } \\
\text { Falha } \\
\text { Potencial }\end{array}$ & $\begin{array}{l}\text { Causa(s) e } \\
\text { Mecanismo(s) } \\
\text { de Falha }\end{array}$ & $\begin{array}{l}\text { Efeito(s) } \\
\text { potencial } \\
\text { (is) de } \\
\text { Falha }\end{array}$ & Conseqüências & 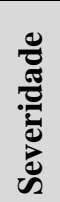 & 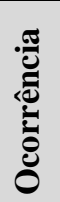 & 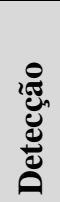 & $\sum_{\underline{a}}$ \\
\hline
\end{tabular}

Como já mencionado no Capítulo 2, os resultados da aplicação da análise do tipo FMEA são apresentados em uma tabela onde os elementos críticos estão claramente identificados.

Com relação à modelagem do cenário de operação do sistema, será utilizada a técnica de análise de risco baseada no Diagrama Causa-Conseqüência. Uma das maiores vantagens desta técnica é a facilidade em representar os possíveis cenários gerados pela ocorrência de uma falha. A falha percorre um caminho dentro do sistema gerando situações que podem ser representadas de forma gráfica, permitindo aos analistas identificar onde poderiam ser instaladas barreiras que impedem a propagação da falha, aumentando a segurança e reduzindo o risco. A redução do risco muito possivelmente torna uma determinada forma de operação mais segura, e assim se garante a disponibilidade do sistema, o que, no caso específico do mercado de comercialização de energia, é refletido em aumento dos lucros por despacho de energia (GREENBERG e CRAMER, 1991; ANDREWS e RIDLEY, 2001).

O princípio fundamental do Diagrama Causa-Consequiência é a identificação do evento crítico, por exemplo, um distúrbio na operação do sistema. A identificação do evento crítico depende da identificação correta do evento iniciador (NIELESEN, 1971). O diagrama da árvore funcional auxilia ao Diagrama Causa-conseqüência nesta tarefa. $\mathrm{Na}$ árvore funcional, os elementos no final da árvore representam os componentes do sistema. As falhas destes componentes no final da árvore podem ser consideradas como os eventos iniciadores para a elaboração do diagrama causa-conseqüência. As falhas destes elementos não necessariamente ocasionaram uma falha crítica, de forma que somente as falhas que afetem a funcionalidade de cada subsistema serão os possíveis 
iniciadores de falhas críticas no sistema e geram um grande distúrbio na condição operacional do mesmo.

\subsection{Quantificação do Risco}

Esta etapa do método é possivelmente a mais importante e a mais complexa. Como já definido, o risco combina a ocorrência de falhas (probabilidades) com os custos ou perdas relacionadas com as mesmas (em termos de dinheiro), de forma que existem dois parâmetros que precisarão ser levantados.

Diversos trabalhos relacionados a planejamento de manutenção baseados em risco focam seus esforços no cálculo das probabilidades associadas à ocorrência de um determinado evento indesejado, com a finalidade de priorizar as atividades de manutenção e desta forma reduzir o risco, (NILSON, 2003; TIEN, HWANG e TSAI, 2007; MARTORELL et al., 1999). Os cálculos das probabilidades de ocorrência de falhas dependerão de diversos fatores, entre eles disponibilidade e qualidade de dados associados com os registros de manutenção. Mesmo com uma base de dados moderna (computadorizada), a dificuldade para selecionar os dados para cada componente individualmente é complexa, pois estas bases de dados normalmente registram as ocorrências de eventos de forma cronológica, sem armazená-las ou diferenciá-las por componente ou sistema.

Na Figura 4.9 apresenta-se o procedimento para a aplicação do método, destacando-se como os resultados são utilizados na seleção de uma nova estratégia de manutenção e/ou equipamentos redundantes.

Ainda com relação ao cálculo das probabilidades, sua exatidão está relacionada à aplicação dos conceitos de confiabilidade e à habilidade do analista em interpretar os resultados. O procedimento para o cálculo destas probabilidades de ocorrência e da disponibilidade do sistema e sugerido Figura 4.10 (CARAZAS et al., 2007e). 


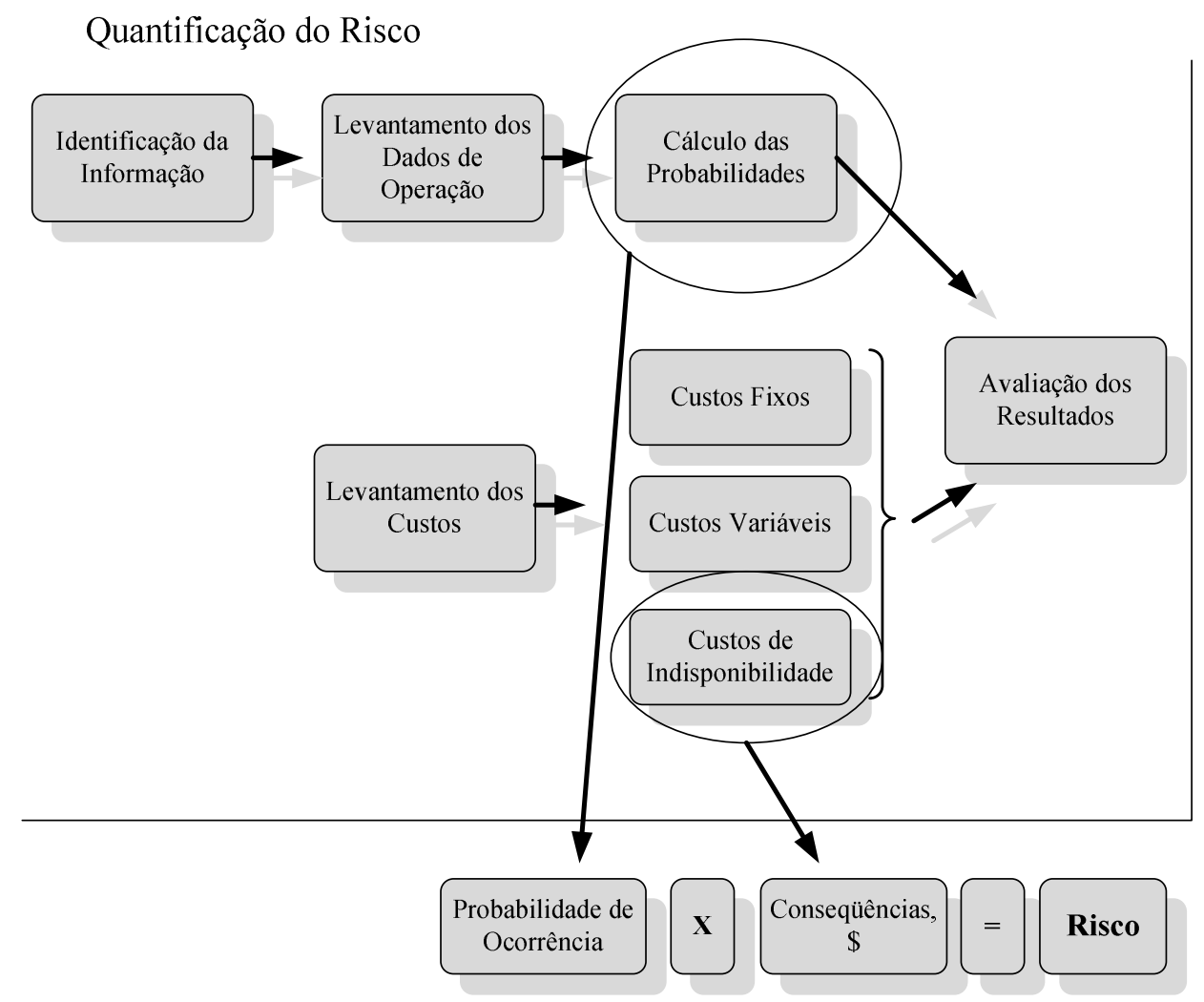

Figura 4.9. Procedimento para a quantificação do risco

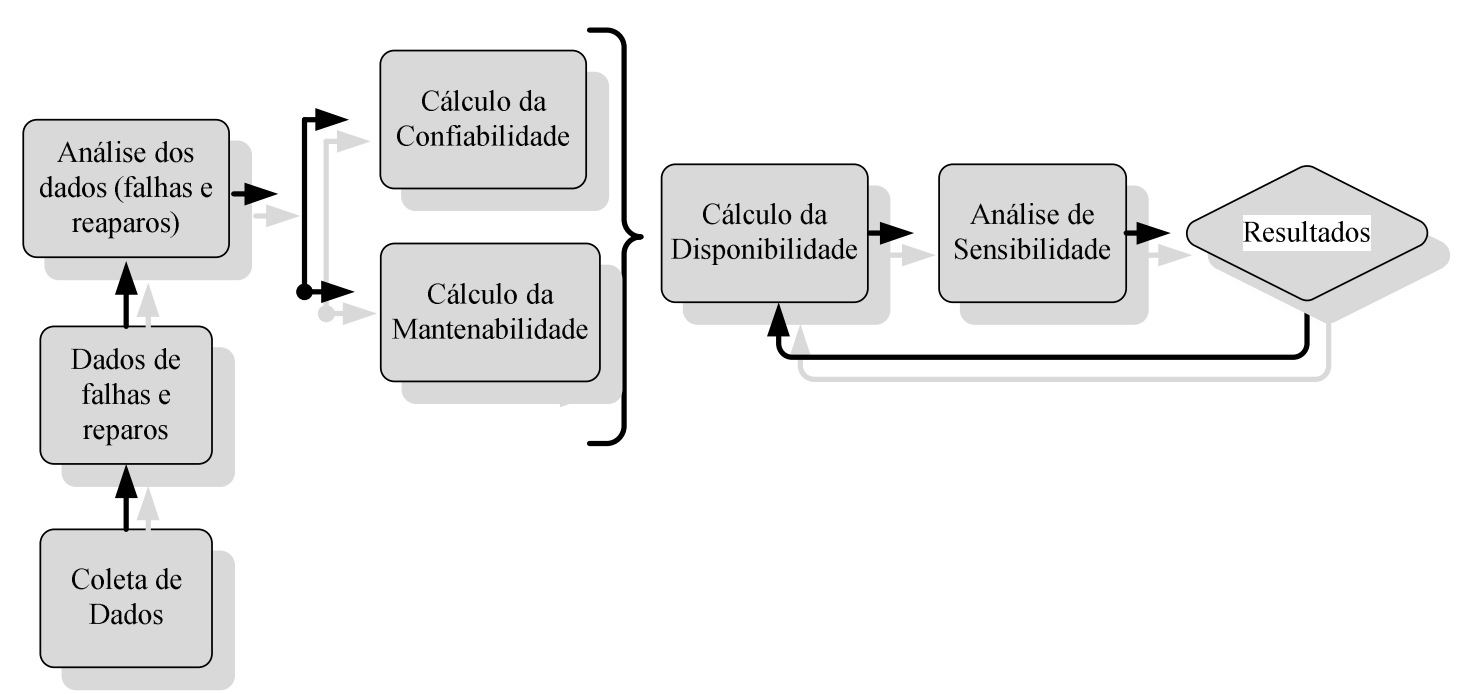

Figura 4.10. Procedimento do cálculo de disponibilidade (CARAZAS et al., 2007e)

Não menos complexa é a estimativa e cálculo dos custos relacionados à operação de um sistema complexo. No mundo das finanças, o objetivo de um gerenciamento é proporcionar o melhor retorno para os investimentos efetuados. Hoje, o 
gerenciamento de risco visa também gerenciar a integridade das pessoas, das instalações físicas e do meio ambiente (DURAN, 2000). Desta forma, para quantificar estes valores é necessário seguir um procedimento, tal como apresentado na Figura 4.11, onde os custos estão relacionados a um determinado cenário de operação.

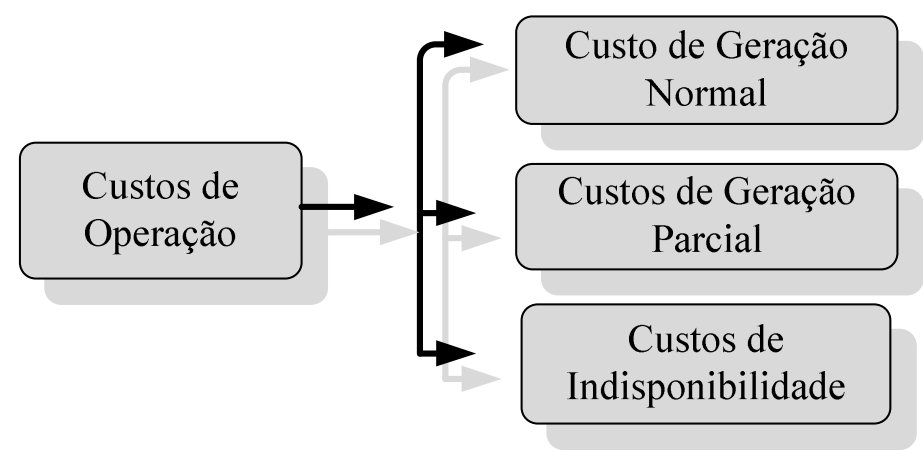

Figura 4.11. Custos relacionados com a operação de sistemas geração de energia elétrica

Nestes termos, os supostos cenários para a análise são: 1) Operação Normal, onde se supõe que o sistema esteja 100\% disponível, cumprindo com todas as suas funções; 2) Operação Parcial, onde o sistema mesmo com uma redução do desempenho operacional, consegue despachar energia (no caso de um sistema de geração de energia elétrica), ou simplesmente cumprir parcialmente com as funções principais e; 3) Cenário de Indisponibilidade, onde o sistema não é capaz de cumprir com suas funções e, sem necessariamente estar em estado de falha total, não atende a um determinado desempenho operacional.

4.6.1. Custos Relacionados à Operação de Sistemas de Geração de Energia Termelétrica

A modelagem dos custos dos cenários de operação é uma tarefa bastante complexa. Isto ocorre devido a algumas variáveis impossíveis de controlar pelo analista, como por exemplo, o custo do gás combustível, o preço de venda da energia elétrica no mercado no período de análise, entre outros. Desta forma, visando simplificar este processo, são modelados os três principais cenários de operação de uma usina geração 
de energia termelétrica a ciclo combinado os quais são: operação normal, operação parcial e usina inoperante.

Os principais custos relacionados à geração são classificados de forma genérica em três, os quais são: 1) Custos Fixos de Operação e Manutenção (O\&M); 2) Custos Variáveis de O\&M e 3) Custos da Indisponibilidade relacionada à parada inesperada e perda de despacho de energia, como será discutido na seqüência. A Figura 4.12 apresenta a composição estrutural geral do custo de geração (CARAZAS, 2007b).

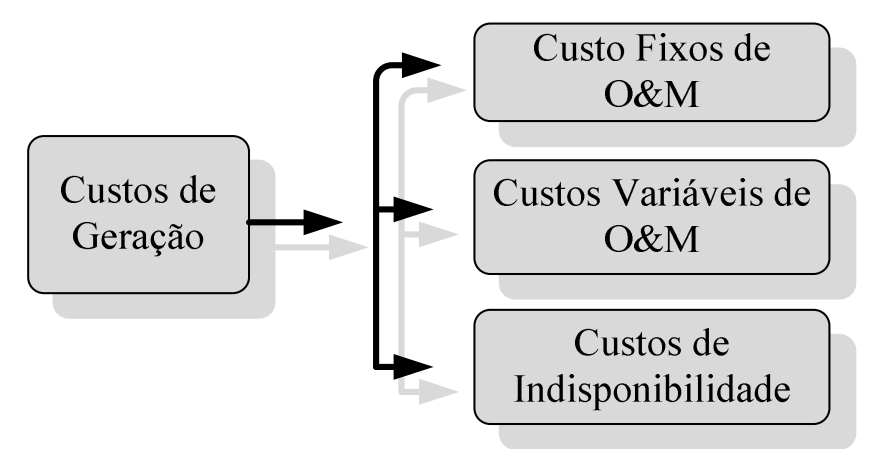

Figura 4.12. Estrutura de custos de geração

Os custos que compõem o Custo Fixo de Operação são, por exemplo, a mão-deobra operacional e administrativa, os custos de manutenções programadas, que levam em consideração os materiais e a mão-de-obra empregada, e os custos regulatórios, como custos de transmissão, meio ambiente, taxas e impostos, entre outros. Na Figura 4.13 são apresentados os principais componentes empregados para a modelagem do custo fixo de O\&M.

Os Custos Variáveis de O\&M dependem diretamente do fator de capacidade da usina, que expressa a razão entre a quantidade de energia efetivamente produzida e a capacidade instalada (SOARES, 2000). A Figura 4.14 apresenta a estrutura de custos variáveis para a usina termelétrica a ciclo combinado (CARAZAS, 2007b). 


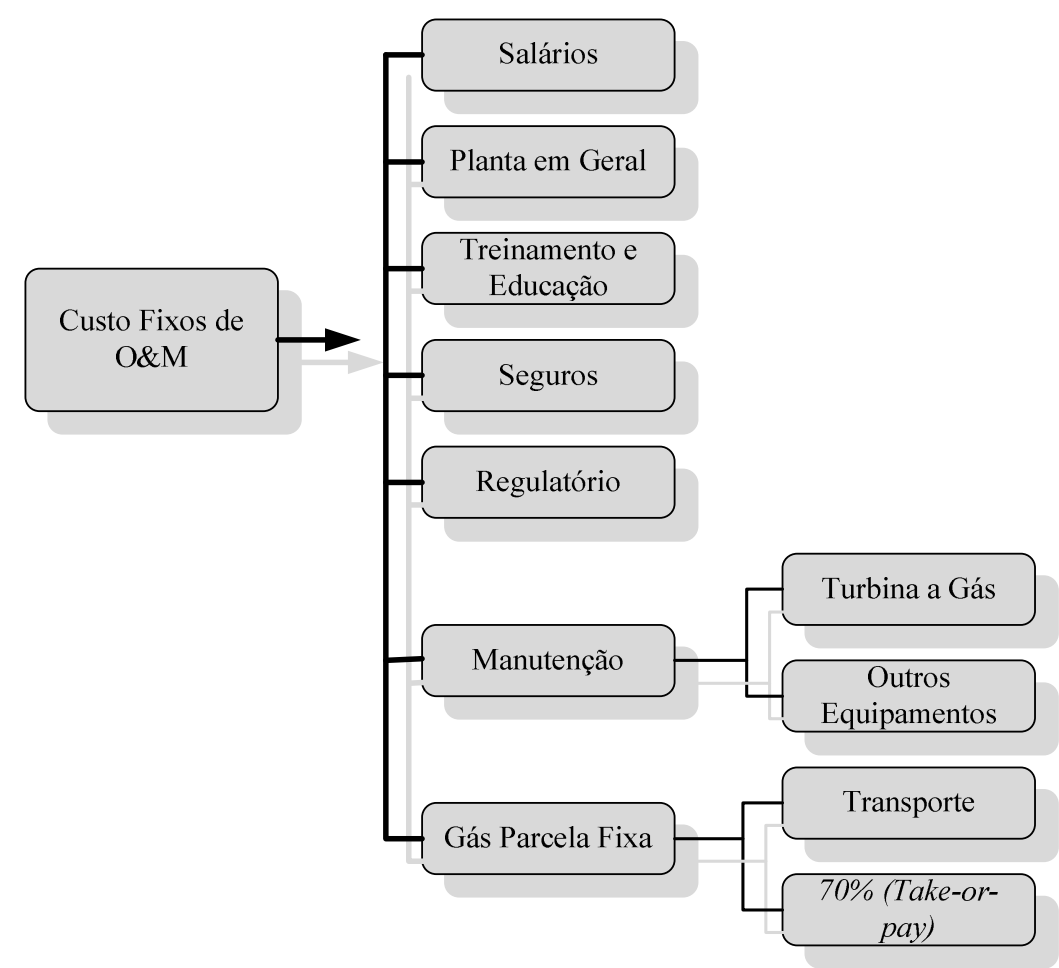

Figura 4.13. Estrutura dos custos fixos de O\&M

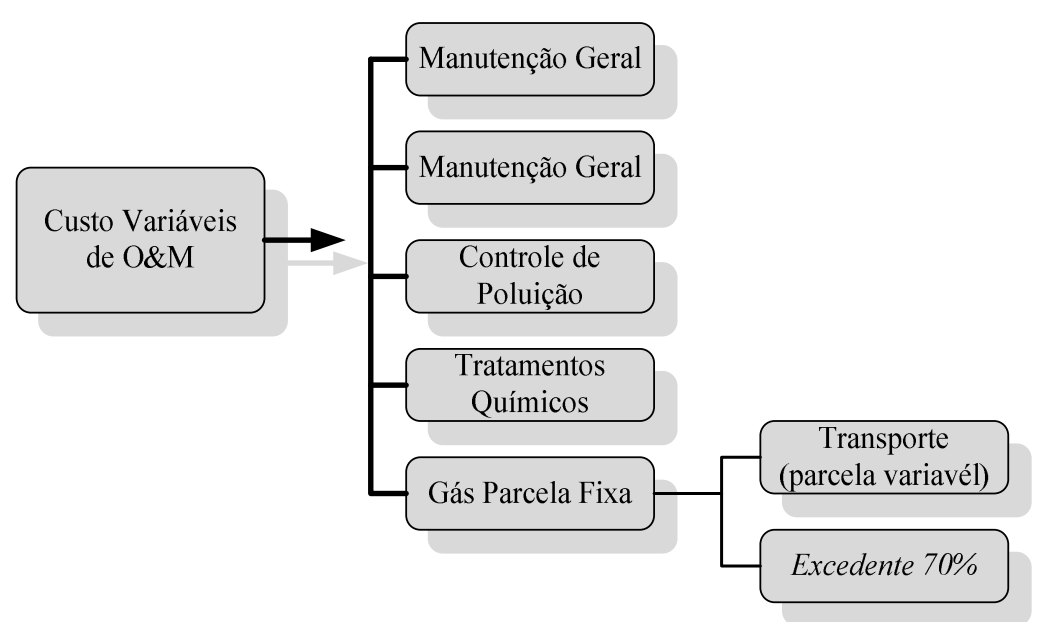

Figura 4.14. Estrutura de custos variáveis

Além dos custos fixos e variáveis, é modelado o custos da indisponibilidade, que possivelmente é o mais complexo de todos. Este custo é composto do valor de compra de energia (que por estar em estado de falha deixou de gerar), de forma a cumprir os contratos de despacho. É incluído também o custo das penalidades, que segundo os operadores poderia ser mitigada em caso de "saber que se está entrando em estado de indisponibilidade". Finalmente é considerado o custo da correção da falha, que 
dependendo da severidade, poder ser desprezado ou tremendamente alto. Tal estrutura de custos é apresentada na Figura 4.15.

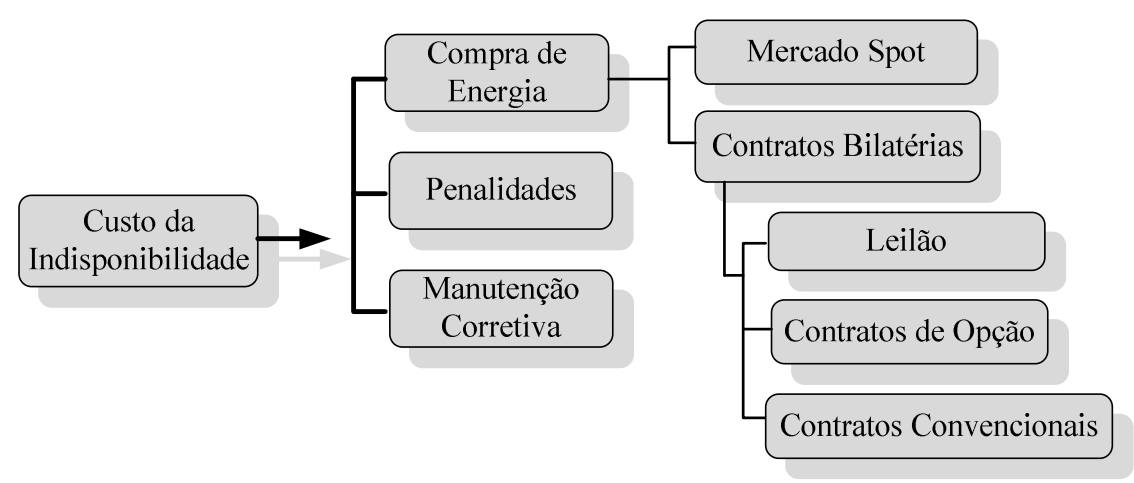

Figura 4.15. Estrutura de custos de disponibilidade

Pode-se concluir que a estrutura de custos de uma usina termelétrica depende não somente de fatores tradicionais, como mão-de-obra e matéria prima, mas também de fatores particulares do sistema, como o tipo de energia disponível no mercado para suprir uma eventual falha da usina. Estes fatores fazem da estrutura de custos uma análise muito complexa, que depende de fatores mercadológicos que envolvem fatores como preço e a disponibilidade do gás, preço e disponibilidade de energia gerada por outras unidades térmicas e hidráulicas, além das regras impostas pelos órgãos reguladores, que impõem penalidades e multas no caso de não cumprimento dos contratos.

\subsection{Avaliação do Risco}

A avaliação de risco, nada mais é que a tomada de decisões baseadas nas informações qualitativas e quantitativas levantadas nas etapas anteriores. A execução desta etapa, com a correta execução das etapas anteriores e a correta aplicação das técnicas de análise de risco, torna-se relativamente simples. Normalmente esta avaliação é executada por um Decisor. Decisor este que pode estar representado por uma ou mais pessoas, das equipes técnicas de operação e manutenção, de estratégia comercial ou/e da própria diretoria da empresa. 
A avaliação de risco, e a conseqüente tomada de decisões, em relação à mudança de estratégias de manutenção e/ou a instalação de novos equipamentos com a finalidade de garantir alta disponibilidade e a segurança operacional, estão relacionadas à aceitação do Decisor de um determinado nível de risco. Estes níveis de aceitação dependem de convicções de política operacional, ambiental e comercial da empresa ou simplesmente associados à necessidade de cumprir com uma determinada faixa pré-estabelecida por uma entidade regulatória.

Na maioria das atividades industriais, e a de geração de energia elétrica não é diferente, estes níveis de aceitação de risco são determinados com antecedência e, de forma geral, considerando o impacto sobre a segurança e a saúde do pessoal de operação; o impacto sobre o meio ambiente e; os interesses econômicos da empresa. Desta forma a abordagem mais simples para a definição de critérios de aceitação de risco é definindo níveis de risco, separado o aceitável do inaceitável por uma estreita faixa onde o risco precisa ser cuidadosamente controlado, como mostra a Figura 4.16. A Figura 4.16, apresenta uma matriz de risco com três zonas de risco. A faixa superior representa uma zona de risco inaceitável onde, entre outros parâmetros que poderiam ser avaliados, as perdas são superiores aos ganhos. A zona central representa a necessidade de intervir com atividades que garantam o retorno para um nível de operação segura. No caso de sistemas complexos de produção de bens, estas intervenções relacionam-se principalmente as atividades de manutenção. Finalmente, a faixa inferior representa a zona de baixo risco, onde as operações são seguras e, entre outros parâmetros, não há perdas econômicas para a empresa e os ganhos, conseqüência da operação bem sucedida, são positivos. A Figura 4.16 é apenas ilustrativa, sendo adaptada de diversas referências (ABS, 2003; JOVANOVIC, 2002; SCHRÖDER e KAUER, 2004). 


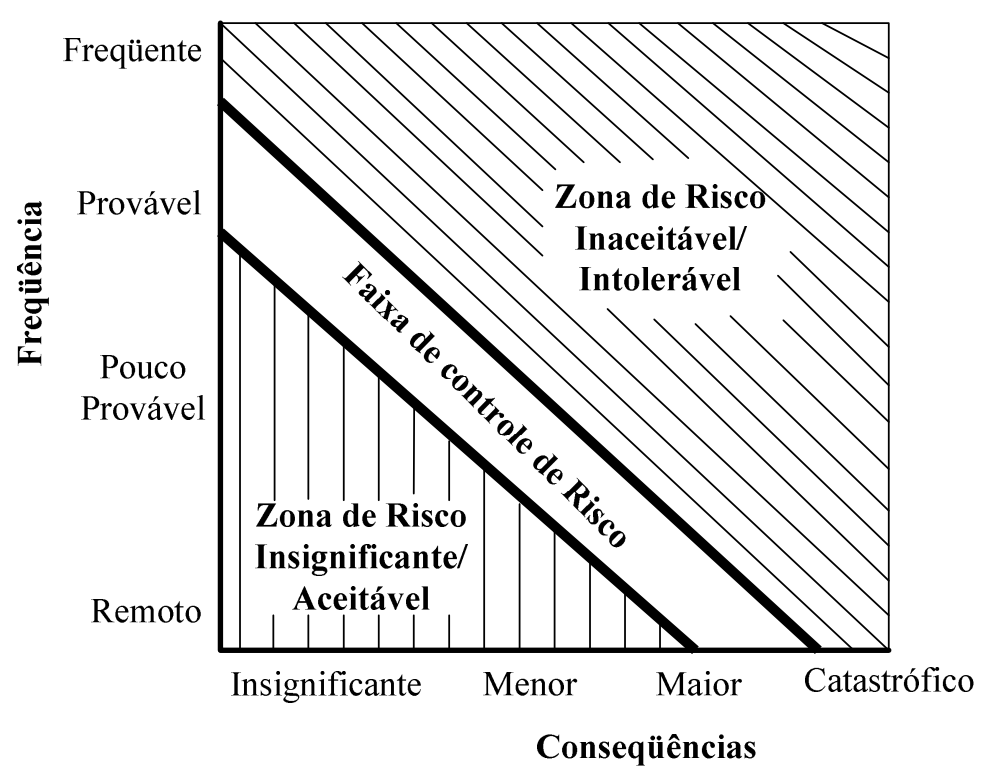

Figura 4.16. Exemplo de matriz de risco

Desta forma, se o Decisor tomará decisões utilizando este tipo de critério de níveis de risco a decisão, será relativamente simples, já que terá que atuar de forma a manter a operação do sistema na zona de baixo risco e intervir e investir quando esta operação entrar na faixa de controle de risco.

Outra forma de avaliar o risco é estabelecendo critérios de aceitação em função das despesas da manutenção preventiva (estabelecida com antecedência para períodos fixos de operação, mensal ou anual, por exemplo), em comparação com as probabilidades de falha associadas a esta política de manutenção, desta forma, se um determinado sistema excede os critérios de aceitação pré-determinados, é necessário reavaliar e modificar o plano de manutenção a fim de reduzir o custo, sem alterar a probabilidade de falha e consequientemente o risco.

Entretanto, o risco (risco operacional de grandes sistemas), por definição é a combinação das probabilidades de falha com as consequiências decorrentes da ocorrência desta falha em um cenário indesejado de operação. O método SMBR (proposto neste trabalho de tese) visa proporcionar ao Decisor valores de risco que permitam representar, em termos econômicos, a necessidade de atuar em relação à 
mudança de uma determinada política de manutenção e/ou a instalação de equipamentos redundantes nos sistemas críticos da planta industrial.

Desta forma, o levantamento dos custos de operação, incluindo os de perdas por contratação de mão-de-obra terceirizada, entre outras, combinados com as probabilidades de falha levantadas do estudo dos históricos de operação da planta, permitem criar pares $\left(\mathrm{p}_{\mathrm{i}}, \mathrm{c}_{\mathrm{i}}\right)$ para determinados cenários de operação, e desta forma $\mathrm{o}$ Decisor pode optar pela alternativa mais rentável (menos prejudicial à economia da empresa), de forma a garantir os mais altos níveis possíveis de segurança, disponibilidade, e confiabilidade, com o menor impacto às operações comerciais e financeiras da empresa.

A técnica que permite utilizar de forma estruturada os valores de probabilidades assim como os de custos é a Árvore de Decisão. Esta ferramenta é selecionada em função das vantagens que possui em comparação a outros procedimentos de avaliação, conforme mencionado no Capítulo 3. Adicionalmente para auxiliar a aplicação da seqüência de instruções do item 3.5 no Capítulo 3, apresenta-se na Figura 4.17 a seqüência de passos para a avaliação de risco e posterior tomada de decisão.

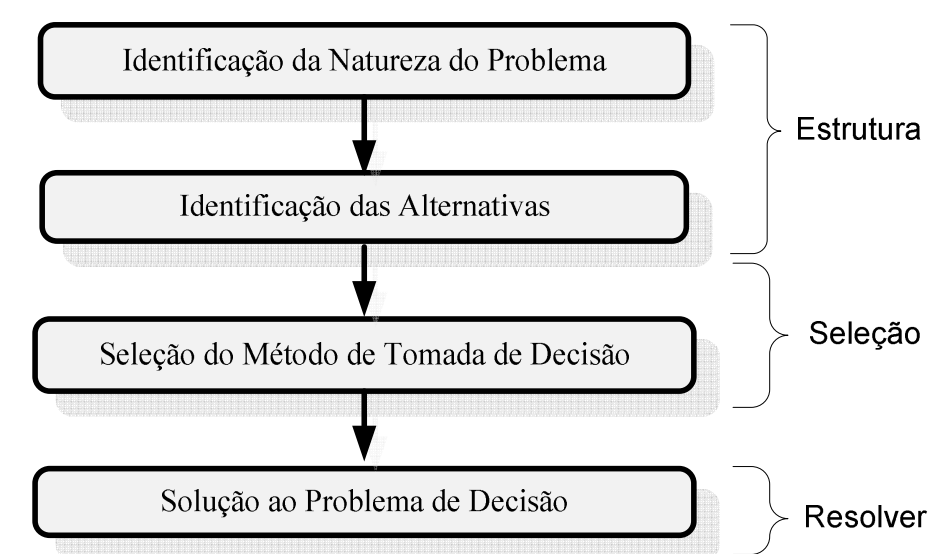

Figura 4.17 Processo de decisão em manutenção

O procedimento sugerido para a avaliação de risco e posterior seleção de política de manutenção está composto por quatro etapas. A primeira visa à identificação da natureza do problema entre três categorias: estruturado; semi-estruturado e; não 
estruturado. A segunda etapa é sugerida para a identificação das alternativas para a solução do problema entre: estratégicas, táticas ou operacionais. A terceira etapa é a seleção do método ou mecanismo de decisão. Para o estudo de caso deste trabalho de tese será utilizada a árvore de decisão, sendo adicionalmente utilizada a técnica do diagrama causa-conseqüência para a modelagem dos cenários de operação e falha e a técnica do FMEA para a identificação dos componentes críticos do sistema. Finalmente, dependendo da natureza da decisão, poderão ser feitas reavaliações a fim de optar pela melhor das decisões, obtendo-se a "solução do problema", última etapa sugerida pelo fluxograma da Figura 4.17.

Para finalizar com a apresentação do método SMBR, no capítulo seguinte (Capítulo 5), é apresentada a breve discussão comparativa deste método com as principais propostas encontradas na revisão bibliográfica. Já na continuação da tese, o Capítulo 6 apresenta a implementação de um caso exemplo ou estudo, que visa corroborar a viabilidade do método SMBR e, de alguma forma, nortear a repetição na hora da implementação em qualquer outro sistema complexo ou em outros sistemas de geração de energia elétrica no Brasil. Finalmente é apresentado o Capítulo 7, contento as principais conclusões e recomendações do trabalho de tese de Doutorado. 


\section{CAPÍTULO 5 - DISCUSSÃO - AS INOVAÇÕES DA PROPOSTA}

Este capítulo apresenta uma comparação de diversos métodos propostos para a análise de risco desenvolvidos nos últimos 10 anos, de forma a destacar as inovações do método proposto para a seleção de políticas de manutenção e novos equipamentos baseados em risco. 


\subsection{Análise Comparativa entre os Diversos Métodos da Bibliografia e o Proposto Neste Trabalho}

Com o objetivo de comparar os métodos apresentados pelos diversos autores da literatura com o método apresentado neste trabalho de doutorado denominado de SMBR 2011 (Método de Seleção de Equipamentos Críticos e Políticas de Manutenção), foi elaborada uma tabela comparativa. Nesta tabela comparativa, foram incluídos os métodos baseados em risco, tanto para a seleção de atividades de inspeção como a seleção de atividades de manutenção. Na tabela são destacadas as técnicas de análise de confiabilidade, de análise de risco e de teoria de decisão, empregadas pelos diversos métodos referenciados, incluindo o método proposto e a filosofia do MCC.

$\mathrm{Na}$ primeira linha da Tabela 5.1 se apresenta quais as etapas de um procedimento genérico de análise de risco poderiam conter, como: 1) definição do escopo; 2) aplicação das técnicas de análise de risco; 3) estimativa do risco; 4) representação do cenário de falha; 5) tomada de decisões e finalmente, 6) seleção do tipo de decisão estratégica.

A segunda e terceira linhas descrevem de forma resumida o conteúdo das possíveis sub-etapas que cada uma das etapas principais, anteriormente numeradas, poderiam conter como, por exemplo, a etapa da "definição do escopo" poderia conter: a preparação dos dados de históricos, a definição do escopo, análise funcional e/ou, elaboração de uma árvore funcional. A tabela apresenta na primeira coluna, após a terceira linha, os autores e os respectivos anos de publicação das suas propostas de análise. Nas últimas duas linhas da tabela está o método e a filosofia do MCC, que é incluído para destacar as diferenças deste com os outros métodos baseados em risco. 
Tabela 5.1. Análise comparativa dos métodos baseados na análise de risco para seleção de políticas de manutenção

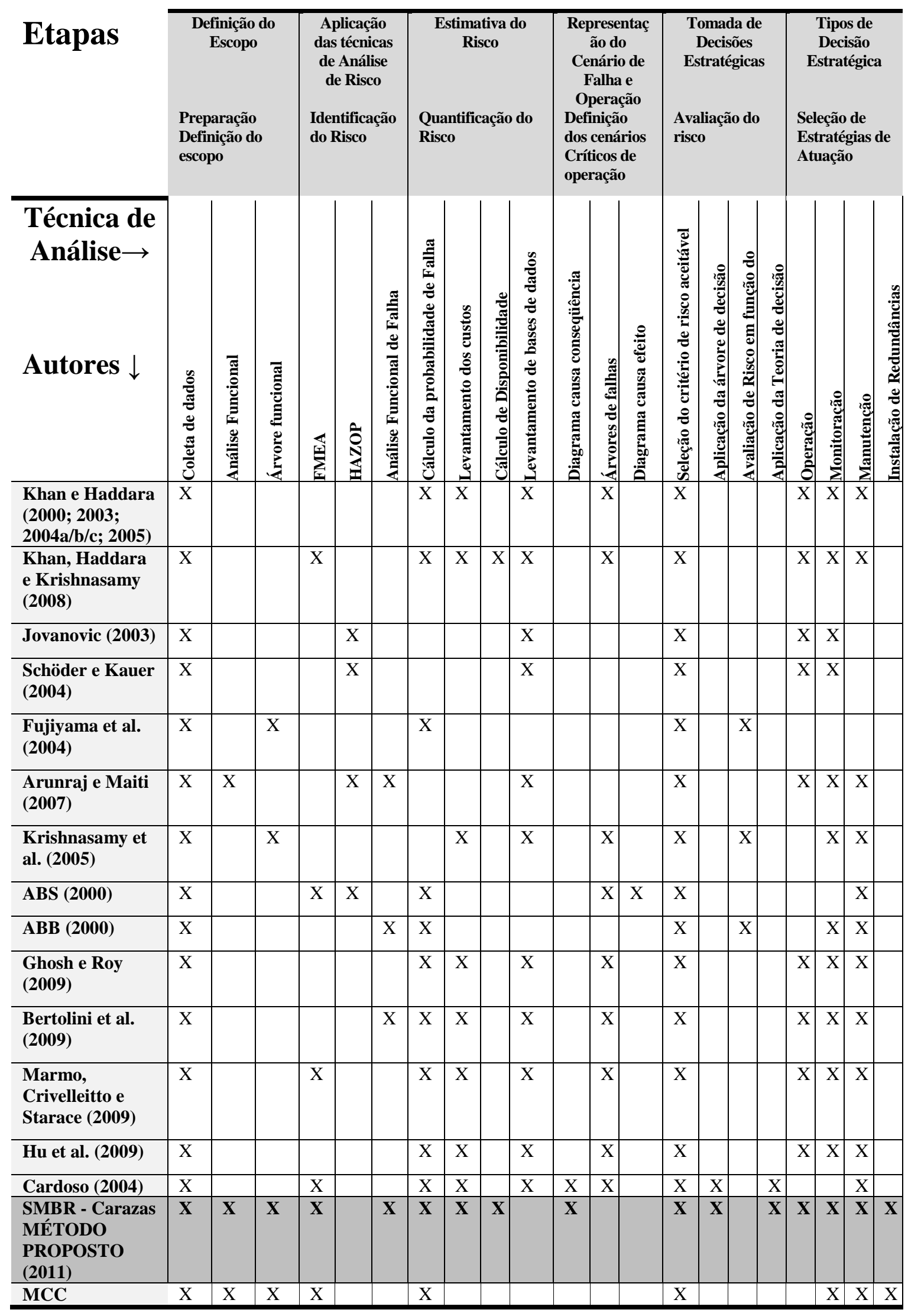


Na Tabela 5.1 são analisadas vinte propostas de métodos para a seleção de políticas de manutenção baseadas na análise de risco e comparadas com a proposta de método SMBR 2011, do presente trabalho de Tese de Doutorado. Da elaboração desta análise pode-se concluir:

- A estrutura seqüencial do método apresentado pelo autor, para a seleção de políticas de manutenção baseado em risco, se encaixa com a de os outros métodos, contendo de forma geral: 1) definição do escopo; 2) identificação do risco; 3) avaliação do risco e 4) tomada de decisões e a seleção da alternativa de menor risco.

- Uma análise desta natureza tem como ponto de partida o levantamento de dados e a coleta de informações com o objetivo de definir a profundidade da análise e os limites da mesma. A qualidade das informações do sistema permitirá uma análise realista e uma adequada quantificação do risco associado à operação do sistema.

- A análise funcional e a elaboração de árvores funcionais são utilizadas pelos autores Arunraj e Maiti (2007), Fujiyana et al. (2004), Krishnasamy et al. (2005) e o método SMBR 2010 (aqui proposto) e, segundo estes, a análise funcional permite um entendimento claro da operação de sistemas complexos, do ponto de vista funcional, e permitirá uma ordenada propagação das conseqüências de uma falha dentro da estrutura funcional do sistema.

- O método SMBR 2011 utiliza a técnica de Análise de Modos e Efeitos de Falhas para a identificação de falhas funcionais e conseqüentemente, em função da criticidade, os possíveis componentes críticos. O FMEA, nos outros métodos apresentados na Tabela 5.1, é pouco utilizado. Os métodos que usam o FMEA o utilizam apenas para a identificação das principais falhas funcionais.

- Todas as propostas analisadas aplicam pelo menos uma das técnicas da estimativa de risco, com a finalidade de quantificar o risco relacionado à operação ou a uma mudança na estratégia de manutenção. As técnicas mais 
usadas são o cálculo das probabilidades de falha baseados nos dados históricos de operação e, o levantamento de probabilidades de falhas de bases de dados (de normas técnicas e outras fontes comerciais).

- Só os autores Carazas, (com o método SMBR 2011, aqui proposto) e Cardoso (2004) aplicam a técnica de análise do diagrama causa-conseqüência como ferramenta para a representação do cenário de operação, ou de falha, de sistemas complexos.

- A análise de árvore de falhas é aplicada por diversos autores nas suas propostas de análise de risco em função da facilidade para combinar as probabilidades associadas aos eventos com um determinado evento crítico.

- Todos os métodos selecionam um critério de risco e, desta forma, poder tomar uma decisão. O critério de risco pode ser quantitativo ou qualitativo dependendo do tipo da análise. Os autores Fujiyama et al. (2004) e Krishnasamy (2005), assim como o apresentado pela ABB (2000), aplicam um critério de risco aceitável apenas considerando os custos, ou seja, em função das perdas.

- O método SMBR 2011, proposto por Carazas aplica os conceitos da teoria de decisão com a finalidade de combinar de forma quantitativa as probabilidades de falha com os custos relacionados com um determinado cenário de falha e/ou de operação.

- Por se tratar de métodos para a seleção de políticas e/ou atividades de manutenção, todos os autores apresentam recomendações seja no campo operacional, da intervenção de manutenção propriamente dita e de atividades de monitoração, como parte das recomendações de manutenção preditiva.

- Só o método aqui proposta SMBR 2011, baseado na aplicação dos conceitos de confiabilidade em combinação com os critérios de seleção baseados em risco, 
propõe, como atividade para o melhoramento da disponibilidade do sistema, a instalação de sistemas redundantes.

- Finalmente, os diversos métodos aqui apresentados evoluem da aplicação da filosofia da manutenção centrada em confiabilidade e da necessidade de fortalecer o mecanismo de decisão para a seleção de políticas de manutenção por meio da aplicação da análise de risco.

Da elaboração da Tabela 5.1, podem-se observar também, notáveis diferenças entre os métodos apresentados pelos autores da revisão bibliográfica com o método proposto SMBR 2011, na presente tese de Doutorado. As mesmas podem ser classificadas como inovações em relação da aplicação dos conceitos da análise de risco para a seleção de políticas de manutenção em grandes sistemas.

\subsection{Principais Inovações do Método}

As principais inovações do método SMBR 2011, proposto neste trabalho de Doutorado, são:

- A inclusão da estrutura de análise funcional como ponto de partida para a análise de risco de sistemas complexos;

- Aplicação da análise da árvore funcional como complemento à identificação dos sistemas a serem analisados. A árvore funcional permite criar uma estrutura funcional do sistema, que mapeia as relações entre os diversos componentes dentro de um sistema complexo.

- Conservação das bases da aplicação do FMEA (aplicado pela filosofia do MCC), para a identificação dos componentes críticos e assim identificação dos potenciais riscos operacionais. A própria árvore funcional já fornece uma representação dos diversos cenários de operação, como comprovado por Carazas e Souza (2009). 
- Permitir uma avaliação real do risco através do levantamento real das probabilidades de falhas relacionadas aos cenários de operação (baseado nos bancos de dados de operação e manutenção) e do levantamento dos custos reais de operação (baseados nos custos de indisponibilidade e os custos relacionados com a própria atividade de manutenção).

- Permitir a identificação de barreiras com a finalidade de garantir a segurança e a alta disponibilidade por meio da aplicação de uma inovadora combinação entre o próprio sistema de controle computadorizado da usina e aplicação da técnica de análise de risco do Diagrama Causa-Conseqüência.

- A aplicação da teoria de decisão, com a finalidade de fortalecer uma tomada de decisões em função do risco, para a seleção de atividades de manutenção e/ou mudanças no planejamento de intervenções e rotinas de inspeção.

- A inclusão de um procedimento de tomada de decisão para a seleção de novos componentes (componentes redundantes e/ou sistemas de segurança), que garantam alta disponibilidade operacional. Além das tradicionais recomendações de manutenção preventiva e preditiva do MCC, assim como das atividades de inspeção do RBI.

- Integrar, de forma lógica e estruturada: os pontos fortes da filosofia do MCC e sua capacidade para identificar os pontos críticos na operação de sistemas complexos com; as técnicas de representação de cenários, que permitem as técnicas de análise de risco (como o diagrama causa-conseqüência); e a análise de confiabilidade, que permite analisar a mantenabilidade e disponibilidade de sistemas; adicionalmente com os princípios da análise de risco (que permitem quantificar os valores de risco), e finalmente de forma que permitir através da teoria de decisão, selecionar a alternativa mais rentável, confiável e segura para a operação de sistemas complexos, como por exemplo, uma planta termelétrica de ciclo combinado. 


\section{CAPÍTULO 6 - IMPLEMENTAÇÃO}

Neste capitulo é apresentada a implementação do método proposto em uma usina termelétrica em ciclo combinado de geração de energia elétrica. Os cálculos e os resultados refletem a real condição operacional do sistema de geração. 


\subsection{Considerações Iniciais}

Como mencionado no decorrer do texto, o método proposto SMBR é desenvolvido para ser implementado em uma usina termelétrica de ciclo combinado que, em função da implementação da filosofia do MCC, sentiu a necessidade de melhorar o processo de seleção de políticas de manutenção, basicamente para desenvolver novas estratégias de comercialização de energia garantindo uma sua garantia física. O estudo de implementação do MCC, em referência foi elaborado por Carazas em 2006.

O novo método SMBR desenvolvido neste trabalho de doutorado procura auxiliar a seleção de políticas de manutenção ou de sistemas redundantes (sistemas de segurança que garantem alta confiabilidade do sistema). O método SMBR é implementado em uma unidade geradora termelétrica de ciclo combinado, que iniciou suas atividades no período da crise energética no Brasil no começo da década de 2000. A usina possui uma capacidade instalada aproximada de 500 MW em um ciclo combinado do tipo 2-1. As turbinas a gás são do tipo serie "Heavy Duty" com pôtencia nominal aproximada de $150 \mathrm{MW}$, associadas a duas caldeiras de recuperação que proporcionam vapor para a turbina de vapor com capacidade de cerca de $200 \mathrm{MW}$, complementando a potência total instalada na usina de ciclo combinado.

Desta forma, o método SMBR visa ser uma ferramenta de planejamento estratégico da manutenção para o agente gerador. Visando garantir alta disponibilidade operacional e desta forma permitir a manutenção de um histórico de operação aceitável para a negociação de futuros contratos de comercialização de energia.

Isto é conseguido principalmente por meio da identificação dos elementos críticos do sistema, ou seja, aqueles elementos que em caso de apresentar falha 
paralisam a operação da usina deixando-a indisponível. A identificação destes componentes é conseguida por meio da elaboração de diversas análises para todos os equipamentos das árvores funcionais (turbina a gás, turbina a vapor, caldeira de recuperação (HRSG), sistema de resfriamento de água e geradores), ou seja, para todos os equipamentos da usina.

Para estimar as probabilidades de ocorrência de falhas dos diversos componentes da usina, foi estudado o próprio banco de dados de 5 anos de operação da usina termelétrica. Como produto desta análise, é possível tomar algumas decisões preliminares como, por exemplo, que o sistema de alimentação de água das caldeiras de recuperação é um dos sistemas com maior frequiência de falha. Isto, somado com a necessidade de apresentar um caso exemplo claro, que permita avaliar o método aqui proposto, possibilitou, durante o desenvolvimento da implementação, tomar decisões restritivas, pois o estudo ia ganhando um volume significativo com mais de 2 mil análises do tipo FMEA. Por tanto decidiu-se implementar o método apenas para o sistema as caldeiras de recuperação (HRSG). Esta decisão que foi apoiada pelo agente gerador, por solicitação da equipe de engenheira, que priorizou a análise da caldeira de recuperação.

Este fato é mencionado entre as considerações iniciais em função de que a implementação centra todas as análises sugeridas pelo método proposto neste trabalho de doutorado para a caldeira de recuperação e em particular para o sistema de alimentação de água.

Portanto, este capítulo apresenta o passo-a-passo da aplicação do método SMBR para a seleção de estratégias de manutenção e seleção de novos equipamentos em uma usina termelétrica a ciclo combinado. O sistema sob análise é considerado complexo, pela grande quantidade de elementos que o compõem. Por este motivo são apresentados apenas os principais resultados obtidos para cada uma das etapas do método. 
A implantação segue as etapas do método, as quais são: 1) definição do escopo; 2) identificação do risco; 3) quantificação do risco; 4) avaliação do risco e 5) tomada de decisão/ seleção da política de manutenção.

\subsection{Identificação do Escopo}

A usina sob estudo representa $0,66 \%$ do total da capacidade instalada no Brasil, com capacidade instalada em torno de 500 MW (ONS, 2006), em um ciclo combinado composto por duas turbinas a gás, duas caldeiras de recuperação e uma turbina a vapor. As turbinas a gás possuem potência em torno de $150 \mathrm{MW}$, e podem ser operadas utilizando gás natural ou óleo diesel como combustível. As duas caldeiras de recuperação possuem três estágios de geração de pressão: baixa, média e alta. As caldeiras descarregam vapor a uma pressão de 170 bar e temperatura de $545^{\circ} \mathrm{C}$ e estão acopladas a uma turbina a vapor com potência aproximada de $200 \mathrm{MW}$, que recebe vapor simultaneamente das duas caldeiras de recuperação. A usina utiliza geradores elétricos de grande porte resfriados por gás inerte acoplados às duas turbinas a gás e a turbina a vapor. Completam a instalação de ciclo combinado, um sistema de resfriamento de água composto por 10 torres de resfriamento, um condensador e um sistema de tratamento de água, que não farão parte do estudo apresentado neste trabalho, mas são apresentados nos resultados do estudo destes sistemas, Carazas e Souza (2009b). A usina sob análise tem as mesmas características da apresentada na Figura 6.1.

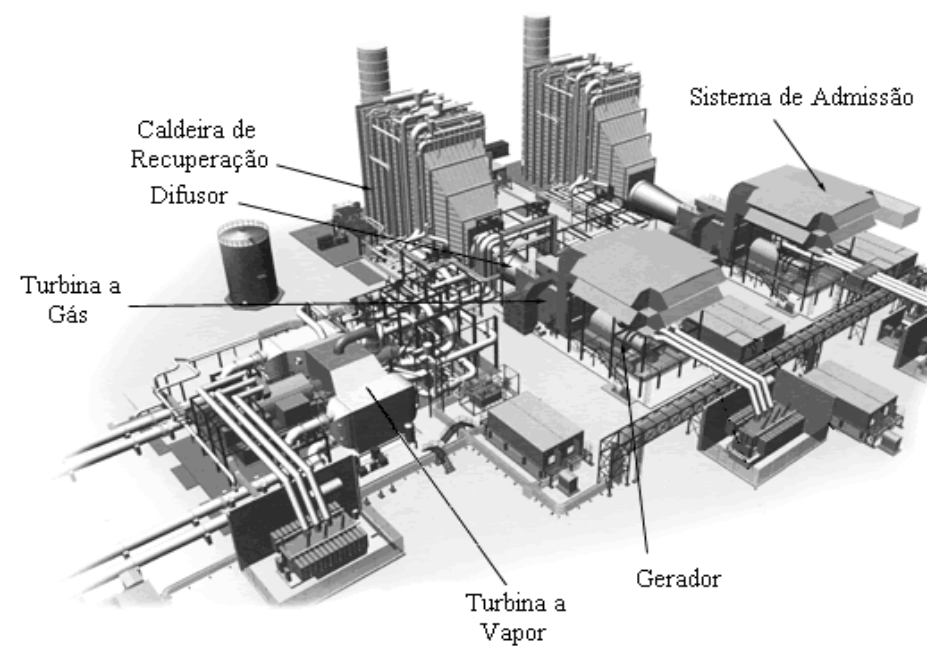

Figura 6.1. Arranjo da usina Termelétrica sob análise 
O projeto e a construção da usina termelétrica foram realizados por um consórcio entre empresas nacionais e internacionais, com um investimento de aproximadamente US\$ 400 milhões.

\subsection{Elaboração da Árvore Funcional}

A representação de uma usina termelétrica de ciclo combinado apresenta alguns sistemas básicos como: as turbinas a gás, as caldeiras de recuperação, a turbina a vapor e o sistema de reposição e resfriamento de água, entre outros. No entanto, as usinas podem ter algumas especificidades particulares decorrentes do projeto do fabricante, da tecnologia e até das modificações aplicadas nas mesmas para operar em um determinado âmbito geográfico, por exemplo, o tipo de combustível, a altitude na qual opera sobre o nível do mar, entre outras características.

A elaboração das árvores funcionais é uma tarefa árdua e é efetuada basicamente mediante o estudo de fontes bibliográficas tais como: Bei (1991), Black e Veatch (1996), Hitachi (2008), Todola (1945), Lora e Nascimento (2004a), Kehlhofer et al. (1999) Siemens (2007), além dos manuais de operação da própria usina que, em cumprimento aos contratos de confidencialidade, não podem ser revelados. A representação da árvore funcional da usina é apresentada na Figura 6.2 e destaca seus componentes principais.

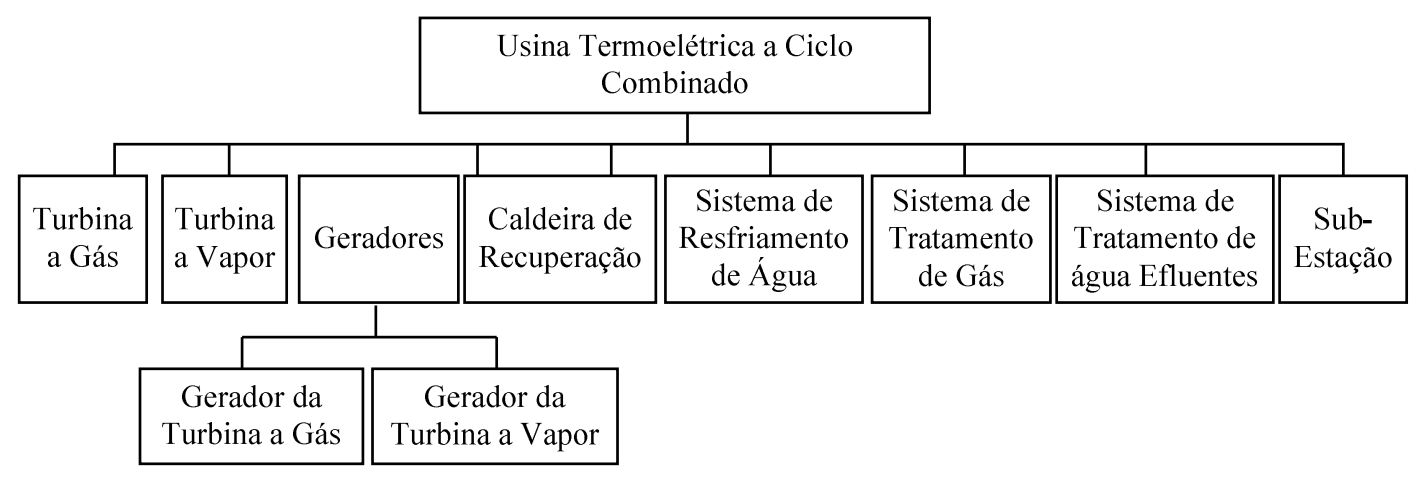

Figura 6.2. Árvore funcional da usina Termelétrica a ciclo combinado 
Para a elaboração das árvores funcionais deve-se observar todos os equipamentos principais como sistemas. Neste sentido, os quadros da árvore não são “caixas pretas" e os sistemas podem ser divididos em subsistemas, e assim subsequientemente possibilitando a sua decomposição em componentes que estão interligados entre eles por um vínculo funcional. Desta forma, o diagrama ou árvore funcional para os sistemas que compõem a usina termelétrica é subdividido em grandes subsistemas até chegar aos componentes que ocupam os ramos finais da árvore funcional (CARAZAS e SOUZA, 2007b).

A descrição funcional consiste na listagem de todos os componentes empregados para suportar a função principal de cada equipamento, acompanhados das suas respectivas funções principais e secundárias, no caso da existência das mesmas. Se ressalta que limita-se a "resolução" da árvore a componentes que são substituídos ou submetidos à manutenção em caso de sua falha.

As árvores funcionais são utilizadas como um plano ou radiografia do sistema e são utilizadas para determinar como as conseqüências das falhas de um componente se propagariam para o subsistema do qual faz parte, bem como para o sistema como um todo. As árvores funcionais também são o ponto de partida para a implementação de técnicas de análise como o Diagrama Causa-conseqüência, Árvore de Falhas, FMEA, HAZOP, entre outros.

Como já mencionado, o estudo foi realizado de uma forma preliminar para a usina inteira, mas como o presente trabalho fora a implementação apenas para as caldeiras de recuperação, as árvores funcionais dos outros sistemas não são apresentadas neste trabalho em particular. Assim, na seqüência são apresentadas as árvores funcionais dos principais sistemas do ciclo de vapor. Na Figura 6.3 é apresentada a árvore funcional da HRSG (Heat Recovery Steam Generator) (CARAZAS e SOUZA, 2007b). E na Figura 6.4 é apresentada a árvore funcional do sistema de resfriamento de água, incluindo as torres de resfriamento e o condensador. Estes sistemas foram selecionados por fazerem parte do foco da análise. 


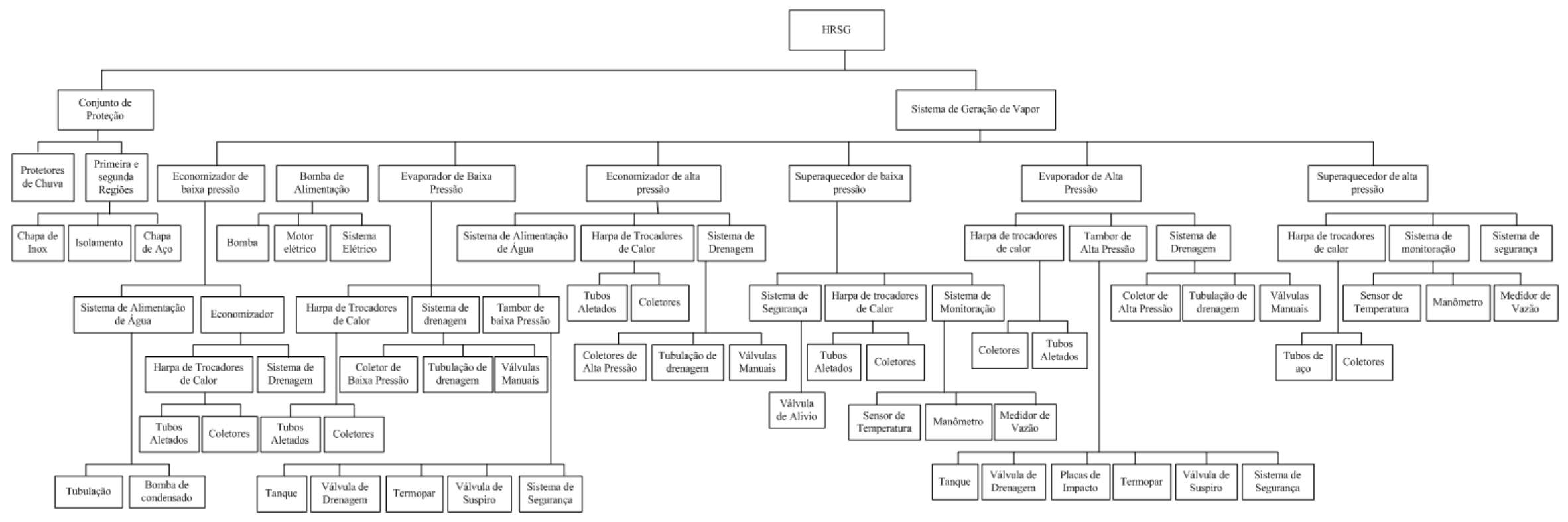

Figura 6.3 Árvore funcional da caldeira de recuperação (HRSG) 


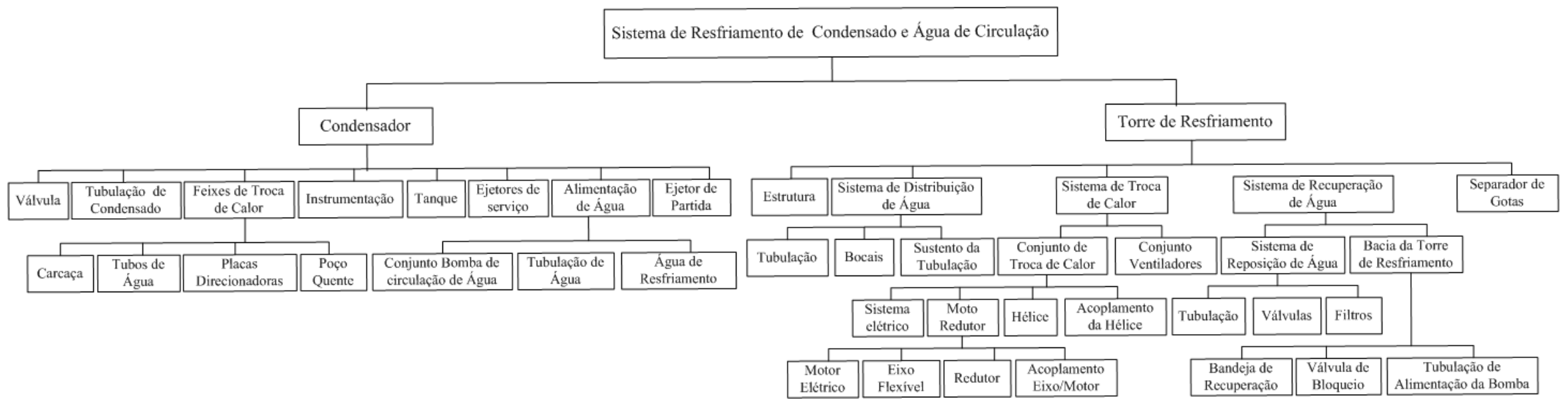

Figura 6.4. Árvore funcional do sistema de resfriamento de condensado e água de circulação 
Novamente, é destacada a importância das análises das árvores funcionais, pois estas permitem, logo após a sua elaboração, que sejam obtidas algumas conclusões preliminares. Assim, é possível notar que, embora os equipamentos instalados em uma usina termelétrica tenham uma configuração basicamente similar, existe uma grande diversidade de possíveis arquiteturas para estes. Por exemplo, os sistemas de alimentação de água das caldeiras podem ou não ter redundância, as bombas de água possuem um sistema de bombeio de óleo de lubrificação que, dependendo do projeto incorporado a eles, possui um sistema de resfriamento ou não, e assim por diante. As diferenças entre os sistemas podem estar relacionados apenas à diferença de modelos e fabricantes, mas os equipamentos cumprem com a mesma função e suas características de solicitação dependerão da solicitação operacional dentro da usina. Desta forma, as diferenças nos componentes influenciam na conseqüência dos seus eventuais modos de falha e, portanto, na condição de operação da própria usina.

Com a elaboração da análise funcional é possível afirmar que o analista e/ou a equipe de análise possuem uma visão funcional do funcionamento de uma usina termelétrica a ciclo combinado. Essa é uma premissa necessária para a execução do FMEA e qualquer outro tipo de análise baseada em confiabilidade ou risco. O FMEA é executado para definir os componentes que exercem maior influência sobre a confiabilidade da usina, os quais devem preferencialmente ser objeto de análise das equipes de manutenção.

\subsection{Implementação da Análise de Risco}

Esta etapa, como discutido na proposta do método, tem por objetivo identificar e quantificar os riscos potenciais que poderiam afetar a usina. O sistema sob análise é o sistema de alimentação de água da caldeira, que em caso de vir a apresentar falhas causaria a parada do sistema de vapor (caldeiras e turbinas a vapor). Para atingir o objetivo da análise, podem ser aplicadas diversas técnicas de análise e, neste caso, foi escolhida a análise do tipo FMEA. 
O FMEA do sistema de geração de energia, em função da sua complexa natureza operacional, deve ser executado tomando como ponto de partida um determinado modo de falha de um componente específico. Para este modo de falha avalia-se a consequiência da falha sobre o sistema no caso a caldeira de recuperação avaliando o grau de deterioração da sua condição operacional. Posteriormente, a repete-se a análise para cada um dos componentes do sistema, preenchendo as colunas da tabela de análise do FMEA (Tabela 4.1, Capítulo 4).

Como resultados da execução do FMEA são identificados os potenciais modos de falhas, as possíveis causas destes modos de falha e as conseqüências de cada modo de falha. À gravidade destas conseqüências é outorgado um valor de severidade que permitirá determinar a criticidade do componente na operação do sistema. As consequiências das falhas são propagadas dentro do sistema com auxílio da árvore funcional, chegando a estimar as conseqüências sobre o sistema como um todo, neste caso a usina termelétrica e a função de gerar energia elétrica.

Se a consequiência de um determinado modo de falha dos componentes põe em risco a operação do sistema, o componente e seus modos de falha são denominados de críticos ou de alta severidade. A severidade é medida numericamente de 1 a 10 , sendo 1 o indicador de baixa severidade e 10 de alta severidade. A tabela de severidade é apresentada na Tabela 6.1.

A análise FMEA permite identificar os modos de falha mais severos e os componentes críticos, neste caso, a aplicação da análise é executada considerando apenas a severidade da falha, definida como o grau de comprometimento da capacidade de geração de energia elétrica da unidade geradora em função da falha do componente (SOUZA, 2003). 
Tabela 6.1. Classificação de severidade para o sistema de geração de energia elétrica (CARAZAS, 2006)

\begin{tabular}{|c|c|}
\hline $\begin{array}{l}\text { Grau } \\
\text { Severidade }\end{array}$ & Efeito sobre a Operacionalidade do Sistema de Geração \\
\hline 1(Sem Efeito) & $\begin{array}{l}\text { - Falha de componentes que exigem reparo ou substituição, mas não imediata; } \\
\text { - Não afeta o desempenho da máquina ou sistema ou sem efeito sobre o meio ambiente. }\end{array}$ \\
\hline 2 (Efeito Leve) & $\begin{array}{l}\text { - Falha de componentes que exigem reparo ou substituição, mas não imediata; } \\
\text { - Desempenho da máquina ou sistema muito pouco degradado, sem efeito sobre o meio } \\
\text { ambiente. }\end{array}$ \\
\hline 3 (Efeito Menor) & $\begin{array}{l}\text { - Falha de componentes que exigem reparo ou substituição, mas não imediata; } \\
\text { - Desempenho da máquina pouco degradado, sem efeito detrimental sobre o meio ambiente.. }\end{array}$ \\
\hline 4(Efeito Moderado) & $\begin{array}{l}\text { - Falha de componentes, com necessidade de reparo ou substituição. } \\
\text { - Desempenho do sistema de geração de energia pouco degradado, mas ainda permite operação, } \\
\text { porém com potência gerada reduzida; } \\
\text { - Perda de desempenho nos sistemas de controle das condições de operação, com pequenas } \\
\text { dificuldades de manutenção das mesmas. } \\
\text { - Possibilidade de efeito pouco detrimental sobre o meio ambiente. }\end{array}$ \\
\hline 5(Efeito & - Falha de componentes, com necessidade de reparo ou substituição. \\
\hline Significante) & $\begin{array}{l}\text { - Desempenho do sistema de geração afetado, mas ainda permite operação, porém com potência } \\
\text { gerada reduzida; } \\
\text { - Perda de desempenho nos sistemas de controle das condições de operação, com dificuldade de } \\
\text { manutenção das mesmas. } \\
\text { - Possibilidade de algum efeito detrimental sobre o meio ambiente. }\end{array}$ \\
\hline 6 (Efeito Maior) & $\begin{array}{l}\text { - Falha de componentes, com necessidade de reparo ou substituição. } \\
\text { - Desempenho do sistema de geração afetado severamente, mas ainda permite operação, porém } \\
\text { com potência gerada bastante reduzida; } \\
\text { - Severa perda de desempenho nos sistemas de controle das condições de operação.. } \\
\text { - Possibilidade de efeito detrimental sobre o meio ambiente, chance de exceder alguma } \\
\text { regulamentação ambiental. }\end{array}$ \\
\hline 7 (Efeito Extremo) & $\begin{array}{l}\text { - Falha de componente, sem danos a outros componentes. Necessidade de substituição e/ou } \\
\text { reparo do componente, com tempo de parada reduzido; } \\
\text { - Falha que não afeta segurança do sistema de geração e dos operadores; } \\
\text { - Falha causa parada de máquina, com não cumprimento de regulamentação governamental. } \\
\text { - Efeito ambiental grave, possibilidade de multa. }\end{array}$ \\
\hline 8(Efeito Sério) & $\begin{array}{l}\text { - Falha de componente que causa danos moderados ao sistema de geração de energia, sem dano a } \\
\text { outros componentes. Necessidade de substituição e/ou reparo do componente; } \\
\text { - Falha que não afeta segurança do sistema de geração e dos operadores; } \\
\text { - Falha causa parada de máquina, com não cumprimento de regulamentação governamental. } \\
\text { - Efeito ambiental muito grave, possibilidade de multa. }\end{array}$ \\
\hline 9 (Efeito Perigoso) & $\begin{array}{l}\text { - Falha de componente que causa danos severos ao sistema de geração, incluindo dano a outros } \\
\text { componentes. Necessidade de substituição e/ou reparo de vários componentes; } \\
\text { - Falha que afeta segurança do sistema de geração e dos operadores; } \\
\text { - Falha causa parada de máquina, com não cumprimento de regulamentação governamental. } \\
\text { - Efeito ambiental perigoso, vazamento de substâncias perigosas, aplicação de multa. }\end{array}$ \\
\hline
\end{tabular}

A tabela selecionada para a execução da análise do tipo FMEA inclui uma coluna para indicar a freqüência da ocorrência das falhas. Esta teria que ser preenchida de forma qualitativa, perdendo valor do ponto de vista de análise de confiabilidade e disponibilidade. Da mesma forma, a tabela selecionada para a análise conta com uma coluna para indicar a possibilidade de detecção dos modos de falha, mas na execução desta análise não serão preenchidas, pois a análise contempla a execução de tabelas específicas para recomendações e atividades preventivas, como recomendado pela filosofia do MCC (LAFRAIA, 2001; MOUBRAY, 2000). Além disso, outro motivo desta decisão está associado com o próprio objetivo desta pesquisa que é quantificar as 
probabilidades de ocorrência baseados nos próprios dados de operação e manutenção, fornecidos pelas equipes de operação e manutenção da usina.

As análises foram desenvolvidas para os principais componentes do sistema de geração de vapor, ou seja, a HRSG, e sistema de resfriamento de água. Para cada componente apresentado no final dos ramos das árvores funcionais foi realizada uma análise FMEA e são apresentados no Apêndice B.

Como resultado da aplicação da análise do tipo FMEA para uma tomada de decisão bem estruturada baseada em risco, são identificados os componentes críticos da HRSG e do sistema de resfriamento de água, baseando-se na severidade das suas falhas funcionais. A Tabela 6.2 apresenta, de forma resumida, o resultado da aplicação da análise do FMEA, indicando o componente analisado, o seu modo de falha funcional crítico e a severidade da consequiência da falha para o sistema de geração de vapor, e por conseqüência, para a própria usina termelétrica.

Da execução da análise do tipo FMEA é possível concluir, preliminarmente, que a técnica é uma poderosa ferramenta para a análise de risco, já que permite a definição e identificação dos modos de falha de cada componente, as consequiências e as causas das falhas, que permitem gerar um estado básico do cenário de operação do sistema sob análise.

Até aqui, o método permite à engenharia de manutenção gerar um critério bastante sólido para a seleção de políticas de manutenção, pois em função de terem sido claramente identificados os modos de falha e suas possíveis causas, a equipe de planejamento da manutenção pode atacá-los diretamente como debilidades do sistema e preparar recomendações que visem reduzir ou mitigar a ocorrência destes modos de falha, tornando o sistema mais confiável e do ponto de vista da segurança, mais robusto. 
Tabela 6.2. Resultados da aplicação da análise de modos e efeitos de falhas em uma usina termelétrica a ciclo combinado

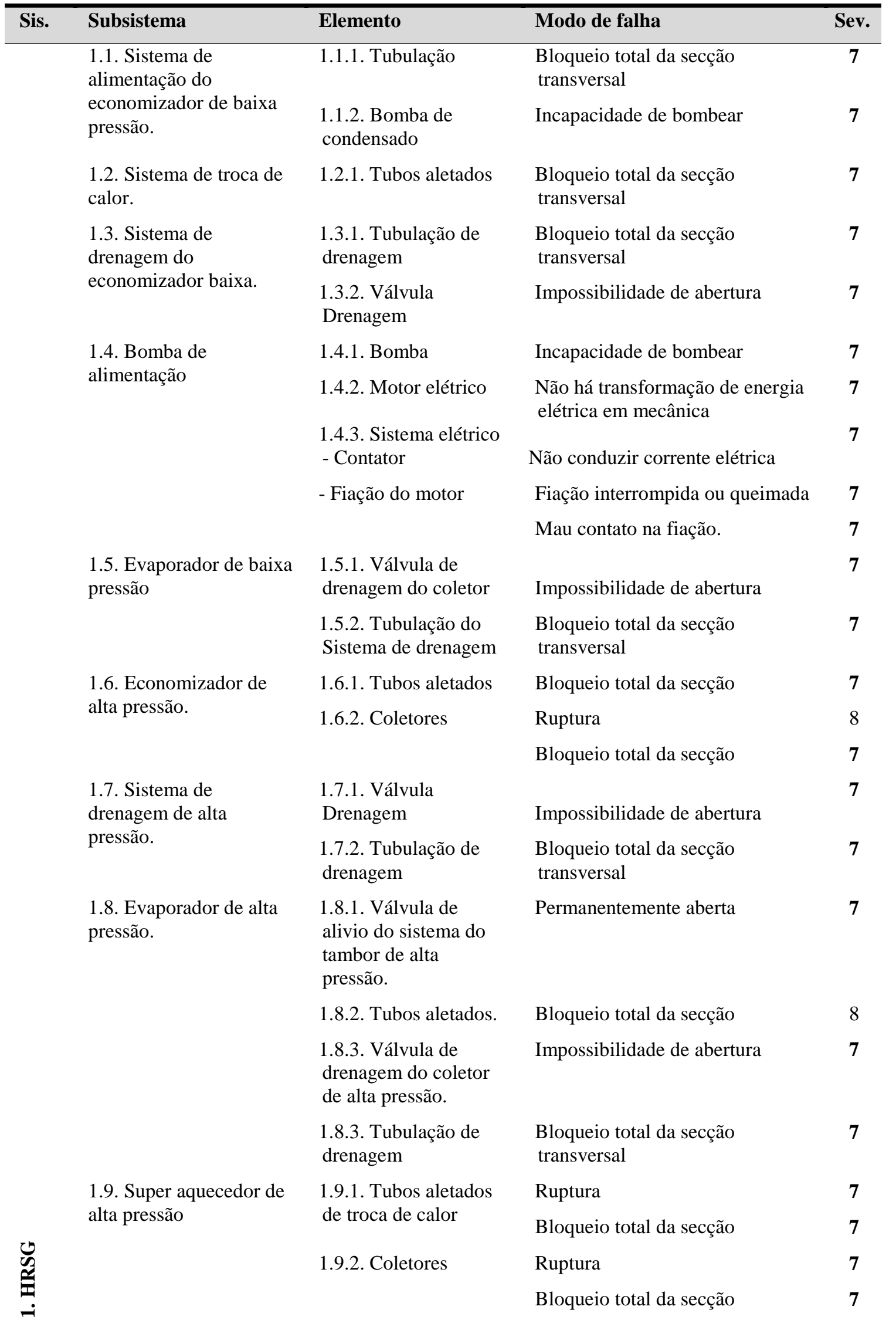


1.9.3. Sensor de temperatura

1.9.4. Manômetro

1.9.5. Válvula de alivio
Operação errada: Indicação de sinal de temperatura com magnitude inferior ao valor real;

Operação errada: Indicação de sinal de pressão com magnitude inferior ao valor real;

Não abre

Permanentemente aberta

Ruptura

Bloqueio total da secção

2.2. Trocadores de calor

2.2.1. Tubos de água.

2.3.1. Bomba água.

- Acoplamento

- Motor elétrico

- Contator

Bloqueio total da secção

transversal

Incapacidade de bombear

Ruptura da fixação entre o acoplamento e eixo do motor elétrico ou eixo da bomba

Ruptura do acoplamento

Não há transformação de energia elétrica em energia mecânica

Não conduzir corrente elétrica;

Atingir estado limite último

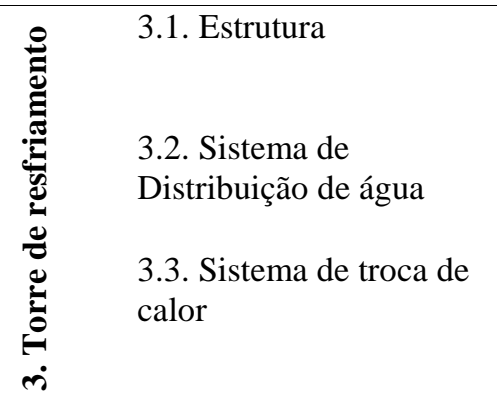

3.2.1. Tubulação

3.2.2. Bocais

3.3.1. Sistema elétrico do ventilador. Contator

3.3.2. Moto redutor Motor elétrico

Atingir estado limite operacional

Bloqueio total da secção

Bloqueio total da secção

Não conduzir corrente elétrica

- Eixo flexível

- Redutor

- Acoplamento

3.4. Sistema de recuperação de água
3.4.1.Válvula Bloqueio 3.4.2. Tubulação
Não há transformação de energia elétrica em energia mecânica

Ruptura do eixo

Falha por fadiga de contato ou

flexão das engrenagens

Ruptura dos eixos

Ruptura da fixação entre o acoplamento e eixo do motor elétrico ou eixo flexível

Impossibilidade de abertura

Bloqueio da secção transversal
8

7

7

7

7

7

8

7

7

7

7

\section{7}

8

8

7

7

Desta forma, a Tabela 6.2 apresenta os componentes do sistema de alimentação de água da caldeira, da caldeira da recuperação, do condensador e do sistema de resfriamento de água, identificados como críticos para a operação da usina termelétrica. Da identificação dos componentes críticos apresentados na tabela anterior, podem ser 
apresentados alguns comentários do ponto de vista operacional, que são apresentados na Tabela 6.3. Nesta tabela procura-se recomendar possíveis ações de manutenção para componentes críticos dos sistemas analisados, considerando a filosofia do MCC.

Verifica-se que a caldeira de recuperação já possui um conjunto de sensores que permitem aplicar a prática de manutenção preditiva para detectar a evolução de uma falha potencial nos componentes dos sistemas de alta /media /baixa pressão. O mesmo acontece com o sistema de controle da qualidade de água circulante da caldeira. Adicionalmente, verifica-se que o sistema de circulação de água na caldeira não apresenta um sistema de monitoração das condições de operação da bomba, o que impossibilita a aplicação da prática da manutenção preditiva. Com relação à freqüência das falhas nos equipamentos identificados como críticos na HRSG e no sistema de resfriamento de água, na Figura 6.5 apresenta-se o Diagrama de Pareto que indica a frequiência destas falhas para os equipamentos críticos, registradas durante 5 anos de operação da usina.

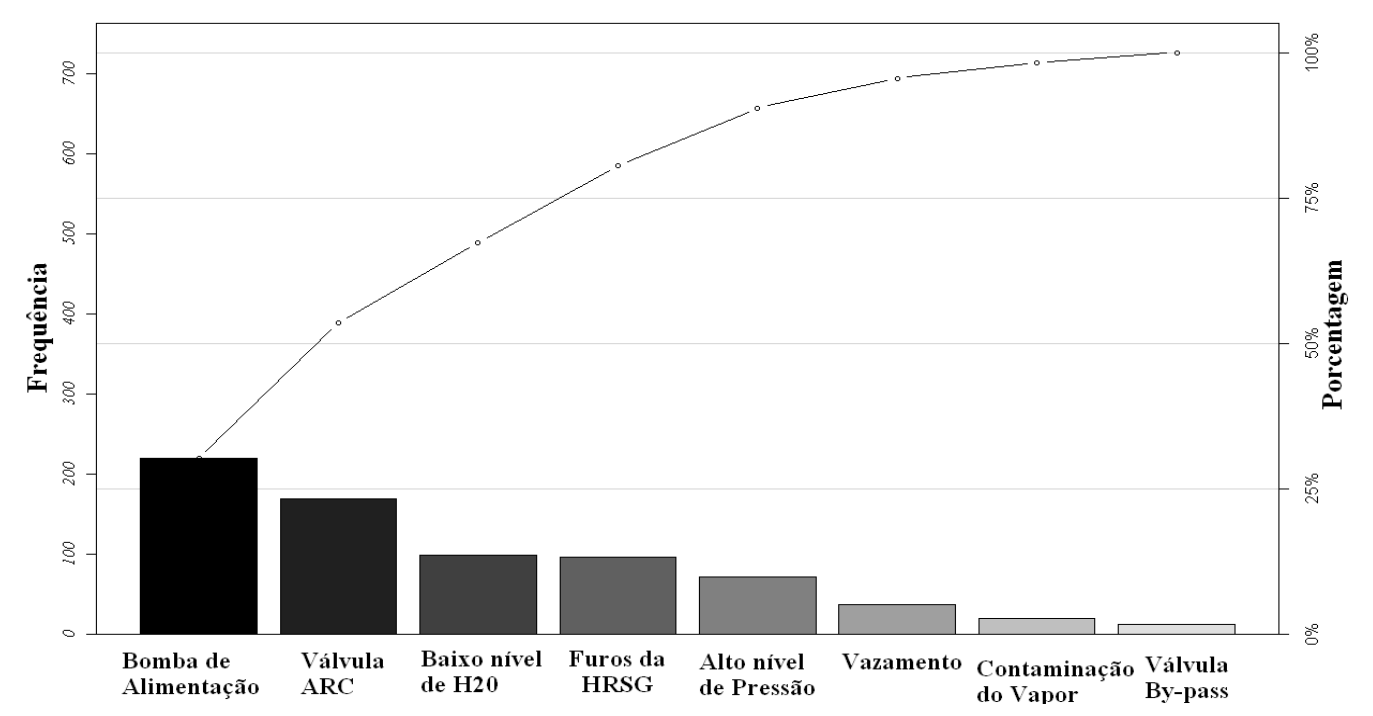

Figura 6.5. Diagrama de pareto das falhas do HRSG 1

Neste diagrama verifica-se a grande incidência de falhas para a bomba de circulação de água. A falha da mesma (e/ou seus sistemas auxiliares) provoca a paralisação da HRSG, reduzindo a potência gerada no ciclo de vapor e portanto a potencia gerada pela usina termelétrica. Ainda, pelo projeto particular da usina, a perda 
deste sistema ocasiona também a paralisação da turbina a gás. Isto levou a diretoria da empresa geradora a avaliar a possibilidade de investir uma grande quantidade de recursos financeiros na instalação de um sistema redundante de alimentação de água para as caldeiras de recuperação.

Este cenário (em que precisa ser tomada uma decisão) é estratégico para a operação do sistema e para o futuro comercial da empresa, fato que motivou a implementação do método SMBR no sistema de alimentação de água das caldeiras de recuperação.

Tabela 6.3. Características e recomendações para a caldeira de recuperação e torres de resfriamento em função do tipo de política de manutenção

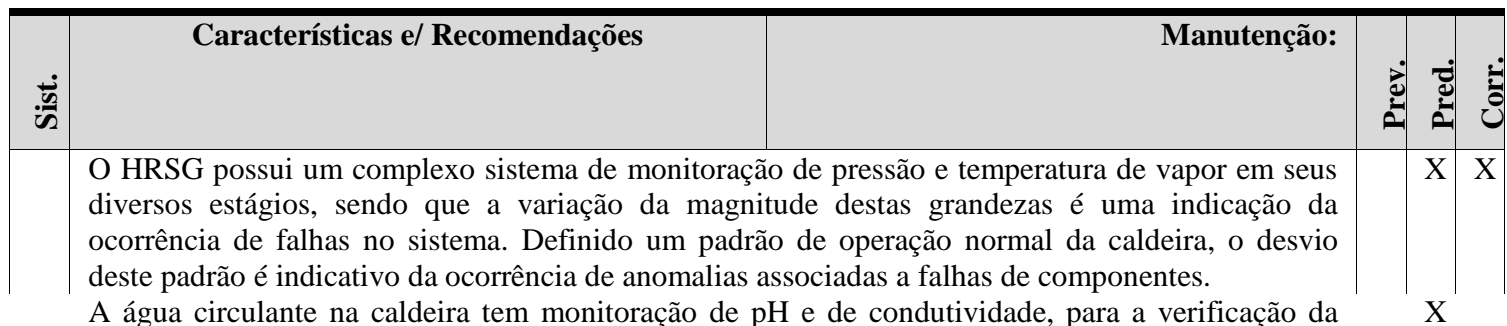

A água circulante na caldeira tem monitoração de $\mathrm{pH}$ e de condutividade, para a verificação da presença de íons, que indicam a deterioração da qualidade da água, o que provoca aumento de agressividade para os materiais da caldeira. /A variação destas propriedades podem servir para indicar uma falha no sistema de tratamento de água ou mesmo a própria deterioração de matérias da caldeira.

Não há uma rotina de inspeção da qualidade da água que vise verificar a presença de materiais ใ estranhos. A presença destes indica a deterioração dos componentes da caldeira em função da agressividade da água./ É possível adotar rotinas de inspeção da qualidade da água com certa periodicidade, subsidiando a adoção de uma prática de manutenção preditiva.

É necessária a monitoração das condições operacionais da bomba de circulação de água na caldeira, sendo que a falha desta bomba causa a falha da caldeira./ É possível aplicar técnicas de monitoração (por análise de vibração e/ou termográfica) para definir o padrão operacional normal da bomba, possibilitando a verificação de desvios nesta operação normal, que podem ser associados a processos de deterioração dos componentes do conjunto. As avaliações periódicas destas condições operacionais possibilitam a verificação de alguma forma de deterioração do conjunto, permitindo a programação de ações de manutenção antes da ocorrência da falha.

Não possui um sistema de monitoração das condições operacionais das bombas de circulação de água no condensador/torre de resfriamento. A falha destas causa a parada do sistema de vapor./ é necessário um plano de manutenção preditiva. Pudendo monitorar o sistema com termográfica, 의 e/ou utilizando sensores de vibração no conjunto moto-bomba para verificar padrões anormais de vibração associados a falhas de componentes mecânicos do conjunto moto-bomba;

Não há uma programada uma rotina de monitoração e/ou inspeção das condições operacionais dos ventiladores da torre de resfriamento./ podem ser instalados sensores para registro de vibração do eixo dos ventiladores, a alteração no padrão de vibração indica o desenvolvimento de falha. Há ausência de monitoração pode estar associada ao alto nível de redundâncias, existem 10 torres de resfriamento, sendo necessária a operação de 8 para garantir operação da usina à plena potência. O grande número de falhas nos redutores implica constantes e dispendiosas ações de manutenção corretiva, pudendo ser implementado o emprego de prática preditiva para reduzir o número de ações de manutenção não previstas.

Pode ser adotado um procedimento de verificação da qualidade da água da bacia da torre de resfriamento, embora sejam adicionados produtos químicos e anti-corrosivo para controlar a agressividade da água, a contaminação da mesma pode causar a parada do sistema de vapor.

Da mesma forma que o empregado na água de circulação da caldeira, podem ser utilizados sensores de $\mathrm{pH}$ e condutividade para verificar a qualidade da água 
Com estes antecedentes a análise de decisão usando a análise de risco foi voltada principalmente para este sistema.

\subsection{Aplicação da Análise de Para o Sistema de Alimentação de Água das Caldeiras de Recuperação}

O sistema de alimentação de água das caldeiras de recuperação pode ser visto como um sistema relativamente simples em comparação com os outros componentes da usina termelétrica, como as turbinas de vapor e de gás, mas não é tão simples assim. Este sistema executa a função de fornecer água para a caldeira à pressão e vazão adequadas, segundo os parâmetros determinados no projeto. O sistema de alimentação é composto basicamente pelos seguintes componentes:

1) Motor da Bomba de Água de Múltiplos Estágios; 2) Bomba de Água de Múltiplos Estágios; 3) Sistema de Lubrificação da Bomba (incluindo o sistema de troca de calor); 4) Tubulações de Água; 5) Sistema de Resfriamento de Óleo; 6) Válvulas de Água; 7) Sistema de Válvulas de Controle; 8) Válvulas de Controle (HP-IP-LP); 9) Válvula de Recirculação (ARC valve); 10) Válvulas Automáticas (HP-IP-LP); 11) Válvula Anti-Flash e 12) Sistema de Instrumentação.

Uma das características particulares do sistema é o projeto que emprega uma bomba de múltiplos estágios de bombeamento e duas descargas, em pressão intermediária e em alta pressão. A arquitetura da bomba é robusta e precisa de sistemas de lubrificação e resfriamento de lubrificante especialmente projetado para ela. Adicionalmente, o conjunto possui um sistema de água de recirculação que é composto por um sistema de bypass e uma redução de pressão que permite, no caso de não ser necessária toda a vazão de água imposta pela bomba, redirecionar o fluxo de água para o tanque de baixa pressão da caldeira de recuperação. Além destes componentes, há 
outros não menos importantes, tal como apresenta a Figura 6.6, representando o diagrama do sistema de alimentação de água das caldeiras. Baseado no estudo funcional do sistema e no levantamento de informações sobre a operação do mesmo, na Figura 6.7, é apresentada a árvore funcional do sistema de alimentação de água das caldeiras de recuperação.

Posteriormente à elaboração da árvore funcional, procedeu-se à identificação dos perigos operacionais do sistema. Desta forma, é necessário identificar os eventos (falhas funcionais) que poderiam ocasionar um cenário de risco.

Para a representação destes possíveis cenários de operação provocados pelas consequiências da ocorrência de falhas como proposto pelo método, são elaborados diagramas causa-conseqüência. Esta técnica de análise permite o acompanhamento ou seguimento, tanto da propagação das falhas dentro do sistema como a identificação de possíveis barreiras dentro do mesmo que interrompam a propagação de falhas e conseqüências dentro do sistema, e desta forma mitigar as conseqüências da ocorrência de falhas nos componentes do sistema.

Para a elaboração do diagrama, é necessário inicialmente identificar o evento iniciador, que representa uma falha na condição de operação de um componente que levaria o sistema a operar em uma condição de falha. A elaboração do diagrama causaconsequiência é uma tarefa complexa e laboriosa, embora o sistema seja relativamente simples (bomba, motor, tubulações, válvulas, etc.). O evento inicial tem que apresentar como conseqüências a possibilidade de parada do sistema de geração, ou seja, qual falha do sistema de alimentação de água da caldeira afeta a operação da usina e quais as possíveis seqüências que levam a este evento. 


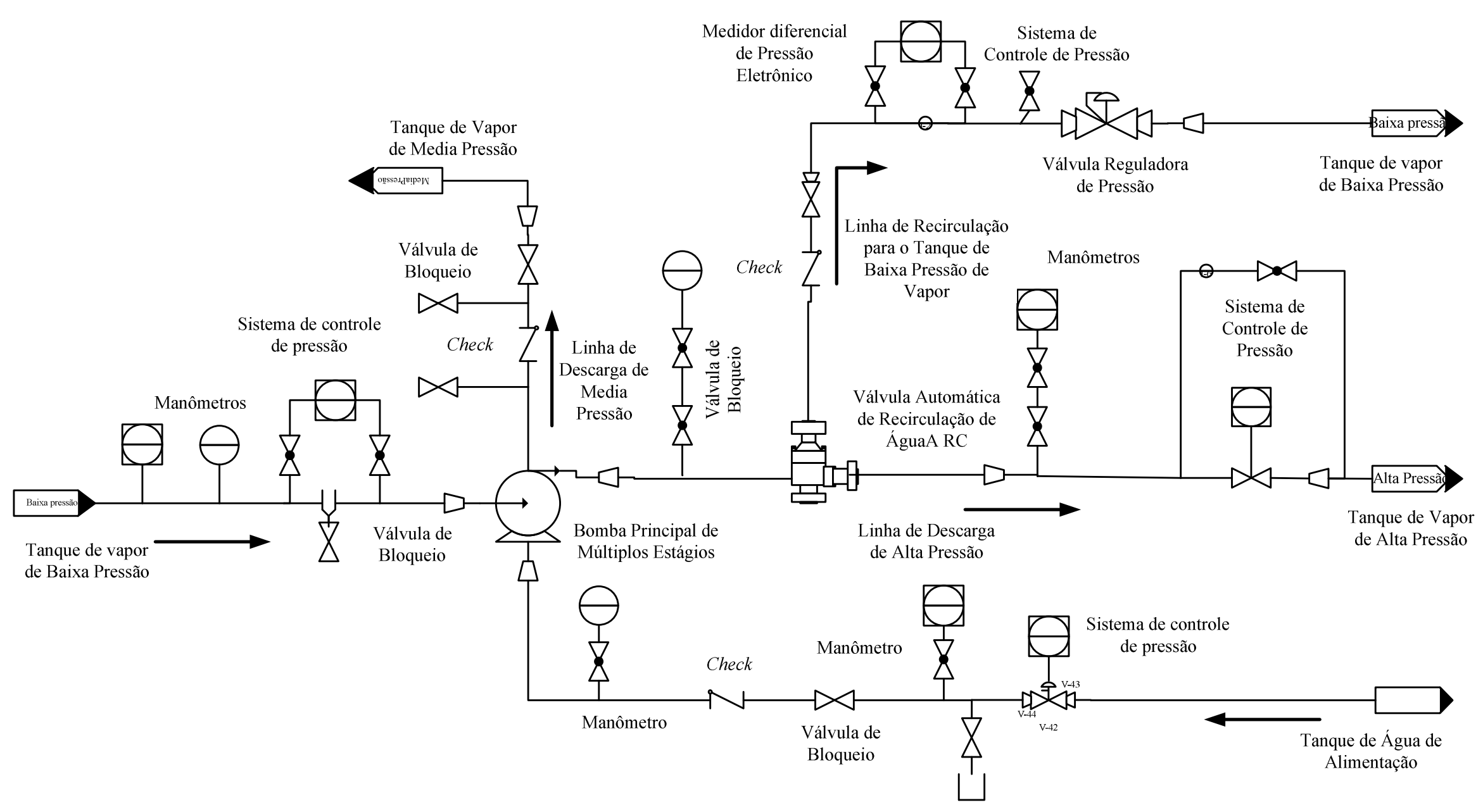

Figura 6.6. Sistema de alimentação de água da caldeira de recuperação 


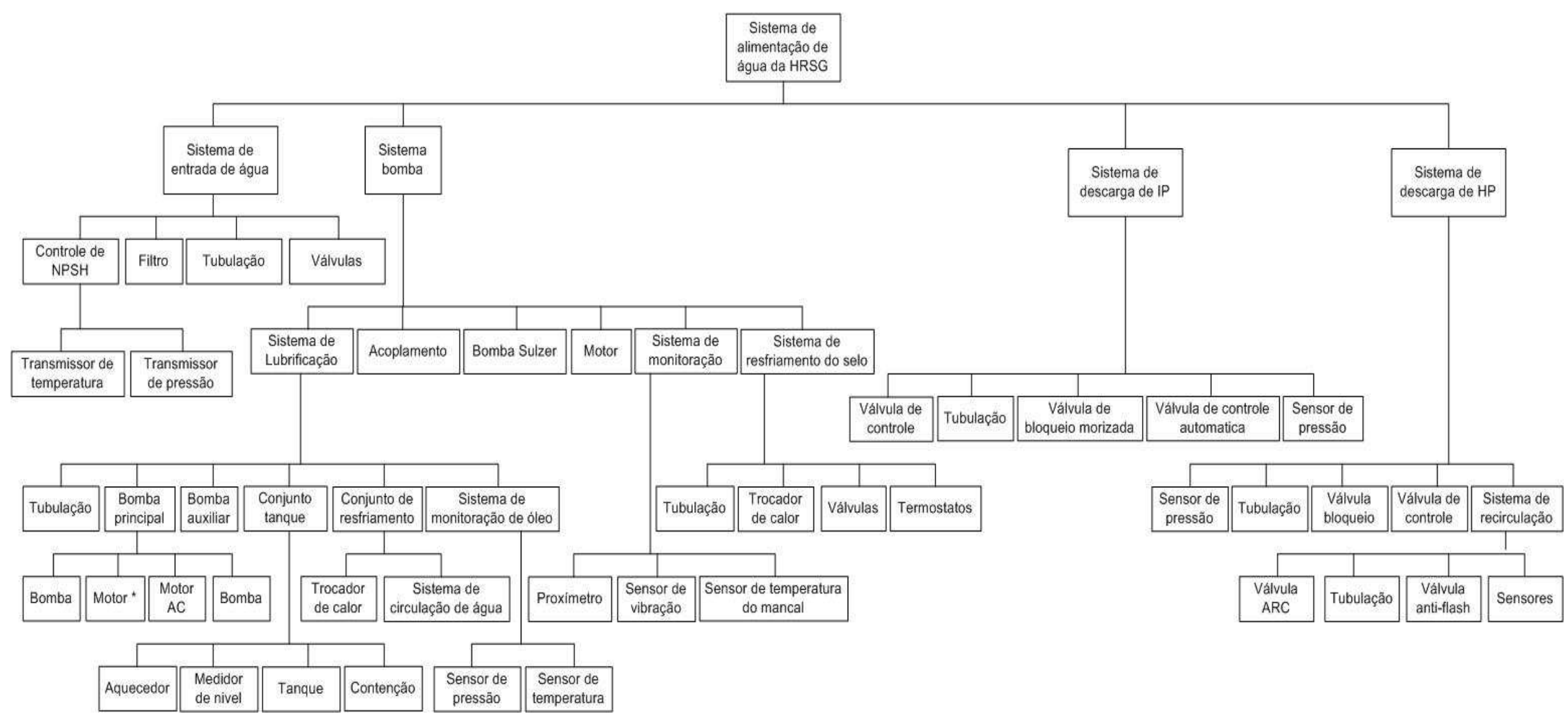

Figura 6.7. Árvore funcional do sistema de alimentação de água da caldeira de recuperação 
É desenvolvida uma profunda análise do sistema, determinando que a usina possui um complexo sistema de controle que alerta a ocorrência de variações dos parâmetros normais de operação. Se algum destes parâmetros se aproxima de níveis perigosos, o sistema de controle dispara uma alerta ou alarme de parada, e no caso do parâmetro não se normalizar, aciona-se uma parada. Estes alarmes são chamados de $T R I P$, traduzido literalmente como tropeço operacional. O trip de máquina é, então, o estado de operação que representa o cenário indesejado. O sistema de controle é denominado de DCS (Distributed Control System) e é composto por uma grande quantidade de sensores e equipamentos de medição, sistemas de armazenamento e processamento de dados e programas e equipamentos de interfase que permitem o acompanhamento da operação através das telas de controle.

A dificuldade em identificar os eventos iniciadores é resolvida logo após a criação de uma relação direta entre os dados fornecidos pelo sistema de controle e o desempenho real de operação do sistema, ou seja, baseado no sistema de controle e os possíveis TRIPs que o sistema poderia vir a sofrer como consequiência da falha do sistema de alimentação de água da caldeira de recuperação. Os próprios TRIPs são utilizados como eventos iniciadores para a análise do diagrama causa-conseqüência. A Figura 6.8, mostra a imagem capturada do DCS onde identifica-se os eventos denominados como TRIPs que seriam usados para a elaboração do diagrama causaconseqüência.

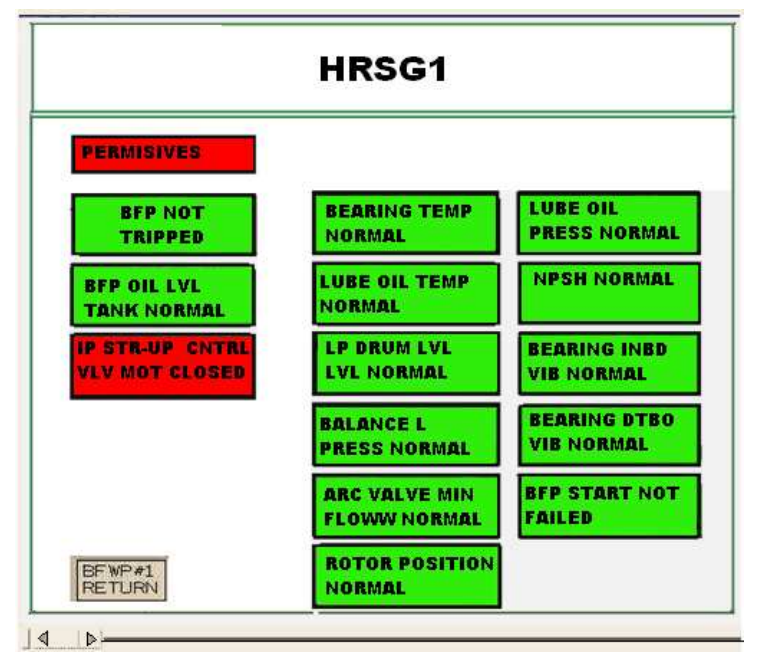

Figura 6.8. TRIPs do sistema de alimentação de água da HRSG 1 (Adaptado) 
Os TRIP's indicam que estes eventos não estão acontecendo e podem passar a cor vermelha, indicando que estão acontecendo. Estes possíveis eventos são associados ao sistema de alimentação de água das caldeiras e causam a parada da unidade geradora ou saída forçada por atuação do próprio sistema de proteção, que são usados como pontos de partida para a elaboração do diagrama causa-conseqüência e são apresentados na Tabela 6.4.

Tabela 6.4. Lista de eventos iniciadores do diagrama causa-conseqüência

\begin{tabular}{ll}
\hline Sistema & Evento TRIP \\
\hline Bomba de múltiplos estágios & Elevada temperatura do mancal da bomba de múltiplos estágios \\
$\begin{array}{l}\text { Bomba de múltiplos estágios/ } \\
\text { Sistema de lubrificação }\end{array}$ & $\begin{array}{l}\text { Alta temperatura do óleo de lubrificação da bomba de múltiplos } \\
\text { estágios. }\end{array}$ \\
Bomba de múltiplos estágios & Baixo nível no tanque de baixa pressão ou problemas no NPSH \\
Bomba de múltiplos estágios & Alta pressão na linha de balance \\
Válvula ARC & Alto nível de re-círculo pela válvula ARC \\
Bomba de múltiplos estágios & Deslocamento do rotor da bomba de múltiplos estágios \\
Sistema de lubrificação & Baixa pressão do óleo de lubrificação \\
Bomba de múltiplos estágios & Alteraçães no NPSH \\
Bomba de múltiplos estágios & Alta vibração no mancal na bomba de múltiplos estágios \\
$\begin{array}{l}\text { Sistema de alimentação de água } \\
\text { da caldeira de recuperação. }\end{array}$ & $\begin{array}{l}\text { Sistema de alimentação de água da caldeira de recuperação com } \\
\text { falha }\end{array}$ \\
\hline
\end{tabular}

A elaboração dos diagramas causa-conseqüência atende a uma lógica seqüencial de ocorrência dos eventos, permitindo identificar as barreiras (ou a falta destas) e as consequiências provocadas pela falha. São definidos como barreira os sistemas ou componentes de segurança que são instalados em determinados sistemas com a finalidade de conter a propagação de um determinado perigo.

O diagrama causa-conseqüência que representa a ocorrência de falhas graves relacionadas no o sistema de alimentação de água das caldeiras de recuperação é apresentado na Figura 6.9. 


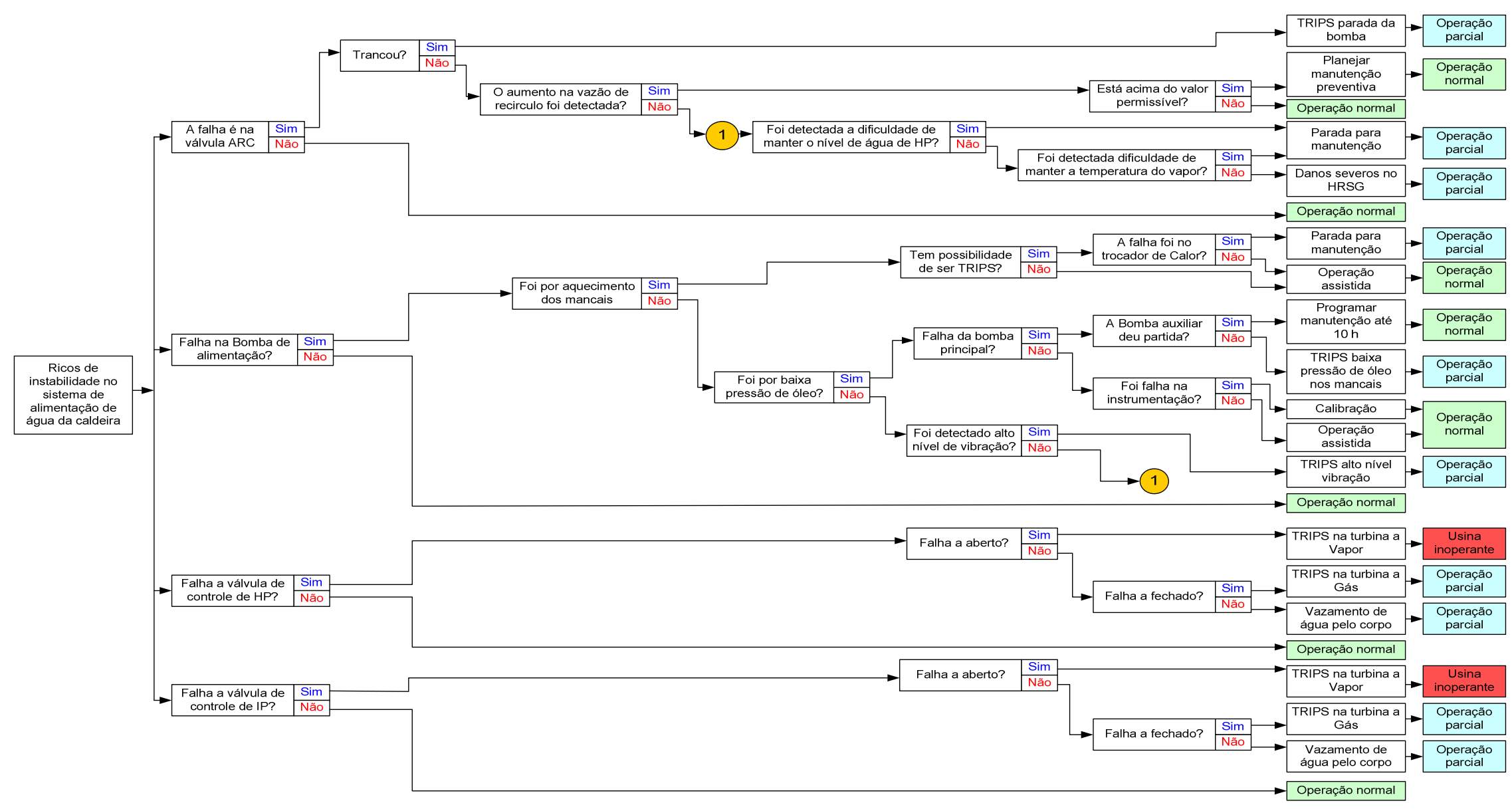

Figura 6.9. Diagrama Causa-Conseqüência para o sistema de alimentação de água da caldeira de recuperação 
Da elaboração do diagrama são obtidas informações e conclusões preliminares importantes para dar continuidade à implementação do método.

O diagrama causa-conseqüência da Figura 6.9 descreve, na parte inicial (esquerda), a possibilidade da ocorrência de instabilidade do sistema de alimentação de água na caldeira de recuperação. Este fenômeno pode ser ocasionado pela ocorrência de outros quatro eventos descritos na sequiência do diagrama: uma falha na válvula ARC (Automatic Recirtulation Valves), falha na bomba de alimentação (chamada também como bomba principal de múltiplos estágios) e falhas nas válvulas de controle de alta e média pressão, respectivamente denominadas de HP (High Pressure) e IP (Intermediate Pressure).

No caso de ocorrência de uma falha na válvula $\mathrm{ARC}$, podem ser identificadas algumas causas de falha, tal como a obstrução da válvula que ocasionará o bloqueio do sistema de recirculação, que ocasionam a parada ou TRIP de máquina, chamado de "sistema de alimentação de água da caldeira de recuperação com falha" e a conseqüente parada da caldeira de recuperação de calor pelo sistema de segurança.

Se a falha não estiver relacionada com o bloqueio da válvula, e sim com o desgaste interno provocado por fenômenos como flash, cavitação e/ou o próprio desgaste mecânico da válvula, o sistema de circulação de água apresenta uma condição de aumento na vazão de água de recirculação. O mesmo pode estar acima do valor máximo permissível e ocasionará o TRIP de máquina chamado "Alto nível de recirculação pela válvula ARC" e, por ser uma ocorrência gravíssima, pois a perda de vazão de água para o sistema de alta pressão de vapor pode ocasionar acidentes gravíssimos como a própria explosão da caldeira. O sistema de segurança da usina aciona a parada do sistema para possibilitar a intervenção de forma corretiva no sistema de alimentação de água, substituindo o componente "válvula ARC". 
Se o nível de re-círculo não estiver acima do valor permissível, o sistema operará com normalidade ou passará por uma condição de "Operação Assistida", onde o operador encarregado está obrigado a monitorar os parâmetros de operação auxiliados pelo sistema de controle (DCS). Como produto da elaboração do diagrama causaconsequiência, é possível determinar a necessidade, neste ponto em especial (nesta condição operacional específica), da instalação de um sistema que atue como barreira e permita controlar ou prevenir a evolução da falha, em função da redução de vazão de água. Neste estado, em que o sistema apresenta um aumento na vazão de recirculação, existe a possibilidade da falha não ser detectada pelos sensores de vazão instalados no sistema. Esta não detecção pode ser associada à falha do próprio sensor (sensor de vazão). Para estes sensores é atribuída uma confiabilidade de 98,34 \% (OREDA, 2002), que é superior a confiabilidade de componentes mecânicos tradicionais, estimada para um ano de operação. No entanto, mesmo com uma confiabilidade alta, estes sensores são propensos a falhar por problemas de calibração, e erro na montagem, entre outros. (KHAN e HADDARA, 2003).

Na condição operacional de aumento de vazão de água de recirculação pela válvula ARC, produto do dano interno da mesma, e este aumento não sendo detectado, o sistema podem chegar a outros dois estados de segurança que permitem a contenção da propagação da falha. O primeiro estado de segurança é obtido com auxilio de um sensor que envia um sinal que indica "dificuldade para manter o nível de água no coletor de vapor de alta pressão (HP)" no sistema de controle. Para este tipo de sensor é atribuída uma confiabilidade de 95,60\%, considerando um ano de operação. (OREDA, 2002).

O segundo estado de segurança, no caso de não ser detectada esta instabilidade do vapor no coletor de HP, é proporcionado pela instalação de outro sistema que atua como barreira que permite identificar a "dificuldade para manter a temperatura do vapor" no sistema de controle. Para estes sensores de temperatura é atribuída uma confiabilidade de 99,20\% para todos os modos de falha em um ano de operação $\left(1,82 \times 10^{-6}\right.$ falhas/hora) (RAC, 1997). Em outras palavras, para estes sensores (sistemas de segurança) também são muito baixas as possibilidades de virem a falhar. Entretanto, frente à ocorrência de falha em todas as barreiras do sistema, as conseqüências seriam 
de danos severos à caldeira de recuperação, sem mensurar o dano relacionado aos operadores e/ou ao meio ambiente.

Considerando a primeira etapa do diagrama causa-conseqüência apresentado na Figura 6.8, pode-se observar que esta análise representa de forma muito clara o cenário de operação, e também permite uma clara identificação de barreiras instaladas para evitar a ocorrência de falhas severas que ocasionem consequiências altamente perigosas. Se o sistema não as possuía, a análise proporciona uma adequada estratégia para indicar onde estas deveriam ser instaladas. Desta forma, são evitadas perdas em reparos no sistema, bem como a perda de capacidade operacional.

A segunda etapa do diagrama causa-conseqüência está relacionada com a possibilidade de ocorrência de falha na bomba de alimentação de água da caldeira chamada de bomba principal de múltiplos estágios no contexto do trabalho. No caso de falhas na bomba que atentem contra a segurança da operação do sistema, o sistema aciona uma série de possíveis TRIPs como mecanismo de segurança. Um destes está representado no diagrama como "aumento na temperatura dos mancais da bomba", por exemplo. O sistema de segurança de detecção do aumento de temperatura pode indicar um risco de $T R I P$, se este aumento for muito elevado (acima de $200^{\circ} \mathrm{C}$ ), supondo que o problema é no sistema de resfriamento de óleo dos mancais da bomba. Se a falha aparece nos trocadores de calor, será necessária uma parada para manutenção corretiva. Se a falha não é no sistema de resfriamento (nos trocadores de calor), o sistema entrará na condição de "operação assistida" para acompanhar certas alterações nos parâmetros operacionais do sistema e permitira ao operador tomar decisões para garantir a disponibilidade e segurança da usina termelétrica.

A condição operacional de aumento na temperatura do óleo de lubrificação é considerada de baixo risco, mas será necessário optar pela condição de operação assistida como medida preventiva. Se a falha no sistema "bomba principal" não for ocasionada pelo aumento da temperatura do óleo de lubrificação, é possível pensar, em função da análise do tipo FMEA, que a causa da instabilidade no sistema de óleo da 
bomba é consequiência da queda na pressão, que pode ser causada pela falha na bomba principal de alimentação de óleo.

Se a bomba principal de alimentação de óleo estiver em estado de falha, entra em operação uma bomba auxiliar de óleo dos mancais, permitindo preparar uma parada para manutenção em um prazo de até 10 horas, que é o tempo em que a bomba auxiliar garante suportar o sistema em plena carga, sendo esta uma condição operacional particular da usina sob análise. A existência de sistemas redundantes é um mecanismo de segurança muito utilizado para componentes críticos e de vital importância operacional e, em alguns casos, indiscutivelmente necessários.

Por outro lado, se a bomba auxiliar apresentasse falha neste período (10 horas), imediatamente o sistema de monitoração dispara o TRIP de segurança "baixa pressão do óleo de lubrificação" e o sistema de alimentação de água é paralisado. A bomba principal de alimentação de água da caldeira ainda pode vir a apresentar estado de falha causado por falha no sistema de instrumentação, levando a disparar um TRIP e torna-se necessária uma parada para calibração dos sensores.

Se o sistema de óleo dos mancais não apresenta irregularidades, a causa da falha na bomba poderá estar relacionada com problemas de vibração. A bomba principal de água possui um complexo sistema de monitoração de vibração que monitora o comportamento da bomba. Desta forma, diante da ocorrência de uma anomalia, o sistema de monitoração e segurança ativa o TRIP "alta vibração no mancal na bomba de múltiplos estágios", que pode levar a equipe de manutenção a executar a calibração dos sensores ou a intervenção para corrigir algum problema mais complexo.

Estes tipos de sensores de vibração, segundo a IEEE Std 500-1984 (1984), são caracterizados por uma taxa de falha equivalente a $1,23 \times 10^{-6}$ falhas/hora, ou $98,92 \%$ de confiabilidade para um período operacional de 8760 horas. Desta forma, é considerada baixa a possibilidade de ocorrência de falhas em relação a outros sistemas que operam 
no conjunto. Mas, no caso de ocorrência de falha no sistema, o sistema de segurança possui barreiras que impedem uma falha catastrófica. Tais barreiras se repetem como no primeiro ramo do diagrama, indicado pelo número um (1), e garantem possibilidade de manobras ou ações antes da ocorrência da falha catastrófica.

Para terminar a análise do diagrama causa-conseqüência, este representa a possibilidade de falhas das válvulas de controle do sistema de média pressão (IP) e de alta pressão de vapor (HP). Diante da possibilidade de falha no fechamento das válvulas (quando a válvula perde a capacidade de fechar), o sistema dispara um TRIP de segurança para a parada da turbina a vapor, ocasionando, conseqüentemente, a parada completa da usina, incluindo os dois ciclos, turbina a gás - HRSG, isto devido ao particular projeto da usina sob análise.

Já no caso de apresentar falha por bloqueio ou falha fechada (quando a válvula perde a capacidade de abrir), o TRIP de segurança aciona um procedimento de parada para a turbina a gás, ocasionando a parada de um dos sistemas turbinas a gás -HRSG. Desta forma, o sistema apresenta a redução de potência, para menos de $50 \%$ da potência nominal instalada, e implementado em todos os prejuízos ao agente operador do sistema de geração.

Da mesma forma como nas outras etapas da análise, como produto da implementação da análise do diagrama causa-conseqüência, há algumas considerações a serem ressaltadas, descritas a seguir.

O diagrama causa-consequiência permite representar a operação do sistema de uma forma muito clara, como afirmado na revisão bibliográfica e como foi apresentado anteriormente. Mas, por outro lado, permite também a identificação de onde poderiam ser instaladas barreiras de segurança operacional. O diagrama mapeia de forma clara onde estes sistemas de segurança (barreiras) poderiam ser instalados de forma a tornar a operação mais segura, e desta forma garantir alta disponibilidade no caso da existência dos sistemas redundantes. O diagrama permite às equipes de operação e manutenção 
selecionar mecanismos e sistemas específicos para conter as potenciais falhas, já que identifica os parâmetros a serem controlados (pressão, temperatura, entre outras, para este exemplo em particular). Se o sistema já as possui, a correta operação e/ou utilização destas barreiras poderão conter a propagação de uma potencial falha e até mesmo evitálas quando acompanhadas de um adequado sistema de controle.

Do ponto de vista operacional ou técnico, podem ser também mencionadas algumas considerações como:

- A detecção de uma falha pelas diversas barreiras de segurança, neste caso em especial, que possui um complexo sistema de monitoração, implicar em um TRIP de máquina, que produzem um alarme ou a paralisação da operação do sistema, evitando desta forma danos severos aos equipamentos e principalmente ao pessoal encarregado da operação e manutenção que trabalham nos arredores das máquinas.

- A implementação do diagrama causa-conseqüência na usina termelétrica de geração de energia elétrica permite identificar três cenários principais de operação, no caso de ocorrências de falhas e permite também identificar os diferentes caminhos que levam a uma determinada condição operacional. Os três cenários principais são: operação normal, operação parcial e parada do sistema ou usina inoperante.

- Com o conhecimento das causas e consequiências de determinadas falhas e seus caminhos lógicos, o analista poderá determinar a necessidade de instalação de barreiras que garantam a segurança ou a alta disponibilidade da usina. No caso específico da implementação do método para o sistema de alimentação de água das caldeiras, estes cenários permitirão no decorrer da sua implementação, a tomada de decisão em relação à instalação de um sistema redundante de alimentação de água da caldeira de recuperação.

É importante destacar que os modos de falha identificados na análise do tipo FMEA como os mais severos e, conseqüentemente, aos componentes que os geram, coincidem com os modos de falha ocasionadores de TRIPs. O método mostra que uma 
análise de Modos e Efeitos de Falha, conscientemente elaborada, permite identificar fraquezas do sistema em função da ocorrência de alguns modos de falhas em componentes críticos. Assim, no caso do sistema sob análise não possuir um complexo sistema de monitoração (não se tenham TRIPs), os eventos de maior severidade selecionado pelo FMEA, podem ser utilizados como eventos iniciadores para a elaboração do diagrama causa-conseqüência.

Na seqüência da implementação do método é quantificado o risco, em duas etapas principais: a primeira é a determinação dos parâmetros relacionados com as ocorrências de falhas. Com o auxílio dos históricos de operação são calculadas as probabilidades de falhas e suas respectivas distribuições de confiabilidade. A segunda etapa está relacionada com a determinação dos custos relacionados com a ocorrência destas falhas. Na seqüência do trabalho são apresentadas todas estas análises.

\subsection{Quantificação do Risco - Sistema de Alimentação da Caldeira de Recuperação}

Para a quantificação do risco, inicialmente, são levantados os dados referentes à operação do sistema, baseados nas próprias fontes do agente operador da usina termelétrica. Após analisar os dados históricos, foi possível identificar que o sistema de alimentação de água da caldeira de recuperação é visto como um sistema de dois componentes: a própria bomba de água e o sistema automático de recirculação de água. Desta forma, nas Tabelas 6.5. a 6.8 são apresentados os registros de operação para cada um dos sistemas selecionados para a análise: duas bombas de alimentação de água das caldeiras de recuperação, dois sistemas de recirculação de água (válvulas ARC) e dois sistemas de alimentação de água da caldeira de recuperação.

Nestas tabelas são apresentados basicamente os tempos de operação e os tempos que foram utilizados para intervenções de manutenção corretiva. É importante destacar que todos estes dados analisados passaram por uma cuidadosa filtragem, de forma que representem as paradas dos sistemas por falhas deles mesmos, ou seja, o sistema em alguns casos indica a parada do sistema de alimentação, mas esta é ocasionada pela 
ocorrência de algum problema externo, como por exemplo, a falta de energia elétrica. Assim, se a bomba de alimentação não opera em um período determinado, causado por uma parada forçada da turbina a gás, o tempo é desconsiderado, pois a falha não é no elemento "bomba de alimentação".

Tabela 6.5. Dados de operação da bomba 1

\begin{tabular}{llrr}
\hline Descrição da Falha da Bomba Principal 1 & \multicolumn{1}{c}{$\begin{array}{c}\text { T. } \\
\text { Operação } \\
\text { (horas) }\end{array}$} & $\begin{array}{c}\text { T. Parada } \\
\text { (horas) }\end{array}$ \\
\hline 1 & Falha na bomba de alimentação. & 5125,76 & 14,23 \\
2 & Bloqueio da bomba de alimentação. & 8785,18 & 16,26 \\
3 & Vazamento no sistema de lubrificação da bomba alimentação. & 3120,30 & 5,08 \\
4 & Quebra da bomba de óleo de lubrificação dos mancais. & 10887,70 & 41,68 \\
5 & Anomalia no sistema de lubrificação da bomba de alimentação. & 615,28 & 2,03 \\
6 & Vazamento de água de resfriamento. & 9267,18 & 35,58 \\
7 & Falha na manutenção & 5202,51 & 30,50 \\
8 & Quebra da bomba de óleo de lubrificação dos mancais. & 357,58 & 43,71 \\
9 & Alta vibração dos mancais da bomba. & 33,93 & 10,16 \\
10 & Falsa indicação do sensor de posição do rotor. & 671,66 & 45,75 \\
\hline
\end{tabular}

Tabela 6.6. Dados de operação da bomba 2

\begin{tabular}{llrr}
\hline Descrição da Falha da Bomba Principal 2 & T. Operação (horas) & $\begin{array}{c}\text { T. Parada } \\
\text { (horas) }\end{array}$ \\
\hline 1 & Alta temperatura do óleo de lubrificação. & 14439,88 & 3,76 \\
2 & Vazamento de água na selagem do mancal. & 14129,73 & 0,90 \\
3 & Vazamento de água na selagem da bomba. & 4462,46 & 3,68 \\
4 & Vazamento de água de resfriamento. & 2511,75 & 5,40 \\
5 & Vazamento de água de resfriamento. & 237,91 & 4,50 \\
\hline
\end{tabular}

Tabela 6.7. Dados de operação de válvula ARC 1

\begin{tabular}{llrr}
\hline Descrição da Falha da Válvula de Re-círculo ARC 1 & T. Operação (horas) & $\begin{array}{l}\text { T. Parada } \\
\text { (horas) }\end{array}$ \\
\hline 1 & $\begin{array}{l}\text { Desarme por baixo nível tambor média pressão, } \\
\text { aumento da vazão de re-círculo }\end{array}$ & 3087,15 & 0,68 \\
2 & $\begin{array}{l}\text { Desarme por Alta Temperatura no tanque de alta } \\
\text { pressão, aumento da vazão de re-circulo. }\end{array}$ & 2057,88 & 0,06 \\
3 & Parada para sanar defeito válvula by-pass alta pressão & 1180,25 & 6,55 \\
4 & $\begin{array}{l}\text { Desarmou com 154MW devido alta temperatura no } \\
\text { by-pass }\end{array}$ & 28989,18 & 1,56 \\
5 & A válvula ARC quebrou no testes. & 6401,36 & 96,08 \\
6 & Alto nível de re-círculo pela válvula ARC. & 482,23 & 32,48 \\
7 & Alto nível de re-círculo pela válvula ARC. & 54,3 & 39,48 \\
8 & Alto nível de re-círculo pela válvula ARC. & 217,75 & 1,45 \\
\hline
\end{tabular}


Tabela 6.8. Dados de operação de válvula ARC 2

\begin{tabular}{llcr}
\hline Descrição da Falha da Válvula de Re-círculo ARC 2 & T. Operação (horas) & $\begin{array}{c}\text { T. Parada } \\
\text { (horas) }\end{array}$ \\
\hline 1 & $\begin{array}{l}\text { Desligamento para manutenção válvula by-pass vapor } \\
\text { reaquecido. }\end{array}$ & 3093,11 & 1,95 \\
2 & $\begin{array}{l}\text { Desarme por alta temperatura sistema by pass vapor } \\
\text { reaquecido. }\end{array}$ & 705,30 & 4,41 \\
3 & $\begin{array}{l}\text { Desligamento para sanar vazamento na válvula de } \\
\text { equalização caldeiras }\end{array}$ & 1701,73 & 11,81 \\
4 & Vazamento na junta da ARC. & 1707,76 & 19,11 \\
\hline
\end{tabular}

Os dados da operação dos sistemas correspondem a um período operacional de cinco anos, e a partir destes são calculadas as distribuições de confiabilidade e mantenabilidade, assim como os respectivos parâmetros das distribuições. Tudo isto para obter os dados de probabilidade de falha dos sistemas que permitam a avaliação do risco. A forma de estimar estas probabilidades é a mesma sugerida por CARAZAS et al., (2007e).

As estimativas das respectivas probabilidades de falha para o componente são executadas com o emprego do programa Weibull++ (REALIASOFT, 2006), utilizando o método da máxima verossimilhança. As distribuições de confiabilidade são apresentadas nas Figuras 6.10 a 6.13. Junto a estas curvas apresenta-se o intervalo de confiança de $95 \%$ a curva de confiabilidade.

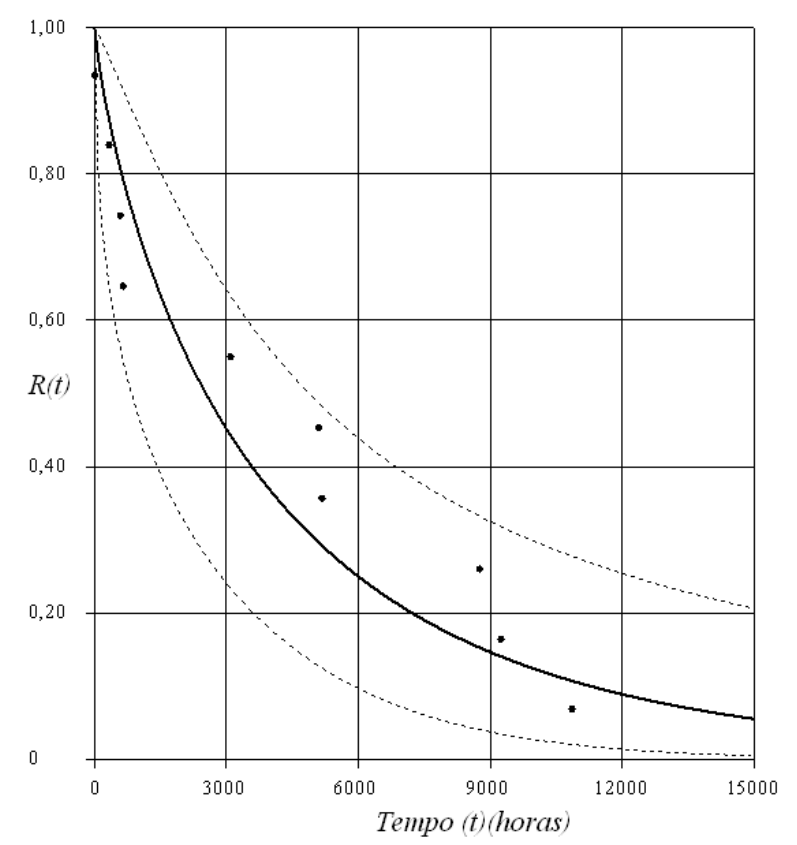


Figura 6.10 Distribuição de confiabilidade da bomba de alimentação 1

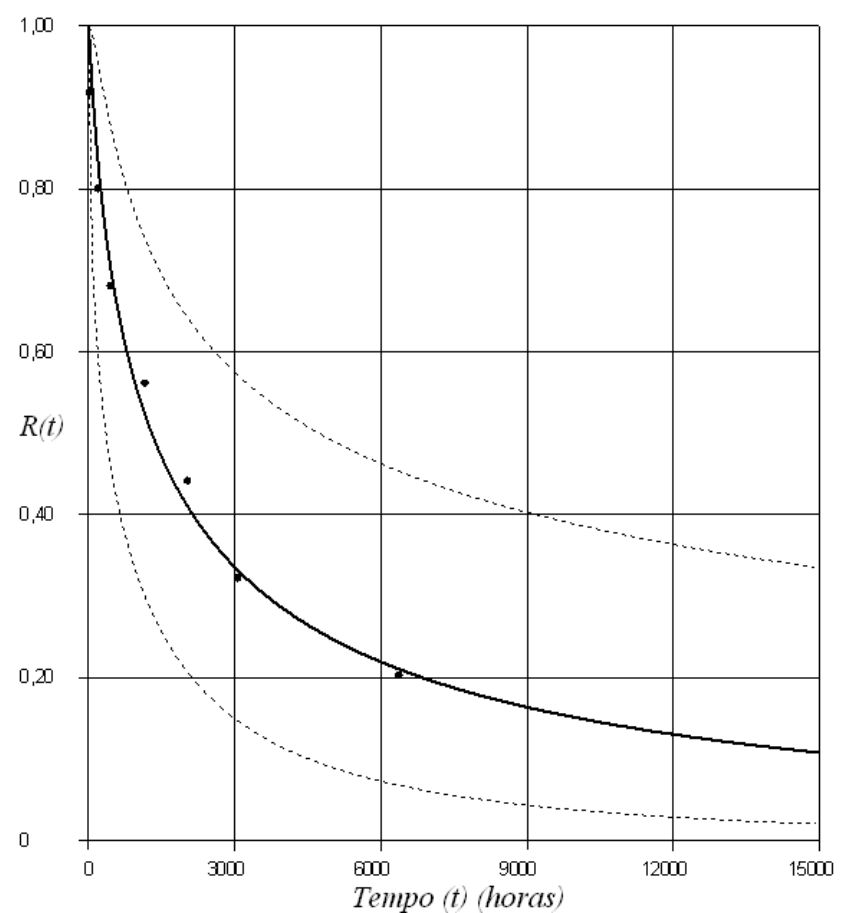

Figura 6.11 Distribuição de confiabilidade da bomba de alimentação 2

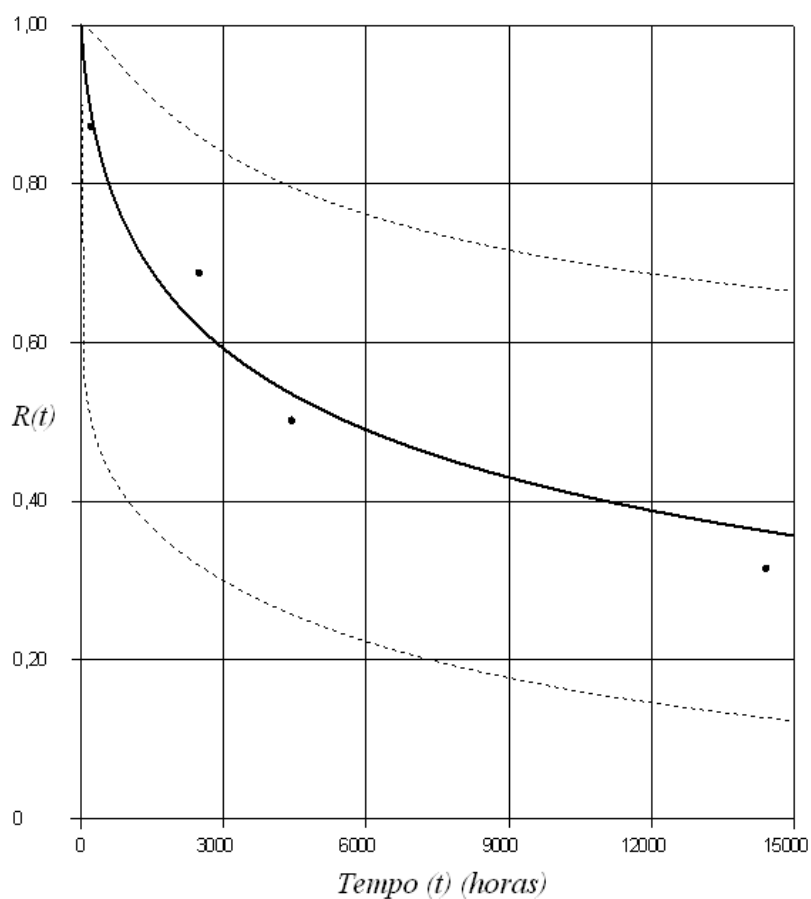

Figura 6.12. Distribuição de confiabilidade da válvula ARC 1 


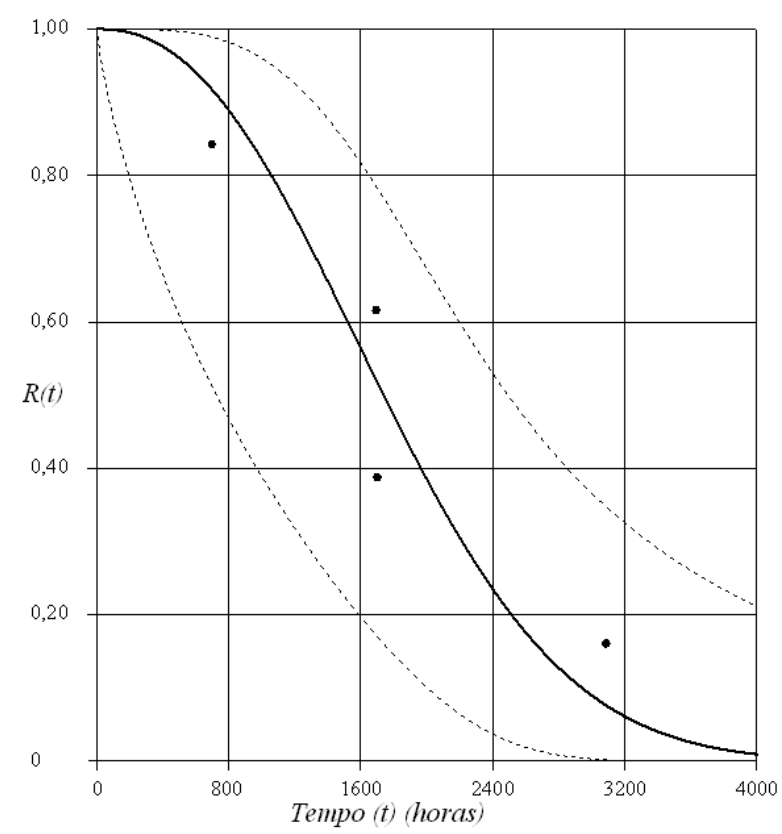

Figura 6.13. Distribuição de confiabilidade da válvula ARC 2

A Figura 6.10, representa a distribuição de confiabilidade da bomba principal 1. Este conjunto, bomba e válvula ARC (Figura 6.11) são os que operaram maior tempo, pois nestes sistemas foram efetuadas as provas iniciais após a montagem. As representações das distribuições de confiabilidade da Figura 6.11 a 6.12 representam o conjunto 2, Bomba de Alimentação 2 e válvula ARC 2. Para representação da confiabilidade destes sistemas é selecionada a distribuição de Weibull com dois parâmetros. Na Tabela 6.9, são apresentados os parâmetros das distribuições das duas bombas de alimentação e das duas válvulas ARC, produto da análise de confiabilidade.

Tabela 6.9. Parâmetros das distribuições de confiabilidade

\begin{tabular}{lccc}
\hline \multicolumn{1}{c}{ Item } & \multicolumn{1}{c}{ Confiabilidade \% } & Beta & Eta \\
& $R(t)=\left(\exp -\left[\frac{t}{\eta}\right]^{\beta}\right)$ & $(\boldsymbol{\beta})$ & $(\boldsymbol{\eta})$ \\
Bomba 1 & & \\
Bomba 2 & 47,33 & 0,6687 & 2223,39 \\
Válvula ARC 1 & 66,67 & 0,7717 & 4655,42 \\
Válvula ARC 2 & 47,34 & 0,6693 & 1851,72 \\
\hline
\end{tabular}


Dos parâmetros das distribuições apresentados na Tabela 6.9, é possível observar que a bomba principal e a válvulas ARC de alimentação de água da caldeira de recuperação possuem confiabilidades modeladas por uma distribuição de Weibull com parâmetro $\beta$ menor que 1,00; o que mostra que o sistema está na fase de mortalidade infantil, dentro da curva da banheira.

Para concluir com a análise de confiabilidade, na Tabela 6.10 são apresentadas as probabilidades de falha calculadas com os parâmetros apresentados na Tabela 6.9, para um período operacional de 1440 horas (dois meses). Este período foi selecionado em função da necessidade de inspeção dos componentes do sistema de alimentação de água da caldeira de recuperação, que normalmente são efetuadas. A escolha deste período é também recomendada pelos especialistas na indústria química, os que consideram como um período razoável para a inspeção dos parâmetros operacionais de máquinas rotativas e seus periféricos (TEIXEIRA, 2006; SCHERER, 2006).

Tabela 6.10. Probabilidades de falha para 1440 horas

\begin{tabular}{lc}
\multicolumn{1}{c}{ Item } & Probabilidade de Falha \% \\
Bomba 1 & 52,66 \\
Bomba 2 & 33,25 \\
Válvula ARC 1 & 52,65 \\
Válvula ARC 2 & 49,63 \\
\hline
\end{tabular}

A segunda análise para a quantificação do risco consiste no levantamento de custos relacionados com os possíveis cenários de falhas. Esta análise é relativamente complexa, devido aos custos relacionados com as falhas dependerem não apenas dos insumos gastos, mas também dos custos com a mão de obra terceirizada, e dos fatores de mercado, por exemplo, o custo do combustível e a expectativa da venda de energia num determinado período do ano.

O sistema elétrico do Brasil se encaixa no modelo de geração basicamente hidrelétrico, que depende de períodos do ano chuvosos para encher os reservatórios das 
usinas hidrelétricas. No entanto, também há os períodos de seca, onde as usinas termelétricas operam de forma complementar. Desta forma, se a parada da usina termelétrica vir a acontecer num período de seca, as perdas são maiores assim como as multas contratuais.

Tais multas são decorrentes do não cumprimento do contrato de fornecimento de energia elétrica, e é a Agência Nacional de Energia Elétrica ("ANEEL") que regula, supervisiona os aspetos do negócio, estabelece as tarifas da energia elétrica, e determina as penalidades, baseadas principalmente na disponibilidade da usina. Destacam-se três penalidades: por insuficiência de lastro de energia; insuficiência de cobertura de consumo e; insuficiência de lastro para venda de potência. Haverão outras penalidades conforme os tipos de Contratos de Comercialização de Energia no Ambiente Regulado (CCEARs). Os CCEARs são contratos bilaterais celebrados entre Agentes Vendedores de energia do Ambiente de Contratação Regulada (ACR), e todos os Agentes de Distribuição, e contemplam cláusulas especifícas com penalidades rigorosas para o caso de indisponibilidade.

Por causa da diversidade de fatores envolvidos na formação do custo da indisponibilidade não é adequado propor a elaboração de uma expressão "fechada", ou seja, uma expressão que contemple um número exato de termos, para representar de uma forma genérica às conseqüências do cenário de falha. Entretanto, é possível supor um cenário "idealmente ruim" ou pessimista, com relação aos custos, sendo suficiente para possibilitar a tomada de decisão com respeito à instalação de um sistema complementar redundante de alimentação de água para as caldeiras de recuperação, dentro do sistema de ciclo combinado.

Desta forma, são três os cenários de operação supostos para a usina termelétrica: Operação Normal (ON), Operação Parcial (OP) e Usina Inoperante (UI). Nestes três cenários estão envolvidos os custos fixos e os custos variáveis. Os denominados custos fixos são os relacionados com o custo do combustível, operação e manutenção e impostos, basicamente. Os custos variáveis estão em função do estado de operação da 
usina e do mercado. O mercado de comercialização de energia, como já foi mencionado, é influenciado por diversos fatores e, conseqüentemente, estes afetam os custos variáveis da usina.

O custo fixo de operação de uma usina de ciclo combinado é difícil de ser calculado, mas, de forma prática, diversos autores propõem formulações resumidas para este cálculo como é o caso da expressão 6.1, para um cenário ideal de operação (HUKAI, 2006):

$$
\text { Custo de Geração/ano }=\text { Custo O\&M/ano }+ \text { Custo do Combustível/ }{ }_{\text {ano }}
$$

onde:

$$
\text { Custo de } O \& M /_{\text {ano }}=5 \% \text { Custo Total do Investimento }
$$

$$
\text { Custo do Combustível/ano }=\text { Consumo das Turbinas } * \text { Custo do Gás Natural }
$$

A Tabela 6.11 apresenta o levantamento e estimativa dos custos relacionados ao consumo de combustível para a usina. O consumo estimado de combustível é de 11,66 $\mathrm{Nm}^{3} / \mathrm{s}$ para cada uma das turbinas a gás. Este dado foi estimado por um cálculo simples, usando como dado de partida o consumo de $9,19 \mathrm{~kg} / \mathrm{s}$ de uma das turbinas a gás para uma rotação de 3600 RPM, quando potência de 150 MW, ou seja, a plena carga. Este dado é adquirido de uma das imagens capturadas das telas de controle fornecidas pelo agente gerador. Assim o cálculo de consumo para as duas turbinas ficou da seguinte forma:

$$
\text { Consumo do Combustivel }=2\left(9,19 \frac{\mathrm{kg}}{\mathrm{g}} \times 0,602 \frac{\mathrm{kg}}{\mathrm{m}^{\mathrm{g}}}\right)=11,66 \frac{\mathrm{Nm}^{\mathrm{s}}}{\mathrm{g}}
$$


Tabela 6.11. Custos do combustível

\begin{tabular}{lcl}
\hline \multicolumn{3}{c}{ Custo do combustível (gás natural) ano } \\
\hline Consumo de combustível & 11,66 & $\mathrm{~m}^{3} / \mathrm{s}$ \\
Densidade do combustível & 0,602 & $\mathrm{~kg} / \mathrm{m}^{3}$ \\
Horas de operação & 8760 & Horas/ano \\
Preço do gás natural & 0,149 & US $\$ / \mathrm{Nm}^{3}$ \\
Custo do combustível por ano & $\mathbf{5 4 ~ 8 2 5 ~ 1 0 9 , 7 7}$ & US $\$ / \mathrm{ano}$ \\
\hline
\end{tabular}

Para o caso em estudo, estima-se o custo de operação anual em US\$ 127150219,54, para um cenário ideal de operação de 8760 horas, com disponibilidade de gás permanente. Este valor é equivalente a 5\% do investimento total de U\$ 350 milhões somado ao custo do combustível por ano (HUKAI, 2006).

Como apresentado no Capítulo 4, os custos relacionados com as multas contratuais em caso de indisponibilidade são desprezados para o cálculo. Para a representação dos cenários de operação parcial e inoperante, os custos podem ser resumidos pelas expressões 6.5 e 6.6 da seguinte forma:

O custo da manutenção corretiva é calculado por:

$$
C_{M C}=C_{H E}+C_{C T}+C_{P R}+C_{C S}
$$

onde:

$\mathrm{C}_{\text {M.C.: }}$ Custo da manutenção corretiva (US\$);

$\mathrm{C}_{\mathrm{HE}}:$ Custo de horas extras (US\$);

$\mathrm{C}_{\mathrm{CT}}$ : Custo da contratação de mão de obra terceirizada (US\$);

$\mathrm{C}_{\mathrm{CS}}$ : Custo de matérias consumíveis e peças de reposição (US\$)

Para o cálculo do Custo de Compra de energia é usada à expressão 6.6:

$$
C_{\text {compra }}=(G F-C A) \times P \times H M
$$


onde,

$C_{\text {compra }}=$ Custo da compra de energia em um mês futuro (US\$)

$G F=$ Garantia física (energia assegurada) (MW médios)

$C A=$ Compra atual de energia $(\mathrm{MWh})$

$P=$ Preço da energia comprada (US\$/MWh)

$H M=$ Horas do mês $(\mathrm{h})$

Para o cálculo dos custos relacionados com a indisponibilidade, especificamente provocada pela falha do sistema de alimentação de água das caldeiras de recuperação, são levantados os custos do próprio histórico de operação da máquina que são fornecidos pela equipe de manutenção da usina. Assim, na Tabela 6.12 são apresentados os custos relacionados com uma falha grave na bomba de alimentação da caldeira de recuperação 1. Estes custos referem-se a uma intervenção de grande porte, denominada de "reparo total da bomba" que, no momento, representou a perda de um dos dois conjuntos de turbina a gás - HRSG, e que, conseqüentemente, gerou o cenário definido como "operação parcial ou simplesmente OP". Para um estado de falha ainda mais crítico, o caso de uma parada geral ou cenário de "usina inoperante UI", considera-se que esta falha na bomba, ocorre com as mesmas características nos dois conjuntos de turbina a gás - HRSG, com a única diferença que, neste caso, soma-se à perda da parada da operação da turbina a vapor.

Tabela 6.12. Custos relacionados com a falha do sistema de bombeio

\begin{tabular}{|c|c|c|c|}
\hline Item & Custo US \$ & $\begin{array}{l}\text { Reparo total da } \\
\text { Bomba US\$ (OP) }\end{array}$ & U. I. US\$ \\
\hline Mão de obra/hora & 14,28 & 228,57 & 457.14 \\
\hline Custo de horas extras & 21,42 & 342,85 & 685,70 \\
\hline $\begin{array}{l}\text { Custo da contratação de mão de obra } \\
\text { terceirizada }\end{array}$ & 14,28 & 2971,42 & 5942,84 \\
\hline $\begin{array}{l}\text { Custo de matérias consumíveis e peças de } \\
\text { reposição }\end{array}$ & & 61904,76 & 123809,52 \\
\hline Total & & 65447,60 & 130895,20 \\
\hline
\end{tabular}


Para o cálculo relacionado com a compra de energia, produto de uma parada inesperada para manutenção corretiva, é usada a expressão 6.6, na Tabela 6.13 são levantados os custos do produto deste cálculo. O cálculo representa o cenário de indisponibilidade do sistema para geração e como conseqüência disso a incapacidade para venda de energia elétrica, ou seja, quando os dois sistemas estão paralisados, produzindo o cenário de Usina Inoperante "UI" (o pior cenário possível). A garantia física da usina sob análise, em condições normais de operação deveria estar em torno de 500 MW, desta forma, para os cálculos é suposto um cenário de disponibilidade de gás e garantia física de $500 \mathrm{MW}$.

Tabela 6.13. Custos de compra energia para uma parada de 68 horas

\begin{tabular}{lr}
\hline \multicolumn{1}{c}{ Item } & (US\$) \\
Garantia Física atual (MW médios) & 550,00 \\
Compra atual de Energia (MW) & 500,00 \\
Preço da energia comprada (US\$/MWh) & 167,22 \\
Horas do mês (h) & 68,00 \\
Custo da compra de energia em um mês futuro & 568 568,40 \\
\hline
\end{tabular}

\subsection{Avaliação do Risco e Tomada de Decisão}

Frente à necessidade de tomar uma decisão, em relação à mudança da estratégia de planejamento da manutenção ou à modificação do projeto inicial de uma instalação industrial, indiscutivelmente encontrar-se-á incertezas relacionadas às hipóteses e variáveis empregadas para modelar o problema de decisão. Por este motivo, é que as decisões a serem tomadas têm que estar bem estruturadas para um correto processo de decisão. Assim, em sintonia com a proposta do método de decisão, a seguir são apresentados os passos ou etapas que devem ser seguidas para a tomada de decisão da instalação de um sistema redundante de alimentação de água para as caldeiras de recuperação em uma instalação de geração de energia termelétrica a ciclo combinado. 


\subsubsection{Identificação da Natureza}

Baseado no exposto no Capítulo 4, onde é apresentado o método para a tomada de decisão e descritos os tipos de natureza dos problemas de decisão, é possível encaixar o problema de decisão analisado como do tipo semi-estruturado, pois se tem conhecimento das consequiências de algumas operações, mas algumas outras consequiências têm comportamento variável, que podem influenciar no resultado da decisão. Estes resultados são influenciados principalmente pelas consequiências do tipo econômico, que não possuem dependência com a natureza da operação e sim com as mudanças dos cenários comerciais de geração de energia elétrica no Brasil.

\subsubsection{Identificação das Alternativas}

As alternativas para garantir alta disponibilidade da usina termelétrica são: a) modificação do projeto atual da usina com a instalação de um sistema redundante de alimentação de água para as duas caldeiras ou; b) dois sistemas redundantes de alimentação de água, um para cada caldeira e; c) modificação na política de manutenção.

A decisão por qualquer das alternativas que garantem a alta disponibilidade da usina é considerada de alta responsabilidade, e considerada do tipo estratégico, isto em virtude de que as mudanças na usina afetarão o resultado das operações da usina nos próximos 2 a 5 anos.

\subsubsection{Classificação dos Problemas de Decisão}

O problema de decisão é classificado como um problema semiestruturado do tipo estratégico, com incerteza ou risco. Os cenários possíveis causados 
pela quebra ou perda de desempenho do sistema de alimentação de água das caldeiras de recuperação, poderiam ser os mais diversos, incluindo a parada total da usina.

Através da análise de risco e a elaboração do diagrama causaconsequiência, as incertezas associadas a um determinado cenário de operação são modeladas e caracterizadas as necessidades de barreiras que atuem como sistemas de segurança e/ou sistemas que venham a garantir uma alta disponibilidade. Por outro lado, por meio da análise dos dados históricos de operação é possível calcular as probabilidades de falha associadas ao sistema de bombeamento e ao sistema de recirculação de água. Combinando estas duas análises é possível construir os possíveis cenários de falha.

\subsubsection{Seleção do Método de Tomada de Decisão}

O método de tomada de decisão será a árvore decisão, pois baseado na estrutura de cenários de operação e falhas apresentados no decorrer do trabalho de pesquisa, verifica-se a necessidade de um método flexível que permita simular cenários complexos, motivo pelo qual é selecionada esta técnica.

\subsubsection{Solução do Problema de Decisão}

A solução do problema de decisão segue os passos apresentados de forma gráfica, em conformidade com a natureza da árvore de decisão. O primeiro passo refere-se a uma tomada de decisão, a qual envolve a instalação de um sistema redundante para o sistema de alimentação de água das caldeiras de recuperação, um sistema para as duas caldeiras. A Figura 6.14 representa o primeiro passo já dentro de uma árvore de decisão.

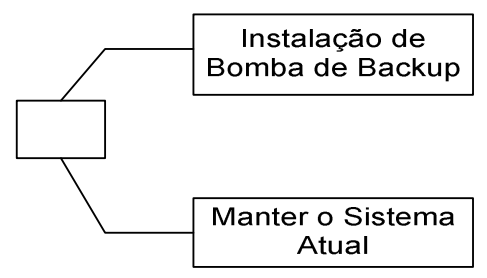


Figura 6.14. Representação da primeira etapa da decisão

A segunda etapa para a solução do problema de decisão é representada pela Figura 6.15, onde as probabilidades de falha do sistema de bombeio são incluídas para representar de uma forma mais clara o cenário para a tomada de decisão.

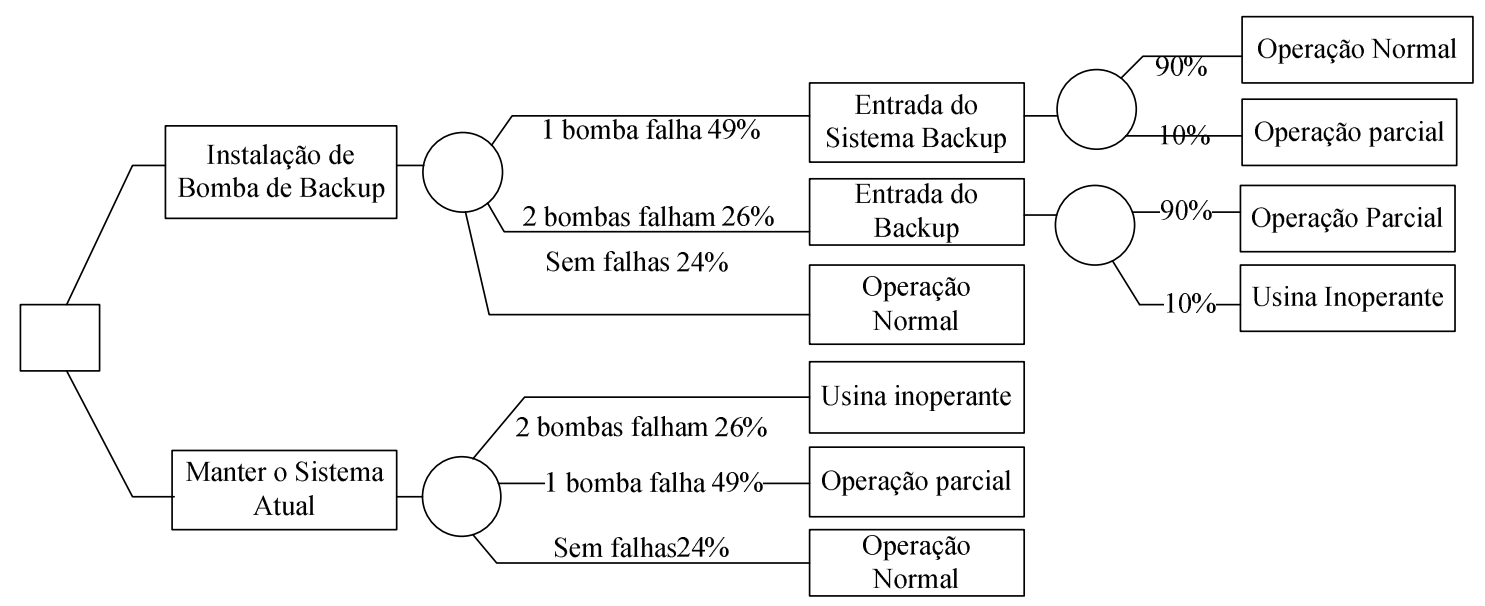

Figura 6.15. Representação da decisão

A probabilidade de falha do sistema de bombeio de água de alimentação da caldeira de recuperação selecionada é a menos favorável, definida a partir da análise feita para o cálculo das probabilidades de falhas. Ou seja, dos dois sistemas analisados, é selecionada a probabilidade de falha do elemento bomba de alimentação e ARC que possuíam a maior ocorrência de falhas, com valor da probabilidade de falha equivalente a $49 \%$.

As probabilidades de falha relacionadas com a operação das duas bombas são calculadas como se estes eventos fossem independentes, ou seja, multiplicando-se as probabilidades de falha dos dois sistemas de bombeamento. A probabilidade da bomba reserva falhar em modo passivo é estimada em 10\%, o que reflete o pior dos cenários para sistemas desta natureza (KRISHNASAMY et al., 2005).

Para a avaliação do problema de decisão, considera-se um ciclo de operação de 1440 horas. Este é o tempo estimado entre atividades de manutenção, 
pressupondo que o sistema de bombeio retorna a um estado de operação "tão bom quanto novo", hipótese suposta pela literatura da manutenção para sistemas reparáveis (SOUZA, 2003; LEWIS, 1987).

O cálculo das probabilidades apresentadas na árvore é detalhado resumidamente a seguir. A probabilidade de dois sistemas falharem é expressa pela eq. 6.7.

$$
P_{2 \text { bombas falhar }}=P_{\text {bomba1 fahar }}=P_{\text {bomba2falhar }}
$$

A probabilidade de uma bomba falhar é determinada pela combinação do sistema de bombeio "Bomba 1" falhar e "Bomba 2" não falhar. ou o sistema de bombeio "Bomba 2" falhar e "Bomba 1" não falhar. Esta relação é expressa pela equação 6.8 .

$$
P_{\text {ibomba fahar }}=\left(P_{\text {bomba } 1 \text { falhar }}+R_{\text {bomba } 2}\right)+\left(P_{\text {bomba } 2 \text { fahar }} R_{\text {bomba } 1}\right)
$$

Nas Tabelas 6.14 e 6.15 são apresentados os custos para cada uma das condições de operação, tanto no caso do investimento de instalação do sistema de bombeio redundante como no caso de manter a instalação sem alterações. Supondo que cada uma das falhas ocorridas produziria à usina todos os gastos relacionados com uma parada ocorrida por um período de 68 horas que, segundo a análise dos dados históricos de operação foi a pior das ocorrências, conforme a análise dos históricos de operação e o discutido com o pessoal de O\&M da usina. (Informação obtida em entrevista com os operadores, Scherer, 2006).

Tabela 6.14. Custos dos cenários de operação com bomba redundante para um período de $1440 \mathrm{~h}$

\begin{tabular}{lrrrr}
\hline Item & \multicolumn{1}{c}{$\begin{array}{c}\text { Custo da Operação } \\
\text { normal (US\$) }\end{array}$} & $\begin{array}{l}\text { Custos } \\
\text { Parcial (US\$) }\end{array}$ & $\begin{array}{c}\text { Operação } \\
\text { inoperante (US\$) }\end{array}$ & $\begin{array}{l}\text { Custos } \\
\text { (Unina }\end{array}$ \\
Custo de operação & 21191703,25 & 21191703,25 & 21191703,25 \\
$\begin{array}{l}\text { Instalação da bomba } \\
\text { Backup }\end{array}$ & 4522608,75 & 4522608,75 & 4522608,75 \\
$\begin{array}{l}\text { Compra de energia baseado } \\
\text { na garantia física. }\end{array}$ & & $568568,40^{*}$ & $568568,40^{*}$ \\
$\begin{array}{l}\text { Custo p/manutenção } \\
\text { corretiva }\end{array}$ & & 65447,60 & 130895,20 \\
\hline
\end{tabular}


* É considerado o mesmo valor em função da garantia física da usina.

É selecionada uma parada de 68 horas porque foi o registro menos favorável para a operação da usina em função de falhas com o sistema de alimentação de água da caldeira de recuperação. Adicionalmente, esta paralisação do sistema pelo período de 68 horas foi o que trouxe maiores prejuízos para a operação do sistema de geração de energia, por diversos fatores, mas que foram registrados pelo operador na época da paralisação. A falha se apresentou especificamente no sistema de recirculação de água, especialmente na válvula ARC, que apresentou uma degradação agressiva, caracterizado por uma erosão nas partes internas da mesma, que até a elaboração deste trabalho era desconhecida para o pessoal de operação e manutenção (SCHERER, 2006), e simplesmente eram efetuadas trocas corretivas da válvula em sua totalidade. O estudo deste fenômeno e as recomendações para a solução do mesmo fazem parte complementar do trabalho e são apresentados no Apêndice A.

Tabela 6.15. Custos dos cenários de operação atual para um período de 1440 horas (sem sistema de redundante)

\begin{tabular}{llll}
\hline Item & $\begin{array}{l}\text { Custo da Operação } \\
\text { normal (US\$) }\end{array}$ & $\begin{array}{l}\text { Custos Operação } \\
\text { Parcial (US\$) }\end{array}$ & $\begin{array}{l}\text { Custos Usina } \\
\text { inoperante } \\
\text { (US\$) }\end{array}$ \\
$\begin{array}{l}\text { Custo de operação } \\
\text { Compra de energia }\end{array}$ & 21191703,25 & 21191703,25 & 21191703,25 \\
$\begin{array}{l}\text { Custo, p/manutenção } \\
\text { corretiva }\end{array}$ & & $568568,40^{*}$ & $568568,40^{*}$ \\
Total & $\mathbf{2 1 1 9 1 7 0 3 , 2 5}$ & 65447,60 & 129752,36 \\
\hline
\end{tabular}

* É considerado o mesmo valor em função da garantia física da usina.

Os resultados da avaliação de risco por meio da árvore de decisão são apresentados na Figura 6.15 de forma gráfica. Nesta figura é possível observar um panorama bastante claro do cenário de tomada de decisão, instalar ou não o sistema redundante em função dos custos relacionados com cada alternativa. Os resultados da análise são apresentados de forma formal na Tabela 6.16 . 


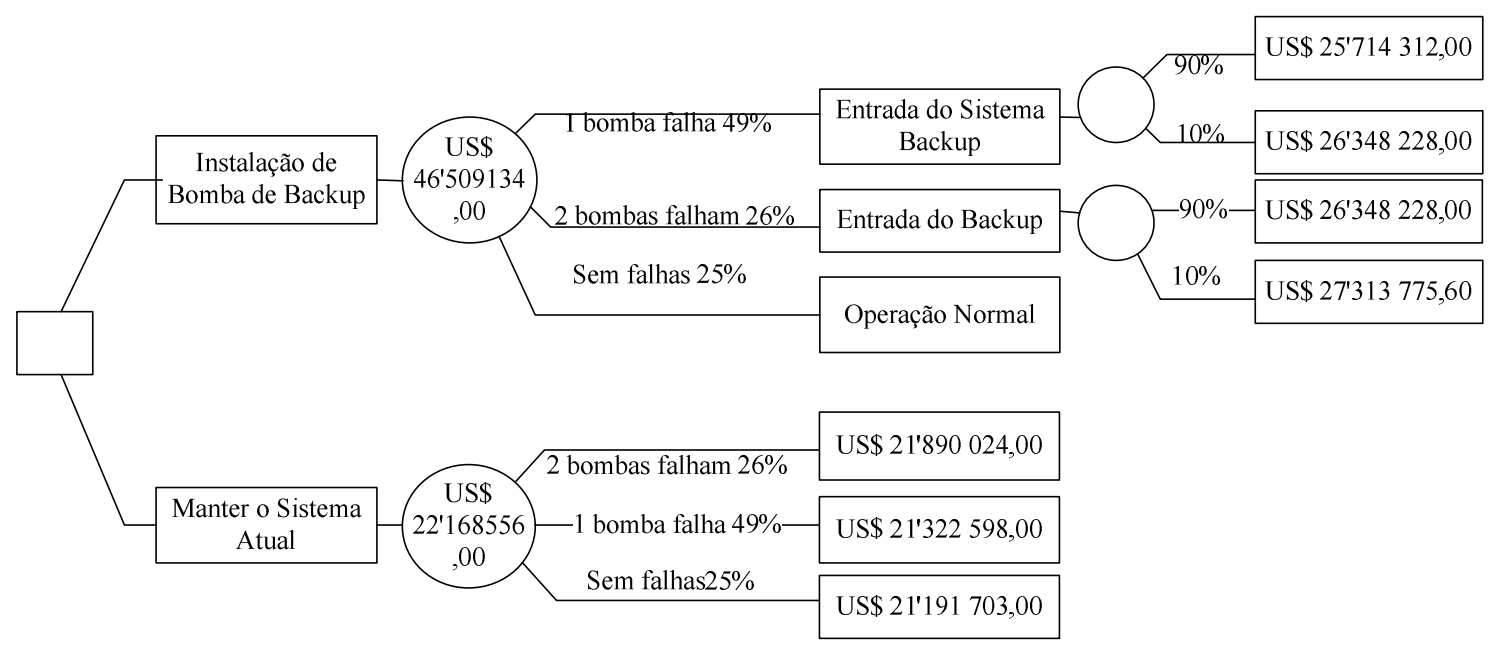

Figura 6.16. Árvore de decisão

Tabela 6.16. Resultados da árvore de decisão

\begin{tabular}{|c|c|}
\hline Cenário/Custos de Decisão * & Custos (US\$) \\
\hline Custo da Instalação de Sistema Redundante de Alimentação de Água & $46,599248,00$ \\
\hline Custo de Manter a Instalação & $22 ’ 168556,00$ \\
\hline
\end{tabular}

* Probabilidade de falha de 51,71\%

Com os resultados mostrados na Tabelas 6.16 e na Figura 6.15 fica claro que a decisão de instalar o sistema redundante de alimentação de água da caldeira de recuperação é inviável economicamente. Desta forma, com o resultado da análise é possível observar que o custo relacionado com o investimento de instalação da bomba de backup é de, aproximadamente, US\$ 46 milhões (US\$ 46599 248,00). E os custos relacionados às falhas, no caso de não investir no sistema redundante de alimentação de água, é de US\$ 22 milhões (US\$ 22168 556,00), ou seja, pouco menos de 50\% do gasto relacionado com o investimento da instalação do sistema redundante.

Como resultado da análise de risco é possível afirmar que não é viável instalar um sistema redundante de alimentação de água para as caldeiras de recuperação. 
Na Tabela 6.17 é apresentada uma análise de sensibilidade supondo que estas probabilidades de falhas variam, apenas para avaliar o comportamento do cenário de decisão, isto como complemento de uma complexa análise de risco para determinar que não é viável economicamente a instalação de um sistema redundante de alimentação de água para as caldeiras de recuperação.

Tabela 6.17. Análise de sensibilidade para o problema de decisão

\begin{tabular}{lcccccccc}
\hline $\begin{array}{l}\text { Variação da Probabilidade de } \\
\text { Falha do Sistema Bomba }\end{array}$ & $\mathbf{8 0 \%}$ & $\mathbf{7 0 \%}$ & $\mathbf{6 0 \%}$ & $\mathbf{5 1 \%}$ & $\mathbf{5 0 \%}$ & $\mathbf{4 0 \%}$ & $\mathbf{3 0 \%}$ & $\mathbf{2 0 \%}$ \\
$\begin{array}{l}\text { Custo do investimento de instalação } \\
\text { da bomba backup em Milhões US\$ }\end{array}$ & 36,45 & 40,57 & 44,08 & 46,65 & 46,96 & 49,22 & 50,86 & 51,88 \\
$\begin{array}{l}\text { Custo relacionado com a operação } \\
\text { do sistema atual em Milhões US\$ }\end{array}$ & 34,39 & 30,06 & 25,74 & 22,17 & 21,43 & 17,13 & 12,83 & 8,54 \\
\hline
\end{tabular}

Analisando a Tabela 6.17, pode-se observar claramente que à medida que as probabilidades de falhas do sistema aumentam o valor dos custos, das duas alternativas se aproximam. De forma mais pontual, claramente nem no mais pessimista dos cenários de operação, com probabilidade de falha do sistema de $80 \%$, é viável a instalação do sistema redundante, ou seja, só com um valor acima de $80 \%$ de probabilidade de falha a decisão mudaria a favor da instalação do sistema redundante de alimentação de água da caldeira.

De forma contrária, à medida que as probabilidades de falha são reduzidas, o mecanismo de decisão revela que o sistema atual deve ser mantido, destacando que todas as atividades que visem à redução destas probabilidades de falha permitirão conservar o sistema tal como o projeto original. Em outras palavras, com o melhoramento dos critérios de planejamento da manutenção do sistema se garantiria a alta disponibilidade do sistema sem ter que alterá-lo. A Figura 6.17 apresenta de forma gráfica a análise de sensibilidade da Tabela 6.17, e pode-se observar com maior claridade a tendência dos custos em função das probabilidades de falha. 


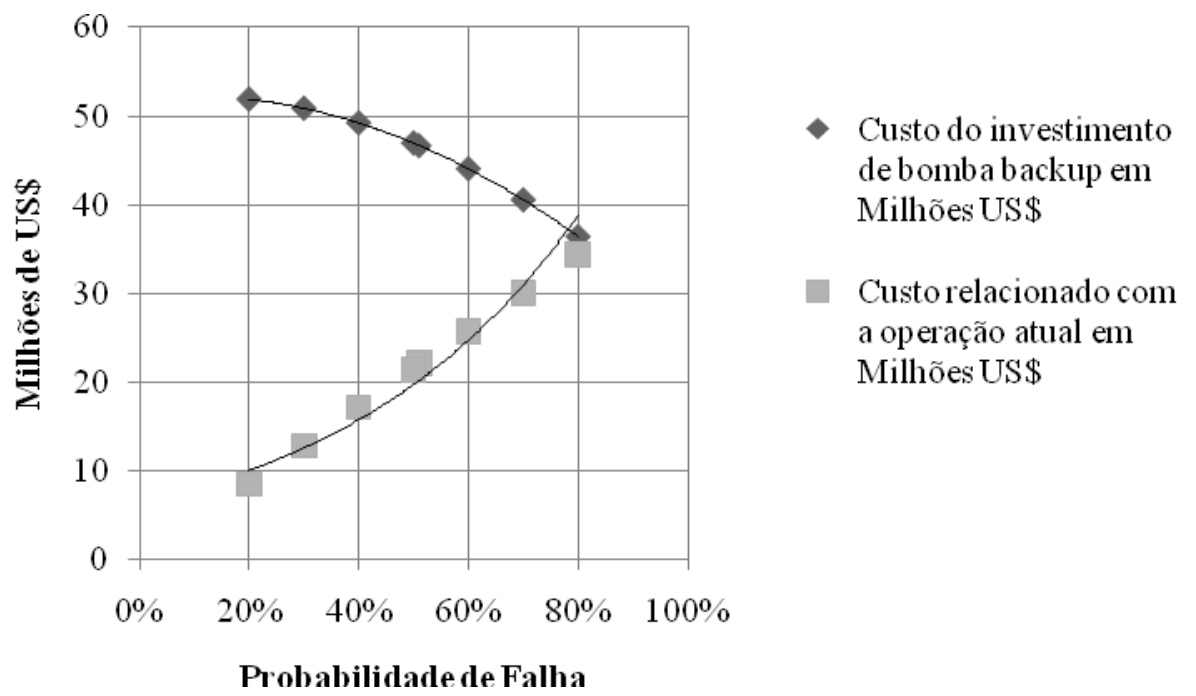

Figura 6.17 Distribuição das custos relacionados com a instalação do sistema redundante de alimentação de água em função das probabilidades

Com a finalidade de reduzir a probabilidade de falha do sistema de alimentação de água e aumentar a sua disponibilidade, são recomendadas rotinas de inspeção permanente e de calibração tanto para o sistema de monitoração da bomba principal, como para o sistema de recirculação de água, - causador de boa parte do tempo de parada para manutenção corretiva. Para o cálculo de disponibilidade são usados os valores de tempos de operação e paradas do próprio sistema, que foram apresentados nas Tabelas 6.5 a 6.8. Na Tabela 6.18, são apresentados os parâmetros das distribuições de Mantenabilidade para as duas bombas de alimentação e para os dois sistemas ARC.

Tabela 6.18. Parâmetros das distribuições de Mantenabilidade

\begin{tabular}{lcc}
\hline Item & \multicolumn{2}{c}{ Parâmetros da Distribuição de } \\
& \multicolumn{2}{c}{ Mantenabilidade (Lognormal) } \\
\hline Bomba 1 & 2,8416 & $\boldsymbol{\sigma}$ \\
Bomba 2 & 1,1425 & 0,7146 \\
ARC 1 & 1,4023 & 2,4689 \\
ARC 2 & 1,8927 & 1,0195 \\
\hline
\end{tabular}


O sistema de alimentação de água da caldeira é representado por um diagrama de blocos em série, tal como mostra a Figura 6.18, sendo este usado para o cálculo da disponibilidade do sistema. Com a finalidade de simplificar a apresentação dos resultados, a seguir é apresentada a análise efetuada para o sistema de alimentação 1, (bomba e ARC1) que são os que apresentam menor disponibilidade, tal como mostra a Tabela 6.19.

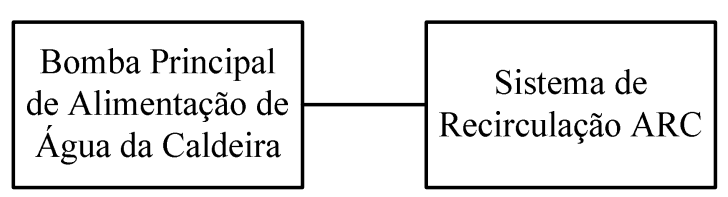

Figura 6.18. Diagrama de blocos do sistema de alimentação de água da caldeira

Utilizando o programa BlockSim 6® é calculada a disponibilidade dos dois sistemas de alimentação de água da caldeira de recuperação sendo apresentados na Tabela 6.19. Pode-se observar uma grande diferença entre os dos sistemas. O sistema 1 apresenta 18 falhas em total contra 9 do sistema 2. Por este motivo, novamente o sistema 1, composto pela bomba 1 e o sistema ARC 1, e selecionado para a análise.

Tabela 6.19. Disponibilidade dos sistemas de alimentação de água da caldeira

\begin{tabular}{lc}
\hline Item & Disponibilidade do Sistema (\%) \\
\hline & Horas de Operação 1440 h \\
Sistema de alimentação de água 1 & 95,61 \\
Sistema de alimentação de água 2 & 99,61 \\
\hline
\end{tabular}

Com a finalidade de reduzir os tempos de parada ocasionados por manutenção corretiva, e conseqüentemente aumentar a disponibilidade do sistema, na Tabela 6.20 são apresentadas recomendações de manutenção e inspeção baseadas em risco principalmente para a calibração dos sensores de monitoração da bomba e, 
calibração no sistema ARC, que podem ser implementadas como atividades preventivas.

Tabela 6.20. Recomendações de inspeção e manutenção para o sistema de alimentação de água da caldeira

\begin{tabular}{|c|c|c|c|}
\hline Sis. & Modos de Falha & Componente/sensor & Recomendações \\
\hline \multirow{6}{*}{ 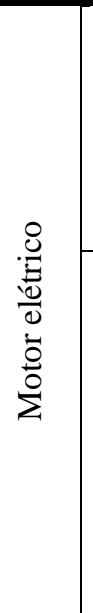 } & \multirow[t]{3}{*}{$\begin{array}{l}\text { Alta temperatura } \\
\text { Deformação da carcaça }\end{array}$} & Extensômetros & $\begin{array}{l}\text { Calibrar; inspeção do conjunto de } \\
\text { fixação; inspeção das conexões }\end{array}$ \\
\hline & & Medidor de temperatura & $\begin{array}{l}\text { Calibrar com instrumento padrão. } \\
\text { Regular as tolerâncias máximas }\end{array}$ \\
\hline & & $\begin{array}{l}\text { Medidor de nível de } \\
\text { óleo }\end{array}$ & Inspeção visual; limpeza freqüente \\
\hline & \multirow[t]{3}{*}{$\begin{array}{l}\text { Falhas na lubrificação/ } \\
\text { ruptura da tubulação }\end{array}$} & $\begin{array}{l}\text { Medidor de temperatura } \\
\text { de óleo. }\end{array}$ & $\begin{array}{l}\text { Calibrar; inspeção do conjunto de } \\
\text { fixação; inspeção das conexões; } \\
\text { inspeção visual permanente. }\end{array}$ \\
\hline & & Medidor de vazão. & $\begin{array}{l}\text { Comprovar operação; inspeção visual } \\
\text { do fluxo. Evidencias e comunicar } \\
\text { vazamentos. }\end{array}$ \\
\hline & & Medidores de pressão & $\begin{array}{l}\text { Instalados na saída da bomba e antes da } \\
\text { entrada dos Mancais; calibração; } \\
\text { limpeza. }\end{array}$ \\
\hline \multirow{5}{*}{ 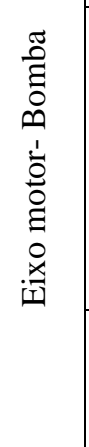 } & \multirow{3}{*}{$\begin{array}{l}\text { Ruptura } \\
\text { Deformação } \\
\text { permanente } \\
\text { Folga radial excessiva }\end{array}$} & Sensor de proximidade. & $\begin{array}{l}\text { Calibração as tolerâncias máximas; } \\
\text { inspeção das conexões. }\end{array}$ \\
\hline & & Medidor de temperatura & $\begin{array}{l}\text { Calibrar com instrumento padrão. } \\
\text { Regular as tolerâncias máximas. }\end{array}$ \\
\hline & & Sensor de Vibração & $\begin{array}{l}\text { Calibrar; inspeção do conjunto de } \\
\text { fixação; inspeção das conexões. }\end{array}$ \\
\hline & \multirow[t]{2}{*}{$\begin{array}{l}\text { Não há transformação } \\
\text { de energia }\end{array}$} & Medidor de temperatura & $\begin{array}{l}\text { Calibrar com instrumento padrão. } \\
\text { Regular as tolerâncias máximas. }\end{array}$ \\
\hline & & Sensor de Vibração & $\begin{array}{l}\text { Calibrar; inspeção do conjunto de } \\
\text { fixação; inspeção das conexões. }\end{array}$ \\
\hline \multirow{3}{*}{ 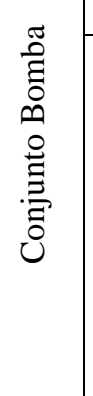 } & \multirow[t]{3}{*}{$\begin{array}{l}\text { Falhas na lubrificação/ } \\
\text { ruptura da tubulação }\end{array}$} & $\begin{array}{l}\text { Medidor de temperatura } \\
\text { de óleo. }\end{array}$ & $\begin{array}{l}\text { Calibrar; inspeção do conjunto de } \\
\text { fixação; inspeção das conexões; } \\
\text { inspeção visual permanente. }\end{array}$ \\
\hline & & Medidor de vazão. & $\begin{array}{l}\text { Comprovar operação; inspeção visual } \\
\text { do fluxo. Evidencias e comunicar } \\
\text { vazamentos. }\end{array}$ \\
\hline & & Medidores de pressão & $\begin{array}{l}\text { Instalados na saída da bomba e antes da } \\
\text { entrada dos Mancais; calibração; } \\
\text { limpeza. }\end{array}$ \\
\hline \multirow{4}{*}{ 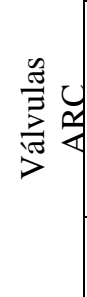 } & \multirow[t]{3}{*}{$\begin{array}{l}\text { Desgaste prematuro } \\
\text { Por Formação de Flash }\end{array}$} & $\begin{array}{lll}\text { Válvula } & \text { redutora } \mathrm{de} \\
\text { pressão. } & & \\
\end{array}$ & $\begin{array}{l}\text { Calibrar a válvula Anti-flash na entrada } \\
\text { do tanque de vapor. }\end{array}$ \\
\hline & & Válvula Anti-flash & Calibração com o instrumento padrão. \\
\hline & & Válvula de By-pass & $\begin{array}{l}\text { Calibrar a válvula Anti-flash na entrada } \\
\text { do tanque de vapor }\end{array}$ \\
\hline & $\begin{array}{l}\text { Recirculação excessiva } \\
\text { de água }\end{array}$ & Válvula unidirecional & $\begin{array}{l}\text { Calibrar a válvula Anti-flash na entrada } \\
\text { do tanque de vapor }\end{array}$ \\
\hline
\end{tabular}

Na Tabela 6.21 é apresentada a variação da disponibilidade do sistema de alimentação de água da caldeira de recuperação em virtude da implementação das recomendações de manutenção e a conseqüente redução do tempo de intervenção para 
manutenção corretiva num período operacional de 1440 horas. Para a simulação é suposta uma redução no tempo de manutenção corretiva referente aos sensores, no caso da bomba de água, e problemas relacionados com a calibração da válvula anti-flash que reduz o desgaste prematuro da válvula ARC, como análise apresentado no Apêndice A.

Tabela 6.21. Simulação da variação da disponibilidade do sistema de alimentação de água

\begin{tabular}{lccc}
\hline Item & \multicolumn{2}{c}{ Disponibilidade do Sistema (\%) Para 1440 horas de Operação } \\
\hline $\begin{array}{l}\text { Sistema de } \\
\text { alimentação } \\
\text { de água 1 }\end{array}$ & Atual & $\begin{array}{l}\text { Tirando as falhas dos sensores da bomba e } \\
\text { falhas provocadas pela falta de calibração }\end{array}$ & $\begin{array}{c}\text { Incremento de } \\
\text { da Válvula anti-flash }\end{array}$ \\
& 95,61 & 99,63 & $4,02 \%$ \\
\hline
\end{tabular}

É possível observar, baseando-se na simulação, que a disponibilidade do sistema aumenta em 4,02\%, para um período operacional de 1440 horas. Adicionalmente a esta análise é simulada a disponibilidade da usina em função da disponibilidade do sistema de alimentação de água da caldeira. Os dados (parâmetros das distribuições de confiabilidade e mantenabilidade para o cálculo da disponibilidade) referentes aos outros componentes principais da usina termelétrica são apresentados na Tabela 6.22, e devidamente referenciados. A usina termelétrica é representada pelo diagrama de blocos, apresentado na Figura 6.19, o que é utilizado para o cálculo da disponibilidade da mesma.

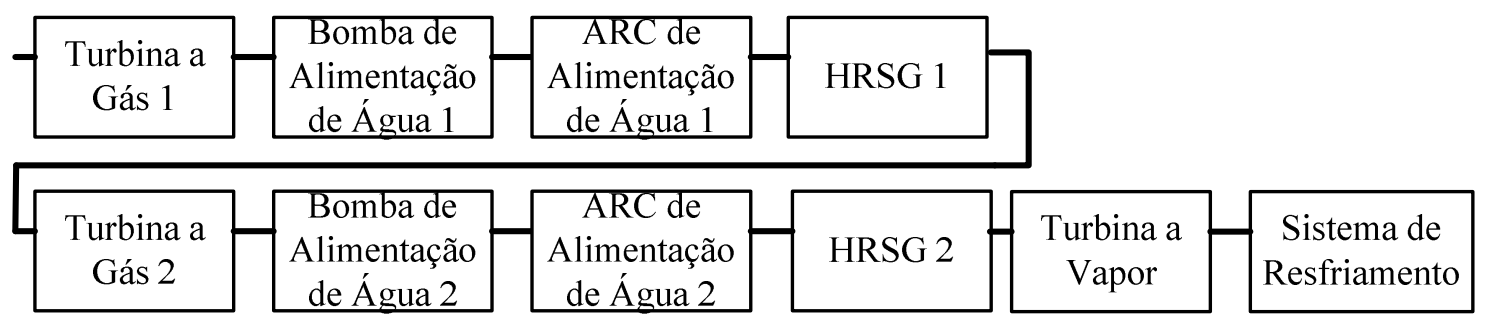

Figura 6.19. Diagrama de blocos de representação da usina termelétrica

Para a análise é assumida a hipótese de que as turbinas gás 1 e 2, as HRSG 1 e 2 e os sistemas de alimentação de água 1 e 2, possuem o mesmo comportamento operacional. 
Tabela 6.22. Parâmetros para o cálculo de disponibilidade da Usina

\begin{tabular}{|c|c|c|c|c|c|}
\hline \multirow[t]{2}{*}{ Item } & \multicolumn{2}{|c|}{$\begin{array}{l}\text { Parâmetros de } \\
\text { Confiabilidade }\end{array}$} & \multicolumn{2}{|c|}{$\begin{array}{l}\text { Parâmetros de } \\
\text { Mantenabilidade }\end{array}$} & \multirow[t]{2}{*}{ Referencia } \\
\hline & $\boldsymbol{\beta}$ & $\eta$ & $\mu$ & $\sigma$ & \\
\hline Turbina a Gás 1 e 2 & 0,58 & 1014,56 & 1,52 & 1,12 & $\begin{array}{l}\text { Carazas e Souza } \\
(2007 c ; 2009 b)\end{array}$ \\
\hline $\begin{array}{l}\text { Bomba de Alimentação } \\
\text { da HRSG } 1 \text { e } 2\end{array}$ & $0,66 / 1,42^{*}$ & $\begin{array}{l}2223,39 / \\
6032,77^{*}\end{array}$ & $2,84 / 2,78^{*}$ & $1,04 / 1,1^{*}$ & \\
\hline $\begin{array}{l}\text { ARC de Alimentação da } \\
\text { HRSG } 1 \text { e } 2\end{array}$ & $0,66 / 1,57^{*}$ & $\begin{array}{l}1851,72 / \\
3807,01^{*}\end{array}$ & $1,40 / 0,73^{*}$ & $2,46 / 2,73^{*}$ & \\
\hline HRSG 1 e 2 & 0,64 & 1531,31 & 0,88 & 1,80 & $\begin{array}{l}\text { Carazas e Souza } \\
(2007 b ; 2009 c)\end{array}$ \\
\hline Turbina a Vapor & \multicolumn{2}{|c|}{$\begin{array}{c}\text { Exponencial } \lambda=0,0007 \\
\text { falhas } / \mathrm{h}\end{array}$} & 1,13 & 2,02 & $\begin{array}{l}\text { Carazas e Souza } \\
(2006)^{* *}\end{array}$ \\
\hline $\begin{array}{l}\text { Sistema de Resfriamento } \\
\text { de Água }\end{array}$ & \multicolumn{2}{|c|}{$\begin{array}{c}\text { Exponencial } \lambda=0,0003 \\
\text { falhas } / \mathrm{h}\end{array}$} & 1,86 & 1,59 & $\begin{array}{l}\text { Carazas e Souza } \\
(2009 a)\end{array}$ \\
\hline
\end{tabular}

*Parâmetros recalculados levando em consideração as recomendações de manutenção.

**Dados apresentados em relatório técnico.

Finalmente, utilizando os parâmetros das distribuições de confiabilidade e mantenabilidade e com o emprego do programa BlockSin $6 \AA$, é calculada a disponibilidade da usina para o mesmo período operacional. No primeiro caso a disponibilidade é de $86,68 \%$. Utilizando os novos parâmetros do sistema de alimentação de água, é possível observar que a disponibilidade aumenta para 93,53\%.

\subsection{Considerações Finais}

Como parte final deste capítulo e antes de apresentar as conclusões finais do trabalho é importante destacar alguns detalhes com a finalidade de que o leitor esteja informado de que, as avaliações técnicas do problema sob análise, foram executadas com maior profundidade e são apresentadas no Apêndice A.

O estudo deste sistema em particular, foi motivado pela alta freqüência de falhas, problema este que não seria resolvido apenas com a instalação de um sistema 
redundante de alimentação de água, como mostra a análise de decisão e risco, pois o sistema estava sofrendo um fenômeno desconhecido de degradação que os próprios fabricantes desconheciam.

Por este motivo é que o objetivo principal deste trabalho de pesquisa é demonstrar a eficácia do método para a seleção de alternativas de manutenção e/ou seleção de equipamentos redundantes em função do risco. No Apêndice A é descrito o procedimento conclusivo de implementação do método. A análise do Apêndice A tem a finalidade de, por meio da aplicação dos conceitos de análise de risco, selecionar estratégias de manutenção para o sistema de alimentação de água da caldeira de recuperação, e assim resolver o problema apresentado com tanta freqüência e que provocou perdas significativamente sérias à atividade comercial da usina termelétrica sob análise. 


\section{CAPÍTULO 7 - CONCLUSÕES}

Este Capítulo apresenta as conclusões assim como as recomendações para trabalhos futuros. 


\subsection{Conclusões}

A execução desta pesquisa proporcionou o desenvolvimento de um método de tomada de decisão para subsidiar estudos de viabilidade de modificação de um projeto ou mesmo a alteração da política de manutenção de subsistemas e/ou componentes presentes em sistemas de geração de energia elétrica, principalmente aqueles que empregam usinas hidrelétricas ou termelétricas.

Este método de tomada de decisão baseou-se no emprego de conceitos de análise de risco e tem por objetivo ponderar as probabilidades de ocorrências de um determinado cenário de falha, baseado em um evento inicial associado com a falha de um componente, com as conseqüências expressas na forma monetária. As consequiências da falha expressam o grau de deterioração do desempenho do sistema de geração de energia elétrica sob o ponto de vista de redução de sua capacidade de geração bem como a degradação da condição de segurança operacional do sistema, associada a uma ameaça à vida humana ou ao meio ambiente.

Para avaliação de um cenário de falha foi proposto o emprego do diagrama causa-conseqüência. Neste diagrama, a partir da suposição da ocorrência de um evento inicial - falha de um componente - constrói-se o cenário de propagação da falha, incluindo a possibilidade de falha de sistemas de segurança (incluindo sistemas de monitoração), que são considerados barreiras para deter o processo de propagação da falha. A construção do diagrama causa-conseqüência permite a identificação das conseqüências da falha não apenas para a condição operacional do sistema de geração de energia elétrica, mas também para o meio ambiente e para a segurança da vida humana (pessoal de operação e ocupantes de propriedades vizinhas ao empreendimento). Alem disso, o exemplo de aplicação permite a identificação dos cenários: Operação Normal, Operação Parcial e Usina Inoperante como conseqüência da falhas de componentes de usina termelétrica. 
Com o auxílio dos conceitos de probabilidade e estatística avalia-se a probabilidade de ocorrência de cada um dos eventos listados no Diagrama CausaConsequiência (Figura 6.9). Empregando-se teoremas da probabilidade define-se a probabilidade de ocorrência de um dado cenário de falha (representado por cada um dos ramos do diagrama) através da composição da probabilidade de ocorrência dos eventos que constituem o cenário sob análise.

Para um sistema que já esteja em operação, às probabilidades de falha de seus componentes podem ser calculadas a partir do histórico de falha dos mesmos, utilizando-se conceitos de confiabilidade para modelar a função distribuição de probabilidade que melhor representa a distribuição dos "tempos entre falhas" de cada componente considerado na análise.

A análise de confiabilidade pode ser complementada com o emprego de banco de dados, tais como os propostos pelo IEEE - Institute of Electrics and Electronics Engineers - ou pela RAC - Reliability Analysis Center, os quais fornecem estimativas para a confiabilidade de componentes mecânicos, eletro-eletrônicos e eletrônicos presentes em sistemas de geração de energia elétrica, no caso de não haver histórico de falhas.

De posse da probabilidade de ocorrência de um cenário de falha e da quantificação de suas conseqüências, propõe-se o uso da Árvore de Decisão para avaliar qual a influência da alteração de um procedimento de manutenção ou mesmo a modificação da instalação física (com a adição de componentes redundantes ou novos sistemas de sensores) sobre o risco associado com a operação da planta. Para tanto se define risco como a probabilidade de ocorrência de um cenário de falha versus a consequiência do cenário de falha. Para a execução desta análise deve-se, em função de uma dada proposta de alteração de política de manutenção ou alteração do projeto, reavaliar as probabilidades de ocorrência dos cenários de falha e de suas conseqüências. 
Para a correta aplicação deste método de tomada de decisão deve-se expressar as consequiências da falha dos sistemas de geração de energia elétrica em uma forma monetária ou de custos. Ao longo do trabalho de pesquisas foi desenvolvido um procedimento de contabilização dos custos associados com a operação e manutenção de um sistema de geração de energia elétrica, bem como os custos associados com as falhas do sistema, expressos pelos custos das ações corretivas, custo da compra de energia no mercado e custo das penalizações que podem ser impostas pelos órgãos reguladores governamentais da área de geração de energia elétrica.

Com relação ao método de seleção de equipamentos críticos e políticas de manutenção baseadas em risco (SMBR), proposto neste trabalho de doutorado, pode-se concluir:

i) O método é baseado nos conceitos da análise de risco, tomada de decisão e análise de confiabilidade. Esta combinação permite modelar as incertezas associadas aos possíveis cenários de falha com uma determinada probabilidade; e os custos das possíveis conseqüências, subsidiado a tomada de decisão mais adequada para os interesses da empresa geradora.

ii) Tendo em vista a necessidade de modelar incertezas associadas com um determinado problema de decisão, o método desenvolvido no Doutorado é abrangente e recomenda-se a sua aplicação no processo de tomada de decisões estratégicas, cujos efeitos afetam os resultados da operação da empresa em um período de tempo superior a dois anos.

iii) A aplicação deste método exige o uso de bancos de dados estruturados contendo informações de classificação e valores de custos de operação e manutenção bem como de históricos de falha de equipamentos. Os dados devem permitir a avaliação das conseqüências das falhas e da probabilidade de ocorrência dos eventos listados no diagrama causaconsequiência, os quais subsidiarão a elaboração da árvore de decisão. 
iv) O mecanismo de decisão baseado na árvore de decisão apresenta flexibilidade para a representação de problemas de decisão estratégicos, concluindo-se que é aplicável em futuras decisões estratégicas, de instalação de equipamento de monitoração, modificações no projeto e implementação de novos sistemas tanto em uma usina com ciclo combinado como em um sistema de geração hidrelétricas.

v) Os cenários criados para um estado operacional da usina termelétrica, operação normal, operação parcial e usina inoperante, permitem relacionar custos de operação, manutenção, além dos relacionados com a ocorrência de uma falha inesperada como mão-de-obra extra, insumos, peças, mão-de-obra terceirizada, de forma que ante a necessidade de tomada de decisão estratégica estes custos são claros e permitem uma correta decisão. Ainda em relação aos cenários destaca-se a dificuldade de chegar a uma expressão única, assim dependendo da decisão estratégica a ser tomada, estes terão que ser revistos usando como referência o trabalho complementar relacionados a custos.

vi) Em relação ao cálculo dos custos se conclui que este é difícil, desta forma são necessárias algumas simplificações para que uma avaliação desses custos seja possível. Os custos de Geração foram divididos de forma genérica em Custos Fixos de Operação e Manutenção (O\&M), Custos Variáveis de O\&M e Custos da Indisponibilidade. Finalmente em relação aos custos, pode-se concluir que a estrutura de uma usina termelétrica depende não somente de fatores tradicionais como mão-deobra e combustível, mas também de fatores particulares do sistema como o tipo de energia disponível no mercado para suprir uma eventual falha da usina. Estes fatos fazem da estrutura de custos uma análise muito complexa que depende de fatores mercadológicos que levam em consideração o preço do gás, disponibilidade de gás, preço e disponibilidade de energia gerada por outras unidades térmicas e principalmente hidráulicas, além das regras impostas pelos órgãos 
reguladores que impõem penalidades e multas no caso de não cumprimento dos contratos.

Especificamente com relação ao caso exemplo selecionou-se o sistema de alimentação de água das caldeiras de recuperação da Usina Termelétrica e a modificação do projeto analisada envolve a possibilidade de instalação de bomba reserva para fornecer vazão de água em caso de falha da bomba principal. Durante o desenvolvimento deste caso exemplo foi possível verificar que a aplicação deste método necessita de um conjunto de informações muito bem organizadas relativas não apenas aspectos de manutenção e operação do sistema em análise, mas também aos aspectos de custos de operação e manutenção. O levantamento destas informações é bastante complexo indicando que o método ora proposto deve ser empregado como modelo de decisão de processos estratégicos dentro da empresa. A aplicação do mesmo em decisões ditas "simples" pode gerar um efeito determinante, pois o custo associado com a sua utilização seria desproporcional em relação aos benefícios associados com a decisão.

Ao longo do desenvolvimento deste caso exemplo foi possível verificar que o agente gerador está preparado para usar o método ora proposto na tomada de decisões estratégicas, pois a empresa possui bancos de dados de custos de operação e manutenção bastante completos além de possuir um registro detalhado das falhas que ocorrem nos equipamentos instalados em suas usinas.

A execução do caso exemplo permitiu que fossem obtidas as seguintes conclusões:

i) O sistema de alimentação de água das caldeiras de recuperação da UTE apresenta um número significativo de falhas em relação ao total de falhas de cada uma das duas caldeiras de recuperação instaladas na usina. Estas falhas estão normalmente associadas com falhas na bomba ou na válvula de recirculação (válvula ARC). As falhas associadas com a válvula ARC 
têm sido analisadas profundamente do ponto de vista técnico chegando a conclusão que o fenômeno causador da falha é o conhecido como flash, que principalmente se manifesta na haste da válvula. Este fenômeno pode ser evitado ou mesmo ter sua freqüência de ocorrência reduzida com o emprego de uma válvula "anti-flash" instalada na linha de baixa pressão. Verificou-se que esta válvula está presente nas instalações da linha de recirculação de baixa pressão.

ii) Através do estudo dos dados históricos de operação também pode-se concluir que as falhas não estão relacionadas à bomba como equipamento e sim como sistema, pois as paradas forçadas (TRIP) foram na maioria das vezes causadas por problemas com o sistema de resfriamento de óleo dos mancais, problemas de calibração de sensores e vazamento de óleo de lubrificação.

iii) A análise de sensibilidade para a árvore de decisão mostrou que mesmo com a redução e o aumento das probabilidades de falha do sistema de alimentação de água da caldeira, os custos relacionados com a decisão de instalar uma bomba de backup são superiores aos de manter o sistema tal como na atualidade.

iv) Vale destacar que todas as análises supuseram um período de operação de dois meses, sem considerar as dificuldades como a indisponibilidade do gás natural ou fenômenos mercado-técnicos, pelo qual se recomenda para trabalhos futuros levar em conta estes parâmetros como complemento desta análise.

v) É importante destacar que o sistema de controle possui um mecanismo de segurança muito eficaz, pois as barreiras "TRIP” reduzem significativamente a probabilidade de ocorrência de uma falha "catastrófica", sendo a possibilidade de uma falha desta natureza desconsiderada. Além disso, a ocorrência de uma destas falhas poderia 
causar danos ao pessoal de operação e manutenção assim como ao meio ambiente e os custos relacionados são simplesmente incalculáveis.

\subsection{Recomendações para Trabalhos Futuros baseados no SMBR 2011}

Da elaboração destra trabalho é possível fazer uma serie de recomendações para trabalhos futuros, divididas em duas características principais, do tipo técnico ou de implementação e, de desenvolvimento.

\subsubsection{Do tipo técnico ou de Implementação}

Grandes sistemas são compostos de pequenos subsistemas que garantem o a operação do sistema principal e o cumprimento das suas funções principais, sistemas como os de lubrificação, resfriamento, monitoração entre outros. Freqüentemente os fabricantes destes grandes sistemas são responsáveis pela manutenção (principalmente como parte de contratos de garantia), deixando aos operadores a responsabilidade da manutenção dos subsistemas. Frente a esta realidade operacional recomenda-se para trabalhos futuros a implementação do método em outros sistemas e indústrias que procurem resolver problemas de decisão relacionado a implementação de sistemas redundantes ou mudanças nas políticas de manutenção.

O método SMBR é flexível para ser implementado em sistemas de geração de energia dos tipos hidroelétricas, pequenas centrais hidroelétricas, termelétrica com motores de combustão, e termelétricas convencionais de caldeira e turbina de vapor. De fato durante a pesquisa o método foi implementado na usina completa obtendo resultados favoráveis no aumento de disponibilidade como resultado da seleção de novas estratégias de manutenção. Mas também o SMBR pode ser implementado em outras áreas da indústria como, por exemplo, nas indústrias de fabricação de pesas onde grandes maquinas possuem componentes periféricos importantes para o suporte da operação da maquina. 
Outras indústrias em crescimento e onde o SMBR poderia ser utilizado são as indústrias de processamento de matéria-prima, como usinas da indústria sucroalcooleiras ou de celulose e papel e até na indústria nuclear. Embora estas indústrias tenham anos no mercado, a crescente demanda de novos produtos, com maior qualidade, e com responsabilidade ambiental no processo de fabricação as forca a fazer mudanças nos seus processos, e uma ferramenta como o SMBR auxiliaria a tomada de decisões na seleção de alternativas seguras e de lata disponibilidade.

\subsubsection{Do tipo de desenvolvimento}

Como resultado da elaboração deste trabalho de doutorado foi possível identificar que, modernos sistemas das diversas áreas da indústria, possuem como parte integral, complexos sistemas de controle e monitoração. Estes sistemas de controle e monitoração embora deixem a operação mais segura, poderiam ser utilizados como ferramenta de predição e planejamento de manutenção, da seguinte forma.

A grande quantidade de informação, dos sistemas de monitoração pode ser estudada e acumulada de forma a criar tendências operacionais, por meio do desenvolvimento de programas computacionais que operem baixo a lógica, por exemplo, do Diagrama Causa-Conseqüência e desta forma permitam a identificação da necessidade de instalação de sistemas de segurança. Ainda podem ser desenvolvidas estratégias de diagnostico de falhas. As técnicas de diagnostico poderiam ser mapeadas por técnicas de análise de risco como as arvores de falha, e alimentadas pelas probabilidades de ocorrência de falhas geradas do próprio sistema de armazenamento de dados de historio de operação que os controle possuem.

Para o desenvolvimento de trabalhos futuros podem ainda ser implementadas técnicas de inteligência artificial para o prognostico de falhas, assim como técnicas de avaliação de parâmetros operacionais termodinâmicos, como eficiência, consumo de combustíveis, análises exegéticas, entre outros. 


\section{CAPÍTULO 8 - REFERÊNCIAS BIBLIOGRÁFICAS}

Este Capítulo apresenta todas as referências utilizadas para a elaboração do presente trabalho de doutorado. As referências são apresentadas em ordem alfabética. 
ABB. POWER AND PRODUCTIVITY FOR A BETTER WORD; RICHARDS D. RBM Risk - Based Maintenance 2003. Disponível em: <http://library.abb.com/global/scot/scot288.nsf/veritydisplay/618e68b575ccc090c12571 a4003e52d8/\$File/RBM\%20Paper\%20v2.pdf>. Acesso em: 26 de Fevereiro de 2009.

ABNT, ASSOCIAÇÃO BRASILEIRA DE NORMAS TÉCNICAS. NBR 5462: Confiabilidade e Mantenabilidade. Rio de Janeiro. Novenbro de 1994.

ABS. AMERICAN BUREAU OF SHIPPING. Guidance Notes on Risk Assessment Applications for the Marine and Offshore Oil and Gas Industries. Guide, Houston, TX, 2000.

ABS. AMERICAN BUREAU OF SHIPPING. Surveys Using Risk-Based Inspection for the Offshore Industry. Guide, Houston, TX, 2003.

AGL Energy. Preliminary Hazard Analysis in: Leafs gully power project environmental assessment. 2006.

AGUIAR, L. A. Metodologia de Análise de Riscos APP \& HAZOP. Universidade Federal do Rio de Janeiro, Instituto Alberto Luiz Coimbra de Pós Graduação e Pesquisa de Engenharia, Programa de Engenharia Nuclear. Rio de Janeiro, 2008.

ALADON. The Aladon Network. RCM2 and Risk Analysis. Disponível em: <http://www.thealadonnetwork.com/PDFs/introUK.pdf>. Acesso em: 10 de abril de 2007. 
AL-MANSOUR, F. e KOZUH, M.. Risk analysis for CHO decision making within the conditions of an open electricity market. Energy 32, p.1905-1916. 2007.

ANDREWS, J D, e RIDLEY L. M. Reliability of sequential systems using the causeconsequence diagram method. Proceedings of the Institution of Mechanical Engineers, Part E: Journal of Process Mechanical Engineering 215, p. 207-220. 2001.

ANEEL. AGÊNCIA NACIONAL DE ENERGIA ELÉTRICA. Justificativa para a Determinação dos Preços do MAE Ex-Post. Disponível em: <http://www.aneel.gov.br/aplicacoes/Audiencia_Publica/audiencia_proton/2000/Justific ativa\%20Preco\%20Ex-post.pdf.>. Acesso em: 12 de febereiro de 2009.

AES Uruguaina. AP007 Turbinas a Gás CTGW501F. Apostila De Treinamento AES Uruguaina. 2003.

APELAND, S. e AVEN, T.. Risk based maintenance optimization: foundational issues. Reliability Engineering \& System Safety 67, p. 285-292. 2000.

ARENDT, J. S. Using Quantitative risk assessment in the chemical process industry. Reliability Engineering \& System Safety 29, p. 133-149. 1990.

ARUNRAJ, N. S. e MAITI, J. Risk-based maintenance - techniques and applications. Journal of Hazardous Materials 142, p. 653-661. 2007.

ASME, AMERICAN SOCIETY OF MECHANICAL ENGINEERS. Gas turbine power plants. New York, 1966.

AVEN, T. e KORTE, J. On the use of risk and decision analysis to support decisionmaking. Reliability Engineering \& System Safety 79. p. 289-299. 2003. 
BAJENESCU, T. e BÂZU M. Reliability of Electronic Components. Berlin: Springer, 1999.

BAREIB, J, BUCK, MATSCHECKO B., JOVANOVIC, A., BALOS, D. e M PERUNICIC. RIMAP demonstration project. Risk-based life management of piping system in power plant Heilbronn. International Journal of Pressure Vessels and Piping 81, p. 807-813. 2004.

BEI, BRITISH ELECTRICITY INTERNATIONAL. Modern Power Station Practice. Oxford: Pergamon Press, 1991.

BERTOLINI, A., BEVILACQUA, M., CIARAPICA, F. e GIACCHTTA, G. Development of risk-based inspection and maintenance procedures for an oil refinery. Journal of Loss Prevention in the Process Industries 22, p. 244-253. 2003.

BIG, Banco de Informações de Geração. Ministério de Minas E Energia; MME. 2008. Brasilia. Disponível em: <http://www.aneel.gov.br/aplicacoes/capacidadebrasil/capacidadebrasil.asp $>$. Acesso em: 12 de abril de 2009.

BLACK, e VEATCH. Power Plant Engineering. New York: International Thomson Publishing Company, 1996.

BORELLI, S. J. S. Método para a análise da composição do custo da eletricidade gerada por usinas termelétricas em ciclo combinado a gás natural, 2005. Dissertação (Mestrado). IEE Instituto de Eletrotécnica e Energia e Escola Politécnica da Universidade de São Paulo, 2005. 
BOUTI, A., e KADI, D. A state-of-the-art review of FMEA / FMECA. International Journal of Reliability, Quality and Safety Engineering 4, p. 515-543.1994.

BOYCE e MEHERWAN. Gas turbine engineering handbook. Houston: Gulf Pub CO, 1982.

CARAZAS, F. J. G. Análise de disponibilidade de turbinas a gás empregadas em usinas a ciclo combinado, 2006. Dissertação (Mestrado). Programa de Engenharia Mecânica Escola Politécnica da Universidade de São Paulo, 2006.

CARAZAS, F. J. G., e SOUZA, G. F. M. Desenvolvimento de políticas de manutenção centrada em confiabilidade para turbinas a gás em usinas termelétricas a ciclo combinado. IV Congresso de Inovação Tecnológica em Energia Elétrica CITENEL. ANEEL. Araxa, Brasil. 2007a.

Availability analysis of heat recovery steam generator used in combined cycle thermoelectric power plant. 19th International Congress of Mechanical Engineering, COBEM. ABCM, Brasilia, Brasil. 2007b.

Availability analysis of gas turbine used in thermoelectric power plants. Proceeding of 20th International Conference On Efficiency, Cost Optimization, Simulation and Enverimental Impact of Enery Systems ECOS, Padova, Italy. p. 277285. 2007c.

Método basado en confiabilidad para el aumento de disponibilidad de sistemas de generación de energía eléctrica. XXI Congreso Panamericano de Ingeniería Mecánica, Eléctrica, Industrial y Ramas afines - COPIMERA. Colegio de Ingenieros del Perú CIP. Lima, Perú. 2007d. 
CARAZAS, F. J. G., KONDO, N. N., SOUZA G. F. M. e PATINO C. E. R. Método para evaluación de disponibilidad de sistemas de generación de energía eléctrica aplicado a turbinas de gas -. Octavo Congreso Ibero Americano de Ingeniería Mecánica-Cibim 8. 2007e.

CARAZAS, F. J. G., e SOUZA, G. F. M. Risk-Based Decision Making Method for Maintenance Policy Selection of Thermoelectric Power Plant. Proceedings of the 21st International Conference on Efficiency, Cost, Optimization, Simulation and Environmental Impact of Energy Systems, ECOS. Cracow, Poland, p. 611-620. 2008.

Method for cooling towers maintenance policy selection based on RCM concepts. Proceedings of International Congress of Mechanical Engineering COBEM, Gramado, Brasil. 2009.

Availability Analysis of Gas Turbine Used in Thermo Electric Power Plants. International Journal of Thermodynamics Vol. 12 (No. 1), pp. 28-37, March $2009 b$.

Risk-based decision making method for maintenance policy selection of thermal power plant equipment. Energy 35, p. 964-975. 2010.

CARdoso, I. A. Desenvolvimento de Método Para Seleção de Políticas de Manutenção Baseado Em Análise de Risco, 2004. Tese (Doutorado). Programa de Engenharia Mecânica Escola Politécnica da Universidade de São Paulo, 2004.

CARDOSO, I. A. Elaboração de Políticas de Manutenção: uma Abordagem Voltada a Análise de Confiabilidade, 2000. Dissertação (Mestrado). Programa de Engenharia Mecânica Escola Politécnica da Universidade de São Paulo. 2000. 
CASAl, J., MONTIEL, H., PlANAS, E. e VÍlCHES, J. Análisis de Riesgo en Instalaciones Industriales. Universitat Politècnica de Catalunya, S1, 1999.

CHALIFOUX, A. e BAIRD, J. Reliability Centered Maintenance RCM Guide. Washington: US Army Corps of Engineers, 1999.

CHANG, M., CHANG, R, SHU, C. e LIN. K. Application of risk based inspection in refinery and processing piping. Journal of Loss Prevention in the industries 18, p. 397-402. 2005.

CHIN, K. et al. Failure mode and effects analysis using a group-based evidential reasoning approach. Computers \& Operations Research, 36 - 6. p. 1768-1779. June 2009.

COELHO, A. TPM - Manutenção Produtiva Total. Grugeen. p. 1-23, 2008.

COSTA NETO, P. L., e BATISTA. Probabilidades. São Paulo: Editor Edgard Blucher ltda, 1974.

DEPARTMENT OF DEFENSE US “MIL-STD-1629A”. Procedures for Performing a failure mode, effects and criticality analysis, 1998.

DUARTE Jr., A. M. A importância do gerenciamento de riscos em bancos. Gestão de Riscos no Brasil. Brasil. 2003.

DUFFUAA, S O., RAOUF. A. e DIXON, J. Planning and Control of Maintenance Systems Modeling and Analysis. New York: John Wiley \& Sons, Inc, 1999. 400p. 
DURAN, J. Gerencia de Activos. Caracas: Copyright The Woodhouse Partnership Limited, 2000.

ECKSTEIN, C. B., JATKOSKI, E, e ETTER, J. Inspeção Baseada em Risco Segundo API 581 Aplicação do API-RBI software. 6a COTEQ Conferencia sobre Tecnologia de Equipamentos. IEV- Conferência Internacional sobre Avaliação de Integridade e Extensão de Vida dos Equipamentos Industriais. Salvador. 2002.

EPE, EMPRESA DE PESQUISAS ENERGÉTICAS, e MME MINISTÉRIO DE MINAS E ENERGIA GOVERNO FEDERAL. Mercado de Energia Elétrica 20062015. Brasília. MME, 2006. 380p.

—, Balanço Energético Nacional 2008. Disponível em: <http://www.worldenergy.org/documents/resultados_pre_ben_2008.pdf> Brasília: Ministério de Minas e Energia, Acesso em: 15 de maio de 2009.

FUJIYAMA, K., et al. Risk-based inspection and maintenance systems for steam turbine. International Journal of Pressure Vessels and Piping 81, p. 825-835. 2004.

GHOSH, D. e ROY, S. Maintenance Optimization using probabilistic cost-benefit analysis. Journal of Loss Prevention in the Process Industries 22, p. 403-407. 2009.

GN, GLOBO NOTICIAS. 2008. Disponível em: <http://g1.globo.com/Noticias/Economia_Negocios/0>. Acesso em 01 de Novembro de 2008.

GOMES, J. E. Cadeia de Suprimentos na Velocidade do Pensamento. Tese (Doutorado) Programa de Engenharia Mecânica, Escola Politécnica da Universidade de São Paulo, 2006. 
GREENBERG, H. R. e CRAMER, J. Risk Assessment and Risk Management in Process Industry. New York: Stone \& Webster Engineering Corporation, 1991. 392 p.

HÄGERBY, M., e JOHANSSON, M. Maintenance Performance Assessment strategies and Indicators. Linkoping: The Department of Production Economics Linköping Institute of Technology, 2002. 177p.

HAIMMES, Y. Y. Risk Modeling Assessment and Management. New York: John Wiley and Sons, 1998. 1010p.

HBE ENGINEERING Inc.. Anti-Flash Valve. 2007. Disponível em: <http://www.hbeengineering.com/download.shtml>. Acesso em: 15 Março de 2008.

HITACHI. Termal and Hidro Power Plants. Disponível em: <http://www.powerhitachi.com/products/gtp/h25h15/pa/ccs_system.html $>$. Acesso em: 6 de Outubro de 2008.

HU, H., et al. Risk-based maintenance strategy and its applications in a petrochemical reforming reaction system. Journal of Loss Prevention in the Process Industries 22, p. 392-397. 2009.

HUKAI, R. Y. Avaliação de projetos de geração e usos de energia. Notas de aula/disciplina de Doutorado, Instituto de Eletrotécnica e Energia da Universidade de São Paulo IEE, 2006.

JANJIC, A. e POPOVIC, D. Selective maintenance schedule of distribution networks based on risk management approach. IEEE Transactions on Power Systems 22-2. p 597-604. 2007. 
JOVANOVIC, A. Risk-Based Component life Management in Fossil Power Plants. Operation Maintenance and Materials Issues OMMI 1-1, p. 1-14. 2002

Risk-based inspection and maintenance in power and process plants in Europe. Nuclear Engineering and Design 226-2, p.165-182. 2003.

KEHLHOFER, R. H., WARNER, J., NIELSEN, H., e BACHANN, R. CombinedCycle Gas and Steam Turbine Power Plants. Tulsa: Penn Well Publishing Company, 1999. 298p.

KHAN, F. I. e HADDARA, M. M. Risk-based maintenance (RBM): a quantitative approach for maintenance/inspection scheduling and planning. Journal of Loss Prevention in the Process Industries 16, p. 561-573. 2003.

Risk-Based Maintenance (RBM): A new approach for process plant inspection and maintenance. 37th Annual Loss Prevention Symposium, p. 252-265. 2004a.

Risk-based maintenance of ethylene oxide production facilities. Journal of Hazardous Materials A108, p. 14-159. 2004b.

. Risk-based maintenance (RBM): A new approach for process plant inspection and maintenance. Wiley Inter Science, p. 1-14. 2004c.

KHAN, F., HADDARA, M e KRISHNASAMY, L. A new methodology for riskbased availability analysis. IEEE Transactions on Reliability Vol.57, No.1., p. 103112. 2008 . 
KHAN, F., SADIQ, R. e HADDARA, M. Risk-based Inspection and maintenance (RBIM) Multi-attribute decision-making with aggregative risk analysis. Trans IchemE, p. 398-412. 2004.

KRISHNASAMY, L., KHAN, F., e HADDARA, M. Development of a risk-based maintenance (RBM) strategy for a power-generating plant. Journal of Loss Prevention in the Process Industries 18, p. 69-81. 2005.

KUMAMOTO, H. e HENLEY, E. Probabilistic Risk Assessment and Management for Engineers and Scientists. New York: IEEE Press, 1996. 597 p.

LAFRAIA, J. R. B. Manual de Confiabilidade e Disponibilidade. Rio de Janeiro: Qualitymark Editora, 2001.

LEE, F. C. Plant maintenance strategy: evidence from four British manufacturing firms. Journal of Quality in Maintenance. p.239-249. 2003.

LEITCH, R. D. Reliability Analysis for Engineers: An introduction. New York: Oxford Press, 1995. 248p.

LEMES, D. V. Proposta de Método de Análise de Confiabilidade de Sistemas Eletrônicos Empregando Dados de Retorno de Garantia, 2006. Dissertação (Mestrado) Programa de Engenharia Mecânica da Escola Politécnica da Universidade de São Paulo, 2006.

LEMOS, A. Cana de açúcar em Energia: Uma contribuição para a solução do apagão. Jornal do IE 30 (Jornal), 13. 2007. 
LEWIS, E E. Introduction to Reliability Engineering. New York: Wiley \& Sons, 1987. 462p.

LORA, E. e NASCIMENTO, M. Geração Termelétrica. Rio de Janeiro: Intercienência, 2004.

MAGEE C. L., de WEECK O.L. Complex System Classification Fourteenth Annual International Symposium of the International Council On Systems Engineering (INCOSE), 2004.

MARMO, L., CRIVELLETTO, V. e STARACE, A. Recursive operability analysis as a decision support tool risk-based maintenance. Journal of Loss Prevention in the Process Industries 22, p. 557-565. 2009.

MARTORELL, S, et al. The use of maintenance indicators to evaluate the effects of maintenance programs on NPP performance and safety. Reliability Engineering and system Safety 65, p. 85-94. 1999.

MENDONÇA, J., REQUEIJO, J., LEAL, R. e PEREIRA Z. Optimização do período de substituição preventiva de componentes em função dos custos. 8 vo Congreso Iberoamericano de Ingeniería Mecánica, CIBIM8. 2007.

MODARRES, M. What Every Engineer Should Know About Reliability and Risk Analysis. New York: Marcel Dekker, INC, 1993.

MOLINARI, R.. Técnicas de manutenção para a qualidade total. São Paulo: Engenharia de Campo Qualidade - Prominp, 2007. 
MOORE, J. H., e WEATHERFORD L. Tomada de Decisão em Administração com Planilhas Eletrônicas. Porto Alegre RS: Artmed Editora S.A., 2005. 642p.

MOTA, J. Inspeção baseada em risco aplicação ao planejamento de paradas de manutenção. 3rd Panamerican conference for nondestructive testing - panndt. Rio de Janeiro. Petrobras, 2003.

MOUBRAY, J. Reliability-Centered Maintenance. Industrial Press, 2000. 426p.

NIELESEN, D S. The cause/consequence diagram method as a basis for quantitative accident analysis. RISO-M-1374. Denmark: Danish Atomic Energy Commission, Risoe. Research Establishment, 1971.

NILSON, F. Risk-based approach to plant life management. Nuclear Engineering and Design 221, p. 293-300. 2003.

NIST, NATIONAL INSTITUTE OF STANDARDS AND TECHNOLOGY. ISD's. Manufacturing Engineering Laboratory. 2008. Disponível em: http://www.isd.mel.nist.gov/projects/processcontrol/members/documents.html Acesso em 26 de 09 de 2008).

NITZ, L. M. Sistema de Inspección Basada en Riesgo. Buenos Aires: Universidad Austral Facultad de Ingeniería, p.1-5. 2004

NOWLAN, F STANLEY, e HEAP, H. Reliability-Centered Maintenance. National Technical Information Service, Report No. AD/A066-579. December 29, 1978.

O’CONNOR, P. D. Practical Reliability Engineering. New York: John \& Sons, 1985. 
OREDA. Offshore Reliability Data Handbook. OREDA Participants. Det Norske Veritas (DNV). Norway, 2002.

ONS. OPERADOR NACIONAL DO SISTEMA. Geração de Energia Elétrica 2008. Disponível em: <http://www.ons.com.br/historico/geracao_energia_out.aspx?area=>. Acesso em 22 de Outubro de 2008.

PAUPERAS, J. Cause-Consequence Analysis of a generic space station computer system. Proceedings annual Reliability and Mantenability Symposium. Huntington Beach: McDonnell Douglas Space Systems Company, p. 196-201. 1991.

PERRYMAN, L., FOSTER, N. e NICHOLLS, D. Using PRA in support of maintenance optimization. International Journal of Pressure Vessels and Piping 61, 2-3, p. 593-608. 1995.

PEZZI, M. F. Aplicação da IBR, Inspeção Baseada em Risco a oleodutos segundo o API851 BRD verificação de consistência com as práticas usuais da indústria para avaliação de risco, 2003. Dissertação (Mestrado) apresentada à Pontifícia Universidade Católica do Rio de Janeiro, Maio de 2003.

PINNA, T., CAPORALI, R., CAMBI, G., BURGAZZI, L., POUCET, A. e PORFIRI, M. Failure mode and effect analysis on ITER heat transfer systems. Fusion Engineering and Design, p. 431-436. 1998.

PRIBERAM. Dicionário Eletrônico Priberam. Disponível em: <http://www.priberam.pt/dlpo/definir_resultados.aspx >. Acesso em 12 de novembro de 2008. 
RAE. Dicionário Electrónico de la Real Academia de la Lengua Española. Disponível em: 〈http://www.rae.es/rae.html.>. Acesso em: 21 de novembro de 2008.

RAUSAND, M. Reliability centered maintenance. Reliability Engineering and System Safety 60, p. 121-132. 1998.

RAUSAND, M, e HOYLAND, A. System Reliability Theory; Models, statistical methods and application. Ney Jersey: Wiley, 2004.

REDLEY, L. M. e ANDREWS, J. Reliability of sequential systems using the Causeconsequence diagram method. Proceedings of the institution of Mechanical Engineering. Part E, Journal of process mechanical engineering ISSN 0954-4089, p. 207-220. 2001.

Application of the Cause-Consequence diagram method to static systems. Proceedings of the Institution of Mechanical Engineers, Part E: Journal of Process Mechanical Engineering 215, p. 207-220. 2000

REIS, M. M. Custos ambientais associados à geração elétrica. Rio de Janeiro: Universidade Federal do Rio de Janeiro, 2001.

RIMAP, RISK BASED INSPECTION AND MAINTENANCE PROCEDURES EUROPEAN INDUSTRY. ANGELSEN S., JOHANSSON M. POLLOCK A., VÅGE G. Risk Based Inspection and Maintenance Procedures for European Industry RIMAP Project. Norway 2001.

ROLL-ROYCE. The Jet Engine Roll-Ryce. London: Roll-Royce, 1986. 
SAE THE SOCIETY OF AUTOMOTIVE ENGINEERS 1739. Potential failure mode and effects analysis. Warrendale SAE International. 2002. 57p

SÁNCHEZ, M. S. Introducción a la confiabilidad y evaluación de Riesgos. BogotáColombia: Ediciones Unidas, 2005. 466p

SANTOS, A. F. Gerenciamento da confiabilidade em projetos de material rodante ferroviário, 2007. Dissertação (Mestrado) Programa de Engenharia Mecânica da Escola Politécnica da Universidade de São Paulo, 2007.

SCHERER, F. Custos De Manutenção na Operação de Sistemas de Geração de Ciclo Combinado. Entrevista realizada em 8 de dezembro de 2006.

SCHÖDER, H-C., e KAUER R. Regulatory requirements related to risk-based inspection and maintenance. International Journal of Pressure Vessels and Piping81. p. 847-854. 2004.

SCHUYLER, J. Risk and Decision Analysis in Projects. Pennsylvania: Project Management Institute, Inc., 2002.

SHIMIZU, T. Decisão nas Organizações. São Paulo: Atlas S.A., 2001.

SIEMENS. Energy Siemens. Disponível em:

<http://www.powergeneration.siemens.com/press/press-pictures/gas-turbines/gasturbine-4.htm>. Acesso em: 06 de abril de 2009.

SIMPSON, J. The application of risk based Inspection to pressure vessels and aboveground storage tanks in petroleum fuel refineries. 5th Australasian Congress on Applied Mechanics, ACAM. 2007. 
SMITH, A. M., e HINCHCLIFFE, G. R. RCM gateway to world class maintenance. Oxford: Linacre House, Jordan Hill, 2004. 336p.

SOARES, D. A inserção e operação otimizada de centrais termelétricas no sistema elétrico Brasileiro. Escola Politécnica da Universidade de São Paulo, 2000.

SOARES, F H, e D RAMOS. Impactos da Operação de Usinas Termelétricas Contratadas por Disponibilidade no Custo da Energia Adquirida em Leilões de Energia Nova. XIII ERIAC Décimo tercer encuentro regional iberoamericano de CIGRÉ. 2009.

SOUZA, G. F. M. Análise de Confiabilidade Aplicada ao Projeto de Sistemas Mecânicos. Disciplina de pós-graduação e Apostila. Departamento de Engenharia Mecatrônica e Sistemas Mecânicos da Escola Politécnica da Universidade de São Paulo. 2003.

PMR 5401 Análise de Risco Aplicada a Avaliação da Integridade de Sistemas Mecânicos. Disciplina de pós-graduação e Apostila. Departamento de Engenharia Mecatrônica e Sistemas Mecânicos da Escola Politécnica da Universidade de São Paulo. 2006.

SUOKAS, J. e ROUHIAINEN, V. Quality management of Safety and Risk Analysis. Elsevier Science Publishers, 1993.

SUSTERAS, G. Luiz. Aplicação de algoritmos genéricos para prevenção do comportamento das distribuidoras como apoio à estratégia de comercialização de energia de agentes geradores, 2006. Dissertação (Mestrado) Programa de Engenharia Mecânica da Escola Politécnica da Universidade de São Paulo. 2006. 
TEIXEIRA, B. S. Análise de Disponibilidade em Máquinas Operatrizes: Uma Aplicação a Máquinas Têxteis. Dissertação (Mestrado) Programa de Engenharia Mecânica da Escola Politécnica da Universidade de São Paulo. 2008.

TIEN, S., HWANG, W. e TSAI, C. Study of risk-based piping inspection guideline system. ISA Transactions 46, p. 119-126. 2007.

TIXIER, J, DUSSERRE, G, SALVI, O e GASTON, D. Review of 62 risk analysis methodologies of industrial plants. Journal of Loss Prevention, p. 291-303. 2002.

TODOLA, A. Steam and Gas Turbine. New York: Loewentein, Peter Shitm, 1945.

TOLMASQUIM, M. T. Energia. 2001. Disponível:

< http://www2.mre.gov.br/cdbrasil/itamaraty/web/port/economia/energia/apresent/index.

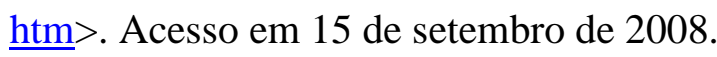

TOSHIBA, Power Systems Company. RBM Risk Based Maintenance. 2000 disponível em:

〈http://www3.toshiba.co.jp/power/english/thermal/service/support/gene7/rbm.htm\#top > . Acesso em 22 de agosto de 2008.

TSURU, D., ENOEDA, M. e AKIBA, M. Recent progress in safety assessment of Japanese water-cooled. Fusion Engineering and Design 83.p. 1747-1752. 2008.

VESELY, W. E., BELHADJ, M, e REZOS, J. T. PRA importance measure for maintenance prioritization applications. Reliability Engineering and System Safety 43, p. 307-318. 1993. 
VILLLEMEUR, A. Reliability, Availability, Maintainability and Safety Assessment. West Sussex: John Wiley \& Sons Ltd, 1992.

VOLKANOSVSKI, A., CEPIN, M., e MAVKO, B. Application of the fault tree analysis for assessment of power system reliability. Reliability Engineering and System Safety 94, p. 1116-1127. 2009

WANG, J. X. e ROUSH, R. L. What Every Engineer should know about Risk Engineering and Management. New York: Marcel Dekker, Inc., 2000.

WYLEN, VAN, SONNTAG, e BORGNAKKE. Fundamentos da Termodinâmica. São Paulo: Edgard Blucher LTDA., 2001.

ZHAO, Y., VOLOVOI, V. e WATERS, D. A sequential approach for gas turbine power plant preventative maintenance scheduling. Journal of Engineering for Gas Turbines and Power, p. 796-805. 2006a

A profit-based approach for gas turbine power plant outage planning. Journal of Engineering for Gas Turbines and Power, p.806-814. 2006b. 


\section{APÊNDICE A - REAVALIAÇÃO DO PROBLEMA DO PONTO DE VISTA TÉCNICO}




\section{A.1. Análise do Problema do Ponto de Vista Técnico}

O problema da alta freqüência de falhas no sistema de alimentação de água, aqui analisado não seria resolvido apenas com a instalação de um sistema redundante de alimentação de água, como mostrou a análise de decisão e risco executada no decorrer do trabalho. Por esse motivo o método apresenta uma etapa de reavaliação e neste item é apresentada tal reavaliação do problema do ponto de vista técnico, para tentar resolver o problema, com aplicação dos conceitos da análise de risco SMBR.

\section{A.1. Reavaliação do Problema}

Baseado em todas as análises efetuadas até aqui, pode-se concluir que a instalação do sistema redundante não resolveria o problema da incapacidade de bombear água do sistema de alimentação de água da caldeira. Os TRIPs que vem ocasionando a parada do sistema são basicamente problemas no aumento da recirculação de água pela válvula ARC. Da mesma forma, o TRIP que descreve a alta pressão na linha de balance é ocasionado pela falha mecânica da válvula ARC.

Estudos da operação do sistema de alimentação de água mostram que este está composto basicamente pelos componentes da bomba principal de múltiplos estágios, sistema de recirculação, tanques e válvulas, sendo a operação da válvula ARC a situação mais delicada de se analisar. Para detalhar a operação do sistema, na Figura A.1, mostra-se a representação do sistema de alimentação de água das caldeiras de recuperação.

A função da válvula ARC é permitir a recirculação automática de água no caso em que a pressão no tanque de vapor é muito alta. Mas quando a válvula opera recirculando por períodos muito longos, sob desgaste acelerado, ocorre o TRIP "aumento 
da recirculação de água pela válvula ARC” e, conseqüentemente, o TRIP que descreve "alta pressão na linha de balance". Ainda provoca um problema mais sério que é o baixo nível de água no tanque de alta pressão da caldeira de recuperação, fato que provoca a parada total do sistema.

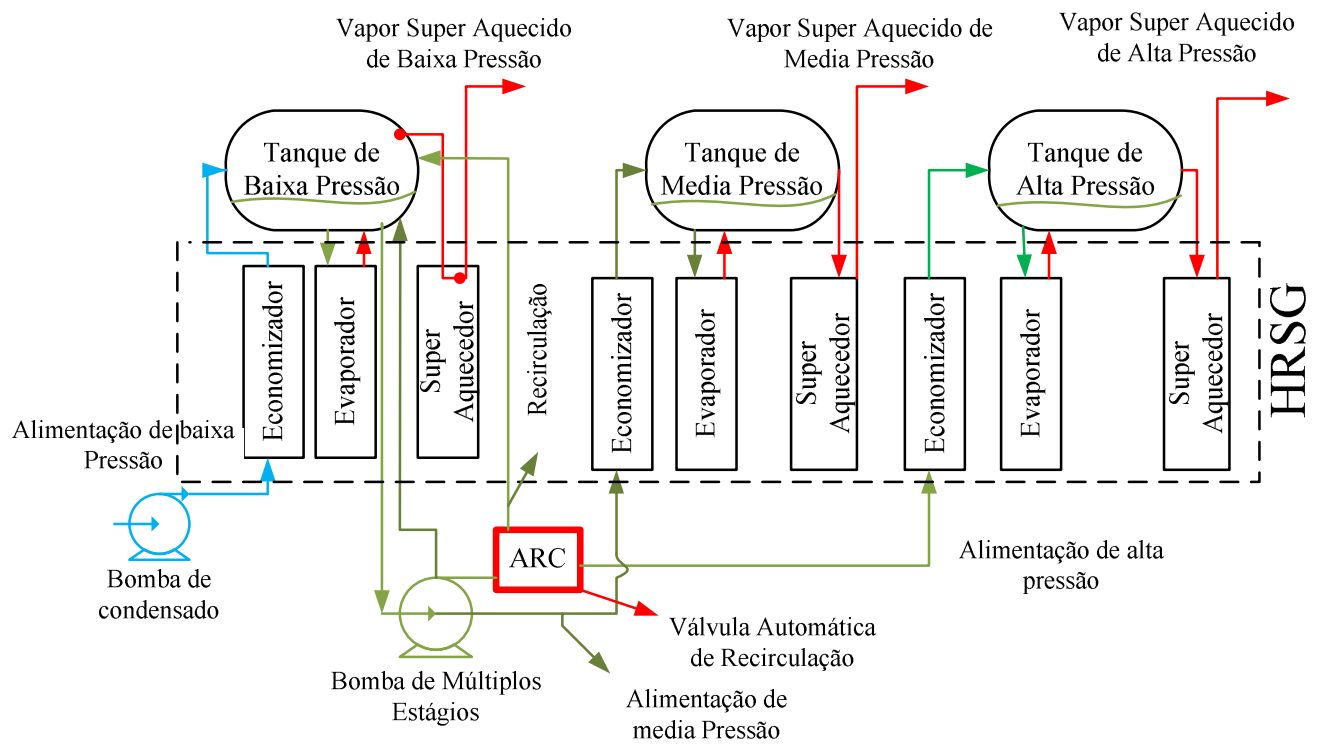

Figura A.1. Sistema de alimentação de água da caldeira de recuperação

Baseado na aplicação do diagrama causa-conseqüência pode-se identificar onde poderiam ser instaladas barreiras a fim de conter as consequiências de uma eventual falha indesejada. Mas também onde poderiam ser instaladas barreiras com a finalidade de evitar a sua ocorrência. Isto não poder ser feito sem um conhecimento do fenômeno físico-mecânico que desencadeia esta falha indesejada na válvula ARC, e o aumento da recirculação de água pela válvula.

A Figura A.2 mostra como o sistema de recirculação de água opera dentro do sistema de alimentação de água da caldeira de recuperação. A válvula é identificada com um quadro vermelho com a sigla ARC dentro da mesma figura. Esta válvula está localizada logo após a descarga de alta pressão da bomba de múltiplos estágios. Em relação à bomba de múltiplos estágios pode-se afirmar que "é muito específica para este tipo de operação e fornece água aos sistemas de geração de vapor de média e alta pressão, com descargas independentes". A função do sistema "ARC” é recircular água 
para o tanque de baixa pressão quando a pressão da linha ou no tanque de alta pressão ultrapasa uma determinada medida especificada pelo projeto.

O que vinha acontecendo é que esta válvula estava sofrendo desgaste prematuro em uma das suas partes, como mostram as Figuras A.2 e A.3. Ao perder a capacidade de vedar o sistema de recirculação, um volume de água fora de controle era retornado para o tanque de baixa pressão, o que disparava o TRIP de "alto nível de re-círculo pela válvula ARC".

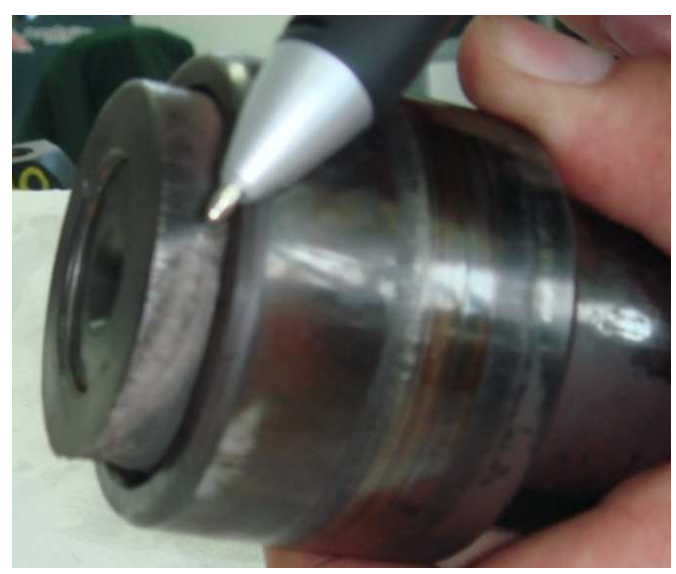

Figura A.2. Desgaste no corpo da válvula redutora de pressão

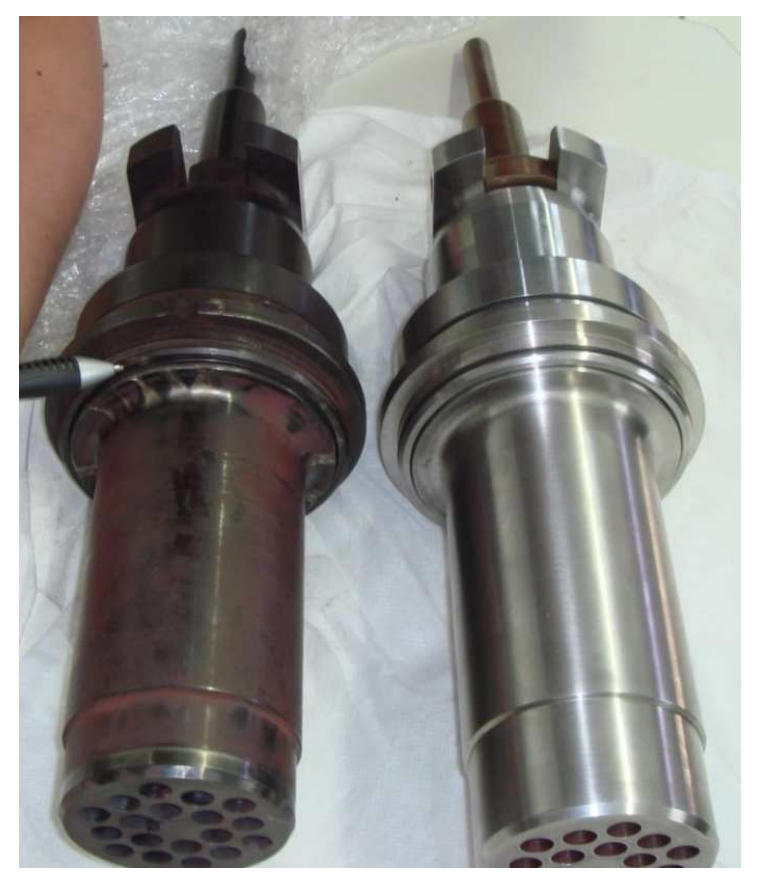

Figura A.3.Válvulas redutoras de pressão 
A composição interna da válvula é mostrada na Figura A.4 onde podem ser identificados os componentes, já bem conhecidos, mas que operam de forma conjunta dentro de uma única válvula.

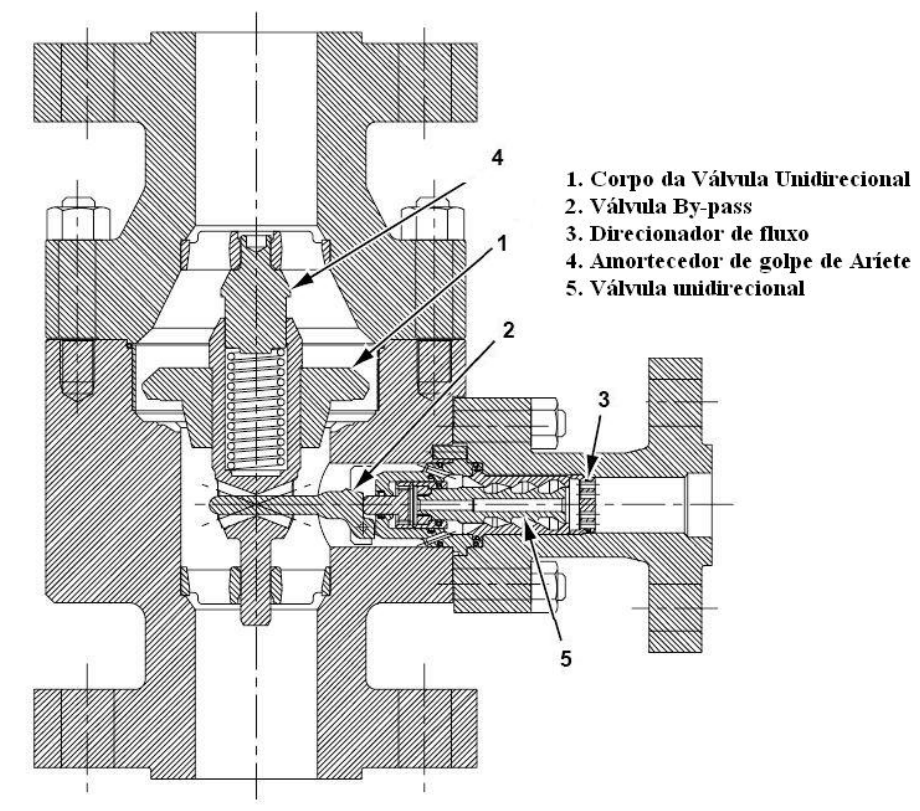

Figura A.4. Válvula automática de recirculação de água

Esses componentes são: 1. Corpo da válvula unidirecional, que evita o retorno de fluxo encaminhando-o para a válvula by-pass; 2 . Válvula by-pass modular que inclui módulos de redução de pressão; 3. Direcionador de fluxo, para eliminar a turbulência do fluxo de descarga; 4. Amortecedor de golpe de aríete (waterhammer dampener); 5. Válvula unidirecional, evita o retorno do fluxo, da forma que a válvula ARC está estruturada (HBE, 2007).

O sistema de recirculação de água é composto pela válvula de recirculação e do lado da descarga está acoplada uma válvula redutora de pressão. É justamente este componente redutor de pressão que está apresentando o desgaste acelerado e/ou excessivo, como mostrado nas Figuras A.2 e A.3, correspondendo aos componentes aos componentes de número 2 e 5 da Figura A.4.

Na Figura A.5 é apresentado o diagrama de operação do sistema de alimentação de água incluindo a presença da válvula de recirculação de água. 


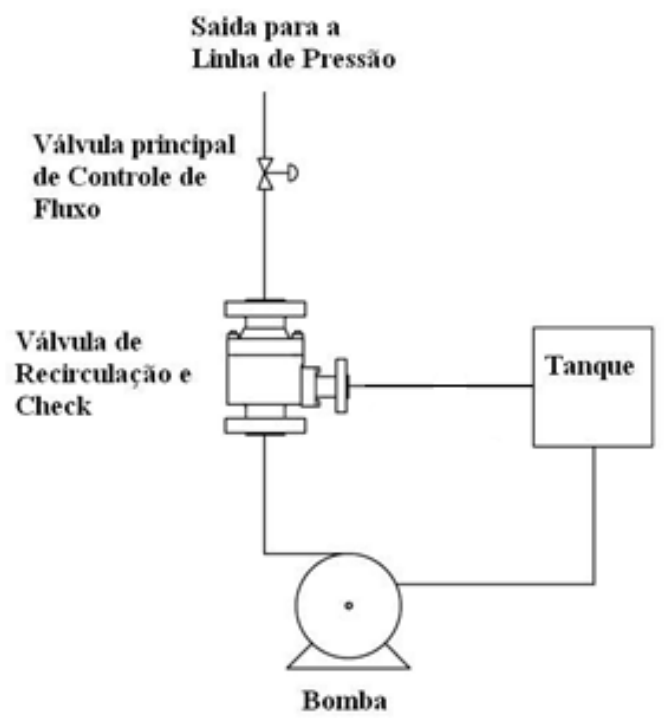

Figura A.5. Sistema de recirculação da água

O estudo para definir o fenômeno que estava ocasionando o desgaste prematuro do componente, trouxe uma série de novas pesquisas que finalmente se transformaram em recomendações a serem implementadas no sistema com a finalidade de reduzir a ocorrência de falhas no mesmo.

O fenômeno que estava produzindo este desgaste é conhecido, na linguagem da termodinâmica, como flash que, de forma resumida, pode ser descrito como uma redução súbita de pressão chegando a níveis abaixo da pressão de saturação da água, o que traz como conseqüência a mudança de estado físico, de água para vapor.

Voltando para a operação do sistema sob análise, em condições normais de operação, a vazão de entrada no tanque de alta pressão da caldeira é regulada pela válvula "controladora de fluxo" que, por sua vez, é controlada pelo sensor de nível no tanque, interligação obtida da elaboração da análise do sistema em combinação com o diagrama causa-conseqüência. Assim, se o nível de água no tanque é o necessário ou superior ao necessário, a válvula controladora de fluxo fecha a passagem de água para o tanque. Neste momento, o sistema de recirculação é ativado, pois a função do mesmo é proteger a bomba e evitar sobrecarga. A vazão de recirculação é encaminhada para o tanque de baixa pressão, mas para evitar danos no mesmo a pressão da água de recirculação é reduzida, por uma válvula redutora de pressão embutida na válvula ARC. 
Fisicamente, para conseguir esta redução de pressão, pode-se optar por reduzir a seção de escoamento, mas se esta não está bem controlada o fenômeno do flash pode ocorrer e, de fato, era isto o que vinha acontecendo no interior da válvula ARC do sistema sob análise.

Neste contexto e com a aplicação dos conceitos de confiabilidade, é sugerida a instalação de uma barreira que permita controlar a queda de pressão de forma gradual evitando o fenômeno de flash e, conseqüentemente, diminuindo o desgaste acelerado da válvula e, desta forma, evitando todos os problemas já discutidos ao longo do presente trabalho.

Após um profundo estudo de um sistema com características similares, chegouse a conclusão de que estes fenômenos são controlados com a instalação de válvulas anti-flash, o que trouxe um novo desafio, pois a possível solução envolveria a modificação do projeto da instalação de qualquer forma.

A operação da válvula anti-flash é simples. Esta opera como uma válvula controladora de pressão que garante uma queda de pressão controlada na linha de pressão na descarga da bomba e no caso específico, na saída da válvula ARC, como ilustrado na Figura A.6 (HBE, 2007).

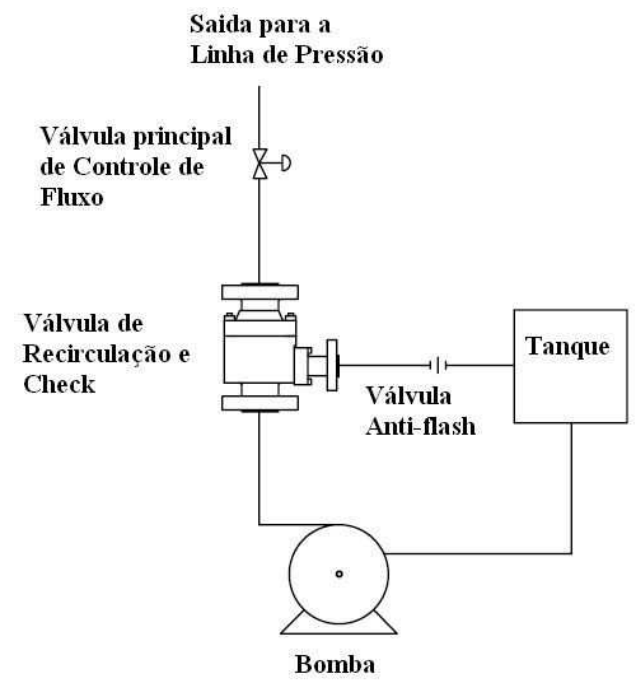

Figura A.6. Sistema de recirculação da água com válvula anti-flash 
Na Figura A.7 é descrito o fenômeno que acontece durante a operação da válvula ARC com linhas vermelhas e o que aconteceria com a correta instalação da válvula anti-flash, pois foi comprovado que apenas a instalação do componente não resolve os problemas, mas este tem que estar perfeitamente calibrado.

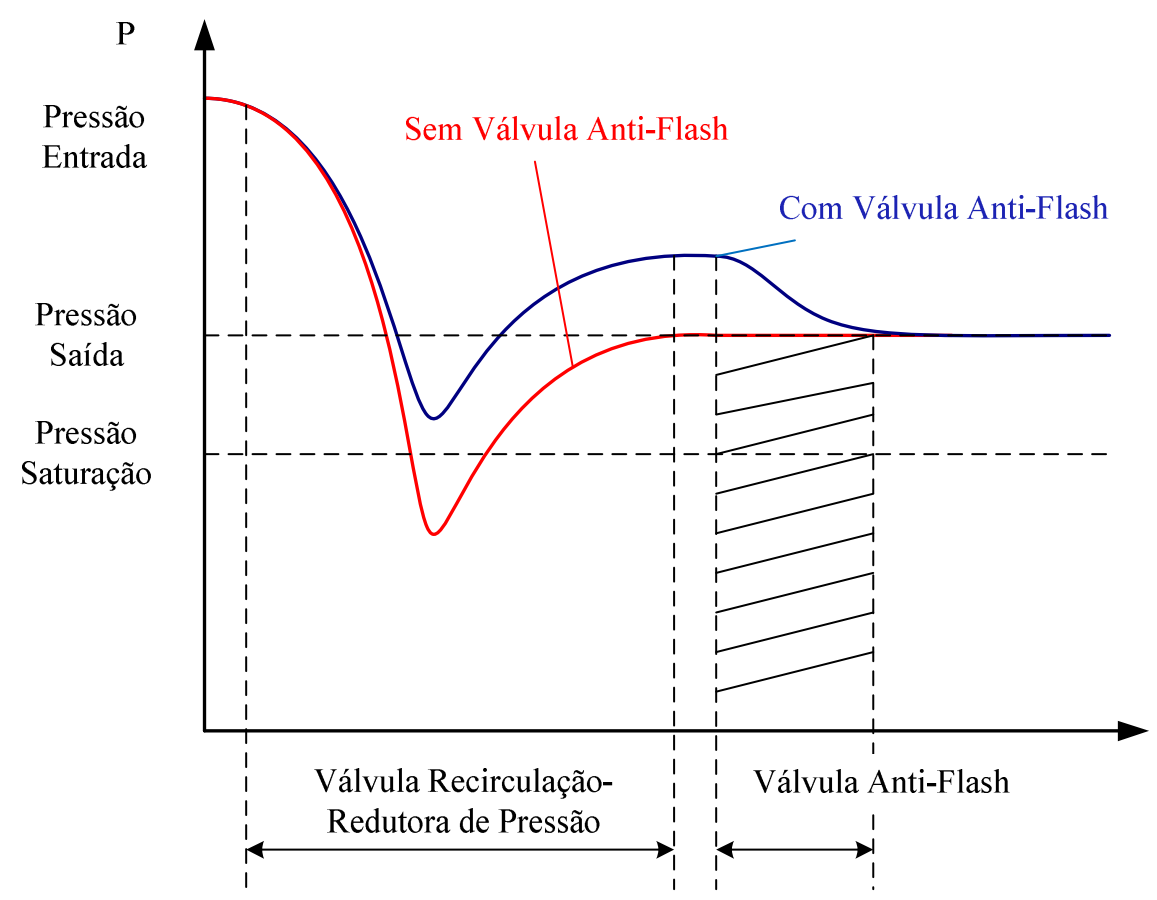

Figura A.7. Comportamento da água dentro do sistema de recirculação

Entendido o fenômeno e como parte das conclusões do estudo, é recomendada a instalação desta válvula anti-flash no sistema de recirculação de água. A válvula e os seus principais componentes são apresentados na Figura A.8.

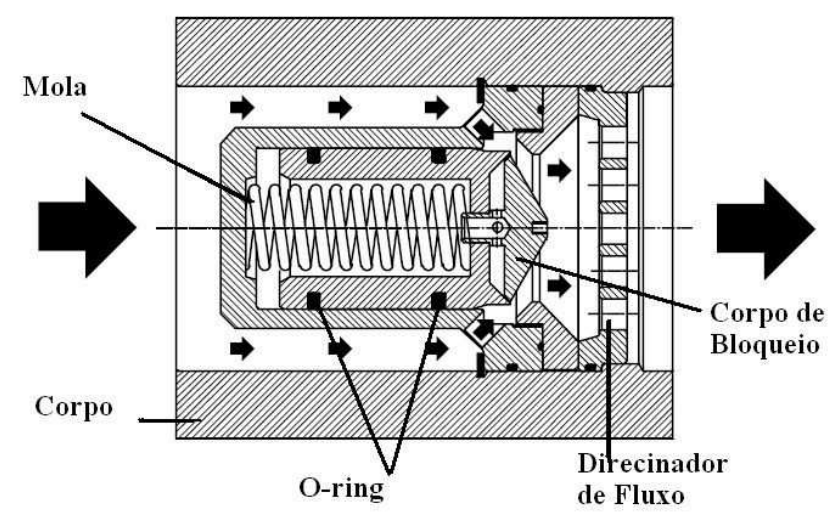

Figura A.8. Válvula anti-flash (HBE, 2007) 
Esta recomendação foi posta em prática para o sistema de recirculação de água em que os problemas de paradas da usina por falha neste sistema foram eliminados e, descartadando-se totalmente a hipótese da instalação de um sistema redundante de água. 
APENDICE B - ANÁLISE DE MODOS E EFEITOS DE FALHAS PARA O SISTEMA DE ALIMENTAÇÃO DE ÁGUA DAS CALDEIRAS DE RECUPERAÇÃO 


\section{B.1. Bomba de Circulação de Água}

\section{B.1.1. Bomba}

\begin{tabular}{|c|c|c|c|c|}
\hline \multicolumn{2}{|c|}{$\begin{array}{l}\text { Componente: Bomba } \\
\text { Sistema: Bomba de Circulação de Água }\end{array}$} & \multirow[b]{2}{*}{$\begin{array}{l}\text { Causa(s) Potencial(is) de } \\
\text { Falha }\end{array}$} & \multicolumn{2}{|l|}{$\begin{array}{l}\text { Página: de } \\
\text { Data inicial: }\end{array}$} \\
\hline Função & Modo de Falha & & Efeito(s) Potencial (is) da Falha & $\mathbf{S}$ \\
\hline \multirow[t]{2}{*}{$\begin{array}{l}\text { Transmitir energia } \\
\text { mecânica para o } \\
\text { condensado, } \\
\text { movimentando-o }\end{array}$} & $\begin{array}{l}\text { Incapacidade de } \\
\text { bombear }\end{array}$ & $\begin{array}{l}\text { 1) Falha nos mancais; } \\
\text { 2) Ruptura do impelidor; } \\
\text { 3) Bloqueio da linha se } \\
\text { sucção e/ou recalque } \\
\text { 4) Falha no motor elétrico }\end{array}$ & $\begin{array}{l}\text { 1) Não há vazão de condensado para o estágio de alta pressão } \\
\text { 2) Bomba de alimentação não fornece vazão de condensado para estágio de alta pressão; } \\
\text { 3) Sistema de geração de vapor inoperante devido à inexistência de vazão de condensado; } \\
\text { 4) Caldeira de recuperação inoperante, devido à falta de condensado no estágio de alta pressão; } \\
\text { 5) Usina com ciclo a vapor inoperante devido à falta de condensado na entrada do estágio de alta pressão, } \\
\text { operação em ciclo aberto. }\end{array}$ & 7 \\
\hline & $\begin{array}{l}\text { Bombear fluxo com } \\
\text { vazão inferior à } \\
\text { especificada no } \\
\text { projeto }\end{array}$ & $\begin{array}{l}\text { 1) Desgaste no impelidor; } \\
\text { 2) Linha de suçãa } \\
\text { parcialmente bloqueada; } \\
\text { 3) Cavitação }\end{array}$ & $\begin{array}{l}\text { 1) Vazão de condensado na saída da bomba inferior ao especificado em projeto; } \\
\text { 2) Sistema bomba de alimentação fornece vazão de condensado no estágio de alta pressão insuficiente para } \\
\text { manter as condições normais de operação previstas em projeto; } \\
\text { 3) Sistema de geração de vapor operando com vazão de condensado no estágio de alta pressão com valor } \\
\text { inferior ao previsto em projeto, vapor com pressão e volume que não atendem as condições de projeto; } \\
\text { 4) Caldeira de recuperação operando com vazão de condensado de alta pressão inferior ao previsto em } \\
\text { projeto, não são atingidas as condições operacionais previstas em projeto; } \\
\text { 5) Possibilidade da usina operar com potência inferior a nominal de projeto devido a falha na caldeira, } \\
\text { afetando a eficiência do ciclo vapor. }\end{array}$ & 5 \\
\hline
\end{tabular}

\section{B.1.2. Motor Elétrico da Bomba de Circulação de Água}

\begin{tabular}{|c|c|c|c|c|}
\hline \multicolumn{2}{|c|}{$\begin{array}{l}\text { Componente: Motor elétrico } \\
\text { Sistema: Bomba de Circulação de água }\end{array}$} & & \multicolumn{2}{|l|}{$\begin{array}{l}\text { Página: de } \\
\text { Data inicial: }\end{array}$} \\
\hline Função & $\begin{array}{l}\text { Modo de Falha } \\
\text { Potencial }\end{array}$ & $\begin{array}{c}\text { Causa(s) Potencial (is) de } \\
\text { Falha }\end{array}$ & \multicolumn{2}{|l|}{ Efeito(s) Potencial (is) da Falha } \\
\hline $\begin{array}{l}\text { Transformar } \\
\text { energia elétrica em } \\
\text { energia mecânica } \\
\text { para o } \\
\text { acionamento da } \\
\text { bomba }\end{array}$ & $\begin{array}{l}\text { Não há } \\
\text { transformação de } \\
\text { energia elétrica em } \\
\text { energia mecânica }\end{array}$ & $\begin{array}{l}\text { 1) Perda do isolamento } \\
\text { devido a ação da } \\
\text { umidade, com queima do } \\
\text { bobinado. } \\
\text { 2) Travamento dos mancais } \\
\text { devido ao processo de } \\
\text { fadiga. }\end{array}$ & $\begin{array}{l}\text { 1) Não há vazão de condensado para o estágio de alta pressão } \\
\text { 2) Bomba de alimentação não fornece vazão de condensado para estágio de alta pressão; } \\
\text { 3) Sistema de geração de vapor inoperante devido a inexistência de vazão de condensado na entrada do } \\
\text { estágio de alta pressão; } \\
\text { 4) Caldeira de recuperação inoperante, devido à falta de condensado no estágio de alta pressão } \\
\text { 5) Usina com ciclo a vapor inoperante devido à falta de condensado na entrada do estágio de alta pressão da } \\
\text { caldeira, operação em ciclo aberto. }\end{array}$ & 7 \\
\hline
\end{tabular}




\section{B.1.3. Sistema Elétrico da Bomba de Circulação de Água}

\begin{tabular}{|c|c|c|c|c|}
\hline \multicolumn{2}{|c|}{$\begin{array}{l}\text { Componente: Sistema elétrico } \\
\text { Sistema: Bomba de Circulação água }\end{array}$} & \multirow[b]{2}{*}{$\begin{array}{l}\text { Causa(s) e Mecanismo(s) } \\
\text { Potencia l(is) de Falha }\end{array}$} & \multicolumn{2}{|l|}{$\begin{array}{l}\text { Página: de } \\
\text { Data inicial: }\end{array}$} \\
\hline Função & $\begin{array}{l}\text { Modo de Falha } \\
\text { Potencial }\end{array}$ & & Efeito(s) Potencial (is) da Falha & $\mathbf{S}$ \\
\hline \multirow[t]{4}{*}{$\begin{array}{l}\text { Controlar a } \\
\text { operação do motor } \\
\text { do conjunto bomba } \\
\text { de alimentação } \\
\text { para estágio de alta } \\
\text { pressão }\end{array}$} & $\begin{array}{l}\text { Disjuntor: } \\
\text { a) Interromper } \\
\text { corrente. }\end{array}$ & $\begin{array}{l}\text { 1) Desgaste do mecanismo } \\
\text { de disparo. }\end{array}$ & $\begin{array}{l}\text { 1) Há acionamento do disjuntor com valores de corrente do motor ao valor admissível em projeto; } \\
\text { 2) Conjunto bomba de alimentação não atinge a condição de operação normal (vazão de projeto do } \\
\text { condensado para alta pressão); } \\
\text { 3) Sistema de geração de vapor impossibilitado de operar na condição de projeto; } \\
\text { 4) Caldeira de recuperação impossibilitada de operar na condição de projeto por falha na alimentação de } \\
\text { condensado para estágio de alta pressão; } \\
\text { 5) Ciclo a vapor impossibilitado de operar na condição nominal de projeto por falha na caldeira de } \\
\text { recuperação. }\end{array}$ & 4 \\
\hline & $\begin{array}{l}\text { Contator; } \\
\text { a) Não conduzir } \\
\text { corrente elétrica; } \\
\text { b) Não interromper } \\
\text { corrente elétrica }\end{array}$ & $\begin{array}{l}\text { a) 1) Bobina queimada; } \\
\text { 2) Contato principal } \\
\text { carbonizado; } \\
\text { b) 1) Contatos principais } \\
\text { fundidos por aquecimento. }\end{array}$ & $\begin{array}{l}\text { a) 1) Não há acionamento do motor elétrico; } \\
\text { 2) Bomba de alimentação não fornece vazão de condensado para estágio de alta pressão; } \\
\text { 3) Sistema de geração de vapor inoperante devido à inexistência de vazão de condensado; } \\
\text { 4) Caldeira de recuperação inoperante, devido à falta de condensado no estágio de alta pressão } \\
\text { 5) Usina com ciclo a vapor inoperante devido à falta de condensado na entrada do estágio de alta pressão da } \\
\text { caldeira, operação em ciclo aberto. }\end{array}$ & 7 \\
\hline & $\begin{array}{l}\text { Rele térmico: } \\
\text { a) Não detectar } \\
\text { aumento de } \\
\text { temperatura para } \\
\text { interromper } \\
\text { corrente; } \\
\text { b) Interromper } \\
\quad \text { corrente. } \\
\end{array}$ & $\begin{array}{l}\text { Envelhecimento, desgaste } \\
\text { dos contatos internos. }\end{array}$ & $\begin{array}{l}\text { 1) Há acionamento do rele térmico com valores de corrente do motor inferior ao valor admissível em projeto; } \\
\text { 2) Conjunto bomba de alimentação de condensado de alta pressão não atinge a condição de operação normal } \\
\text { (vazão de projeto); } \\
\text { 3) Sistema de geração de vapor impossibilitado de operar na condição nominal de projeto por falha no } \\
\text { conjunto bomba de alimentação de condensado de alta pressão; } \\
\text { 4) Caldeira de recuperação impossibilitada de operar na condição de projeto por falha na bomba de } \\
\text { alimentação; } \\
\text { 5) Ciclo a vapor impossibilitado de operar na condição nominal de projeto por falha na caldeira. }\end{array}$ & $\begin{array}{l}1 \\
14\end{array}$ \\
\hline & $\begin{array}{l}\text { Fiação do motor } \\
\text { a) Fiação } \\
\text { interrompida ou } \\
\text { queimada. } \\
\text { b) Mau contato na } \\
\text { fiação. }\end{array}$ & $\begin{array}{l}\text { a)1)Ação ambiental externa } \\
\text { (corrosão); } \\
\text { 2)Aquecimento. } \\
\text { b)1) Perda de torque nas } \\
\text { conexões elétricas. }\end{array}$ & $\begin{array}{l}\text { a) 1) Não há acionamento do motor elétrico; } \\
\text { 2) Bomba de alimentação não fornece vazão de condensado para estágio de alta pressão; } \\
\text { 3) Sistema de geração de vapor inoperante devido a inexistência de vazão de condensado na entrada do } \\
\text { estágio de alta pressão; } \\
\text { 4) Caldeira de recuperação inoperante, devido à falta de condensado no estágio de alta pressão } \\
\text { 5) Usina com ciclo a vapor inoperante devido a falta de condensado na entrada do estágio de alta pressão da } \\
\text { caldeira, operação em ciclo aberto. } \\
\text { b) 1) Acionamento intermitente do motor elétrico; } \\
\text { 2) Conjunto bomba de alimentação de condensado de alta pressão com operação intermitente; } \\
\text { 3) Sistema de geração de vapor com operação intermitente do estágio de alta pressão; } \\
\text { 4) Caldeira de Recuperação com operação intermitente por falha na alimentação de condensado; } \\
\text { 5) Ciclo a vapor com operação intermitente. }\end{array}$ & 7 \\
\hline
\end{tabular}


B.1.4. Sistema Pneumático de Controle do Sistema de Alimentação de Água

B.1.4.1. Válvula de Pneumática

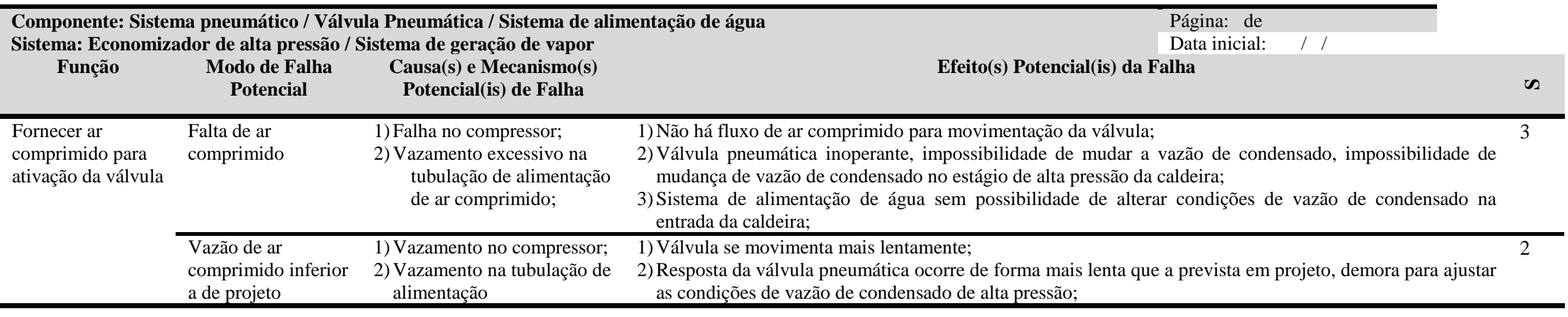

\section{B.1.4.2. Controle Pneumático}

\begin{tabular}{|c|c|c|c|c|}
\hline \multirow{2}{*}{\multicolumn{4}{|c|}{$\begin{array}{l}\text { Componente: Controle pneumático /Válvula Pneumática / Sistema de alimentação de água } \\
\text { Sistema: Economizador de alta pressão / Sistema de geracão de vapor }\end{array}$}} & \multirow[b]{3}{*}{ n } \\
\hline & & & \multirow{2}{*}{$\begin{array}{l}\text { Data inicial: } \\
\text { Efeito(s) Potencial(is) da Falha }\end{array}$} & \\
\hline Função & $\begin{array}{l}\text { Modo de Falha } \\
\text { Potencial }\end{array}$ & $\begin{array}{l}\text { Causa(s) Potencial(is) de } \\
\text { Falha }\end{array}$ & & \\
\hline \multirow[t]{3}{*}{$\begin{array}{l}\text { Controlar abertura } \\
\text { ou fechamento da } \\
\text { válvula }\end{array}$} & $\begin{array}{l}\text { Movimentação } \\
\text { com velocidade } \\
\text { instável }\end{array}$ & $\begin{array}{l}\text { 1) Contaminação do ar } \\
\text { comprimido com detritos, } \\
\text { 2) Vazamentos internos. } \\
\end{array}$ & $\begin{array}{l}\text { 1) Tempo de resposta da válvula diferente do previsto em projeto; } \\
\text { 2) Válvula pneumática com variação no tempo de resposta, variação no tempo de ajuste da condição } \\
\text { operacional da caldeira; }\end{array}$ & 2 \\
\hline & Falha no atuador & $\begin{array}{l}\text { 1) Falta de ar comprimido; } \\
\text { 2) Quebra/Desgaste de } \\
\text { elementos mecânicos no } \\
\text { atuador; } \\
\text { 3) Bloqueio da linha de ar } \\
\text { comprimido. }\end{array}$ & $\begin{array}{l}\text { 1) Não há imposição de movimento à válvula, } \\
\text { 2) Válvula automatizada inoperante, impossibilidade de mudança de condição operacional (alteração da } \\
\text { vazão de condensado de alta pressão); }\end{array}$ & 3 \\
\hline & $\begin{array}{l}\text { Operação } \\
\text { intermitente do } \\
\text { sensor que envia } \\
\text { sinal para o } \\
\text { atuador }\end{array}$ & $\begin{array}{l}\text { 1) Falha do sensor; } \\
\text { 2) Problemas internos no } \\
\text { registrador/condicionador de } \\
\text { sinais; } \\
\text { 3) Problemas na ligação entre } \\
\text { sensor e atuador. }\end{array}$ & $\begin{array}{l}\text { 1) Válvula recebe comando de movimentação de forma intermitente; } \\
\text { 2) Válvula pneumática apresenta operação de forma intermitente; } \\
\text { 3) Sistema de alimentação apresentando falha no controle da vazão de condensado na entrada do estágio de } \\
\text { alta pressão da caldeira; } \\
\text { 4) Economizador de alta pressão apresentando falha no controle de vazão de condensado; } \\
\text { 5) Sistema de geração de vapor apresentando falha no controle de vazão de condensado; }\end{array}$ & 5 \\
\hline
\end{tabular}


6) Caldeira de recuperação apresentando falha na manutenção da condição operacional por falha no controle de vazão executado pela válvula pneumática;

7) Usina operando com dificuldade de manutenção da condição operacional do ciclo vapor por falha na

Operação errada:

a) Indicação de sinal de alteração de

vazão para

valores acima

do necessário

para

manutenção da

condição

operacional;

b) Indicação de

sinal de

alteração de

vazão para

valores abaixo

do necessário

para

manutenção da

condição

operacional.
1) Sensor não está calibrado no início da operação,

2) Perda da calibração ao longo do tempo,

3) Problemas no registrador condicionador de sinais

4) Outros sinais interferindo no funcionamento da instrumentação. deira.

1) Sensor envia sinal de abertura indevida, a válvula aumenta a vazão de condensado;

2) Válvula pneumática permitindo vazão de condensado superior a necessária para a manutenção da condição operacional do ciclo vapor;

3) Sistema de alimentação com falha de controle de vazão, maior vazão que a necessária;

4) Economizador de alta pressão operando em desacordo com o ajuste operacional, maior vazão de condensado;

5) Sistema de geração de vapor operando com maior vazão de condensado , impossibilidade de manter a condição operacional exigida no ciclo vapor;

6) Caldeira de recuperação apresenta falha de controle de vazão de vapor, não é atingida a condição operacional prevista para o ciclo vapor, mudança da eficiência térmica da caldeira;

7) Usina operando com falha no ciclo vapor que não atinge as condições exigidas para a operação.

b)

1) Sensor envia sinal de fechamento indevido, a válvula reduz a vazão de condensado;

2) Válvula pneumática permitindo vazão de condensado inferior a necessária para a manutenção da condição operacional do ciclo vapor;

3) Sistema de alimentação com falha de controle de vazão, menor vazão que a necessária;

4) Economizador de alta pressão operando em desacordo com o ajuste operacional, menor vazão de condensado;

5) Sistema de geração de vapor operando com menor vazão de condensado , impossibilidade de manter a condição operacional exigida no ciclo vapor;

6) Caldeira de recuperação apresenta falha de controle de vazão de vapor, não é atingida a condição operacional prevista para o ciclo vapor, mudança da eficiência térmica da caldeira;

7) Usina operando com falha no ciclo vapor que não atinge as condiç̃es exigidas para a operação 


\section{B.1.4.3. Válvula}

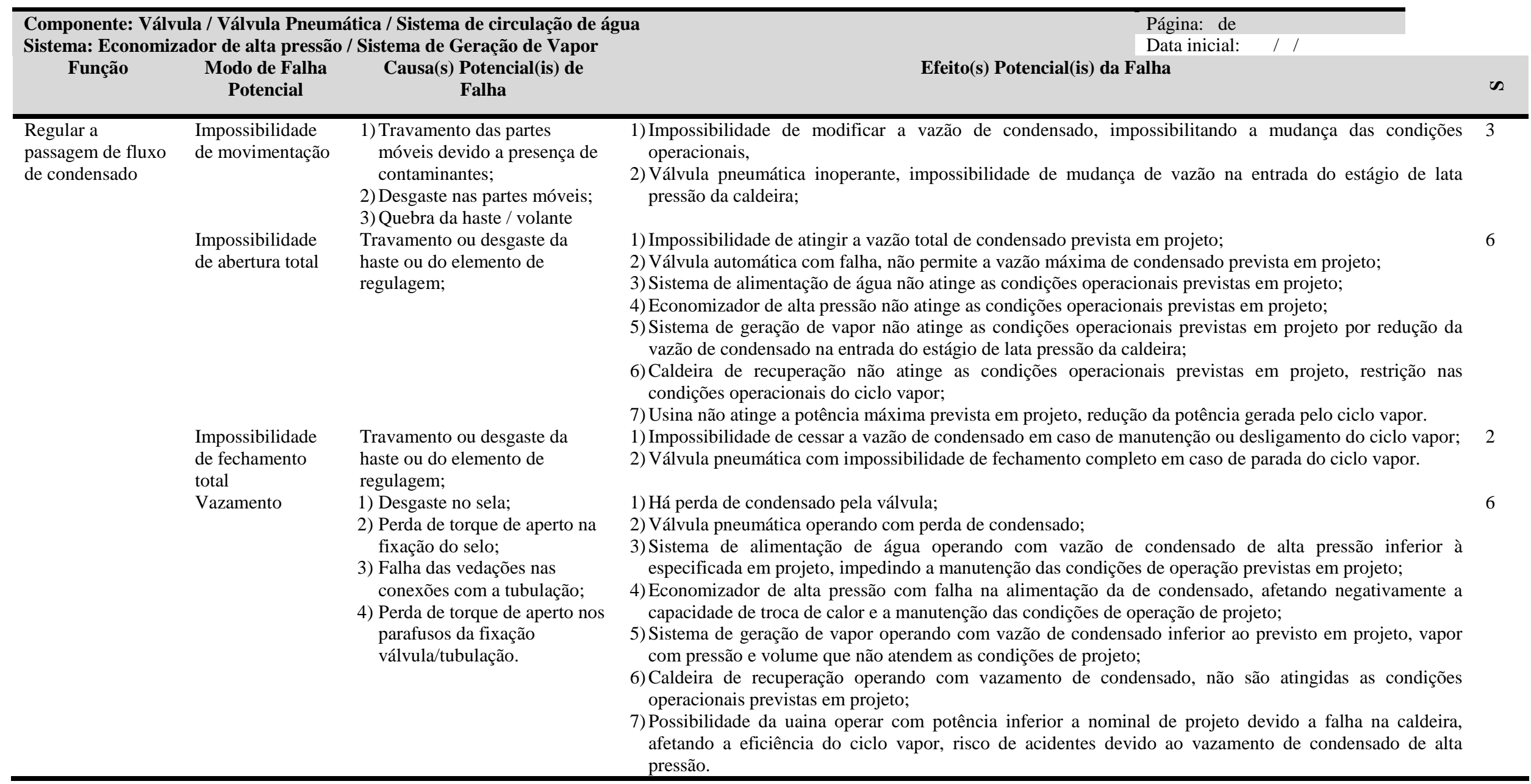




\section{B.1.5. Tubulação do Sistema de Circulação}

\begin{tabular}{|c|c|c|c|c|}
\hline \multicolumn{3}{|c|}{$\begin{array}{l}\text { Componente: Tubulação / Sistema de circulação } \\
\text { Sistema: Economizador de alta pressão / Sistema de geração de vapor }\end{array}$} & \multicolumn{2}{|l|}{$\begin{array}{l}\text { Página: de } \\
\text { Data inicial: }\end{array}$} \\
\hline Função & $\begin{array}{l}\text { Modo de Falha } \\
\text { Potencial }\end{array}$ & $\begin{array}{l}\text { Causa(s) Potencial(is) de } \\
\text { Falha }\end{array}$ & Efeito(s) Potencial(is) da Falha & n \\
\hline \multirow[t]{3}{*}{$\begin{array}{l}\text { Encaminhar o } \\
\text { fluxo de } \\
\text { condensado de alta } \\
\text { pressão até o } \\
\text { economizador }\end{array}$} & Ruptura & $\begin{array}{l}\text { Pressão de operação superior a } \\
\text { especificada em projeto; } \\
\text { Corrosão na parede da } \\
\text { tubulação; } \\
\text { Falha nas uniões soldadas e } \\
\text { conexões; } \\
\text { Erro no projeto; } \\
\text { Utilização de material não } \\
\text { conforme com as especificações } \\
\text { de projeto; } \\
\text { Sobrecarregamento mecânico } \\
\text { devido a falhas em suportes. }\end{array}$ & $\begin{array}{l}\text { 1) Vazamento de condensado; } \\
\text { 2) Sistema de alimentação de água operando com vazão de condensado à especificada em projeto, impedindo } \\
\text { a manutenção das condições de operação previstas em projeto; } \\
\text { 3) Economizador de alta pressão com falha na alimentação da de condensado, afetando negativamente a } \\
\text { capacidade de troca de calor e a manutenção das condições de operação de projeto; } \\
\text { 4) Sistema de geração de vapor operando com vazão de condensado inferior ao previsto em projeto, vapor } \\
\text { com pressão e volume que não atendem as condições de projeto; } \\
\text { 5) Caldeira de recuperação operando com vazamento de condensado, não são atingidas as condições } \\
\text { operacionais previstas em projeto; } \\
\text { 6) Possibilidade da uaina operar com potência inferior a nominal de projeto devido a falha na caldeira, } \\
\text { afetando a eficiência do ciclo vapor, risco de acidentes devido ao vazamento de condensado. }\end{array}$ & 5 \\
\hline & $\begin{array}{l}\text { Bloqueio total da } \\
\text { secção transversal }\end{array}$ & $\begin{array}{l}\text { Acúmulo de detritos; } \\
\text { Acúmulo de produtos de } \\
\text { corrosão e de detritos; } \\
\text { Presença de detritos de grande } \\
\text { porte. }\end{array}$ & $\begin{array}{l}\text { 1) Não há fluxo de condensado no sistema de alimentação de água; } \\
\text { 2) Sistema de alimentação de água inoperante devido a falta de condensado; } \\
\text { 3) Economizador de alta pressão inoperante devido à falha na alimentação de condensado; } \\
\text { 4) Sistema de geração de vapor inoperante devido a inexistência de vazão de condensado na entrada do } \\
\text { estágio de alta pressão da caldeira; } \\
\text { 5) Caldeira de recuperação inoperante, devido à falta de condensado de alta pressão; } \\
\text { 6) Usina com ciclo a vapor inoperante devido a falta de condensado na entrada do estágio de alta pressão da } \\
\text { caldeira, operação em ciclo aberto }\end{array}$ & 7 \\
\hline & $\begin{array}{l}\text { Bloqueio parcial } \\
\text { da secção } \\
\text { transversal }\end{array}$ & $\begin{array}{l}\text { 1) Acúmulo de detritos; } \\
\text { 2) Acúmulo de produtos de } \\
\text { corrosão. }\end{array}$ & $\begin{array}{l}\text { 1) Redução do fluxo de água de condensado; } \\
\text { 2) Sistema de alimentação de água operando com limitação na vazão de condensado de alta pressão; } \\
\text { 3) Economizador de alta pressão com falha na alimentação da de condensado, afetando negativamente a } \\
\text { capacidade de troca de calor e a manutenção das condições de operação de projeto; } \\
\text { 4) Sistema de geração de vapor operando com vazão de condensado inferior ao previsto em projeto, vapor } \\
\text { com pressão e volume que não atendem as condições de projeto; } \\
\text { 5) Caldeira de recuperação operando com vazamento de condensado, não são atingidas as condições } \\
\text { operacionais previstas em projeto; } \\
\text { 6) Possibilidade da uaina operar com potência inferior a nominal de projeto devido a falha na caldeira, } \\
\text { afetando a eficiência do ciclo vapor, risco de acidentes devido ao vazamento de condensado.. }\end{array}$ & 5 \\
\hline
\end{tabular}




\section{B.2. Alimentação principal de Água da caldeira de Recuperação}

\section{B.2.1. Conjunto Bomba de Alimentação de Água}

\section{B.2.1.1. Bomba}

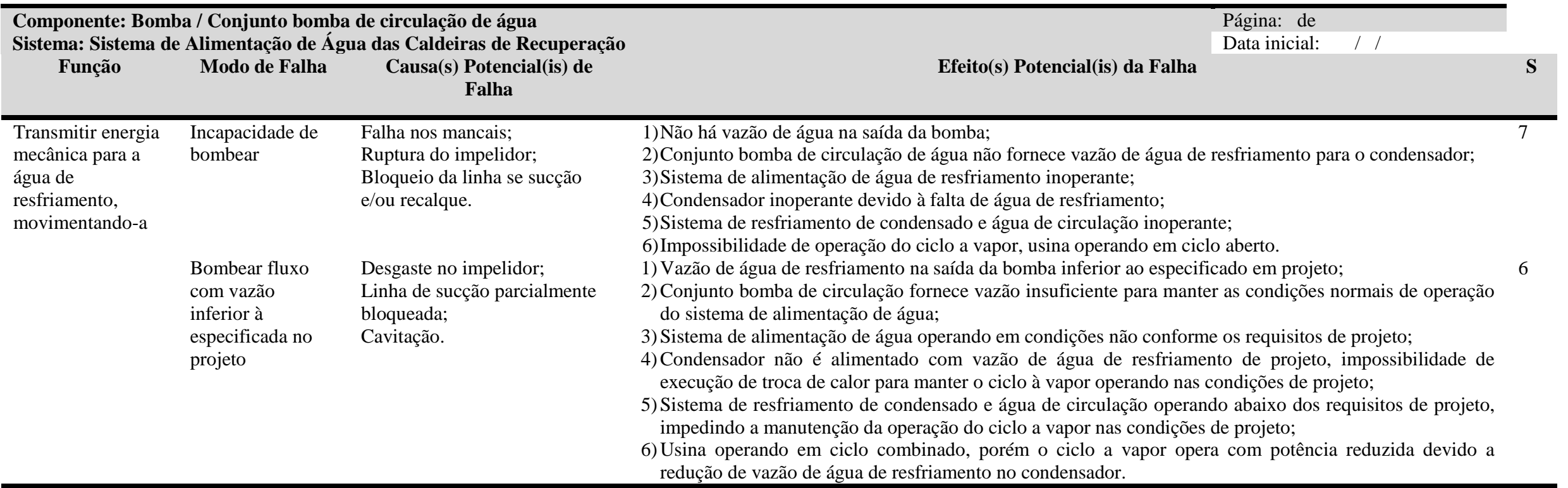




\section{B.2.1.2Acoplamento}

\begin{tabular}{|c|c|c|c|c|}
\hline \multicolumn{4}{|c|}{ Componente: Acoplamento Bomba - Motor Elétrico / Conjunto bomba de circulação de água } & \multirow[b]{2}{*}{$\mathbf{S}$} \\
\hline Função & Modo de Falha & $\begin{array}{l}\text { Causa(s) Potencial(is) de } \\
\text { Falha }\end{array}$ & Efeito(s) Potencial(is) da Falha & \\
\hline $\begin{array}{l}\text { Transmitir o } \\
\text { momento torsos do } \\
\text { eixo do motor } \\
\text { elétrico para o eixo } \\
\text { da bomba }\end{array}$ & $\begin{array}{l}\text { Ruptura da } \\
\text { fixação entre o } \\
\text { acoplamento e } \\
\text { eixo do motor } \\
\text { elétrico ou eixo da } \\
\text { bomba }\end{array}$ & $\begin{array}{l}\text { 1) Sobrecarregamento } \\
\text { durante a operação do } \\
\text { conjunto motor/bomba; } \\
\text { 2) Falha de projeto; } \\
\text { 3) Material com } \\
\text { características mecânicas } \\
\text { em não conformidade } \\
\text { com as especificações de } \\
\text { projeto. } \\
\text { Propagação de trinca } \\
\text { associada ao fenômeno de } \\
\text { fadiga,; } \\
\text { Sobre carregamento durante a } \\
\text { operação do conjunto } \\
\text { motor/bomba; } \\
\text { Desalinhamento excessivo na } \\
\text { montagem; } \\
\text { Falha de projeto; } \\
\text { Material com características } \\
\text { mecânicas em não } \\
\text { conformidade com as } \\
\text { especificações de projeto. }\end{array}$ & $\begin{array}{l}\text { 1) Não há transmissão de potência e movimento entre o motor elétrico e a bomba de circulação de água; } \\
\text { 2) Conjunto bomba de circulação de água não fornece vazão de água de resfriamento; } \\
\text { 3) Sistema de alimentação de água inoperante; } \\
\text { 4) Condensador inoperante, não havendo circulação da água de resfriamento; } \\
\text { 5) Sistema de refrigeração de condensado e agua de circulação com falha na alimentação de água do } \\
\text { condensador, impedindo o resfriamento do condensado; } \\
\text { 6) Turbina a vapor inoperante, a usina deve operar em ciclo aberto } \\
\text { 1) Não há transmissão de potência e movimento entre o motor elétrico e a bomba de circulação de água; } \\
\text { 2) Conjunto bomba de circulação de água não fornece vazão de água de resfriamento; } \\
\text { 3) Sistema de alimentação de água inoperante; } \\
\text { 4) Condensador inoperante, não havendo circulação da água de resfriamento; } \\
\text { 5) Sistema de refrigeração de condensado e água de circulação com falha na alimentação de água do } \\
\text { condensador, impedindo o resfriamento do condensado; } \\
\text { 6) Turbina a vapor inoperante, a usina deve operar em ciclo aberto }\end{array}$ & 7 \\
\hline
\end{tabular}




\section{B.2.1.3. Motor Elétrico da Bomba de Alimentação}

\begin{tabular}{|c|c|c|c|c|c|}
\hline $\begin{array}{l}\text { Componente: Mot } \\
\text { Sistema: Sistema d }\end{array}$ & $\begin{array}{l}\text { Elétrico do Conj } \\
\text { Alimentação de Á }\end{array}$ & $\begin{array}{l}\text { to Bomba de Circulação de Ág } \\
\text { la das Caldeiras de Recuperac }\end{array}$ & & $\begin{array}{l}\text { Página: de } \\
\text { Data inicial: }\end{array}$ & \\
\hline Função & $\begin{array}{c}\text { Modo de Falha } \\
\text { Potencial }\end{array}$ & $\begin{array}{l}\text { Causa(s) Potencial(is) de } \\
\text { Falha }\end{array}$ & Efeito(s) Potencial(is) da Falha & & $\mathbf{S}$ \\
\hline $\begin{array}{l}\text { Transformar } \\
\text { energia elétrica em } \\
\text { energia mecânica } \\
\text { para o } \\
\text { acionamento da } \\
\text { bomba }\end{array}$ & $\begin{array}{l}\text { Não há } \\
\text { transformação de } \\
\text { energia elétrica } \\
\text { em energia } \\
\text { mecânica }\end{array}$ & $\begin{array}{l}\text { Perda do isolamento devido a } \\
\text { ação da umidade, com queima } \\
\text { do bobinado; } \\
\text { Travamento dos mancais } \\
\text { devido ao processo de fadiga. }\end{array}$ & $\begin{array}{l}\text { 1) Não há fornecimento de energia mecânica para o acionamento da bon } \\
\text { 2) Conjunto bomba de circulação de água não fornece vazão de água de } \\
\text { 3) Sistema de alimentação de água inoperante; } \\
\text { 4) Condensador inoperante, não havendo circulação da água de resfriam } \\
\text { 5) Sistema de refrigeração de condensado e água de circulação con } \\
\text { condensador, impedindo o resfriamento do condensado; } \\
\text { 6) Turbina a vapor inoperante, a usina deve operar em ciclo aberto }\end{array}$ & $\begin{array}{l}\text { ba; } \\
\text { resfriamento; } \\
\text { falha na alimentação de água do }\end{array}$ & 7 \\
\hline
\end{tabular}

B.2.1.4. Sistema Elétrico da Bomba de Alimentação

\begin{tabular}{|c|c|c|c|}
\hline \multicolumn{3}{|c|}{$\begin{array}{l}\text { Componente: Sistema Elétrico / Conjunto Bomba Circulação de Água } \\
\text { Sistema: Sistema de Alimentação de Água das Caldeiras de Recuperação }\end{array}$} & $\begin{array}{l}\text { Página: de } \\
\text { Data inicial: }\end{array}$ \\
\hline Função & $\begin{array}{l}\text { Modo de Falha } \\
\text { Potencial }\end{array}$ & $\begin{array}{l}\text { Causa(s) Potencial(is) de } \\
\text { Falha }\end{array}$ & Efeito(s) Potencial(is) da Falha \\
\hline \multirow[t]{2}{*}{$\begin{array}{l}\text { Controlar a } \\
\text { operação do motor } \\
\text { do conjunto bomba } \\
\text { de circulação de } \\
\text { água de } \\
\text { resfriamento }\end{array}$} & $\begin{array}{l}\text { Disjuntor: } \\
\text { a) Não interromper } \\
\text { corrente; } \\
\text { b) Interromper } \\
\text { corrente } \\
\text { indevidamente. }\end{array}$ & $\begin{array}{l}\text { Desgaste dos mecanismos de } \\
\text { disparo. }\end{array}$ & $\begin{array}{l}\text { 1) Há acionamento do disjuntor com valores de corrente do motor ao valor admissível em projeto; } \\
\text { 2) Conjunto bomba de circulação de água de resfriamento não atinge a condição de operação normal } \\
\text { (vazão de projeto); } \\
\text { 3) Sistema de alimentação de água impossibilitado de operar na condição de projeto; } \\
\text { 4) Condensador impossibilitado de operar na condição nominal de projeto por falha no conjunto bomba } \\
\text { de circulação de água de resfriamento; } \\
\text { 5) Sistema de resfriamento de condensado e água de circulação impossibilitado de operar na condição de } \\
\text { projeto por falha no condensador; } \\
\text { 6) Ciclo a vapor impossibilitado de operar na condição nominal de projeto por falha no condensador. }\end{array}$ \\
\hline & $\begin{array}{l}\text { Contator; } \\
\text { a) Não conduzir } \\
\text { corrente elétrica; } \\
\text { b) Não interromper } \\
\text { corrente elétrica }\end{array}$ & $\begin{array}{l}\text { a) Bobina queimada; } \\
\text { Contato principal carbonizado. } \\
\text { b) Contatos principais fundidos } \\
\text { por aquecimento. }\end{array}$ & $\begin{array}{l}\text { a) Não há acionamento do motor elétrico; } \\
\text { 1) Conjunto bomba de circulação de água inoperante; } \\
\text { 3) Sistema alimentação de água inoperante; } \\
\text { 4) Condensador inoperante por falha no sistema de circulação de água de resfriamento; } \\
\text { 5) Sistema de resfriamento de condensado e água de circulação inoperante por falha no condensador; } \\
\text { 6) Ciclo a vapor inoperante, usina operando em ciclo aberto. } \\
\text { b) } \\
\text { 1) Não há interrupção de acionamento do motor. }\end{array}$ \\
\hline
\end{tabular}




\section{B.2.1.5. Tubulação de Água}

\begin{tabular}{|c|c|c|c|c|}
\hline \multicolumn{3}{|c|}{$\begin{array}{l}\text { Componente: Tubulação / Sistema de Alimentação de Água } \\
\text { Sistema: Sistema de Alimentação de Água das Caldeiras de Recuperação }\end{array}$} & \multicolumn{2}{|l|}{$\begin{array}{l}\text { Página: de } \\
\text { Data inicial: }\end{array}$} \\
\hline Função & $\begin{array}{l}\text { Modo de Falha } \\
\text { Potencial }\end{array}$ & $\begin{array}{l}\text { Causa(s) Potencial(is) de } \\
\text { Falha }\end{array}$ & Efeito(s) Potencial(is) da Falha & $S$ \\
\hline \multirow[t]{3}{*}{$\begin{array}{l}\text { Encaminhar fluxo } \\
\text { de água de } \\
\text { resfriamento para } \\
\text { o interior do } \\
\text { condensador }\end{array}$} & Ruptura & $\begin{array}{l}\text { Pressão de operação superior a } \\
\text { especificada em projeto; } \\
\text { Corrosão na parede da } \\
\text { tubulação; } \\
\text { Falha nas uniões soldadas e } \\
\text { conexões; } \\
\text { Erro no projeto; } \\
\text { Utilização de material não } \\
\text { conforme com as especificações } \\
\text { de projeto; } \\
\text { Sobrecarregamento mecânico } \\
\text { devido a falhas em suportes. }\end{array}$ & $\begin{array}{l}\text { 1) Vazamento de água de resfriamento; } \\
\text { 2) Sistema alimentação de água operando com limitação de vazão, devido a presença de vazamentos; } \\
\text { 3) Condensador operando com vazão de água de resfriamento inferior à especificada em projeto, } \\
\text { impedindo a manutenção das condições de operação previstas em projeto; } \\
\text { 4) Sistema de resfriamento de condensado e água de circulação operando com falha na alimentação da } \\
\text { água de resfriamento do condensador, afetando negativamente a capacidade de troca de calor e a } \\
\text { manutenção das condições de operação de projeto; } \\
\text { 5) Ciclo a vapor operando com potência inferior a nominal de projeto devido a perda de alimentação de } \\
\text { água de resfriamento no condensador.. }\end{array}$ & 6 \\
\hline & $\begin{array}{l}\text { Bloqueio total da } \\
\text { secção transversal }\end{array}$ & $\begin{array}{l}\text { Acúmulo de detritos; } \\
\text { Acúmulo de produtos de } \\
\text { corrosão e de detritos; } \\
\text { Presença de detritos de grande } \\
\text { porte. }\end{array}$ & $\begin{array}{l}\text { 1) Não há fluxo de água de resfriamento no condensador; } \\
\text { 2) Sistema de alimentação de água inoperante; } \\
\text { 3) Condensador inoperante devido a falta de água de resfriamento; } \\
\text { 4) Sistema de resfriamento de condensado e água de circulação inoperante devido à falha na alimentação } \\
\text { de água de resfriamento; } \\
\text { 5) Ciclo Vapor inoperante, usina operando em ciclo aberto. }\end{array}$ & 7 \\
\hline & $\begin{array}{l}\text { Bloqueio parcial da } \\
\text { secção transversal }\end{array}$ & $\begin{array}{l}\text { Acúmulo de detritos; } \\
\text { Acúmulo de produtos de } \\
\text { corrosão. }\end{array}$ & $\begin{array}{l}\text { 1) Redução do fluxo de água de resfriamento; } \\
\text { 2) Sistema de alimentação de água operando com limitação de vazão; } \\
\text { 3) Condensador operando com limitação na capacidade de troca de calor; } \\
\text { 4) Sistema de resfriamento de condensado e água de circulação operando com falha no condensador, } \\
\text { afetando a capacidade de troca de calor no condensador; } \\
\text { 5) Ciclo Vapor operando com geração de potência inferior à nominal de projeto.. }\end{array}$ & 6 \\
\hline
\end{tabular}




\section{B.2.1.6. Válvulas Automáticas}

\begin{tabular}{|c|c|c|c|c|}
\hline \multicolumn{3}{|c|}{$\begin{array}{l}\text { Componente: Válvula Automática / Sistema de Alimentação de Água } \\
\text { Sistema: Sistema de Alimentação de Água das Caldeiras de Recuperação }\end{array}$} & \multicolumn{2}{|l|}{$\begin{array}{l}\text { Página: de } \\
\text { Data inicial: }\end{array}$} \\
\hline Função & $\begin{array}{l}\text { Modo de Falha } \\
\text { Potencial }\end{array}$ & $\begin{array}{l}\text { Causa(s) Potencial(is) de } \\
\text { Falha }\end{array}$ & Efeito(s) Potencial(is) da Falha & \\
\hline \multirow[t]{5}{*}{$\begin{array}{l}\text { Permitir passagem } \\
\text { de água de } \\
\text { resfriamento para } \\
\text { o condensador }\end{array}$} & $\begin{array}{l}\text { Sensor não envia } \\
\text { sinal para o atuador }\end{array}$ & $\begin{array}{l}\text { Falha do sensor; } \\
\text { Falha no } \\
\text { registrador/condicionador de } \\
\text { sinais; } \\
\text { Falha da fiação (entre sensor e } \\
\text { atuador). }\end{array}$ & $\begin{array}{l}\text { 1) Não há regulagem de vazão da água de resfriamento para atender à novas condições operacionais; } \\
\text { 2) Sistema de alimentação de água com vazão desregulada para as novas condições operacionais do } \\
\text { sistema de resfriamento de condensado e água de circulação; } \\
\text { 3) Condensador não atende às novas condições operacionais do ciclo vapor; } \\
\text { 4) Sistema de resfriamento de condensado e água de circulação não possibilita alteração de condições } \\
\text { operacionais; } \\
\text { 5) Impossibilidade de alteração de condição operacional do ciclo a vapor. }\end{array}$ & 5 \\
\hline & $\begin{array}{l}\text { Operação } \\
\text { intermitente do } \\
\text { sensor que envia } \\
\text { sinal para o atuador }\end{array}$ & $\begin{array}{l}\text { Falha do sensor; } \\
\text { Problemas internos no } \\
\text { registrador/condicionador de } \\
\text { sinais; } \\
\text { Problemas na ligação entre } \\
\text { sensor e atuador. }\end{array}$ & $\begin{array}{l}\text { 1) Ocorre regulagem da vazão de água de resfriamento para o condensador, de forma a atender as } \\
\text { condições operacionais do ciclo a vapor, de forma intermitente; } \\
\text { 2) Sistema de alimentação de água com problemas para regular a vazão para as novas condições } \\
\text { operacionais do sistema de resfriamento de condensado e água de circulação; } \\
\text { 3) Condensador de forma intermitente às novas condições operacionais do ciclo vapor; } \\
\text { 4) Sistema de resfriamento de condensado e água de circulação não possibilita a correta alteração de } \\
\text { condições operacionais; } \\
\text { 5) Impossibilidade de alteração/manutenção de condição operacional do ciclo a vapor. Grave deterioração } \\
\text { na condição de operação do ciclo vapor. }\end{array}$ & 6 \\
\hline & $\begin{array}{l}\text { Operação errada: } \\
\text { a) Indicação de } \\
\text { sinal de alteração de } \\
\text { vazão para valores } \\
\text { acima do necessário } \\
\text { para manutenção da } \\
\text { condição } \\
\text { operacional. }\end{array}$ & $\begin{array}{l}\text { Sensor não está calibrado no } \\
\text { início da operação, } \\
\text { Perda da calibração; } \\
\text { Problemas no registrador } \\
\text { condicionador de sinais, } \\
\text { Outros sinais interferindo no } \\
\text { funcionamento da } \\
\text { instrumentação. }\end{array}$ & $\begin{array}{l}\text { 1) Não há regulagem de vazão da água de resfriamento para atender à novas condições operacionais; } \\
\text { 2) Sistema de alimentação de água com vazão desregulada para as novas condições operacionais do } \\
\text { sistema de resfriamento de condensado e água de circulação; } \\
\text { 3) Condensador não atende às novas condições operacionais do ciclo vapor; } \\
\text { 4) Sistema de resfriamento de condensado e água de circulação não possibilita alteração de condições } \\
\text { operacionais; } \\
\text { 5) Impossibilidade de alteração/manutenção de condição operacional do ciclo a vapor. Grave deterioração } \\
\text { da condição de operação do ciclo vapor }\end{array}$ & 6 \\
\hline & Falha no atuador & $\begin{array}{l}\text { Falta de ar comprimido; } \\
\text { Quebra/Desgaste de elementos } \\
\text { mecânicos no atuador; } \\
\text { Bloqueio da linha de ar } \\
\text { comprimido. }\end{array}$ & $\begin{array}{l}\text { 1) Não há regulagem de vazão da água de resfriamento para atender à novas condições operacionais; } \\
\text { 2) Sistema de alimentação de água com vazão desregulada para as novas condições operacionais do } \\
\text { sistema de resfriamento de condensado e água de circulação; } \\
\text { 3) Condensador não atende às novas condições operacionais do ciclo vapor; } \\
\text { 4) Sistema de resfriamento de condensado e água de circulação não possibilita alteração de condições } \\
\text { operacionais; } \\
\text { 5) Impossibilidade de alteração de condição operacional do ciclo a vapor. }\end{array}$ & 5 \\
\hline & $\begin{array}{l}\text { Impossibilidade de } \\
\text { movimentação }\end{array}$ & $\begin{array}{l}\text { Travamento das partes móveis } \\
\text { devido a presença de } \\
\text { contaminantes; } \\
\text { Desgaste nas partes móveis; }\end{array}$ & $\begin{array}{l}\text { 1) Não há regulagem de vazão da água de resfriamento para atender à novas condições operacionais; } \\
\text { 2) Sistema de alimentação de água com vazão desregulada para as novas condições operacionais do } \\
\text { sistema de resfriamento de condensado e água de circulação; } \\
\text { 3) Condensador não atende às novas condições operacionais do ciclo vapor; }\end{array}$ & 5 \\
\hline
\end{tabular}




\section{Quebra da haste / volante.}

Travamento ou desgaste da haste ou do elemento de regulagem
4) Sistema de resfriamento de condensado e água de circulação não possibilita alteração de condições operacionais;

5) Impossibilidade de alteracão de condição operacional do ciclo a vapor

\begin{tabular}{ll}
\hline $\begin{array}{l}\text { Impossibilidade de } \\
\text { abertura total }\end{array}$ & $\begin{array}{l}\text { Travamento ou desgaste da } \\
\text { haste ou do elemento de } \\
\text { regulagem; }\end{array}$
\end{tabular}

1) Não há possibilidade de obtenção da máxima vazão de projeto de água de resfriamento

2) Sistema de alimentação de água incapaz de atender as condições de projeto em termos de vazões máximas;

3) Condensador não atende às condições operacionais máximas previstas em projeto;

4) Sistema de resfriamento de condensado e água de circulação não atende às condições operacionais previstas em projeto;

5) Ciclo vapor não atinge potência máxima prevista em projeto.

\begin{tabular}{|c|c|c|c|}
\hline $\begin{array}{l}\text { Impossibilidade de } \\
\text { fechamento total }\end{array}$ & $\begin{array}{l}\text { Travamento ou desgaste da } \\
\text { haste ou do elemento de } \\
\text { regulagem. }\end{array}$ & 1) Não há possibilidade de eliminação de vazão de água de resfriamento em caso de manutenção; & 2 \\
\hline Vazamento & $\begin{array}{l}\text { Desgaste no sela; } \\
\text { Perda de torque de aperto na } \\
\text { fixação do selo; } \\
\text { Falha das vedações nas } \\
\text { conexões com a tubulação; } \\
\text { Perda de torque de aperto nos } \\
\text { parafusos da fixação } \\
\text { válvula/tubulação. }\end{array}$ & $\begin{array}{l}\text { 1) Redução na vazão de água de resfriamento para o interior do condensador; } \\
\text { 2) Sistema de alimentação de água operando com vazão inferior a necessária para manutenção das } \\
\text { condições exigidas do ciclo vapor; } \\
\text { 3) Condensador operando em condições que não atendem as exigidas para a manutenção da condição } \\
\text { operacional do ciclo vapor; } \\
\text { 4) Sistema de resfriamento de condensado e água de circulação incapaz de atender aos requistos } \\
\text { operacionais do ciclo vapor; } \\
\text { 5) Usina operando com limitações de potência obtida com o ciclo vapor, em função de vazamentos de } \\
\text { água de resfriamento no condensador. }\end{array}$ & $\overline{5}$ \\
\hline
\end{tabular}

\section{B.3.1. Sistema de Recírculo de Condensado}

\section{B.3.1.1. Bomba de Condensado}

\begin{tabular}{|c|c|c|c|c|}
\hline \multicolumn{5}{|c|}{$\begin{array}{l}\text { Componente: Bomba de condensado / Sistema de alimentação de água } \\
\text { Sistema: Aquecedor de condensado - Economizador de baixa de pressão / Sistema de geração de vapor }\end{array}$} \\
\hline Função & Modo de Falha & $\begin{array}{l}\text { Causa(s) Potencial(is) de } \\
\text { Falha }\end{array}$ & Efeito(s) Potencial(is) da Falha & $\mathbf{S}$ \\
\hline \multirow[t]{2}{*}{$\begin{array}{l}\text { Transmitir } \\
\text { energia mecânica } \\
\text { para o } \\
\text { condensado, } \\
\text { movimentando-o }\end{array}$} & $\begin{array}{l}\text { Incapacidade de } \\
\text { bombear }\end{array}$ & $\begin{array}{l}\text { 1)Falha nos mancais; } \\
\text { 2)Ruptura do impelidor; } \\
\text { 3)Bloqueio da linha se } \\
\text { sucção e/ou recalque } \\
\text { 4)Falha no motor elétrico }\end{array}$ & $\begin{array}{l}\text { 1)Não há vazão de condensado; } \\
\text { 2)Sistema de alimentação de água não fornece vazão de condensado; } \\
\text { 3)Economizador de baixa pressão inoperante devido à falha na alimentação de condensado; } \\
\text { 4)]Sistema de geração de vapor inoperante devido a inexistência de vazão de condensado na } \\
\text { entrada da caldeira; } \\
\text { 5)Caldeira de recuperação inoperante, devido à falta de condensado; } \\
\text { 6)Usina com ciclo a vapor inoperante devido a falta de condensado na entrada da caldeira, } \\
\text { operação em ciclo aberto }\end{array}$ & 7 \\
\hline & Bombear fluxo & 1)Desgaste no impelidor; & 1) Vazão de condensado na saída da bomba inferior ao especificado em projeto; & 5 \\
\hline
\end{tabular}


com vazão

inferior à

especificada no

2)Linha de sucção

parcialmente bloqueada;

projeto
2) Sistema alimentação de água fornece vazão insuficiente para manter as condições normais de operação previstas em projeto;

3) Economizador de baixa pressão com falha na alimentação da de condensado, afetando negativamente a capacidade de troca de calor e a manutenção das condições de operação de projeto;

4) Sistema de geração de vapor operando com vazão de condensado inferior ao previsto em projeto, vapor com pressão e volume que não atendem as condições de projeto;

5) Caldeira de recuperação operando com vazão de condensado inferior ao definido em projeto, não são atingidas as condições operacionais previstas em projeto

6) Possibilidade da usina operar com potência inferior a nominal de projeto devido a falha na caldeira, afetando a eficiência do ciclo vapor.

\section{B.4. Sistema de Monitoração}

\section{B.4.1. Sensor de Temperatura}

\begin{tabular}{|c|c|c|}
\hline \multicolumn{3}{|c|}{$\begin{array}{l}\text { Componente: Sensor de temperatura / Sistema de monitoração } \\
\text { Sistema: Superaquecedor de baixa pressão }\end{array}$} \\
\hline Função & $\begin{array}{l}\text { Modo de Falha } \\
\text { Potencial }\end{array}$ & Causa(s) Potencial(is) de Falha \\
\hline $\begin{array}{l}\text { Registrar a } \\
\text { temperatura do } \\
\text { vapor de baixa } \\
\text { pressão. }\end{array}$ & $\begin{array}{l}\text { Sensor não registra } \\
\text { a magnitude da } \\
\text { temperatura }\end{array}$ & $\begin{array}{l}\text { 1) Falha do sensor; } \\
\text { 2) Falha no } \\
\text { registrador/condicionador de } \\
\text { sinais; } \\
\text { 3) Falha da fiação (entre sensor e } \\
\text { registrador) }\end{array}$ \\
\hline
\end{tabular}

\begin{tabular}{ll}
\hline & Página: de \\
& Data inicial: / / \\
\hline
\end{tabular}

1) Não há indicação da temperatura do vapor de baixa pressão;

2) Sistema de monitoração com falha no registro de temperatura;

3) Superaquecedor de baixa pressão operando com falha na monitoração das condições operacionais, causando dificuldades para mudança do regime operacional da caldeira;

4) Sistema de geração de vapor operando normalmente, falha no monitoramento da temperatura do vapor superaquecido de baixa pressão, dificuldade de mudança no regime de operação da caldeira;

5) Caldeira operando normalmente, falha na monitoração da temperatura do vapor superaquecido de baixa pressão causando dificuldade para a alteração no regime de operação da caldeira.

6) Usina operando normalmente, devido a problemas de monitoração da temperatura do vapor superaquecido de baixa pressão há dificuldade de mudança no regime operacional do ciclo vapor.

Operação intermitente do

sensor de

temperatura

\section{1) Falha do sensor;}

2) Problemas internos no registrador/condicionador de sinais;

3) Problemas na ligação entre sensor e condicionado
1) Há indicação intermitente da temperatura do vapor de baixa pressão

2) Sistema de monitoração com falha no registro de temperatura;

3) Superaquecedor de baixa pressão operando com falha na monitoração das condições operacionais do vapor, causando dificuldades para mudança do regime operacional do ciclo a vapor;

4) Sistema de geração de vapor operando normalmente, dificuldade na mudança do regime de operação por falha em monitoração;

5) Caldeira de recuperação operando normalmente, dificuldade na mudança de regime de operação por falha na monitoração do superaquecedor de baixa pressão;

6) Usina operando normalmente, devido a problemas de monitoração da caldeira há dificuldade de mudança no regime operacional do ciclo vapor. 
Operação errada: a) Indicação de sinal de temperatura com magnitude inferior ao valor real.

b) Indicação de sinal de temperatura com magnitude superior ao valor real.
Sensor não está calibrado no início da operação,

2) Perda da calibração ao longo do tempo,

3) Problemas no registrador condicionador de sinais,

4) Outros sinais interferindo no funcionamento da instrumentação.
1) Há indicação errônea da temperatura do vapor de baixa pressão, indicando necessidade de correção;

2) Sistema de monitoração com falha que indica necessidade de alteração da condição operacional, com correção de parâmetros do fluxo de vapor;

3) Superaquecedor de baixa pressão operando com falha na monitoração das condições operacionais, gerando mudança desnecessária do regime operacional do ciclo a vapor;

4) ]Sistema de geração de vapor em operação normal, mudança de regime de operação indevida por falha em monitoração do vapor de baixa pressão;

5) Caldeira de recuperação em operação normal, mudança de regime gerada por falha na monitoração do superaquecedor de baixa pressão;

6) Usina operando normalmente, devido a problemas de monitoração do superaquecedor de baixa pressão há dificuldade de ajuste no regime operacional do ciclo vapor;

1) Há indicação errônea da temperatura do vapor de baixa pressão, indicando necessidade de correção para valores menores, reduzindo a eficiência da troca térmica;

2) Sistema de monitoração com falha que indica necessidade de alteração da condição operacional, com correção de parâmetros do fluxo de condensado para ajuste da temperatura do vapor, redução da eficiência de troca térmica;

3) Superaquecedor de baixa pressão operando com falha na monitoração das condições operacionais, gerando mudança desnecessária do regime operacional do ciclo a vapor;

4) Sistema de geração de vapor operando normalmente, mudança indevida de condição operacional por falha na monitoração do superaquecedor de baixa pressão;

5) Caldeira de recuperação operando normalmente, mudança indevida de regime de operação por falha na monitoração, perda de eficiência na troca térmica;

6) Usina operando normalmente, devido a problemas de monitoração da caldeira há dificuldade de ajuste no regime operacional do ciclo vapor, com redução do rendimento do mesmo.

\section{B.4.2. Manômetro}

\begin{tabular}{|c|c|c|}
\hline \multicolumn{3}{|c|}{$\begin{array}{l}\text { Componente: Manômetro / Sistema de monitoração } \\
\text { Sistema: Superaquecedor de baixa pressão }\end{array}$} \\
\hline $\begin{array}{l}\text { Registrar a pressão } \\
\text { do vapor de baixa } \\
\text { pressão. }\end{array}$ & $\begin{array}{l}\text { Sensor não registra } \\
\text { a magnitude da } \\
\text { pressão }\end{array}$ & $\begin{array}{l}\text { 1) Falha do sensor; } \\
\text { 2) Falha no } \\
\text { registrador/condicionador de } \\
\text { sinais; } \\
\text { 3) Falha da fiação (entre sensor e } \\
\text { registrador) }\end{array}$ \\
\hline
\end{tabular}

Componente: Manômetro/Sistema de monitoração

Data inicial:

1) Não há indicação da pressão do vapor de baixa pressão;

2) Sistema de monitoração com falha no registro de pressão;

3) Superaquecedor de baixa pressão operando com falha na monitoração das condições operacionais, causando dificuldades para mudança do regime operacional da caldeira;

4) Sistema de geração de vapor operando normalmente, falha no monitoramento da pressão do vapor superaquecido de baixa pressão, dificuldade de mudança no regime de operação da caldeira;

5) Caldeira operando normalmente, falha na monitoração da pressão do vapor superaquecido de baixa pressão causando dificuldade para a alteração no regime de operação da caldeira.

6) Usina operando normalmente, devido a problemas de monitoração da pressão do vapor superaquecido de baixa pressão há dificuldade de mudança no regime operacional do ciclo vapor. 
Operação

intermitente do

manômetro

Operação errada: a) Indicação de sinal de pressão com magnitude inferior ao valor real;

b) Indicação de sinal de pressão com magnitude superior real.
1) Falha do sensor;

2) Problemas internos no registrador;

3) Problemas na ligação entre sensor e condicionador

1) Sensor não está calibrado no início da operação,

2) Perda da calibração ao longo do tempo,

3) Problemas no registrado condicionador de sinais,

4) Outros sinais interferindo no funcionamento da instrumentação.
1) Há indicação intermitente da pressão do vapor de baixa pressão

2) Sistema de monitoração com falha no registro de pressão;

3) Superaquecedor de baixa pressão operando com falha na monitoração das condições operacionais do vapor, causando dificuldades para mudança do regime operacional do ciclo a vapor.

1) Há indicação errônea da pressão do vapor de baixa pressão, indicando necessidade de correção;

2) Sistema de moniotação com falha que indica necessidade de alteração da condição operacional, com correção de parâmetros do fluxo de vapor;

3) Superaquecedor de baixa pressão operando com falha na monitoração das condições operacionais, gerando mudança desnecessária do regime operacional do ciclo a vapor;

4) ]Sistema de geração de vapor em operação normal, mudança de regime de operação indevida por falha em monitoração do vapor de baixa pressão;

5) Caldeira de recuperação em operação normal, mudança de regime gerada por falha na monitoração do superaquecedor de baixa pressão;

6) Usina operando normalmente, devido a problemas de monitoração do superaquecedor de baixa pressão há dificuldade de ajuste no regime operacional do ciclo vapor;

1) Há indicação errônea da pressão do vapor de baixa pressão, indicando necessidade de correção para valores menores, reduzindo a eficiência da troca térmica;

2) Sistema de monitoração com falha que indica necessidade de alteração da condição operacional, com correção de parâmetros do fluxo de condensado para ajuste da pressão do vapor, redução da eficiência de troca térmica;

3) Superaquecedor de baixa pressão operando com falha na monitoração das condições operacionais, gerando mudança desnecessária do regime operacional do ciclo a vapor;

4) Sistema de geração de vapor operando normalmente, mudança indevida de condição operacional por falha na monitoração do superaquecedor de baixa pressão;

5) Caldeira de recuperação operando normalmente, mudança indevida de regime de operação por falha na monitoração, perda de eficiência na troca térmica;

6) Usina operando normalmente, devido a problemas de monitoração da caldeira há dificuldade de ajuste no regime operacional do ciclo vapor, com redução do rendimento do mesmo. 


\section{B.4.3. Medidor de Vazão}

\begin{tabular}{|c|c|c|}
\hline \multicolumn{3}{|c|}{$\begin{array}{l}\text { Componente: Medidor de vazão / Sistema de monitoração } \\
\text { Sistema: Superaquecedor de baixa pressão }\end{array}$} \\
\hline Função & Modo de Falha & Causa(s) Potencial(is) de Falha \\
\hline $\begin{array}{l}\text { Registrar a vazão } \\
\text { do vapor de baixa } \\
\text { pressão. }\end{array}$ & $\begin{array}{l}\text { Sensor não registra } \\
\text { a magnitude da } \\
\text { vazão }\end{array}$ & $\begin{array}{l}\text { 1) Falha do sensor; } \\
\text { 2) Falha no } \\
\text { registrador/condicionador de } \\
\text { sinais; } \\
\text { 3) Falha da fiação (entre sensor e } \\
\text { registrador) }\end{array}$ \\
\hline
\end{tabular}

\section{Operação \\ intermitente do} medidor de vazão

\section{1) Falha do sensor;}

2) Problemas internos no registrador/condicionador de sinais;

3) Problemas na ligação entre sensor e condicionador

Operação errada: a) Indicação de sinal de vazão com magnitude inferior ao valor real;
1) Sensor não está calibrado no início da operação,

2) Perda da calibração ao longo do tempo,

3) Problemas no registrador condicionador de sinais,

4) Outros sinais interferindo no funcionamento $\mathrm{d} a$ instrumentação.
Página: de

Data inicial:
1) Não há indicação da vazão do vapor de baixa pressão;

2) Sistema de monitoração com falha no registro de vazão;

3) Superaquecedor de baixa pressão operando com falha na monitoração das condições operacionais, causando dificuldades para mudança do regime operacional da caldeira;

4) Sistema de geração de vapor operando normalmente, falha no monitoramento da vazão do vapor superaquecido de baixa pressão, dificuldade de mudança no regime de operação da caldeira:

5) Caldeira operando normalmente, falha na monitoração da vazão do vapor superaquecido de baixa pressão causando dificuldade para a alteração no regime de operação da caldeira.

6) Usina operando normalmente, devido a problemas de monitoração da vazão do vapor superaquecido de baixa pressão há dificuldade de mudança no regime operacional do ciclo vapor.

1) Há indicação intermitente da vazão do vapor de baixa pressão

2) Sistema de monitoração com falha no registro de vazão;

3) Superaquecedor de baixa pressão operando com falha na monitoração das condições operacionais do vapor, causando dificuldades para mudança do regime operacional do ciclo a vapor;

4) Sistema de geração de vapor operando normalmente, dificuldade na mudança do regime de operação por falha em monitoração;

5) Caldeira de recuperação operando normalmente, dificuldade na mudança de regime de operação por falha na monitoração do superaquecedor de baixa pressão;

6) Usina operando normalmente, devido a problemas de monitoração da caldeira há dificuldade de mudança no regime operacional do ciclo vapor.

1) Há indicação errônea da vazão do vapor de baixa pressão, indicando necessidade de correção;

2) Sistema de moniotação com falha que indica necessidade de alteração da condição operacional, com correção de parâmetros do fluxo de vapor;

3) Superaquecedor de baixa pressão operando com falha na monitoração das condições operacionais, gerando mudança desnecessária do regime operacional do ciclo a vapor;

4) Sistema de geração de vapor em operação normal, mudança de regime de operação indevida por falha em monitoração do vapor de baixa pressão;

5) Caldeira de recuperação em operação normal, mudança de regime gerada por falha na monitoração do superaquecedor de baixa pressão;

6) Usina operando normalmente, devido a problemas de monitoração do superaquecedor de baixa pressão há dificuldade de ajuste no regime operacional do ciclo vapor;

1) Há indicação errônea da vazão do vapor de baixa pressão, indicando necessidade de correção para 5 valores menores, reduzindo a eficiência da troca térmica; 
b) Indicação de

sinal de vazão com

magnitude superior

ao valor real.
2) Sistema de monitoração com falha que indica necessidade de alteração da condição operacional, com correção de parâmetros do fluxo de condensado para ajuste da vazão do vapor, redução da eficiência de troca térmica;

3) Superaquecedor de baixa pressão operando com falha na monitoração das condições operacionais, gerando mudança desnecessária do regime operacional do ciclo a vapor;

4) Sistema de geração de vapor operando normalmente, mudança indevida de condição operacional por falha na monitoração do superaquecedor de baixa pressão;

5) Caldeira de recuperação operando normalmente, mudança indevida de regime de operação por falha na monitoração, perda de eficiência na troca térmica;

6) Usina operando normalmente, devido a problemas de monitoração da caldeira há dificuldade de ajuste no regime operacional do ciclo vapor, com redução do rendimento do mesmo. 